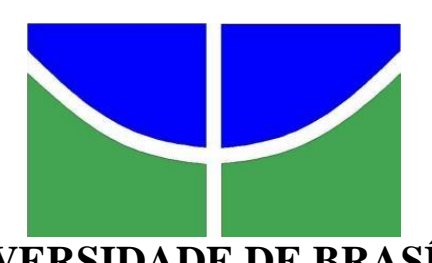

UNIVERSIDADE DE BRASÍLIA

INSTITUTO DE GEOCIÊNCIAS

PÓS-GRADUAÇÃO EM GEOCIÊNCIAS APLICADAS

DADOS ESPECTRORRADIOMÉTRICOS DE CAMPO E ÍNDICES DE VEGETAÇÃO PARA ESTIMAR PORCENTAGEM DE COBERTURA VEGETAL VERDE DE PASTAGENS CULTIVADAS

DISSERTAÇÃO DE MESTRADO nº 080

KAREN LÍDIA CASTRO BORGES 


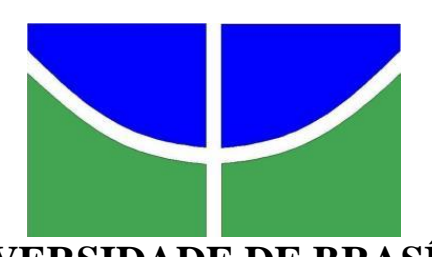

UNIVERSIDADE DE BRASÍLIA

INSTITUTO DE GEOCIÊNCIAS

PÓS-GRADUAÇÃO EM GEOCIÊNCIAS APLICADAS

\section{DADOS ESPECTRORRADIOMÉTRICOS DE CAMPO E ÍNDICES DE VEGETAÇÃO PARA ESTIMAR PORCENTAGEM DE COBERTURA VEGETAL VERDE DE PASTAGENS CULTIVADAS}

\section{DISSERTAÇÃO DE MESTRADO nº80}

KAREN LÍDIA CASTRO BORGES

Orientador:

Dr. Edson Eyji Sano

Examinadores:

Dr $^{a}$. Tati de Almeida (interno) - Universidade de Brasília

Dr$^{\circ}$. Roberto Rosa (externo) - Universidade Federal de Uberlândia 


\section{DADOS ESPECTRORRADIOMÉTRICOS DE CAMPO E ÍNDICES DE VEGETAÇÃO PARA ESTIMAR PORCENTAGEM DE COBERTURA VEGETAL VERDE DE PASTAGENS CULTIVADAS}

Dissertação aprovada como requisito parcial para obtenção do grau de Mestre em Geociências Aplicadas - Universidade de Brasília, pela seguinte banca examinadora:

Orientador:

Prof. Drº. Edson Eyji Sano

Embrapa Cerrados

Examinador Interno:

Prof. Dra ${ }^{\mathrm{a}}$ Tati de Almeida

Universidade de Brasília

Examinador Externo:

Prof. Dro. Roberto Rosa

Universidade Federal de Uberlândia

Aprovada em: 27 de março de 2015

Brasília - DF

Março de 2015 


\section{FICHA CATALOGRÁFICA}

Borges, Karen L C.

Dados espectrorradiométricos de campo e índices de vegetação para estimar porcentagem de cobertura vegetal verde de pastagens cultivadas / Karen Lídia Castro Borges; orientação de Edson Eyji Sano. Brasília, 2015

92p.

Dissertação de Mestrado (M) - Universidade de Brasília / Instituto de Geociências, 2015.

1. Índices de vegetação; 2.Porcentagem de Cobertura Vegetal Verde; 3. Espectrorradiometria; 4. Pastagens.

\section{REFERÊNCIA BIBLIOGRÁFICA}

Borges, Karen Lídia Castro

Dados espectrorradiométricos de campo e índices de vegetação para estimar porcentagem de cobertura vegetal verde de pastagens cultivadas. Brasília, Instituto de Geociências, Universidade de Brasília, 2015, 92p. Dissertação de Mestrado.

\section{CESSÃO DE DIREITOS}

NOME DA AUTORA: Karen Lídia Castro Borges

TÍTULO DA DISSERTAÇÃO DE MESTRADO: Dados espectrorradiométricos de campo e índices de vegetação para estimar porcentagem de cobertura vegetal verde de pastagens cultivadas.

\section{GRAU: Mestre $\quad$ ANO: 2015}

É concedida à Universidade de Brasília permissão para reproduzir cópias desta dissertação de mestrado e para emprestar ou vender tais cópias somente para propósitos acadêmicos e científicos. Esse direito poderá ocorrer somente após a publicação do artigo contido no documento. $\mathrm{O}$ autor reserva-se a outros direitos de publicação e nenhuma parte desta dissertação de mestrado pode ser reproduzida sem a autorização por escrito da autora.

Karen Lídia Castro Borges

karencastro18@gmail.com 
A Deus, pelo dom da vida! A minha família, por todo suporte, dedicação, carinho, amor e confiança! 


\section{AGRADECIMENTOS}

Agradeço, em primeiro lugar, a Deus e a Nossa Senhora, por SEMPRE me acompanhar e por me dar saber e disposição para a realização deste estudo.

Um agradecimento especial às pessoas que foram essenciais para este trabalho: meu orientador, Dr. Edson Eyji Sano, pela amizade, dedicação, paciência e empenho durante o desenvolvimento deste trabalho; e Embrapa Cerrados, pela oportunidade de realização da pesquisa de campo; toda a equipe do Laboratório de Biofísica Ambiental da Embrapa Cerrados, que, desde a minha época de graduação, vem me 'aturando', em especial, o Heleno Bezerra, a Thaise Sussane e o Sr. Edim Borges que, com sua paciência e apoio, esteve presente em todas as visitas de campo.

Não posso me esquecer de cada um dos professores do Departamento de Geociências Aplicadas que participaram da minha formação de alguma forma.

Agradeço ao $\operatorname{Dr}^{\circ}$ Roberto Rosa e a $\operatorname{Dr}^{\mathrm{a}}$ Tati de Almeida, por, gentilmente, terem aceitado o convite de fazer parte desta banca, e também pelas ricas contribuições feitas a este trabalho.

Adriana Bayma e Lilian Rocha, amigas do mestrado e da vida, dividimos aprendizados e muitas expectativas durante esses dois anos, vocês foram fundamentais!

Aos meus pais, por todo apoio, carinho e dedicação durante toda a jornada acadêmica. À minha irmã, e aos meus amados e queridos sobrinhos, Arthur e Maria Eduarda, fonte de inspiração nos muitos momentos que me faltavam. Ao meu noivo Egidio Ramalho, pelo apoio e ajuda durante o desenvolvimento deste trabalho, foi fundamental!

$\mathrm{E}$ aos amigos que sempre estiveram presentes na minha vida e na minha formação acadêmica e a todos os colegas de curso, pelos ricos momentos divididos durante o mestrado. 
"Se pude chegar mais longe foi porque estava sobre os ombros de gigantes"

(Isaac Newton)

"De tudo ficaram três coisas: a certeza de que estamos sempre a começar, a certeza de que é preciso continuar, e a certeza de que seremos interrompidos antes de terminar. Portanto, devemos fazer da interrupção um caminho novo, da queda um passo de dança, do medo uma escada, do sonho uma ponte, da procura um encontro".

(Fernando Sabino) 


\section{SUMÁRIO}

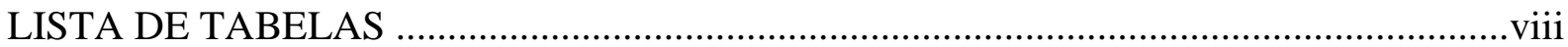

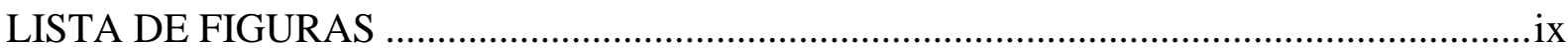

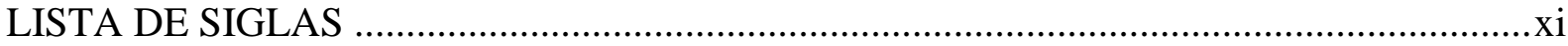

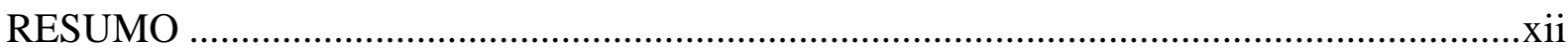

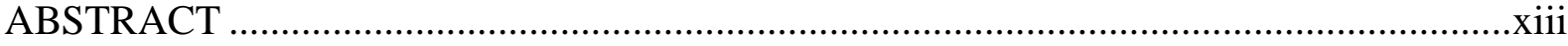

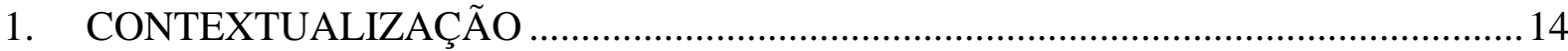

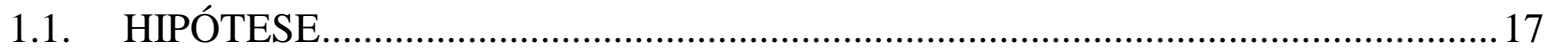

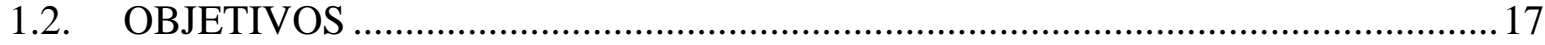

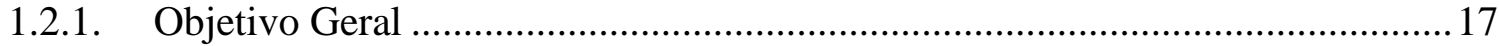

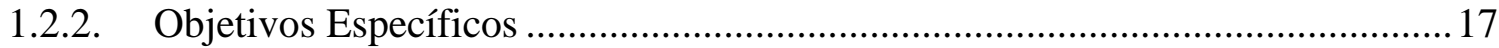

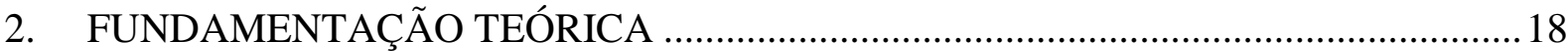

2.1. PASTAGENS CULTIVADAS DO CERRADO ….................................................. 18

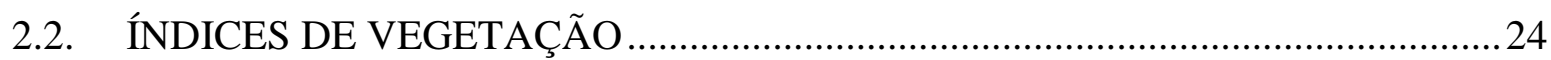

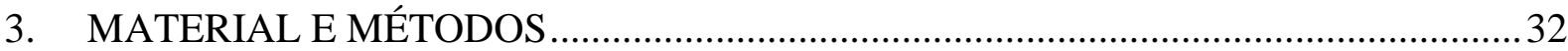

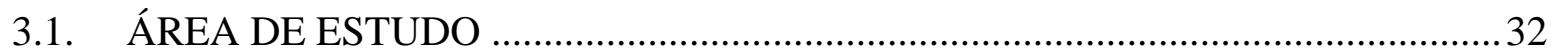

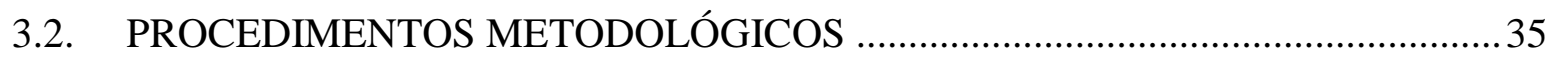

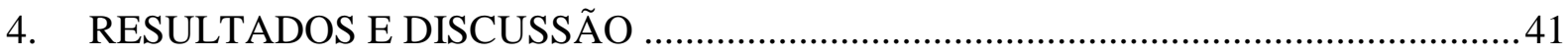

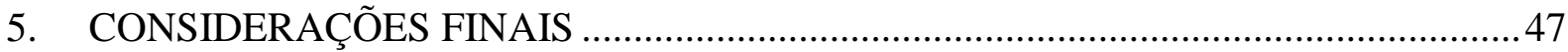

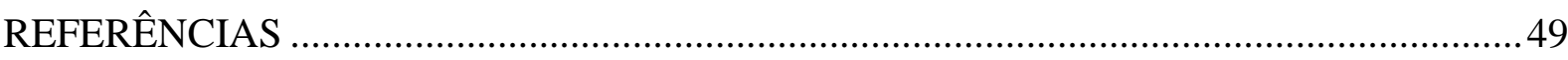

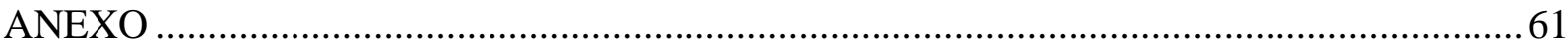




\section{LISTA DE TABELAS}

Tabela 1. Distribuição das áreas de pastagens em hectares nos estados que compreendem o bioma Cerrado.

Tabela 2. Área e porcentagem de ocupação das principais espécies de pastagens cultivadas no Cerrado.

Tabela 3. Fases de degradação de pastagens segundo os parâmetros limitantes e níveis de degradação.

Tabela 4. Data das coletas de dados espectrorradiométricos de campo e de fotografias digitais.

Tabela 5. Relação dos índices de vegetação considerados nesse estudo para estimar \% de cobertura vegetal verde de pastagens cultivadas. $\rho=$ reflectância; NIR $=$ infravermelho próximo; $R E D=$ vermelho; $G R E E N=$ verde; $B L U E=$ azul. 37

Tabela 6. Especificações técnicas dos satélites do sistema RapidEye. 38

Tabela 7. Lista de sistemas sensores orbitais e multiespectrais selecionados para identificar o sistema mais apropriado para estimar \% cobertura verde.

Tabela 8. Coeficientes de correlação entre bandas do satélite RapidEye e 12 índices de vegetação propostos na literatura e \% de cobertura verde de pastagens cultivadas para os meses de julho, setembro, outubro e novembro de 2013 e janeiro de 2014. 44

Tabela 9. Coeficientes de correlação entre SAVI derivados de faixas espectrais de oito satélites multiespectrais e \% de cobertura verde de pastagens cultivadas para os meses de julho, setembro, outubro e novembro de 2013 e janeiro de 2014. 45

Tabela 10. Coeficientes de correlação entre EVI derivados de faixas espectrais de oito satélites multiespectrais e \% de cobertura verde de pastagens cultivadas para os meses de julho, setembro, outubro e novembro de 2013 e janeiro de 2014. 46 


\section{LISTA DE FIGURAS}

Figura 1. Vista geral de áreas plantadas com Brachiaria decumbens no campo experimental da Embrapa Cerrados, em Planaltina/DF (a) área de pastagem no pico da estação seca setembro/2013; (b) área de pastagem no pico da estação chuvosa - janeiro/2014. Foto: K. Borges.

Figura 2. Aumento da produção de forragem de Brachiaria decumbens em função da prática de calagem associada à fertilização. Fonte: Oliveira et al. (2003). Médias de um mesmo ano, seguidas de letras distintas diferem entre si pelo teste $\mathrm{F}(\mathrm{p} \leq 0,01)$. 23

Figura 3. Reflectâncias na faixa espectral de 300 a $900 \mathrm{~nm}$ de uma amostra de solo vermelho (Latossolo Vermelho Escuro) e de um a área coberta com pastagem cultivada verde. Os termos Red e NIR correspondem, respectivamente, às bandas de absorção da vegetação verde na faixa espectral do vermelho e à alta reflexão da radiação incidente na faixa espectral do infravermelho próximo. A faixa espectral situada entre o Red e o NIR é conhecida como rededge (aumento abrupto da reflectância de folhas verdes).

Figura 4. Composição colorida das bandas R(5) 760-850 nm G(4) 690-730 nm B(3) 630-685 nm do RapidEye (a) e índice de vegetação denominada Razão Simples (SR) (b) da porção centro-norte do Distrito Federal (cena: 2331802; data da imagem: 01 de setembro de 2011). Áreas de cobertura vegetal verde aparecem, respectivamente, com coloração avermelhada e tonalidade clara.

Figura 5. Relação entre NDVI e as bandas espectrais originais do vermelho (Red) (a) e do infravermelho próximo (NIR) da porção centro-norte do Distrito Federal. Dados obtidos por meio da cena RapidEye de 01 de setembro de 2011, identificação da cena: 2331802.

Figura 6. Relação entre EVI e EVI2 da porção centro-norte do Distrito Federal. Dados obtidos por meio da cena RapidEye de 01 de setembro de 2011, identificação da cena: 2331802. Total de pontos: 1.845 valores de reflectância.

Figura 7. Localização das áreas amostrais nos campos experimentais da Embrapa Cerrados em Planaltina/DF. A imagem corresponde a uma cena do satélite QuickBird de julho de 2013, disponível no programa Google Earth ${ }^{\mathrm{TM}}$. 33

Figura 8. Precipitação e temperatura média mensal nos meses de amostragem de campo de dados espectrorradiométricos e fotografias digitais. 
Figura 9. Exemplo de fotografia digital obtida no campo em 08 de janeiro de 2014 e correspondente classificação em três classes espectrais: vegetação verde (em vermelho),

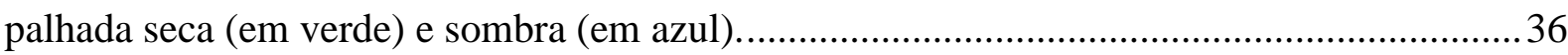

Figura 10. Curvas espectrorradiométricas de pastagem cultivada para os meses de julho, setembro, outubro e novembro de 2013 e janeiro de 2014.

Figura 11. Média e correspondente desvio-padrão de $\%$ de cobertura verde de pastagens cultivadas obtidas pela classificação MAXVER das fotografias de campo nos meses de julho,

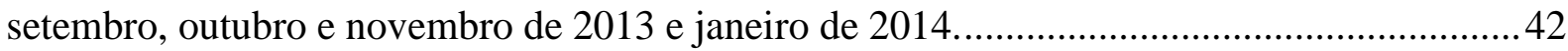

Figura 12. Coeficientes de correlação entre dados espectrorradiométricos de campo e \% cobertura verde. 


\section{LISTA DE SIGLAS}

\begin{tabular}{|c|c|}
\hline $\mathrm{ABC}$ & Agricultura de Baixo Carbono \\
\hline ALOS & Advanced Land Observing Satellite \\
\hline ASD & Analytical Spectral Devices \\
\hline ASTER & Advanced Spaceborne Thermal Emission and Reflection Radiometer \\
\hline AVIRIS & Airborne Visible/Infrared Imaging Spectrometer \\
\hline AWIFS & Advanced Wide Field Sensor \\
\hline CBERS & Satélite Sino-Brasileiro de Recursos Terrestres \\
\hline $\mathrm{CI}$ & Chlorophyll Index \\
\hline CNPC & Conselho Nacional da Pecuária de Corte \\
\hline CNPQ & Conselho Nacional de Desenvolvimento Científico e Tecnológico \\
\hline$\% \mathrm{CV}$ & Porcentagem de cobertura verde \\
\hline EMBRAPA & Empresa Brasileira de Pesquisa Agropecuária \\
\hline EVI & Enhanced Vegetation Index \\
\hline FAO & Food and Agriculture Organization \\
\hline fAPAR & Fração de Radiação Fotossinteticamente Ativa Absorvida \\
\hline GNDVI & Green Normalized Difference Vegetation Index \\
\hline IAF & Índice de Área Foliar \\
\hline IBGE & Instituto Brasileiro de Geografia e Estatística \\
\hline ILPF & Integração Lavoura Pecuária Floresta \\
\hline INPE & Instituto Nacional de Pesquisas Espaciais \\
\hline IV & Índice de Vegetação \\
\hline JPG & Joint Photographic Experts Group \\
\hline LVAd & Latossolo Vermelho-Amarelo distrófico \\
\hline LVd & Latossolo Vermlho distrófico \\
\hline MAXVER & Máxima Verossimilhança \\
\hline MMA & Ministério do Meio Ambiente \\
\hline MODIS & Moderate Resolution Imaging Spectrorradiometer \\
\hline MSAVI & Modified Soil Adjusted Vegetation Index \\
\hline MTCI & MERIS Terrestrial Chlorophyll Index \\
\hline MUXCam & Câmera Multiespectral Regular \\
\hline NDVI & Normalized Difference Vegetation Index \\
\hline NIR & Near Infrared \\
\hline NPP & Produtividade Primária Bruta \\
\hline OLI & Operacional Terra Imager \\
\hline OSAVI & Optimization of Soil-Adjusted Vegetation Index \\
\hline RDVI & Renormalized Difference Vegetation Index \\
\hline RGB & Red, Green, Blue \\
\hline RVI & Ratio Vegetation Index \\
\hline SAVI & Soil-Adjusted Vegetation Index \\
\hline SPOT & Satellite Pour l'Observation de la Terre \\
\hline SR & Simple Ratio (Razão Simples) \\
\hline TVI & Triangular Vegetation Index \\
\hline UA & Unidade Animal \\
\hline WGS & World Geodetic System \\
\hline
\end{tabular}




\section{RESUMO}

Pastagens cultivadas correspondem a principal atividade antrópica do Cerrado, concentrandose principalmente em Goiás, Mato Grosso do Sul, Mato Grosso e Minas Gerais. Mais de 50\% das áreas de pastagens apresentam algum tipo de degradação, os quais são difíceis de serem mapeados com base em imagens de satélite. Diante de uma necessidade de quantificar os parâmetros biofísicos das pastagens do Cerrado, esta pesquisa objetivou analisar o potencial de dados espectrorradiométricos de campo para estimar porcentagem de cobertura vegetal verde $(\% \mathrm{CV})$ de pastagens cultivadas como Brachiaria, no campo experimental da Embrapa Cerrados em Planaltina/DF. Dados espectrorradiométricos foram obtidos por meio do espectrorradiômetro portátil FieldSpec da Analytical Spectral Devices (ASD) Inc. (que adquire dados de reflectância na faixa espectral de 325 - $1075 \mathrm{~nm}$, com $1 \mathrm{~nm}$ de intervalo e $25^{\circ}$ de IFOV), nos meses de julho, setembro, outubro e novembro de 2013, além de janeiro de 2014 (50 pontos de amostragem para cada mês). Nesses mesmos pontos de amostragem, foram obtidas fotografias verticais do terreno que foram classificadas pelo método de classificação supervisionada por máxima verossimilhança para estimar a correspondente \% CV. Os dados espectrorradiométricos foram ainda convertidos para índices de vegetação, os quais têm apresentado boa correlação com parâmetros da vegetação em diversos estudos anteriores. Os dados espectrais e de \% CV foram comparados estatisticamente por meio de coeficientes de correlação (r), em termos de: comprimentos de onda (faixa espectral de 400 a $900 \mathrm{~nm}$ ); 12 diferentes índices de vegetação (IV); e faixas espectrais de oito plataformas orbitais com larguras de bandas estreitas e largas. Resultados dessa pesquisa indicaram que: a estimativa de \%CV é mais favorável na estação chuvosa que na estação seca, setembro foi o mês em que a \%CV esteve mais baixa ( $23 \%)$, o mês de janeiro foi o que apresentou maior $\% \mathrm{CV}$ verde $(\sim 57 \%)$. A faixa espectral do vermelho e do infravermelho próximo mostraram ser as mais apropriadas para estimar \%CV. O Soil-Adjusted Vegetation Index (SAVI) e o Enhanced Vegetation Index (EVI) foram os Índices de Vegetação que apresentaram melhores correlações com a \% CV. E as variações nas larguras das bandas das oito plataformas orbitais não interferiram significativamente na correlação entre IV e \%CV.

Palavras chaves: sensoriamento remoto; processamento digital de imagens; Brachiaria; pecuária. 


\begin{abstract}
Cultivated pastures are the main anthropogenic activity in the Cerrado, mainly concentrated in Goiás, Mato Grosso do Sul, Mato Grosso and Minas Gerais. More than 50\% of the areas under pasture show some type of degradation, which are difficult to map using satellite images. Faced with a need to quantify the biophysical parameters of the Cerrado grasslands, this study aims to analyze the potential of field spectro-radiometric data to estimate percentage of green vegetation cover (\% CV) of cultivated pastures, like Brachiaria at the experimental field of Embrapa-Cerrados in Planaltina, DF. Spectro-radiometric data were obtained through the portable spectro-radiometer FieldSpec of Analytical Spectral Devices (ASD) Inc. (acquiring reflectance data in the spectral range of 325-1075 nm, $1 \mathrm{~nm}$ range and $25^{\circ}$ of IFOV), in July, September, October and November 2013, and January 2014 (50 sampling points for each month). In these same sampling points, vertical terrain photographs were taken, that were classified by the classification method using maximum likelihood estimation to obtain the corresponding\% $\mathrm{CV}$. The spectro-radiometric data were also converted to vegetation indices that have shown good correlation with vegetation parameters in several previous studies. The spectral data and CV\% were statistically compared by means of correlation coefficients (r), in terms of: wavelength (spectral range of 400 to $900 \mathrm{~nm}$ ); 12 different vegetation indices (VI); and spectral bands of eight orbital platforms with narrow and broad wavebands. Results from this study indicated that: the estimation of $\% \mathrm{CV}$ is more favorable in the rainy season than in the dry season, September being the month in which the\% CV was lowest ( 23\%), the month of January showing the highest\% CV ( 57\%). The red and near infrared wavelengths were the most appropriate spectra to estimate CV\%. The Soil-Adjusted Vegetation Index (SAVI) and the Enhanced Vegetation Index (EVI) were the Vegetation Indices that were best correlated with the $\% \mathrm{CV}$. The variations in the widths of the bands of the eight orbital platforms did not influence significantly the correlation between VI and $\mathrm{CV} \%$.
\end{abstract}

Key words: remote sensing; digital image processing; Brachiaria; livestock. 


\section{CONTEXTUALIZAÇÃO}

O Brasil, com aproximadamente 204 milhões de cabeças de gado em 2010 (CNPC, 2009), é o principal produtor comercial de carne bovina no mundo. A maior parte da pecuária bovina do país é caracterizada pela pecuária extensiva. Segundo dados do Censo Agropecuário do Instituto Brasileiro de Geografia e Estatística de 2006 (IBGE, 2012), as pastagens cultivadas ocupam uma área aproximada de 170 milhões de hectares em todo o território nacional, aproximadamente 102,5 milhões de hectares de pastagens plantadas (PP) e aproximadamente 57,5 milhões hectares de pastagens naturais (PN). Ela é a classe de cobertura vegetal antrópica mais representativa na Amazônia Legal e no bioma Cerrado: 46 milhões e 54 milhões de hectares, respectivamente (INPE, 2010; SANO et al., 2010). O Cerrado se destaca por sua grande extensão, o segundo maior bioma da América do Sul, depois da Amazônia (MMA, 2007). Esse bioma ocupa uma área de 204,7 milhões de hectares, dos quais 80 milhões de hectares correspondem à cobertura vegetal antrópica (SANO et al., 2010).

Essas áreas de pastagens cultivadas têm apresentado uma acentuada dinâmica espaçotemporal. Por exemplo, paisagens ocupadas por pastagens cultivadas da Amazônia têm sido alteradas de forma intensa devido a invasão de plantas daninhas popularmente conhecidas como "juquira" (SOUZA FILHO et al., 2001; MARTHA JÚNIOR \& VILELA, 2002). No Cerrado, o uso continuado e sem uma estratégia de recuperação da capacidade de produção vegetal, seja por reposição de nutrientes (calagem e fertilizantes químicos), seja por adoção de práticas de rotação animal, também têm alterado de forma intensa a paisagem ocupada por pastagens cultivadas.

Com o passar do tempo, começam a surgir manchas de solo exposto, cupinzeiros e sulcos de erosão (MARTHA JÚNIOR \& VILELA, 2002; PERON \& EVANGELISTA, 2004). Ainda no Cerrado, pastagens cultivadas têm sido alvos preferenciais para a expansão da produção de grãos e de cana-de-açúcar (BRANDÃO et al., 2006; CASTRO et al., 2010). Mais recentemente, algumas áreas de pastagens vêm sendo utilizadas para a implantação de sistemas de produção conhecidas como integração lavoura-pecuária-floresta (ILPF) (MACEDO, 2009; BALBINO et al., 2011).

Essa dinâmica na paisagem ocupada por pastagens cultivadas precisa ser monitorada, por exemplo, para formulação de políticas públicas de controle de perdas de solo ou para atender parte das metas previstas no programa governamental conhecido como Agricultura de 
Baixo Carbono (ABC) - pastagens em plena capacidade de produção de biomassa conseguem estocar maior quantidade de carbono no solo. O manejo de pastagens tem sido citado como a segunda mais importante tecnologia agrícola disponível para a mitigação das mudanças climáticas globais, podendo armazenar até $30 \%$ do carbono do solo no mundo (FAO, 2009).

As tentativas para mapear pastagens a partir da análise de imagens de satélite em regiões tropicais e subtropicais, frequentemente têm sucesso limitado. Nessas regiões, as pastagens podem ter respostas espectrais similares à vegetação nativa e à cana-de-açúcar (PRICE et al., 1992; HERNANDEZ et al., 1998). Contudo, os dados de sensoriamento remoto são os mais indicados para monitorar a cobertura vegetal de áreas extensas como é o caso de pastagens cultivadas brasileiras. Tradicionalmente, no Brasil, têm-se utilizado imagens de satélites da série Landsat e mais recentemente imagens do satélite RapidEye para mapear e monitorar a cobertura vegetal natural e antrópica a níveis de bioma ou estado (e.g., FRANÇA ROCHA et al., 2007; SANO et al., 2008; 2010).

As imagens do satélite Landsat apresentam uma excelente combinação entre área imageada (185 km x $185 \mathrm{~km}$ ) e nível de detalhamento (resolução espacial de 30 metros). Outra vantagem do Landsat é a sua série histórica de imageamento da superfície terrestre que já dura 40 anos (desde 1974, ano em que foi lançado o primeiro satélite da série Landsat). O lançamento da constelação de cinco satélites RapidEye permitem a aquisição de imagens multiespectrais com alta resolução espacial (6,5 metros, reamostrados para 5 metros durante o procedimento de ortorretificação). Esse satélite adquire ainda cenas com uma nova banda espectral denominada red-edge $(700-750 \mathrm{~nm})$, situada entre as faixas espectrais do vermelho (600-700 nm) e do infravermelho próximo $(750-900 \mathrm{~nm})$. Em termos de novas técnicas de processamento digital de imagens, podem ser citados os diferentes índices de vegetação que têm sido propostos na literatura, substituindo-se a banda convencional do vermelho por essa nova banda denominada red-edge.

Tais imagens permitem ainda a obtenção de estimativas de parâmetros biofísicos como \% de cobertura verde (\% CV, proporção em área do terreno ocupada por vegetação verde), índice de área foliar (IAF), produtividade primária bruta (NPP) e biomassa (SEAQUIST \& ARDO, 2003; ZHENG et al., 2004; LU, 2005; BEZERRA et al., 2007; NUMATA et al., 2007). Essas estimativas são importantes em diversos estudos de modelagem de ciclos hidrológicos, erosão de solos e estoque de carbono, entre outros (KING et al., 2005; VRIELING, 2006; HOUGHTON et al., 2009). 
Ambas as aplicações (monitoramento e estimativa de parâmetros biofísicos) possuem grande potencial de serem otimizadas em termos de acurácia a partir do uso de dados espectrorradiométricos (centenas de dados espectrais coletados em vários comprimentos de onda próximos entre si) e de técnica de divisão de bandas conhecida como índice de vegetação. Em 1987, foi construído um dos primeiros sensores imageadores hiperespectrais, o Airborne Visible/Infrared Imaging Spectrometer (AVIRIS) (GREEN et al., 1998). Em seguida, no ano 2000, foi lançado o sensor orbital Hyperion, a bordo da plataforma EO-1 (PEARLMAN et al., 2003; UNGAR et al., 2003). O futuro do sensoriamento remoto orbital e hiperespectral inclui o lançamento do ALOS-3 pela Agência de Exploração Aeroespacial do Japão (JAXA) (OHGI et al., 2010).

Os índices de vegetação consistem em uma técnica de divisão de bandas entre as faixas espectrais do vermelho ( $600-700 \mathrm{~nm}$; elevada absorção da radiação eletromagnética pela clorofila) e do infravermelho próximo $(\sim 700-900 \mathrm{~nm}$; elevada reflexão interna da radiação devido à estrutura do mesófilo) e possuem o intuito de realçar áreas do terreno parcial ou totalmente cobertas por vegetação verde (JENSEN, 1999; PONZONI \& SHIMABUKURO, 2007).

Vários estudos têm sido realizados com base em espectrorradiometria de campo [e.g,, Batista et al. (1988), comportamento espectral de duas variedades de soja; Rudorff et al. (1990), comportamento espectral de soja no Distrito Federal; Moreira (1997), comportamento espectral do trigo; Franco \& Rosa (2003), comportamento espectral de diferentes estágios de degradação em Brachiaria; e Papa (2009), comportamento espectral da cultura de feijão no Distrito Federal]. Contudo, o uso de dados hiperespectrais e de índices de vegetação requer um estudo prévio sobre as faixas espectrais e os índices mais apropriados, os quais dependem basicamente das características físicas, químicas e topográficas da área de estudo e das condições atmosféricas durante a aquisição de imagens.

Dentro deste contexto, esta dissertação de mestrado aborda o potencial de dados de sensoriamento remoto, mais especificamente, dados espectrorradiométricos de campo originais e convertidos para diferentes índices de vegetação, para estimar porcentagem de cobertura verde de pastagens cultivadas representativas do Cerrado. 


\subsection{HIPÓTESE}

A porcentagem de cobertura verde de pastagens cultivadas do bioma Cerrado pode ser estimada por meio de dados espectrorradiométricos, originais ou realçados pela técnica de índice de vegetação.

\subsection{OBJETIVOS}

\subsubsection{Objetivo Geral}

O objetivo desse estudo foi analisar os dados de espectrorradiometria de campo obtidos em diferentes épocas, de seca e de chuva, originais e convertidos para diferentes índices de vegetação, para estimar porcentagem de cobertura verde de pastagens cultivadas representativas do bioma Cerrado.

\subsubsection{Objetivos Específicos}

- Analisar o desempenho dos dados espectrorradiométricos originais de campo para estimar a porcentagem de cobertura verde de pastagens cultivadas do bioma Cerrado;

- Analisar o desempenho de dados espectrorradiométricos de campo, convertidos para diferentes índices de vegetação e diferentes larguras de faixas espectrais, para estimar a porcentagem de cobertura verde de pastagens cultivadas do bioma Cerrado. 


\section{FUNDAMENTAÇÃO TEÓRICA}

Nesta seção, são descritos os principais conceitos e a fundamentação teórica de dois dos principais temas discutidos neste trabalho; Pastagens Cultivadas do Cerrado e Índices de Vegetação. Inicialmente serão abordados os conceitos referentes ao histórico de ocupação das pastagens cultivadas no Cerrado. Posteriormente são apresentados os conceitos referentes aos Índices de Vegetação mais utilizados na bibliografia.

\subsection{PASTAGENS CULTIVADAS DO CERRADO}

O Brasil é o sexto maior produtor mundial de leite e essa produção é dependente basicamente das pastagens cultivadas, ou seja, a produção de leite está intimamente ligada à produtividade das pastagens. O Brasil é ainda detentor do maior rebanho bovino comercial do mundo (acima de 204 milhões de cabeças em 2010) (CNPC, 2009), possuindo aproximadamente 170 milhões de hectares de pastagens cultivadas (IBGE, 2012). Em relação aos biomas brasileiros, esta ocupação ocorre principalmente no Cerrado (Tabela 1) ( 54,6 milhões de hectares, em torno de 26,8\% da área total do bioma e cerca de $37 \%$ da área total de pastagens no Brasil) (SANO et al., 2010). Estima-se que, entre 1980-2005, a área de pastagens no Brasil aumentou em 151\% (ALVIN et al., 2005).

Tabela 1. Distribuição das áreas de pastagens em hectares nos estados que compreendem o bioma Cerrado.

\begin{tabular}{lccc}
\hline \multicolumn{1}{c}{ Estado } & Área Total (ha) & $\begin{array}{c}\text { Pastagens Plantadas no } \\
\text { Cerrado (ha) }\end{array}$ & Porcentagem \\
\hline Goiás & 34.011 .178 & 11.999 .881 & $35,28 \%$ \\
Mato Grosso do & 35.714 .553 & 10.886 .905 & $30,48 \%$ \\
Sul & 27.772 .052 & 3.939 .535 & $14,19 \%$ \\
Tocantins & 58.652 .212 & 6.490 .333 & $11,07 \%$ \\
Minas Gerais & 578.000 & 46.876 & $8,11 \%$ \\
Distrito Federal & 90.336 .619 & 7.208 .811 & $7,98 \%$ \\
Mato Grosso & 33.193 .745 & 1.798 .870 & $5,42 \%$ \\
Maranhão & 24.822 .280 & 881.262 & $3,55 \%$ \\
São Paulo & 56.473 .318 & 1.630 .542 & $2,89 \%$ \\
Bahia & 23.759 .055 & 521.000 & $2,19 \%$ \\
Rondônia & 25.157 .774 & 288.038 & $1,14 \%$ \\
Piauí & 124.795 .467 & 227.000 & $0,18 \%$ \\
Pará & 19.930 .792 & 28.671 & $0,14 \%$ \\
Paraná & A & $2012)$. & \\
\hline
\end{tabular}

Fonte: Adaptado de Censo Agropecuário 2006 (IBGE, 2012). 
O uso de pastagens como principal fonte de alimento para ruminantes é comprovadamente a alternativa mais barata de alimentação dos rebanhos. O potencial das pastagens tropicais para a produção de carne e leite tem sido bastante discutido nos últimos 30 anos (FARIA et al., 1997) e reconhecido como superior aos das pastagens temperadas (SILVA \& SBRISSIA, 2000). Segundo Brossard \& Barcellos (2005), no Cerrado, a produção pecuária, particularmente a de gado de corte, passou rapidamente do manejo de recursos forrageiros da savana herbácea e arbórea, como fonte de alimento para o gado, à exploração dos recursos de pastagens cultivadas. De acordo com os mesmos autores, a conversão da vegetação nativa em pastagens cultivadas representou uma alternativa para aumentar a produção de carne da região. Isso foi obtido pela introdução de espécies forrageiras de origem africana do gênero Brachiaria, com grande capacidade de adaptação a diferentes condições de solos e clima. A taxa de lotação passou rapidamente de 0,2 a 0,4 UA/ha/ano para 0,8 a 1,0 $\mathrm{UA} / \mathrm{ha} / \mathrm{ano}(\mathrm{UA}=$ unidade animal) (MARTHA Jr. et al., 2006).

Atualmente, a Brachiaria corresponde a mais de $80 \%$ das pastagens cultivadas do Centro-Oeste brasileiro. Segundo Souza (1991) e EMBRAPA (2004), a expansão das áreas de pastagens cultivadas com Brachiaria no Brasil foram expressivas: nos últimos 20 anos, essa expansão foi de tal magnitude que espécies como Brachiaria decumbens (Figura 1a,b), Brachiaria brizantha e Brachiaria humidicola passaram, da condição de espécies desconhecidas em nosso meio, para se constituírem na base da alimentação de uma considerável fração do rebanho brasileiro, ocupando milhões de hectares, especialmente, nas áreas de Cerrado. Ainda dentro dessa linha, Soares Filho (1994) afirmou que a Brachiaria é o capim mais plantado no país, sendo utilizado na cria, recria e engorda dos animais. Aproximadamente $85 \%$ das pastagens cultivadas do Cerrado correspondem ao gênero Brachiaria (Tabela 2). Ela vem ocupando áreas de pastagens nativas, as quais apresentam baixo rendimento de forragem, especialmente na estação seca, ocasionando perda de peso nos animais. Outras espécies forrageiras que são encontradas no Cerrado são o Panicum e o Andropogon (MARTHA Jr. \& VILELA, 2002).

Tabela 2. Área e porcentagem de ocupação das principais espécies de pastagens cultivadas no Cerrado.

\begin{tabular}{lcc}
\hline \multicolumn{1}{c}{ Gênero } & Área & Distribuição relativa (\%) \\
\hline Brachiaria & 42,5 & 85 \\
Panicum & 5,5 & 11 \\
Andropogon e outros & 2,0 & 4
\end{tabular}

Fonte: adaptado de Martha Jr. \& Vilela (2002). 


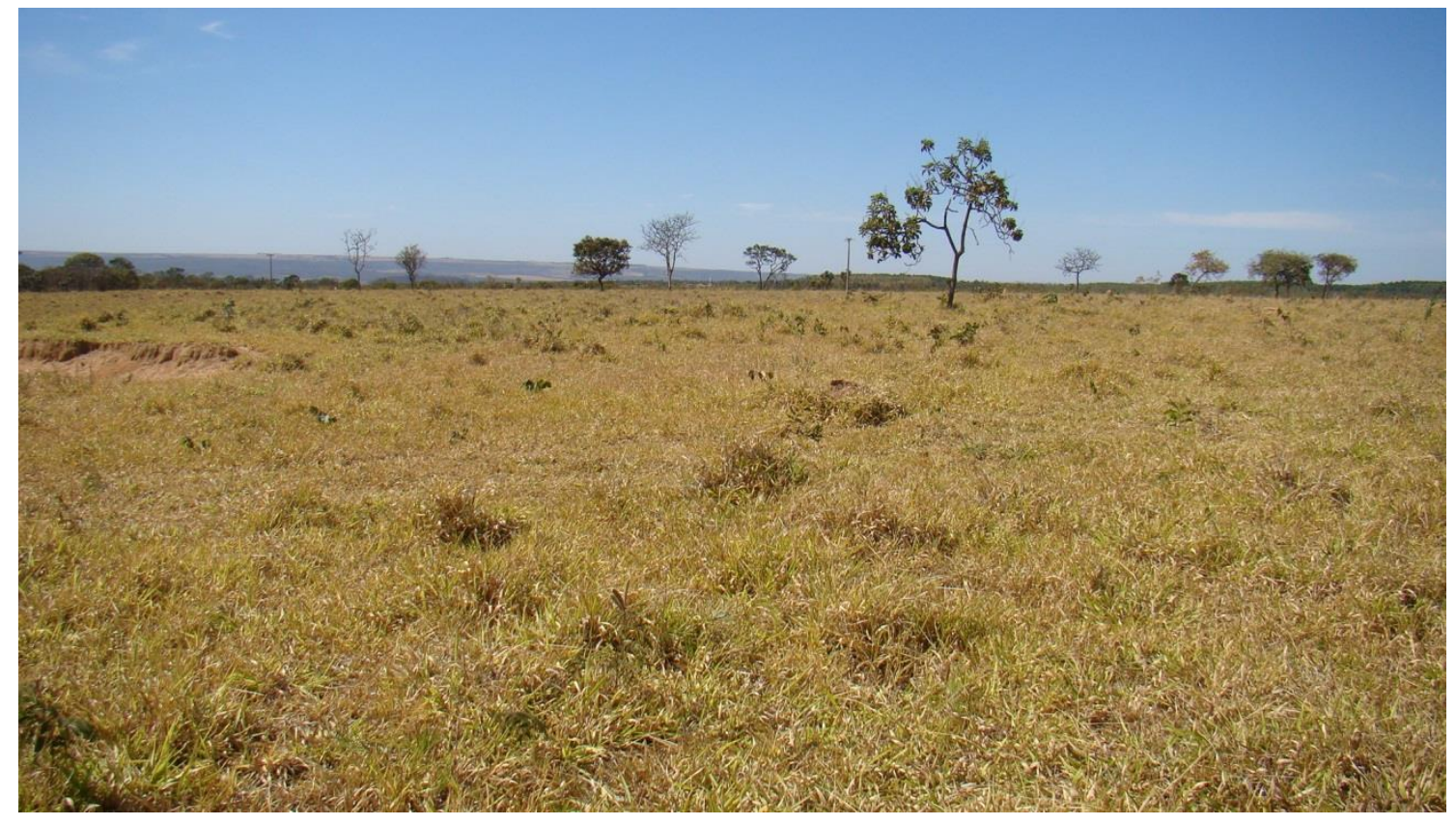

(a)

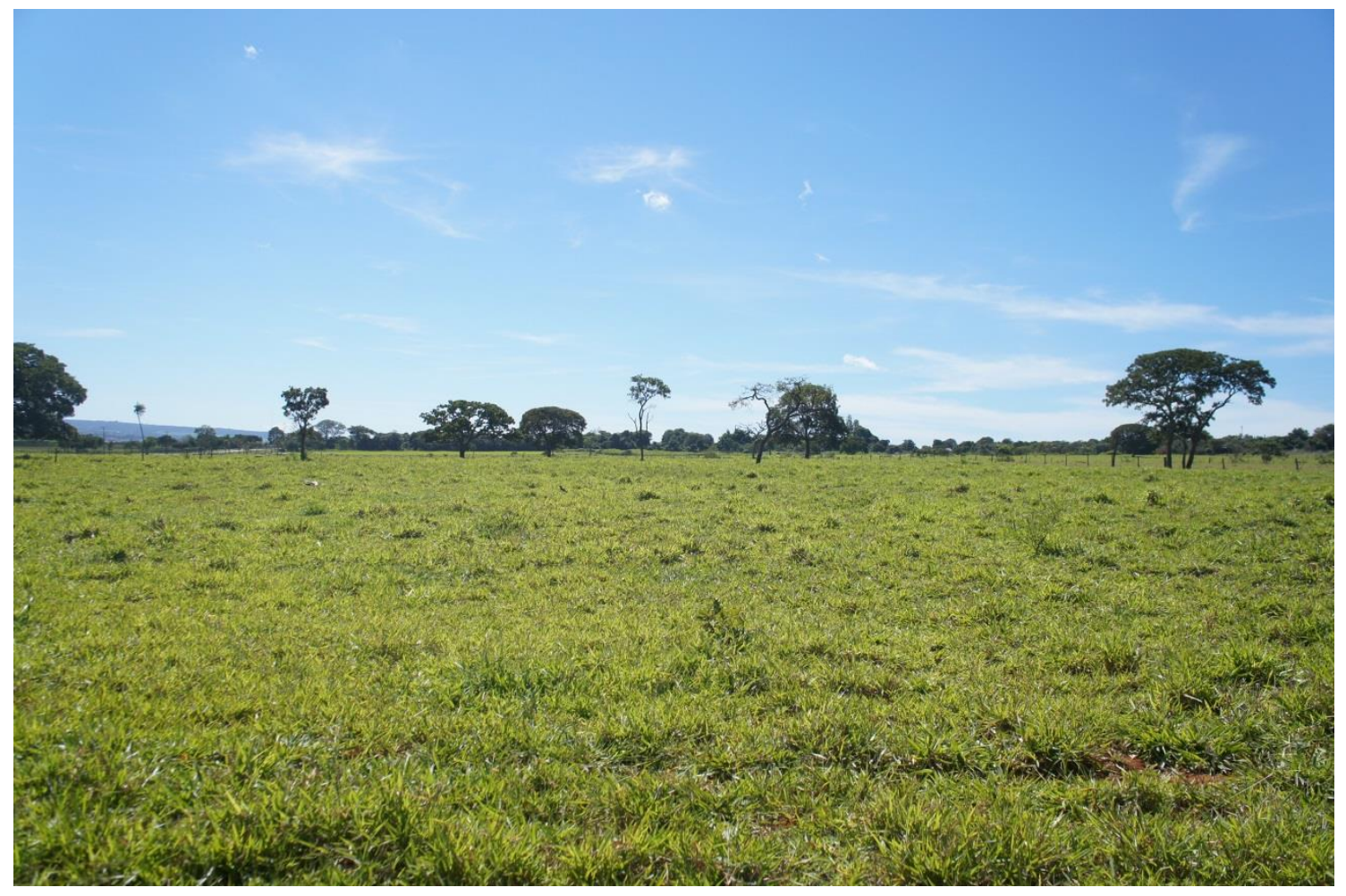

(b)

Figura 1. Vista geral de áreas plantadas com Brachiaria decumbens no campo experimental da Embrapa Cerrados, em Planaltina/DF (a) área de pastagem no pico da estação seca setembro/2013; (b) área de pastagem no pico da estação chuvosa - janeiro/2014. Foto: K. Borges. 
Franco \& Rosa (2003) aferiram que, com o passar do tempo, após o seu estabelecimento, uma pastagem vai aos poucos perdendo o seu vigor vegetativo e consequentemente diminuindo a sua capacidade de produção de forragem e sua cobertura vegetal do solo, o que permite o aparecimento de plantas invasoras. Vários fatores são responsáveis por essa perda na capacidade produtiva das pastagens, dentre os quais podem ser destacadas a perda de fertilidade do solo, o manejo inadequado, o sobrepastejo e as condições climáticas desfavoráveis. Tais fatores são responsáveis pela degradação das pastagens. Segundo Macedo (2005), os solos ocupados por pastagens são, em geral, marginais, quando comparados àqueles usados pela agricultura. Esses solos apresentam problemas de fertilidade natural, acidez, topografia, pedregosidade ou limitações de drenagem.

O mau manejo do sistema solo-forrageira-animal e o gerenciamento ineficiente do negócio explicam o fato de que, atualmente, $60 \%$ a $70 \%$ das pastagens cultivadas no Cerrado apresentam algum grau de degradação (MARTHA Jr. \& VILELA, 2002). Entende-se por degradação das pastagens o processo evolutivo de perda e vigor, de produtividade, de capacidade de recuperação natural das pastagens para sustentar os níveis de produção e de qualidade exigidos pelos animais, assim como, a de superar os efeitos nocivos de pragas, doenças e plantas invasoras, culminando com a degradação avançada dos recursos naturais, em razão de manejos inadequados (MACEDO \& ZIMMER, 1993). Em outro extremo, Dias Filho (2011) afirmou que a degradação das pastagens pode ser caracterizada pela intensa diminuição da vegetação da área, provocada pela degradação do solo, que, por diversas razões de natureza química (perda dos nutrientes e acidificação), física (erosão e compactação), biológica (perda da matéria orgânica), ou climática (estiagem excessiva) estaria perdendo a capacidade de sustentar a produção vegetal significativa. Neste sentido, o uso sustentável das áreas de pastagens é altamente relevante, haja vista que uma boa parte das pastagens cultivadas no Brasil encontra-se com algum nível de degradação (PERON \& EVANGELISTA, 2004; ABDON et al., 2009).

De acordo com Spain \& Gualdrón (1988) e Barcellos et al. (1997) o parâmetro cobertura vegetal representa um dos elementos de discriminação da fase de degradação das pastagens (Tabela 3). A cobertura do solo, associada a outros componentes bióticos como revegetação por espécies nativas e exóticas e termiteiros constitui indicador do processo de perda da capacidade produtiva das pastagens. 
Tabela 3. Fases de degradação de pastagens segundo os parâmetros limitantes e níveis de degradação.

\begin{tabular}{ccc}
\hline $\begin{array}{c}\text { Fases de } \\
\text { Degradação }\end{array}$ & Parâmetros Limitantes & Deterioração \\
\hline 1 & Vigor e qualidade & Leve \\
2 & Fase $1+$ baixa população & Moderado \\
3 & Fase $1+2+$ invasoras & Forte \\
4 & Fase $1+2+3+$ formigas e cupins & Muito forte \\
5 & Fase $1+2+3+4+$ baixa cobertura do & Muito forte \\
6 & solo & Muito forte \\
\hline
\end{tabular}

Fonte: Adaptado de Spain \& Gualdrón (1988).

O manejo inadequado, em particular o uso sistemático de densidades animais que excedam a capacidade do pasto de se recuperar do pastejo e do pisoteio, tem sido apontado como uma das principais causas, de influência antrópica direta, que contribui para a degradação das pastagens no mundo (FAO, 2009). Considerando que as pastagens produtivas podem aumentar os estoques de carbono no sistema além dos níveis encontrados na vegetação nativa adjacente, e sabendo-se que existem mais de 50 milhões de hectares de pastagens cultivadas no Cerrado, das quais pelo menos $50 \%$ podem ser consideradas como tendo algum nível de degradação, há que se levar em conta que a recuperação destas pastagens terá um grande impacto do ponto de vista não só do aumento da produção animal, mas também do aumento de estoque de carbono em solos sob pastagens cultivadas. Concomitantemente, o aumento das áreas de pastagens produtivas poderá contribuir, significativamente, para a melhoria dos parâmetros hídricos e para a redução da erosão de solos nestas regiões, além da diminuição do efeito estufa pelo sequestro de C (BODDEY et al., 2001).

Do ponto de vista ambiental, a recuperação de pastagens também é vista de forma positiva, pois reduz o desmatamento de novas áreas para a formação de pastagens (OLIVEIRA \& CORSI, 2005). Em ambiente de Cerrado os solos descobertos podem perder até 59 toneladas de solo/ha/ano, enquanto as pastagens, quando bem formadas, representam o sistema de maior proteção aos riscos de erosão (DEDECEK et al., 1986). Nos últimos anos, o aumento na conscientização com as questões ambientais tem levado a mudanças no paradigma de produção animal a pasto no Brasil, levando a que um número crescente de produtores busque mais eficiência (i.e., produzir mais em menos área), modernizando os sistemas de produção atualmente existentes (DIAS FILHO, 2010). 
Segundo Oliveira \& Corsi (2005), a sustentabilidade econômica de um sistema pecuário em que as pastagens estão degradadas é muito pequena. Esses autores identificaram três etapas básicas de recuperação de uma pastagem degradada: correção da acidez do solo (calagem, aplicação superficial de calcário); correção da fertilidade do solo (principalmente fósforo e potássio); e adubação de manutenção (principalmente nitrogênio). A calagem e a aplicação de fertilizantes químicos permitem aumentos crescentes ao longo de alguns anos da produção de forragem (Figura 2). Com isso, é possível dobrar a média de lotação animal, passando de algo ao redor de $1 \mathrm{UA} / \mathrm{ha}$ para $2 \mathrm{UA} / \mathrm{ha}(\mathrm{UA}=$ unidade animal, $450 \mathrm{~kg}$ de peso vivo).

$\square$ Calagem + Fertilização $\square$ Testemunhas

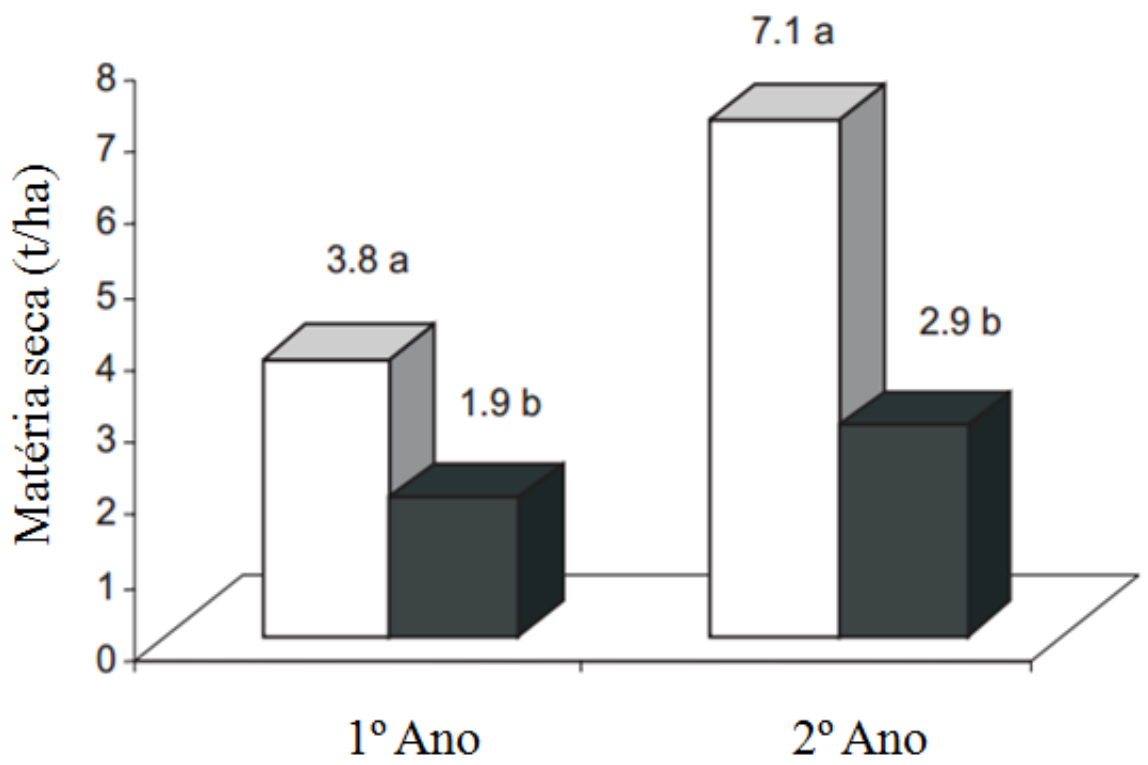

Figura 2. Aumento da produção de forragem de Brachiaria decumbens em função da prática de calagem associada à fertilização. Fonte: Oliveira et al. (2003). Médias de um mesmo ano, seguidas de letras distintas diferem entre si pelo teste $\mathrm{F}(\mathrm{p} \leq 0,01)$.

Leva-se em conta também que com um acréscimo no suprimento de $\mathrm{N}$ estimula o crescimento, atrasa a senescência, e muda a morfologia das plantas. Além disso, o aumento nos níveis de adubação nitrogenada causa um aumento significativo no conteúdo de clorofila das folhas (FERNÁNDEZ et al., 1994).

Oliveira \& Corsi (2005) ressaltaram ainda que recuperar uma pastagem é muito mais barato do que estabelecê-la em uma outra área, embora a possibilidade de recuperação depende da densidade populacional da forrageira, ou seja, devem existir número suficiente de plantas para permitir o restabelecimento da pastagem. Técnicas que têm sido indicadas para 
recuperação de pastos degradados incluem o sistema Voisin (sistema intensivo de manejo de gado e pastagem, não utiliza o fogo no manejo e o animal deve permanecer poucos dias no mesmo piquete para preservar a rebrota das forrageiras), o pousio, a gradagem para reduzir a compactação de solos causada pelo pisoteio dos animais e a integração lavoura-pecuáriafloresta.

\section{2. ÍNDICES DE VEGETAÇÃO}

Índices de vegetação correspondem a uma técnica de realce de imagens por divisão de bandas que objetiva realçar áreas da imagem com cobertura vegetal moderada ou densa e têm sido amplamente empregados em diversos trabalhos que buscam relacionar as informações captadas pelos sensores com a vegetação presente na área imageada. Através destes índices, são obtidas informações a respeito da quantidade de biomassa verde e dos parâmetros de crescimento e desenvolvimento da vegetação (JUNGES et al., 2007). Esses índices, ao invés de realçar a área toda da imagem, realçam apenas porções da imagem, no caso, as que contêm cobertura vegetal verde.

O índice de vegetação resulta da combinação da medida da radiação eletromagnética refletida pela vegetação em algumas bandas espectrais do espectro-eletromagnético, que guardam certa relação com a quantidade e o estado da vegetação em uma dada área da superfície terrestre (HUETE \& JUSTICE, 1999). Em função disto, uma característica inerente aos índices de vegetação é a redução no volume dos dados a ser analisado, pois praticamente toda a informação referente à vegetação fica resumida somente a um intervalo (RIZZI, 2004). Estes índices são relacionados a parâmetros biofísicos da cobertura vegetal, como biomassa e índice de área foliar, além de minimizarem os efeitos de iluminação da cena, declividade da superfície e geometria de aquisição que influenciam os valores de reflectância da vegetação (PONZONI \& SHIMABUKURU 2010).

Ao utilizar índices de vegetação, um fator relevante é a possibilidade de sua aplicação independentemente da situação temporal ou espacial, ou seja, sua aplicação não pode ser restrita a determinada região ou período. Para um índice de vegetação ser considerado ideal, ele deve responder a variações sutis no estado fenológico da vegetação, e não pode ser fortemente influenciado por variações nas condições e tipos de solo, na geometria de iluminação e visada e nas condições atmosféricas (JACKSON \& HUETE, 1991) 
As faixas do vermelho e do infravermelho próximo são mais utilizadas, por conter mais de $90 \%$ da variação da resposta espectral da vegetação; portanto, estes índices realçam o comportamento espectral da vegetação, correlacionando-os com os parâmetros biofísicos da mesma (ROSA, 2003).

A grande maioria dos índices de vegetação utiliza bandas espectrais posicionadas na faixa espectral do vermelho (Red) e do infravermelho próximo (NIR) (Figura 3), as quais apresentam, respectivamente, forte absorção da radiação eletromagnética incidente, relacionada com a atividade fotossintética das plantas e elevada reflexão da radiação, relacionada com a estrutura interna das folhas. Nos diferentes índices de vegetação, as áreas da cena que correspondem à cobertura vegetal verde apresentam valores elevados de reflectância ou tonalidades de cinza mais claras enquanto as áreas sem cobertura vegetal verde ou com cobertura incipiente tendem a apresentar valores baixos de reflectância ou tonalidades de cinza mais escuros (MENESES \& ALMEIDA, 2012).

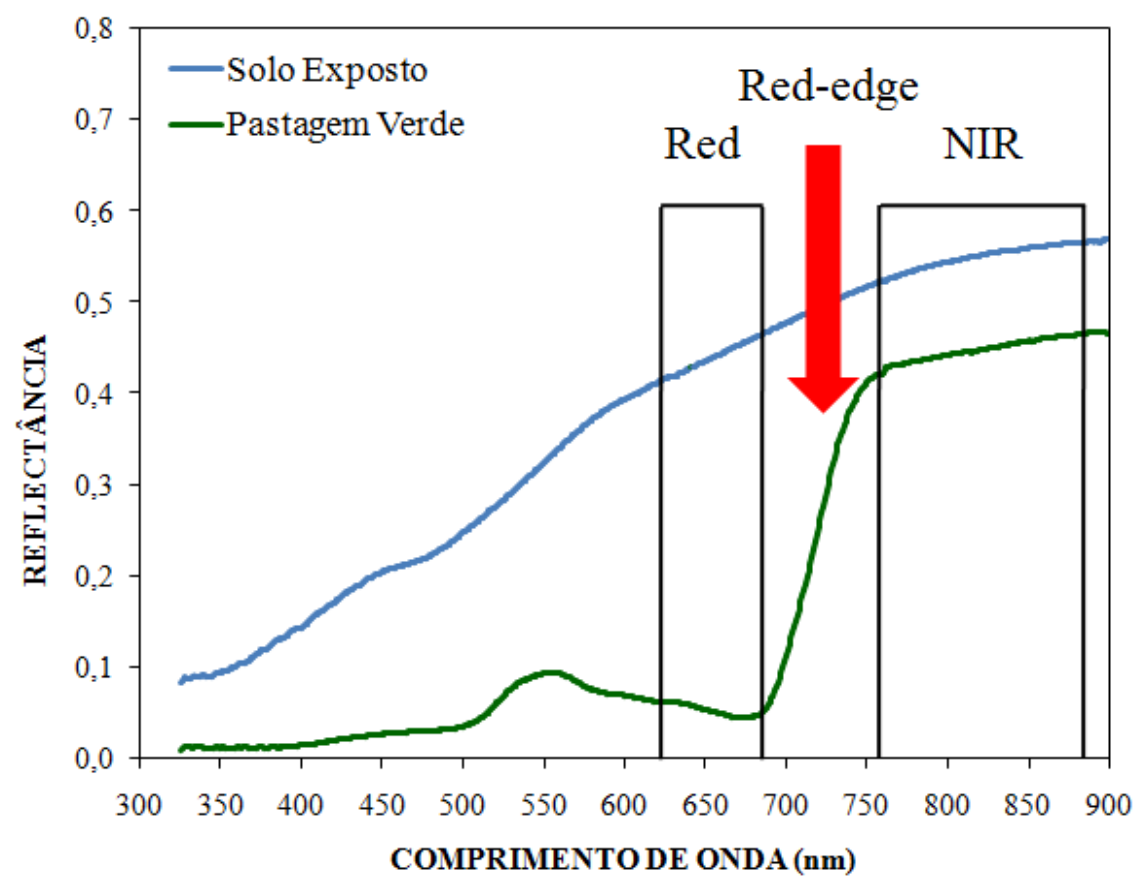

Figura 3. Reflectâncias na faixa espectral de 300 a $900 \mathrm{~nm}$ de uma amostra de solo vermelho (Latossolo Vermelho Escuro) e de um a área coberta com pastagem cultivada verde. Os termos Red e NIR correspondem, respectivamente, às bandas de absorção da vegetação verde na faixa espectral do vermelho e à alta reflexão da radiação incidente na faixa espectral do infravermelho próximo. A faixa espectral situada entre o Red e o NIR é conhecida como rededge (aumento abrupto da reflectância de folhas verdes). 
O índice de vegetação mais simples em termos de formulação matemática foi proposto por Tucker (1979) e foi denominado de Razão Simples (SR, em inglês, Simple Ratio): divisão simples entre as bandas do NIR e do Red (Eq. 1). O intervalo de valores resultantes pode variar de 0 a mais de 30, embora coberturas vegetais densas geralmente são representadas por índices que variam de 2 a 8 (EXCELIS, 2015).

$$
S R=\frac{N I R}{R e d}
$$

onde NIR = reflectância na banda espectral do infravermelho próximo; $R e d=$ reflectância na banda espectral do vermelho.

A título de ilustração, na Figura 4a, é mostrada uma composição colorida RGB das bandas 5, 4 e 3 do satélite RapidEye, realçada pela técnica de equalização de histograma. Nessa composição colorida, áreas com cobertura vegetal verde aparecem com coloração avermelhada, áreas urbanas, solo exposto e palhada seca aparecem com coloração esbranquiçada, vegetações herbácea e arbustiva aparecem com coloração marrom-escuro e massas d'água com coloração escura ou azul-escuro. Na Figura 4b, é mostrado o resultado da divisão das bandas do NIR e do Red do RapidEye. As áreas com tonalidades bastante claras correspondem às áreas com maior densidade de cobertura vegetal verde. Por outro lado, os corpos d'água aparecem com tonalidade muito escura. Finalmente, terrenos com cobertura vegetal esparsa apresentam tonalidade acinzentada.

Rouse et al. (1973) propuseram o Índice de Vegetação por Diferença Normalizada (NDVI, Normalized Difference Vegetation Index) (Eq. 2), o qual corresponde à diferença entre as reflectâncias das bandas no NIR e Red, normalizada pela soma das duas bandas. De acordo com Jensen (2009), o NDVI apresenta elevada capacidade de monitorar mudanças sazonais e interanuais da vegetação e de reduzir ruídos multiplicativos provocados pelas diferenças nas condições de iluminação solar, presença de nuvens, atenuações atmosféricas e variações topográficas. De modo geral, o NDVI é mais sensível à presença de pigmentos que participam dos processos fotossintéticos, em particular ao conteúdo de clorofila (GITELSON et al., 1996; HUETE et al., 1997, 2002) e minimiza algumas fontes externas de ruído como, por exemplo, sombras de nuvens (JUSTICE et al., 1998). O NDVI assume valores reais que variam dentro do intervalo de -1 a 1 (PONZONI \& SHIMABUKURO, 2010). Quanto mais próximo de 1, mais densa é a vegetação; valor nulo indica superfície não vegetada. 


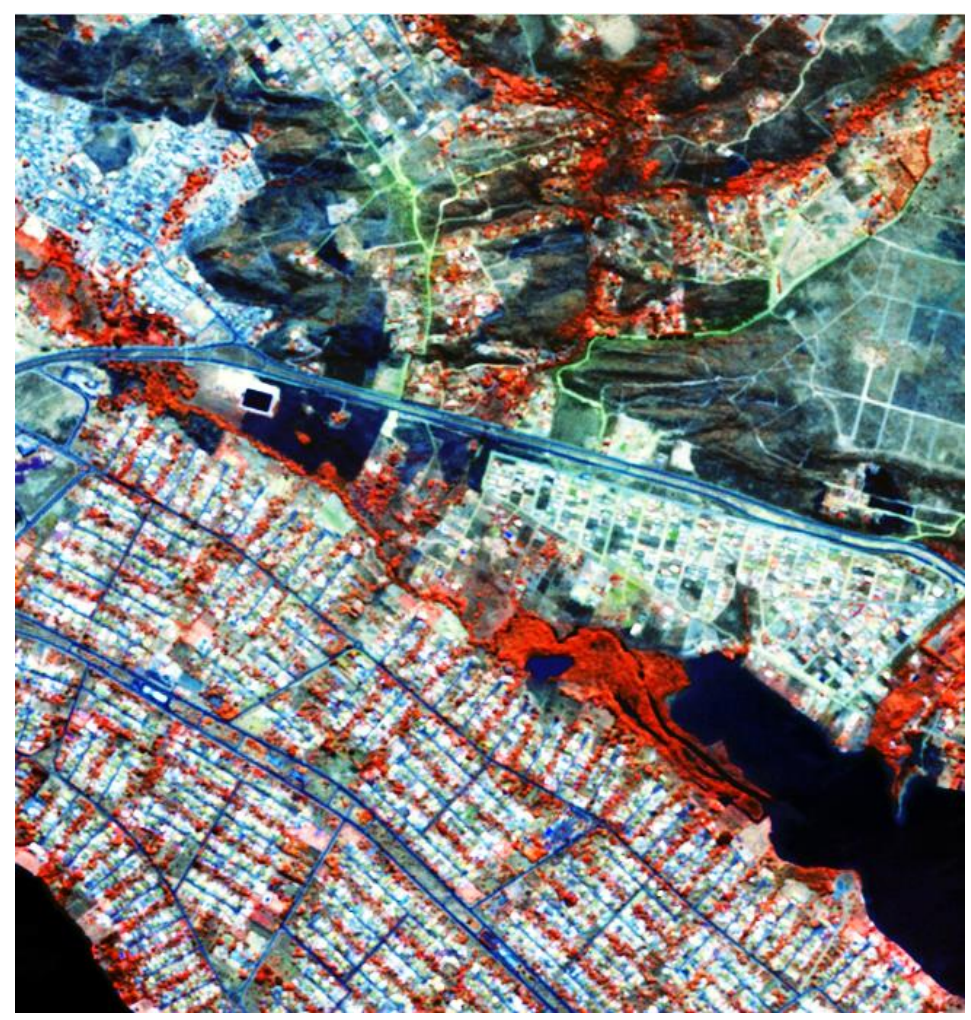

(a)
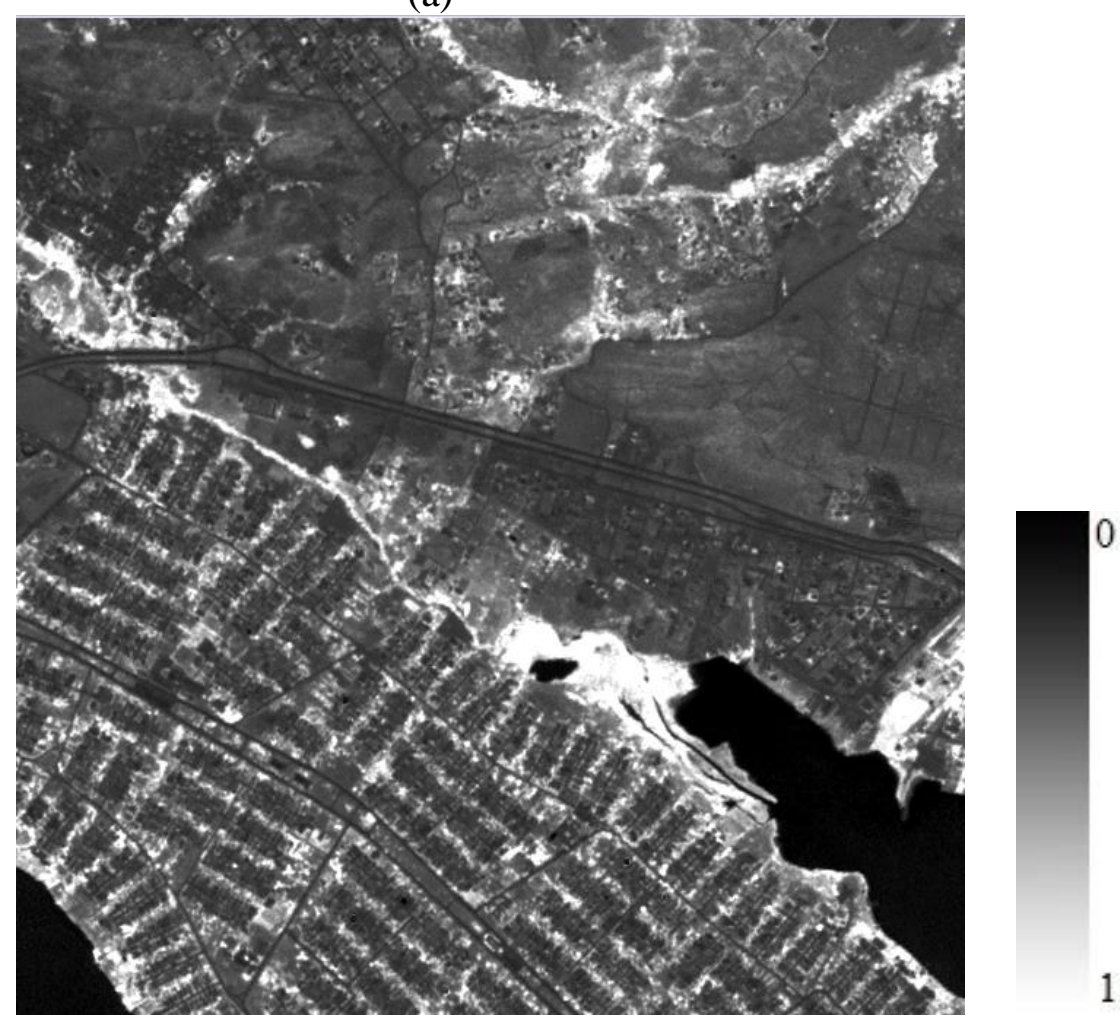

(b)

Figura 4. Composição colorida das bandas R(5) 760-850 nm G(4) 690-730 nm B(3) 630-685 nm do RapidEye (a) e índice de vegetação denominada Razão Simples (SR) (b) da porção centro-norte do Distrito Federal (cena: 2331802; data da imagem: 01 de setembro de 2011). Áreas de cobertura vegetal verde aparecem, respectivamente, com coloração avermelhada e tonalidade clara. 


$$
N D V I=\frac{N I R-R e d}{N I R+R e d}
$$

Esse índice é sensível à presença da vegetação sadia, pois, usualmente, essa diminui a resposta no vermelho, devido à absorção por clorofila, e aumenta no infravermelho próximo, devido ao espalhamento pelos tecidos da folha, fazendo com que os alvos diferentes da vegetação (como água, solo exposto, etc.) sejam facilmente distinguíveis (ALMEIDA, 1998). Outra característica importante é o fato do NDVI minimizar os efeitos topográficos, o que permite uma análise da distribuição da biomassa sem a influência do relevo (LAU, 1997). O NDVI é um dos índices de vegetação mais utilizados na literatura e faz parte dos produtos do sensor Moderate Resolution Imaging Spectrorradiometer (MODIS) denominados de readyto-use, isto é, prontos para serem utilizados. Limitações do NDVI estão relacionadas com a saturação em áreas com cobertura vegetal muito densa, como é o caso de florestas tropicais úmidas (HUETE et al., 1997) e com a forte interferência do solo (HUETE, 1988).

A Figura 5 mostra a relação entre dados de NDVI e as bandas originais do Red e do NIR para 1850 pontos distribuídos por toda a área da imagem considerada na figura anterior, em diferentes classes espectrais. Percebe-se que o NDVI possui uma forte relação não-linear com a banda Red (Figura 5a) e uma fraca relação com a banda do NIR (Figura 5b), corroborando com os resultados obtidos por outros autores, por exemplo, Galvão et al. (1998), e Epiphanio \& Huete (1995). Isto significa que o NDVI é sensível às variações nas atividades fotossintéticas da vegetação, as quais estão diretamente relacionadas com a intensidade de absorção da radiação incidente na faixa espectral do vermelho.

Visando minimizar os efeitos do solo no NDVI, Huete (1988) propôs o Índice de Vegetação Ajustado pelos Efeitos do Solo (SAVI em inglês Soil Adjusted Vegetation Index) e que, posteriormente, evoluiu para o Índice de Vegetação Realçado (EVI, em inglês, Enhanced Vegetation Index) (HUETE et al., 2002). Em relação ao SAVI, o EVI minimiza os efeitos da atmosfera por meio da incorporação de uma banda na faixa espectral do azul (JUSTICE et al., 1998) (Eq. 3). Este último índice de vegetação também faz parte de um dos produtos do sensor MODIS ready-to-use. 


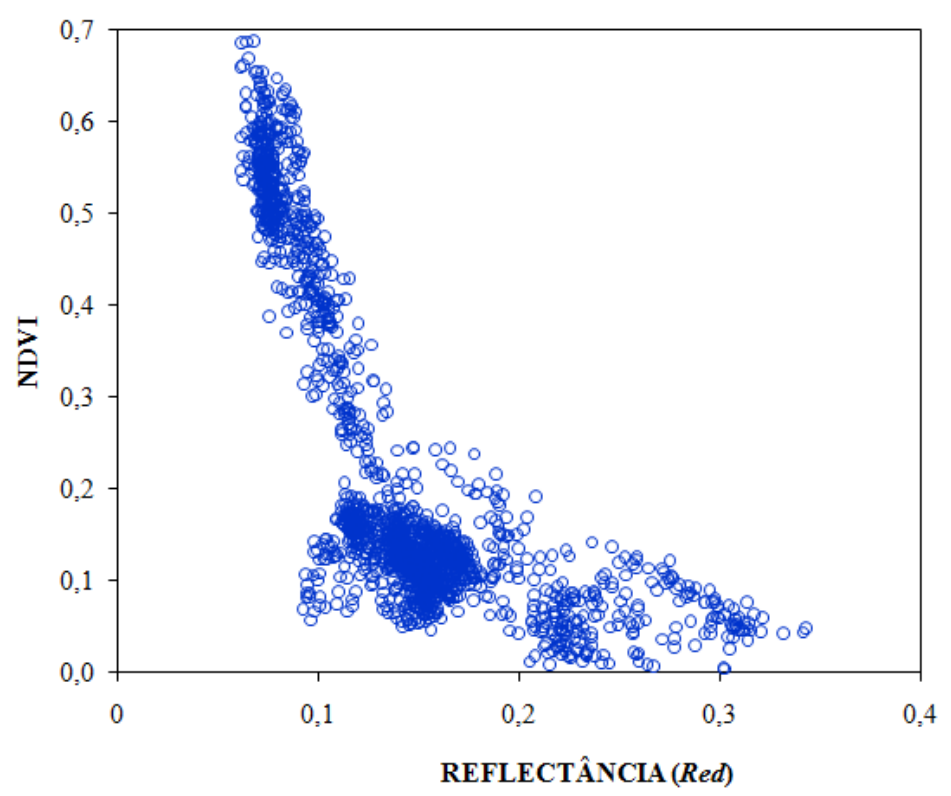

(a)

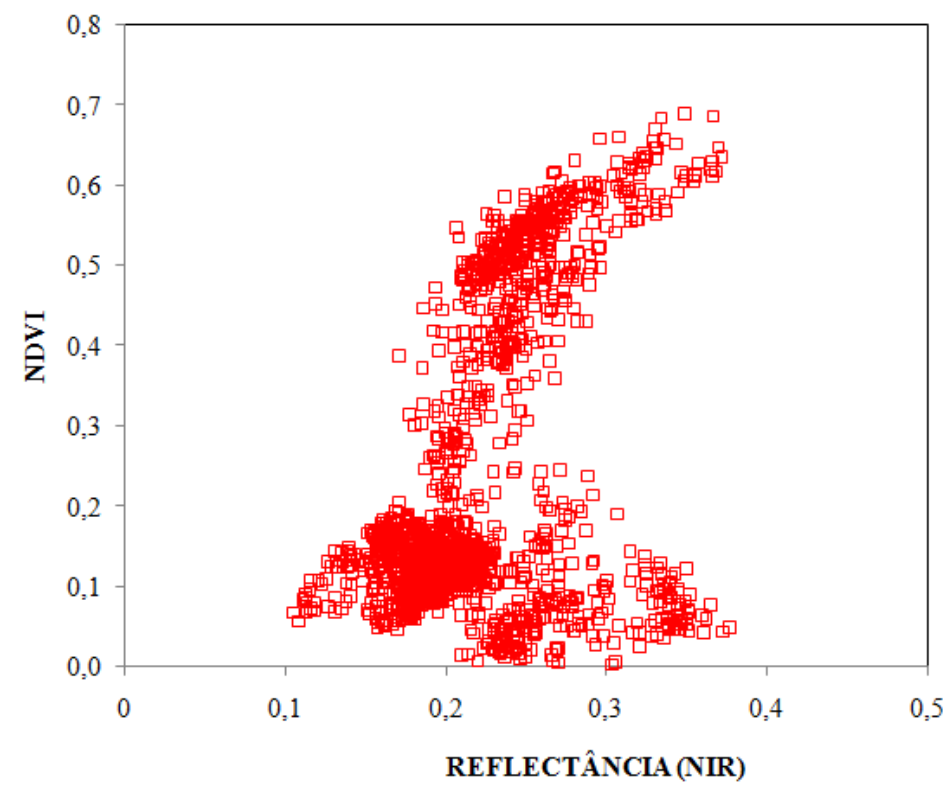

(b)

Figura 5. Relação entre NDVI e as bandas espectrais originais do vermelho (Red) (a) e do infravermelho próximo (NIR) da porção centro-norte do Distrito Federal. Dados obtidos por meio da cena RapidEye de 01 de setembro de 2011, identificação da cena: 2331802.

$$
E V I=2,5 \frac{N I R-\text { Red }}{\text { NIR }+6 \text { Red }-7,5 \text { Blue }+1}
$$

onde: $\mathrm{NIR}=$ fluxo radiante refletido no infravermelho próximo; $R e d=$ fluxo radiante refletido no vermelho; e Blue = fluxo radiante refletido no azul. 
Trabalhos como o de Shimabukuro et al. (2001), Ferreira et al. (2001) e Ratana et al. (2003) têm mostrado que o índice EVI pode ser utilizado em análises de cobertura vegetal com eficiência, uma vez que foi desenvolvido para otimizar o sinal da vegetação, melhorando a sensibilidade em regiões com maiores densidades de biomassa, além do monitoramento da vegetação por meio de uma ligação do sinal de fundo do dossel e da redução das influências atmosféricas (LATORRE et al., 2003). Estudos anteriores têm demonstrado que o EVI é mais sensível à estrutura da vegetação, isto é, mais sensível às variações espectrais na banda do NIR (BREUNIG et al., 2011).

Considerando-se que nem todos os sistemas sensores imageadores possuem banda na faixa espectral do azul (por exemplo, sensor ASTER), Jiang et al. (2008) propuseram o EVI2 sem o uso da banda azul. A fundamentação teórica por trás do EVI2 é a de que as bandas espectrais no visível são altamente correlacionadas entre si para diversos tipos de uso e cobertura de terras. Dentro desse contexto, por meio do uso da relação Red $=\mathrm{c}$ x Blue, a equação do EVI2 foi proposto conforme formulação abaixo (Eq. 4). Comparação empírica entre EVI e EVI2 de diferentes regiões do Brasil tem mostrado coeficientes de correlação superiores a 0,98 (Figura 6).

$$
E V I 2=2,5 \frac{N I R-R e d}{N I R+2,4 \text { Red }+1}
$$

Outra linha de desenvolvimento são os índices que substituem ou não a banda Red pela red-edge. Por exemplo, Gitelson \& Merzlyak (1994), Gitelson (2003) e Dash \& Curran

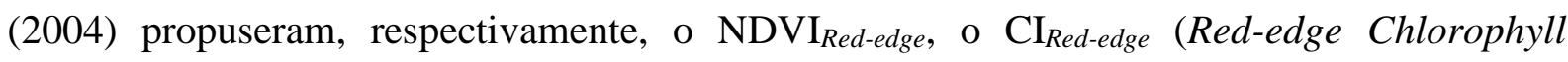
Index) (Eq. 5) e o MTCI (MERIS Terrestrial Chlorophyll Index) (Eq. 6).

$$
\begin{gathered}
C I_{\text {Red-edge }}=\frac{N I R}{\text { Red-edge }}-1 \\
M T C I=\frac{N I R-\text { Red-edge }}{\text { Red-edge-Red }}-1
\end{gathered}
$$

onde NIR = reflectância na banda do infravermelho próximo; Red-edge $=$ reflectância na banda do red-edge; e Red = reflectância na banda do vermelho. 


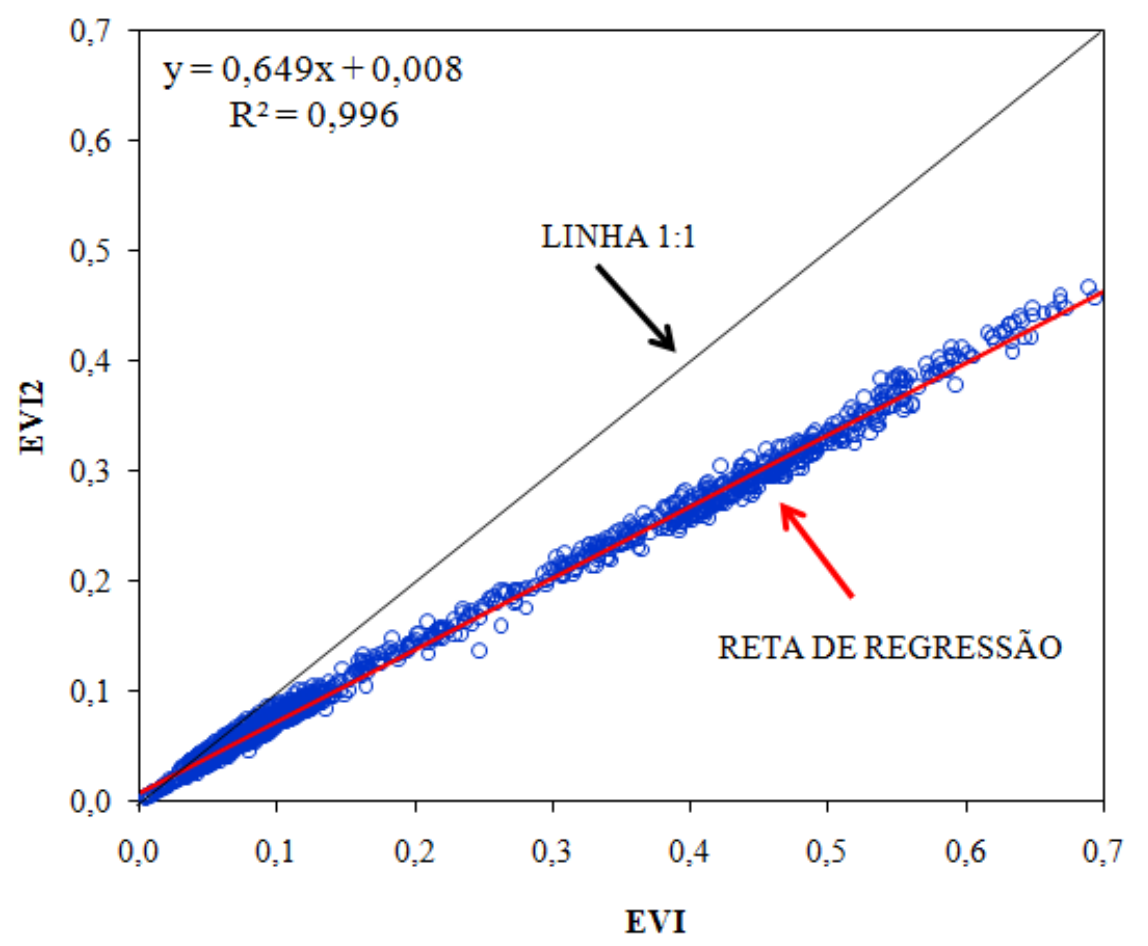

Figura 6. Relação entre EVI e EVI2 da porção centro-norte do Distrito Federal. Dados obtidos por meio da cena RapidEye de 01 de setembro de 2011, identificação da cena: 2331802. Total de pontos: 1.845 valores de reflectância.

Atualmente, é relativamente comum encontrar estudos que testam diversos índices de vegetação para diferentes aplicações. Por exemplo, Haboudane et al. (2004) avaliaram 12 índices de vegetação para estimar IAF de soja, milho e trigo. Ramoello et al. (2012) testaram 24 índices para estimativa de conteúdo de nitrogênio em formações campestres da África do Sul. Li et al. (2014) também testaram 24 índices para estimativa de IAF de trigo. 


\section{MATERIAL E MÉTODOS}

Nesta seção, são descritos a área onde foi realizado os trabalhos de campo, e os procedimentos metodológicos utilizados para a realização do trabalho. Dados espectrorradiométricos, fotografias verticais, processamento de imagens, por exemplo, o classificador supervisionado MAXVER, índices de vegetação e alguns dados auxiliares, como valores de pluviosidade na região, foram necessários para alcançar os resultados desta pesquisa.

\section{1. ÁREA DE ESTUDO}

O Distrito Federal subdivide-se em 31 Regiões Administrativas, ocupa uma área de $5.814 \mathrm{~km}^{2}$ no Planalto Central do Brasil e possui altitude média em torno 1.100 metros e população média de 2.570 .160 habitantes (IBGE, 2010). Localizado entre as latitudes $15^{\circ} 30^{\prime}$ $\mathrm{S}$ e $16^{\circ} 03^{\prime} \mathrm{S}$, é delimitada a leste pelo Rio Preto e a Oeste pelo Rio Descoberto, aproximadamente entre as longitudes $47^{\circ} 25^{\prime}$ ' W e $48^{\circ} 12^{\prime}$ W. O Distrito Federal se insere totalmente sob a vegetação característica do Cerrado, caracteriza-se por clima tropical chuvoso, tipo Aw (de acordo com a classificação de Köppen) com médias anuais de 1.500 $\mathrm{mm}$ de precipitação e temperatura média de $21,9^{\circ} \mathrm{C}$, apresenta período chuvoso correspondente aos meses de outubro a março e período seco ocorre de abril a setembro. As características pedológicas mais representativas, de acordo com Reatto et al. (2004), são os Latossolos e os Cambissolos, os quais ocupam aproximadamente $55 \%$ e $30 \%$ do DF, respectivamente.

As áreas de estudo localizadas nos campos experimentais da Embrapa Cerrados em Planaltina/DF. Uma das áreas ( $15^{\circ} 59^{\prime} 60^{\prime}$ 'de latitude sul e $47^{\circ} 72^{\prime} 70^{\prime}$ ' de longitude oeste) correspondeu a Latossolo Vermelho distrófico ( $\mathrm{LVd})$, enquanto a outra área $\left(15^{\circ} 61^{\prime} 30^{\prime \prime} \mathrm{de}\right.$ latitude sul e $47^{\circ} 73^{\prime} 30^{\prime}$ de longitude oeste) correspondeu a Latossolo Vermelho-Amarelo distrófico (LVAd) (Figura 7). 

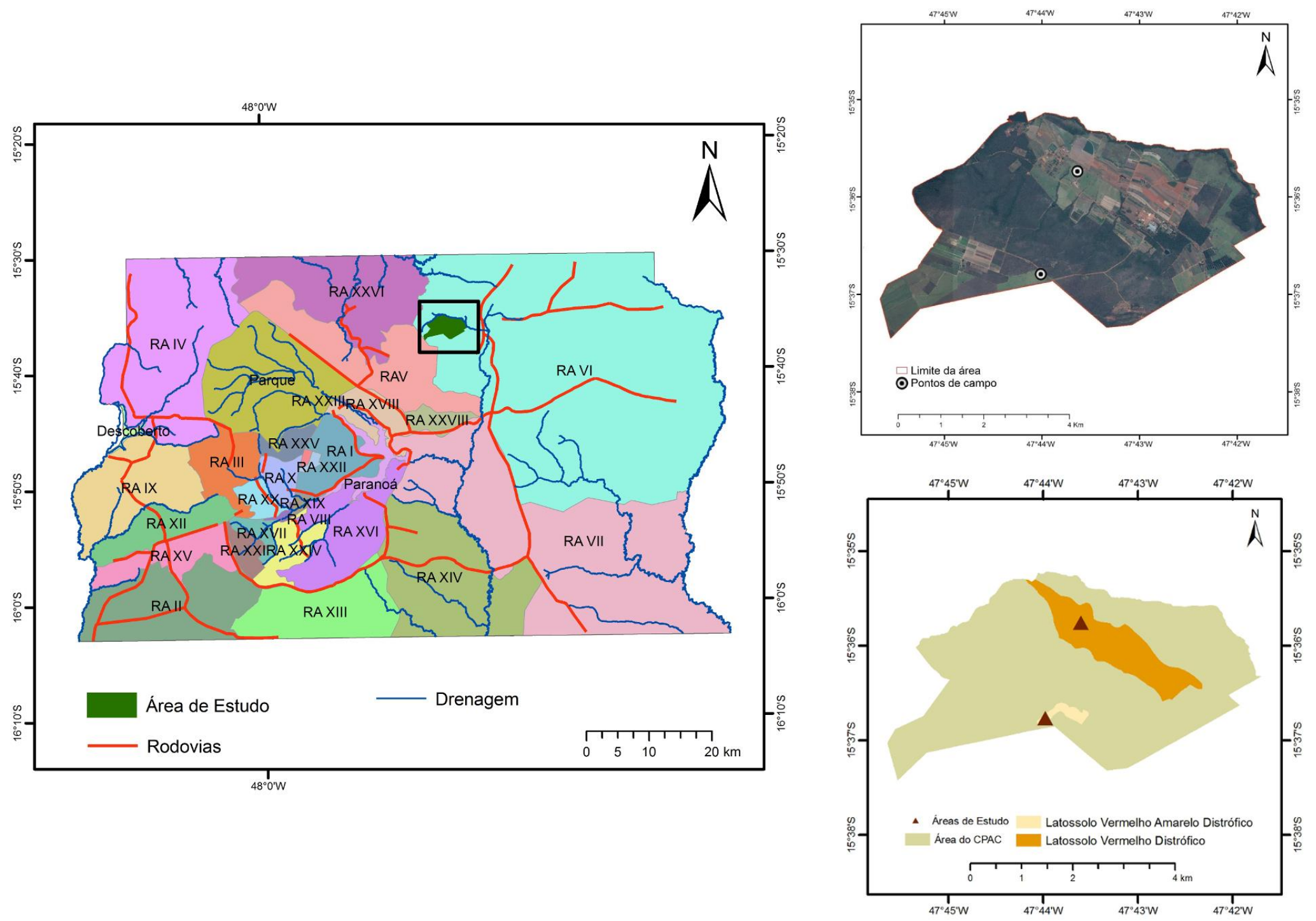

Figura 7. Localização das áreas amostrais nos campos experimentais da Embrapa Cerrados em Planaltina/DF. A imagem corresponde a uma cena do satélite QuickBird de julho de 2013, disponível no programa Google Earth ${ }^{\mathrm{TM}}$. 
Foram adquiridos concomitantemente dados de espectrorradiometria de campo e fotografias digitais verticais de duas áreas de pastagens cultivadas (Brachiaria decumbens). Os dados foram adquiridos em julho de 2013 (estação seca), setembro de 2013 (pico da estação seca), outubro de 2013 (início da estação chuvosa), novembro de 2013 (estação chuvosa) e janeiro de 2014 (pico da estação chuvosa) (Tabela 4). Na Figura. 8, são mostrados os dados de precipitação média mensal e de temperatura, registrados pela estação meteorológica da Embrapa Cerrados ( $15^{\circ} 59^{\prime}$ de latitude sul e $47^{\circ} 71^{\prime}$ de longitude oeste) nos meses de amostragens de campo.

Tabela 4. Data das coletas de dados espectrorradiométricos de campo e de fotografias digitais.

\begin{tabular}{lccccc}
\hline \multicolumn{1}{c}{$\begin{array}{c}\text { Tipo de } \\
\text { solos }\end{array}$} & \multicolumn{5}{c}{ Coleta de dados } \\
\cline { 2 - 6 } & $1^{\mathrm{a}}$ & $2^{\mathrm{a}}$ & $3^{\mathrm{a}}$ & $4^{\mathrm{a}}$ & $5^{\mathrm{a}}$ \\
\hline LVd* $^{*}$ & $26 / 07 / 2013$ & $09 / 09 / 2013$ & $02 / 10 / 2013$ & $18 / 11 / 2013$ & $08 / 01 / 2014$ \\
LVAd** $^{*}$ & $24 / 07 / 2013$ & $02 / 09 / 2013$ & $14 / 10 / 2013$ & $20 / 11 / 2013$ & $08 / 01 / 2014$ \\
\hline
\end{tabular}

* LV d corresponde a Latossolo Vermelho distrófico; **LVAd a Latossolo VermelhoAmarelo distrófico.

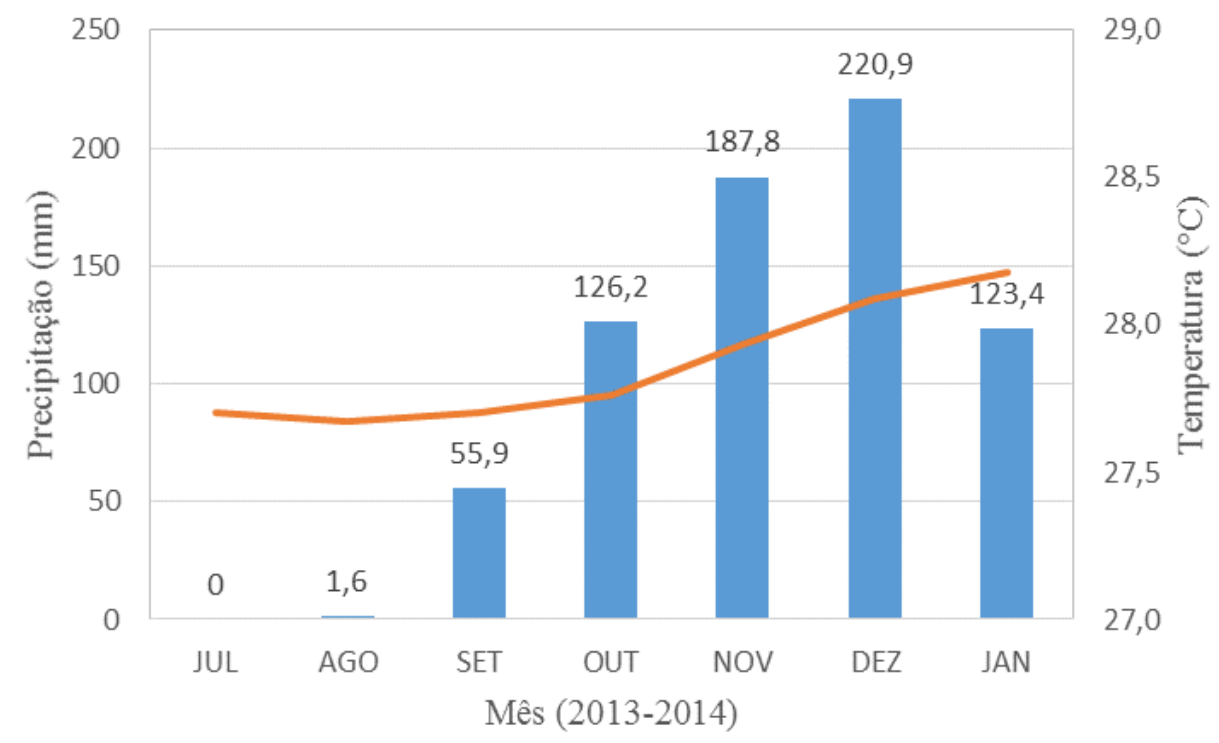

Figura 8. Precipitação e temperatura média mensal nos meses de amostragem de campo de dados espectrorradiométricos e fotografias digitais. 


\subsection{PROCEDIMENTOS METODOLÓGICOS}

Para cada data, foram coletadas 50 amostras de dados espectrorradiométricos e de fotografias digitais (25 amostras para cada tipo de solo, distribuídas aleatoriamente em cada área de pastagem). Foi utilizado o espectrorradiômetro portátil FieldSpec Spectroradiometer da Analytical Spectral Devices (ASD) modelo Handheld Inc. do Instituto de Geografia da Universidade Federal de Uberlândia, o qual adquire dados de reflectância na faixa espectral de 325 - $1075 \mathrm{~nm}$, com $1 \mathrm{~nm}$ de intervalo e IFOV de 25 . A altura do espectrorradiomentro foi de aproximadamente 1 metro do terreno, fixado a uma estrutura metálica. Para cada data e cada área amostral foram obtidas cinco leituras, as quais foram convertidas em uma única leitura por meio de cálculo de média aritmética simples.

Em seguida, foram obtidas fotografias digitais por meio de uma câmera digital RGB convencional de 8 bits e lente com distância focal de 6,1-18,3 mm. As fotos foram obtidas com a câmera disposta verticalmente no terreno a uma altura aproximada de 1 metro. Todas as fotos foram gravadas no formato jpg. e resolução espacial de 1.280 pixels x 960 pixels. A área no terreno fotografada pela câmera correspondeu a aproximadamente 1 metro $\times 80$ centímetros. A aquisição dos dados de radiometria e fotografias sempre foram obtidas no mesmo horário (de 9h da manhã às $11 \mathrm{~h}$ da manhã) e buscando sempre as mesmas condições atmosféricas.

As fotos digitais foram classificadas por meio de um classificador supervisionado por máxima verossimilhança (MAXVER) (SCHOWENGERDT, 1997), disponível no sistema de processamento digital de imagens ENVITM 4.5 para estimar a porcentagem de cobertura verde $(\% \mathrm{CV})$ de cada fotografia obtida. As três classes consideradas na classificação foram folhas verdes, folhas secas e sombras (Figura 9). 

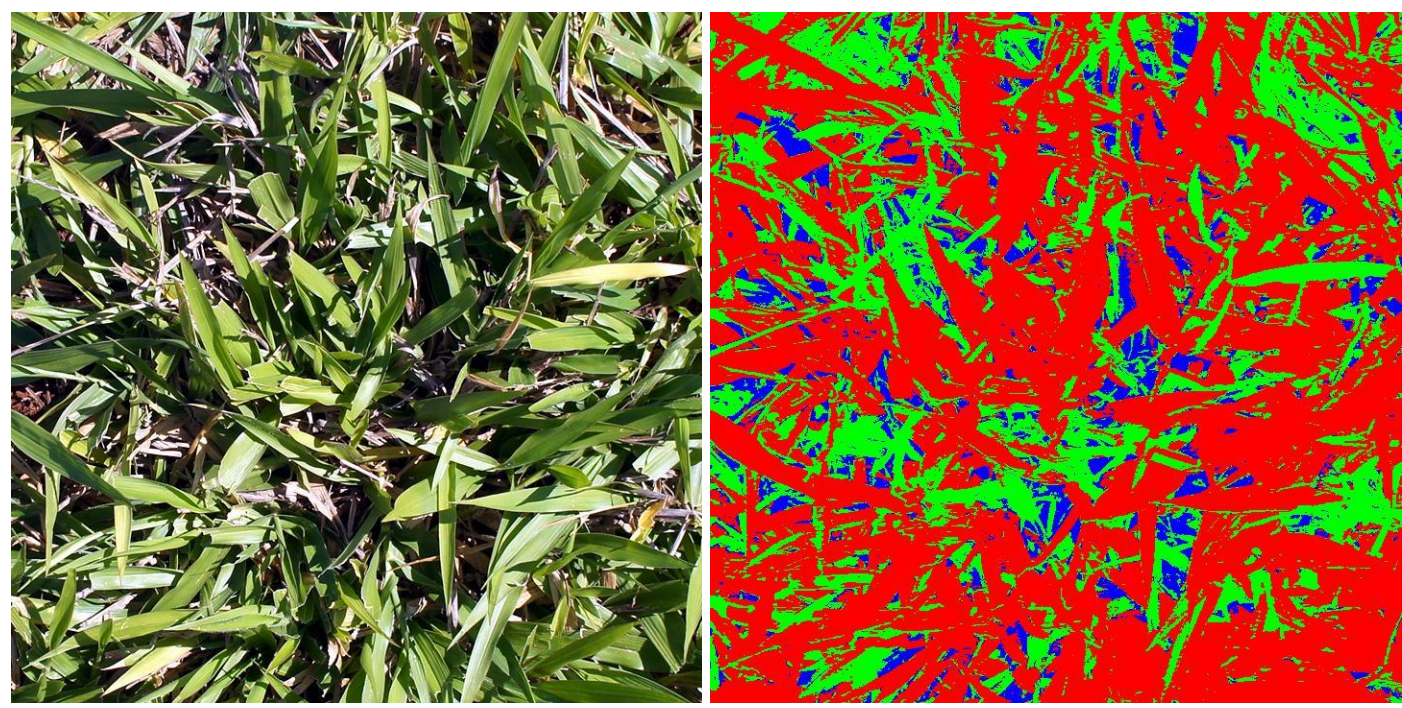

Figura 9. Exemplo de fotografia digital obtida no campo em 08 de janeiro de 2014 e correspondente classificação em três classes espectrais: vegetação verde (em vermelho), palhada seca (em verde) e sombra (em azul).

$\mathrm{O}$ uso de câmeras digitais para estimativa de métricas fenológicas como \% $\mathrm{CV}$, índice de área foliar (IAF) e biomassa tem-se tornado popular nos últimos anos por causa da sua facilidade de operação, baixo custo do equipamento e, de acordo com White et al. (2000), eficiente e preciso. Podem ser destacados, por exemplo, os estudos conduzidos por Bezerra et al. (2007) e Liu et al. (2013) que estimaram, respectivamente, \%CV e frações de radiação fotossinteticamente ativa (fAPAR) por meio de câmeras digitais dispostas verticalmente no terreno. Outra vantagem é a sua capacidade de operação de forma rotineira, ou seja, não requer condições de céu claro ou completamente nublado, como são os casos de radiômetros de campo e de medidores de IAF (e.g., LAI-2000 da Licor) (PEKIN \& MACFARLANE, 2009).

Os dados espectrorradiométricos foram ainda convertidos para índices de vegetação (IV), pois muitos deles que têm sido relatados na literatura vem apresentando uma boa correlação com parâmetros da vegetação (LI et al., 2014). Um total de 12 índices comumente utilizados na literatura foram analisados no presente estudo: RVI (Ratio Vegetation Index), NDVI (Normalized Difference Vegetation Index), MTCI (MERIS Terrestrial Chlorophyll Index), Red-Edge NDVI (Red-Edge Normalized Difference Vegetation Index), MSAVI (Modified Soil-Adjusted Vegetation Index), SAVI (Soil-Adjusted Vegetation Index), GNDVI (Green-Normalized Difference Vegetation Index), TVI (Triangular Vegetation Index), RDVI (Renormalized Difference Vegetation Index), OSAVI (Optimization of Soil-adjusted Vegetation Index), CI Red Edge (Red-Edge Chlorophyll Index) e EVI (Enhanced Vegetation Index) (Tabela 5). 
Tabela 5. Relação dos índices de vegetação considerados nesse estudo para estimar \% de cobertura vegetal verde de pastagens cultivadas. $\rho=$ reflectância; NIR $=$ infravermelho próximo; $R E D=$ vermelho GREEN = verde; $B L U E=$ azul.

\begin{tabular}{|c|c|c|}
\hline $\begin{array}{l}\text { Índice de } \\
\text { vegetação }\end{array}$ & Fórmula & Referência \\
\hline $\begin{array}{l}\text { Ratio Vegetation } \\
\text { Index }\end{array}$ & $R V I=\frac{\rho_{\text {NIR }}}{\rho_{\text {RED }}}$ & $\begin{array}{l}\text { Jordan } \\
(1969)\end{array}$ \\
\hline $\begin{array}{l}\text { Normalized } \\
\text { Difference } \\
\text { Vegetation Index }\end{array}$ & $N D V I=\frac{\rho_{\text {NIR }}-\rho_{R E D}}{\rho_{\text {NIR }}+\rho_{R E D}}$ & $\begin{array}{l}\text { Rouse et al. } \\
\qquad(1973)\end{array}$ \\
\hline $\begin{array}{l}\text { MERIS Terrestrial } \\
\text { Chlorophyll Index }\end{array}$ & $M T C I=\frac{\rho_{\text {NIR }}-\rho_{R E D-E D G E}}{\rho_{R E D-E D G E}-\rho_{R E D}}$ & $\begin{array}{l}\text { Dash et al. } \\
\text { (2004) }\end{array}$ \\
\hline $\begin{array}{l}\text { Red-Edge } \\
\text { Normalized } \\
\text { Difference } \\
\text { Vegetation Index }\end{array}$ & $N D V I_{R E D-E D G E}=\frac{\rho_{N I R}-\rho_{R E D-E D G E}}{\rho_{N I R}+\rho_{R E D-E D G E}}$ & $\begin{array}{l}\text { Gitelson et } \\
\text { al. (1994) }\end{array}$ \\
\hline $\begin{array}{l}\text { Modified Soil } \\
\text { Adjusted } \\
\text { Vegetation Index }\end{array}$ & $M S A V I=\frac{1}{2}\left[2 R_{800}+1-\sqrt{\left(2 R_{800}+1\right)^{2}-8\left(R_{800}-R_{670)}\right.}\right]$ & $\begin{array}{l}\text { Qi et al. } \\
\text { (1994) }\end{array}$ \\
\hline $\begin{array}{l}\text { Soil Adjusted } \\
\text { Vegetation Index }\end{array}$ & $S A V I=\frac{\rho_{\text {NIR }}-\rho_{\text {RED }}}{\rho_{\text {NIR }}+\rho_{\text {RED }}+0,5} 1,5$ & $\begin{array}{l}\text { Huete } \\
(1988)\end{array}$ \\
\hline $\begin{array}{l}\text { Green Normalized } \\
\text { Difference } \\
\text { Vegetation Index }\end{array}$ & $G N D V I=\frac{\rho_{\text {NIR }}-\rho_{\text {GREEN }}}{\rho_{\text {NIR }}+\rho_{\text {GREEN }}}$ & $\begin{array}{l}\text { Gitelson et } \\
\text { al. (1996) }\end{array}$ \\
\hline $\begin{array}{l}\text { Triangular } \\
\text { Vegetation Index }\end{array}$ & $T V I=60\left(\rho_{\text {NIR }}-\rho_{\text {GREEN }}\right)-100\left(\rho_{R E D}-\rho_{\text {GREEN }}\right)$ & $\begin{array}{l}\text { Broge et al. } \\
\quad(2001)\end{array}$ \\
\hline $\begin{array}{l}\text { Renormalized } \\
\text { Difference } \\
\text { Vegetation Index }\end{array}$ & $R D V I=\frac{\rho_{\text {NIR }}-\rho_{R E D}}{\sqrt{\rho_{\text {NIR }}+\rho_{\text {RED }}}}$ & $\begin{array}{l}\text { Roujean et } \\
\text { al. (1995) }\end{array}$ \\
\hline $\begin{array}{l}\text { Optimization of } \\
\text { Soil-Adjusted } \\
\text { Vegetation Index }\end{array}$ & $O S A V I=(1+0,16) \frac{\rho_{N I R}-\rho_{R E D}}{\rho_{N I R}+\rho_{R E D}+0,16}$ & $\begin{array}{c}\text { Rondeaux et } \\
\text { al. } \\
\text { (1996) }\end{array}$ \\
\hline $\begin{array}{l}\text { Red-edge } \\
\text { Chlorophyll Index }\end{array}$ & $C I_{R E D-E D G E}=\frac{\rho_{\text {NIR }}}{\rho_{R E D-E D G E}}-1$ & $\begin{array}{l}\text { Gitelson et } \\
\text { al. (2003) }\end{array}$ \\
\hline $\begin{array}{l}\text { Enhanced } \\
\text { Vegetation Index }\end{array}$ & $E V I=2,5 \frac{\rho_{\text {NIR }}-\rho_{\text {RED }}}{\rho_{\text {NIR }}+6 \rho_{\text {RED }}-7,5 \rho_{\text {BLUE }}+1}$ & $\begin{array}{l}\text { Justice et al. } \\
\qquad(1998)\end{array}$ \\
\hline
\end{tabular}


Como três dos índices selecionados utilizam, nas suas formulações, bandas espectrais do red-edge, o desempenho dos 12 índices foram analisados com base nas bandas do satélite RapidEye, lançado no início de 2009. A única exceção foi o MSAVI, por conter na sua formulação matemática posições específicas do espectro eletromagnético. As principais vantagens desse satélite é a sua operação com uma constelação de cinco satélites em uma mesma órbita, o que permite a aquisição de imagens com alta resolução espacial (6,5 metros, reamostrada para cinco metros durante o processo de ortorretificação) e, ao mesmo tempo, com alta periodicidade (TYC et al., 2005). Outras vantagens desse sistema é a sua resolução radiométrica de 12 bits e a presença de uma banda no red-edge, faixa espectral que coincide com o aumento brusco de reflectância da vegetação verde na faixa de transição entre o vermelho e o infravermelho próximo (SCHUSTER et al., 2012). A Tabela 6 mostra as principais especificações do satélite RapidEye.

Tabela 6. Especificações técnicas dos satélites do sistema RapidEye.

\begin{tabular}{ll}
\hline \multicolumn{1}{c}{ Parâmetros } & \multicolumn{1}{c}{ Especificações } \\
\hline Número de satélites & 5 \\
Altitude da órbita & $630 \mathrm{~km}$, órbita síncrona com o Sol \\
Hora de passagem no equador & $11: 00 \mathrm{hs}$ (aproximadamente) \\
Faixa de imageamento & $77 \mathrm{~km}$ \\
Tempo de revisita & Diária (off-nadir); 5,5 dias (nadir) \\
Tipo de sensor & Multiespectral (sistema pushbroom) \\
Bandas espectrais & Azul (440-510 nm) \\
& Verde $(520-590 \mathrm{~nm})$ \\
& Vermelho $(630-685 \mathrm{~nm})$ \\
& Red-edge $(690-730 \mathrm{~nm})$ \\
& Infravermelho próximo (760- $850 \mathrm{~nm})$ \\
Resolução espacial (nadir) & $6,5 \mathrm{~m}$ \\
Tamanho do pixel (ortorretificado) & $5 \mathrm{~m}$ \\
Resolução radiométrica & $12 \mathrm{bits}$ \\
Velocidade de download (banda X) & $80 \mathrm{Mbps}$ \\
\hline
\end{tabular}
Fonte: Adaptado de Felix et al. (2009).

Considerando-se que as larguras das faixas espectrais dos diferentes sistemas sensores não são coincidentes, esse estudo analisou ainda o desempenho de sete satélites multiespectrais que operam com altas (Ikonos e WordView), médias (Landsat, Spot, CBERS 4 e Resourcesat) e baixas resoluções espaciais (Terra MODIS) (Tabela 7) para estimar \%CV. Essa análise foi conduzida considerando-se o índice de vegetação que apresentou o melhor desempenho na etapa anterior desse estudo. 
Tabela 7. Lista de sistemas sensores orbitais e multiespectrais selecionados para identificar o sistema mais apropriado para estimar \% cobertura verde.

\begin{tabular}{|c|c|c|c|c|c|c|c|}
\hline \multirow{2}{*}{ Sistema Sensor } & \multicolumn{2}{|c|}{ Azul } & \multicolumn{2}{|c|}{ Vermelho } & \multicolumn{2}{|c|}{$\begin{array}{l}\text { Infravermelho } \\
\text { Próximo }\end{array}$} & \multirow{2}{*}{ Referências } \\
\hline & $\begin{array}{c}\text { Faixa } \\
\text { Espectral }\end{array}$ & Largura & $\begin{array}{c}\text { Faixa } \\
\text { Espectral }\end{array}$ & Largura & $\begin{array}{c}\text { Faixa } \\
\text { Espectral }\end{array}$ & Largura & \\
\hline Ikonos-2 & $455-520$ & 65 & $630-700$ & 70 & $760-850$ & 90 & Dial et al. (2003) \\
\hline WorldView-3 & $450-510$ & 60 & $630-690$ & 60 & $770-895$ & 125 & Digital Globe (2015) \\
\hline Landsat-8 OLI & $450-510$ & 60 & $640-670$ & 30 & $850-880$ & 30 & Roy et al. (2014) \\
\hline Spot-6 MS & $450-520$ & 70 & $625-695$ & 70 & $760-890$ & 130 & $\begin{array}{l}\text { Satellite Imaging Corporation } \\
(2015)\end{array}$ \\
\hline $\begin{array}{l}\text { CBERS-4 } \\
\text { MUXCam }\end{array}$ & $450-520$ & 70 & $630-690$ & 60 & $770-890$ & 120 & ESA (2015a) \\
\hline $\begin{array}{l}\text { Resourcesat } \\
\text { AWIFS }\end{array}$ & $520-590$ & 70 & $620-680$ & 60 & $770-860$ & 90 & ESA $(2015 b)$ \\
\hline Terra MODIS & $459-479$ & 20 & $620-670$ & 50 & $841-876$ & 35 & Justice et al. (2002) \\
\hline RapidEye & $440-510$ & 70 & $630-685$ & 55 & $760-850$ & 90 & Tyc et al. (2005) \\
\hline
\end{tabular}


O desempenho dos dados espectrorradiométricos de campo para estimar \% $\mathrm{CV}$ de pastagens cultivadas e de índices de vegetação foi basicamente analisados por meio de coeficientes de correlação $(r)$. Tal correlação representa a força da relação entre duas variáveis; valor igual a zero corresponde a uma correlação inexistente e valor igual a 1 corresponde a uma correlação perfeita. 


\section{RESULTADOS E DISCUSSÃO}

Na Figura. 10 são mostradas as curvas espectrais das pastagens cultivadas para cinco épocas diferentes do ano. Percebe-se a presença de ruído em todas as curvas espectrais para comprimentos de onda superiores a $900 \mathrm{~nm}$, por isso esses dados foram omitidos nas análises subsequentes desse trabalho. Percebe-se ainda uma acentuada interferência da sazonalidade climática nos dados espectrorradiométricos, notadamente na faixa espectral do vermelho, em torno de $690 \mathrm{~nm}$. Curvas espectrais de novembro/2013 e janeiro/2014 apresentam forte absorção nesse comprimento de onda, indicando índices elevados de \%CV. Por outro lado, a ausência de banda de absorção na curva espectral de setembro/2013 indica presença de folhas predominantemente secas.

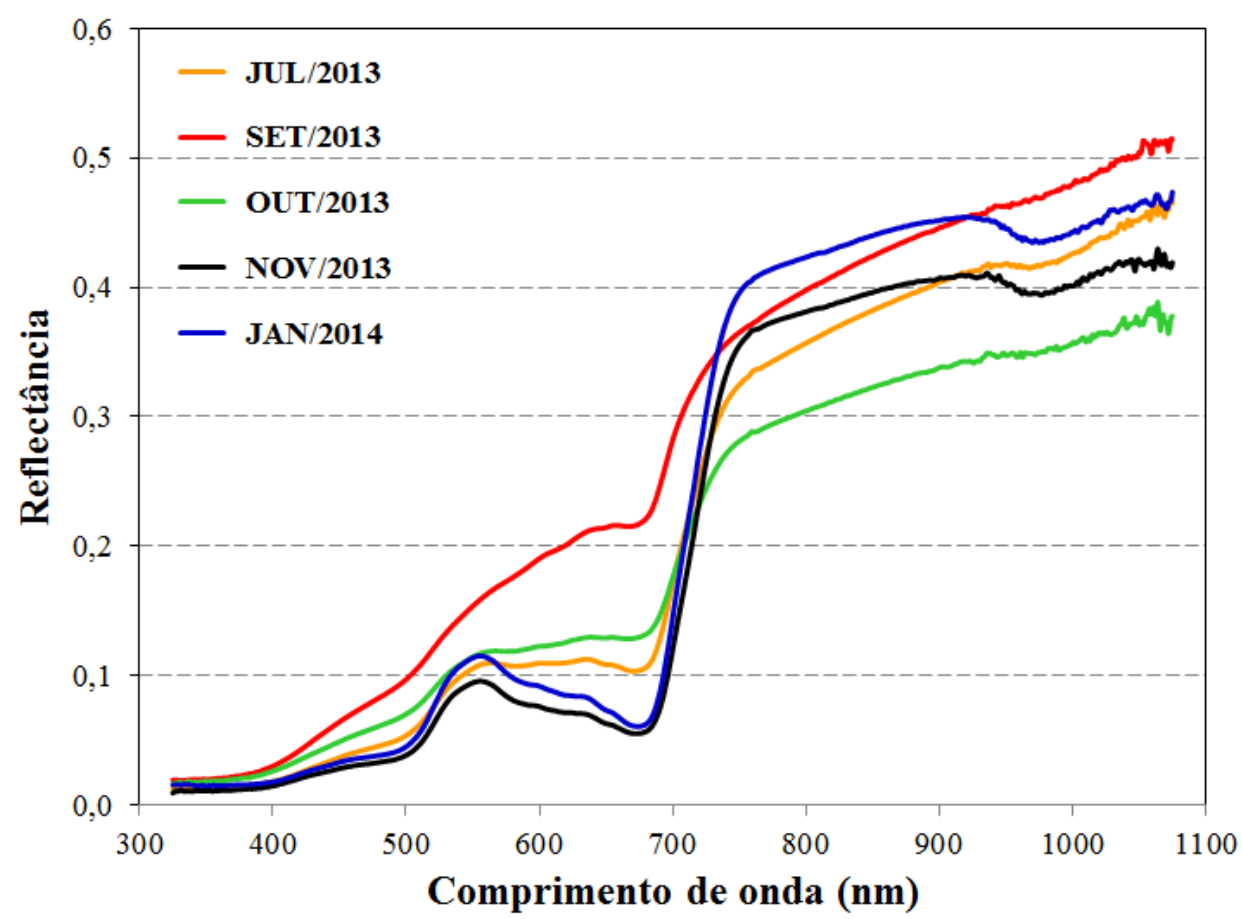

Figura 10. Curvas espectrorradiométricas de pastagem cultivada para os meses de julho, setembro, outubro e novembro de 2013 e janeiro de 2014.

As faixas espectrais ao redor de $550 \mathrm{~nm}$ (faixa espectral do verde) e no intervalo de 750-900 nm (faixa espectral do infravermelho próximo) destacam-se pela alta reflectância da pastagem. Pastagens no mês de setembro possuem reflectâncias destacadamente mais elevadas do que as de outros meses, principalmente na faixa espectral do visível (400-900 nm), indicando ausência de absorção da radiação eletromagnética associada à atividade fotossintética. Na faixa espectral ao redor de $950 \mathrm{~nm}$ dos meses de julho, novembro e janeiro 
existe uma forte absorção independente do ruído do sensor, isso ocorre devido à alta umidade dos solos. Os índices pluviométricos mostrados na Figura 8 corroboram esse comportamento espectral. A precipitação mensal acumulada em setembro/2013 ficou em torno de $56 \mathrm{~mm}$, enquanto as de novembro/2013 e janeiro/2014 foram superiores a $120 \mathrm{~mm}$.

Na Figura 11, é mostrada a variação dos dados de \%CV calculadas pela classificação das fotografias de campo para os cinco meses considerados: julho, setembro, outubro e novembro de 2013, além de janeiro de 2014. Setembro foi o mês em que \% CV esteve mais baixa (\% CV 23\%), passando a aumentar gradativamente até chegar em torno de $57 \%$ em janeiro. Esse valor máximo está de acordo com o obtido por Bezerra et al. (2007) para pastagens cultivadas do Distrito Federal: $55 \%$ de cobertura verde.

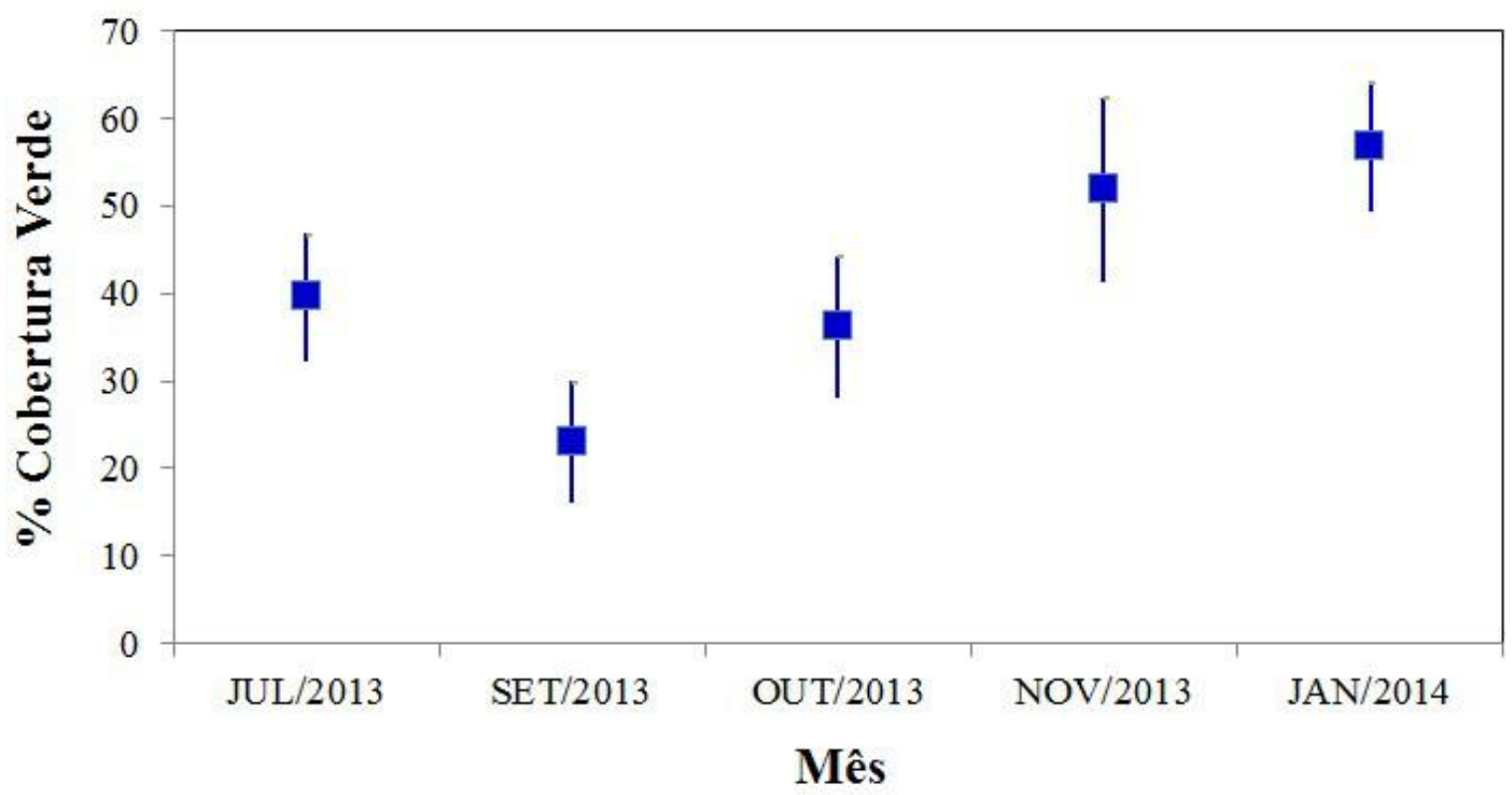

Figura 11. Média e correspondente desvio-padrão de \% de cobertura verde de pastagens cultivadas obtidas pela classificação MAXVER das fotografias de campo nos meses de julho, setembro, outubro e novembro de 2013 e janeiro de 2014.

Ao analisar esses valores de \%CV com os dados espectrorradiométricos (Figura 12), percebe-se uma tendência de a correlação ser inversamente proporcional na faixa espectral do visível e diretamente proporcional na faixa do infravermelho próximo. Dados de setembro de 2013 foram os únicos que apresentaram correlações significativamente mais baixas em relação aos demais meses. Nos meses de julho e novembro, as correlações na faixa espectral do vermelho atingiram valores similares ou superiores aos encontrados na faixa do infravermelho próximo. As faixas espectrais de 660-680 nm (vermelho) e de 750-820 nm (infravermelho próximo) foram as que apresentaram os coeficientes de correlação mais altos: r > 0,69 (dados de julho/2013), r > 0,64 (dados de novembro/2013) e r > 0,65 (dados de 
janeiro/2014). Thenkabail et al. (2004) e Wang et al. (2008) também citaram, respectivamente, os comprimentos de onda de $723 \mathrm{~nm}$ e $735 \mathrm{~nm}$ como sendo os mais favoráveis.
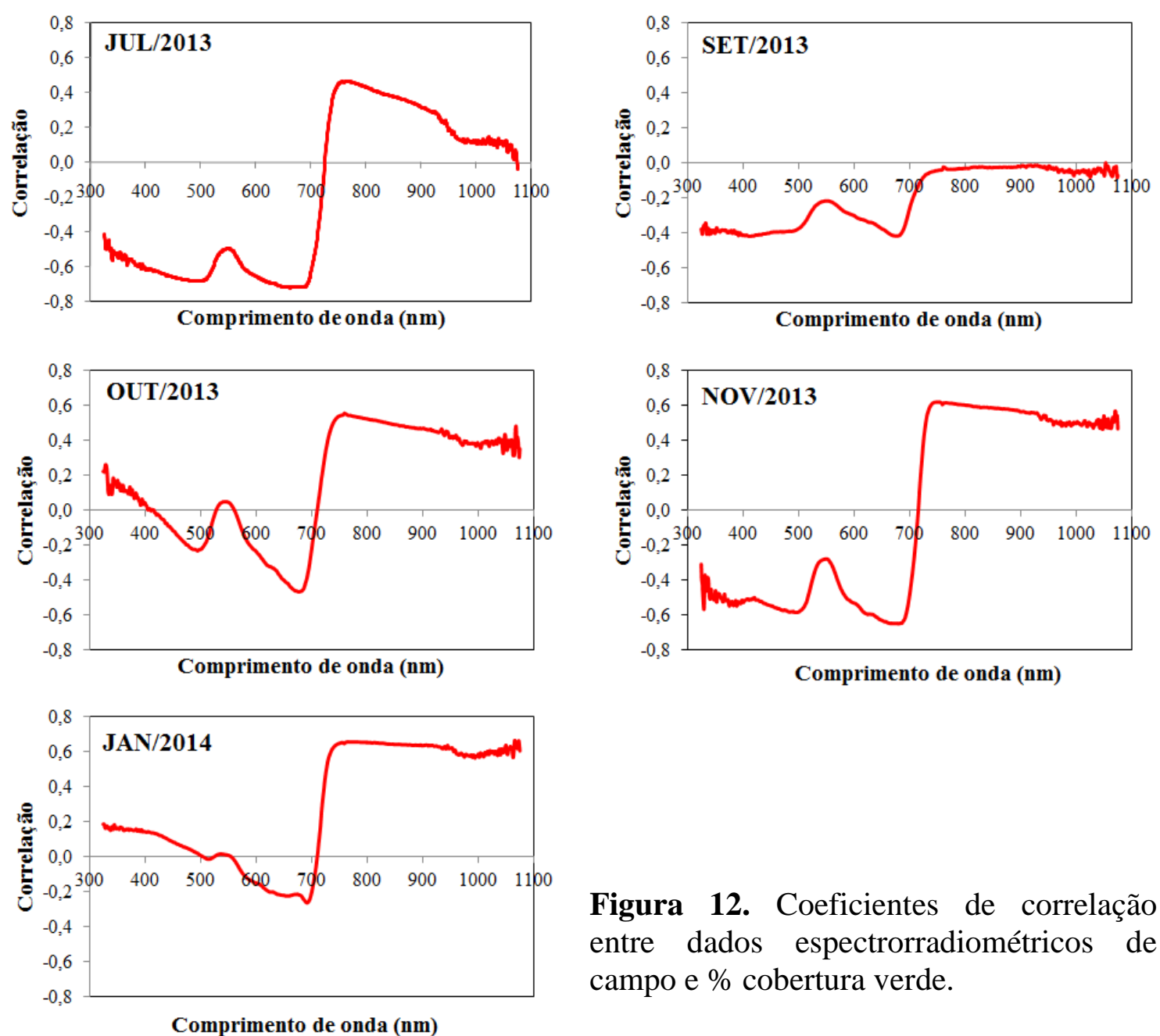

Figura 12. Coeficientes de correlação entre dados espectrorradiométricos de campo e \% cobertura verde.

Esses dados mostram que a região do red-edge $(700-750 \mathrm{~nm})$ localizada entre o vermelho (600-700 nm) e o infravermelho próximo (750-900 nm), caracterizada pelo aumento acentuado na reflectância de vegetações verdes, não é a mais apropriada para estimar \%CV de pastagens cultivadas. Essa região tem sido considerada como sendo a mais favorável para estimar biomassa e IAF (MUTANGA \& SKIDMORE, 2004; HERRMANN et al., 2011; DELEGIDO et al., 2013), entretanto, resultados desse estudo mostram que as faixas do vermelho e do infravermelho próximo são mais apropriadas.

De uma maneira geral, o desempenho dos índices de vegetação foram superiores em relação às bandas individuais do RapidEye, independentemente da data de obtenção dos dados (Tabela 8). A única exceção foi o MTCI, com desempenho nitidamente inferior aos demais 
índices. Comparando-se o desempenho dos três índices que utilizaram a banda do red-edge (MTCI, NDVI ${ }_{\text {red-edge }}$ e $\mathrm{CI}_{\text {red-edge }}$ ), é correto afirmar que há outros índices que apresentam desempenhos superiores, principalmente para dados obtidos na época chuvosa. Os dois índices mais utilizados na literatura (NDVI e EVI) apresentaram desempenhos similares, com exceção do mês de janeiro/2014. Nesse caso, o desempenho do EVI foi superior $(r=0,73 \mathrm{e}$ 0,61 para EVI e NDVI, respectivamente). Contrariando os resultados obtidos por Li et al. (2014), os índices modificados de NDVI (GNDVI e RDVI) e SAVI (MSAVI e OSAVI) não apresentaram melhoria em relação aos respectivos índices originalmente propostos.

Tabela 8. Coeficientes de correlação entre bandas do satélite RapidEye e 12 índices de vegetação propostos na literatura e \% de cobertura verde de pastagens cultivadas para os meses de julho, setembro, outubro e novembro de 2013 e janeiro de 2014.

\begin{tabular}{cccccc}
\hline Bandas do RapidEye/Índice de & \multicolumn{5}{c}{ Mês/Ano } \\
Vegetação & $-0,67$ & $-0,39$ & $-0,18$ & $-0,57$ & 0,05 \\
\cline { 2 - 6 } Auzul & $-0,56$ & $-0,25$ & $-0,04$ & $-0,37$ & $-0,03$ \\
Verde & $-0,71$ & $-0,39$ & $-0,42$ & $-0,64$ & $-0,22$ \\
Vermelho & $-0,43$ & $-0,18$ & 0,03 & $-0,08$ & 0,12 \\
Red-Edge & 0,43 & $-0,03$ & 0,52 & 0,60 & 0,65 \\
Infravermelho Próximo & & & & & \\
& 0,72 & 0,54 & 0,57 & 0,69 & 0,63 \\
RVI & 0,78 & 0,53 & 0,75 & 0,75 & 0,61 \\
NDVI & 0,55 & $-0,10$ & 0,38 & 0,57 & 0,60 \\
MTCI & 0,75 & 0,54 & 0,67 & 0,73 & 0,63 \\
NDVI RED-EDGE & 0,75 & 0,43 & 0,73 & 0,78 & 0,71 \\
MSAVI & 0,75 & 0,45 & 0,74 & 0,75 & 0,70 \\
SAVI & 0,75 & 0,46 & 0,61 & 0,74 & 0,55 \\
GNDVI & 0,72 & 0,39 & 0,74 & 0,68 & 0,71 \\
TVI & 0,76 & 0,44 & 0,75 & 0,75 & 0,71 \\
RDVI & 0,77 & 0,50 & 0,75 & 0,77 & 0,68 \\
OSAVI & 0,71 & 0,54 & 0,61 & 0,67 & 0,63 \\
CI RED-EDGE & 0,76 & 0,44 & 0,74 & 0,74 & 0,73 \\
EVI & & & & &
\end{tabular}


O MSAVI e o EVI, por terem apresentado os maiores valores de $r$ nos dois meses mais chuvosos (novembro/2013 e janeiro/2014), podem, a princípio, serem considerados os melhores índices de vegetação para estimar \%CV. Entretanto, o MSAVI apresenta restrições para sistemas sensores multiespectrais, pois, na sua formulação matemática são utilizadas posições específicas do espectro eletromagnético $(670 \mathrm{~nm}$ e $800 \mathrm{~nm})$. Nesse caso, a segunda opção é o SAVI, devido ao seu alto desempenho em outubro, novembro e janeiro.

Não houve interferência significativa na largura de bandas do vermelho e do infravermelho próximo provenientes de diferentes plataformas orbitais para estimativa de \%CV para SAVI e EVI (Tabela 9 e 10). De uma forma geral, variações nos coeficientes de correlação foram verificadas apenas na segunda ou na terceira casa decimal, dependendo da plataforma e do mês de aquisição de dados. Tais resultados estão de acordo com os dados obtidos por Elvidge \& Chen (1995) que também compararam diferentes índices de vegetação derivados de faixas espectrais estreitas e largas do vermelho e infravermelho próximo e concluíram que a acurácia das faixas estreitas eram apenas ligeiramente superiores às das faixas mais largas. Os resultados também vão de encontro com o estudo conduzido por Thenkabail et al. (2002): das 12 bandas espectrais consideradas como as mais favoráveis para estimar IAF, biomassa, cobertura do dossel, altura da planta e conteúdo de nitrogênio relativos a seis diferentes culturas agrícolas, apenas uma apresenta faixa espectral relativamente larga no infravermelho próximo: $120 \mathrm{~nm}$. A largura das outras faixas é inferior a $30 \mathrm{~nm}$, sendo a maioria delas de $15 \mathrm{~nm}$. Isto significa que, de uma maneira geral, as plataformas avaliadas no presente estudo não possuem larguras das faixas espectrais no vermelho e no infravermelho próximo adequadas para estimar parâmetros vegetacionais como $\% \mathrm{CV}$.

Tabela 9. Coeficientes de correlação entre SAVI derivados de faixas espectrais de oito satélites multiespectrais e \% de cobertura verde de pastagens cultivadas para os meses de julho, setembro, outubro e novembro de 2013 e janeiro de 2014.

\begin{tabular}{lccccc}
\hline \multicolumn{1}{c}{ Plataformas } & \multicolumn{5}{c}{ Mês/Ano } \\
\cline { 2 - 5 } & Jul/2013 & Set/2013 & Out/2013 & Nov/2013 & Jan/2014 \\
\hline Ikonos & 0,757 & 0,459 & 0,744 & 0,754 & 0,702 \\
WorldView & 0,751 & 0,455 & 0,739 & 0,751 & 0,701 \\
Landsat & 0,747 & 0,452 & 0,730 & 0,748 & 0,697 \\
Spot & 0,753 & 0,456 & 0,739 & 0,752 & 0,700 \\
CBERS 4 & 0,752 & 0,455 & 0,740 & 0,751 & 0,701 \\
Resourcesat & 0,752 & 0,449 & 0,738 & 0,752 & 0,699 \\
TERRA MODIS & 0,746 & 0,445 & 0,723 & 0,747 & 0,694 \\
RapidEye & 0,753 & 0,454 & 0,744 & 0,753 & 0,702 \\
\hline
\end{tabular}


Tabela 10. Coeficientes de correlação entre EVI derivados de faixas espectrais de oito satélites multiespectrais e \% de cobertura verde de pastagens cultivadas para os meses de julho, setembro, outubro e novembro de 2013 e janeiro de 2014.

\begin{tabular}{lccccc}
\hline \multirow{2}{*}{ Plataformas } & \multicolumn{5}{c}{ Mês/Ano } \\
\cline { 2 - 6 } & Jul/13 & Set/13 & Out/13 & Nov/13 & Jan/14 \\
\hline Ikonos & 0,320 & 0,447 & 0,741 & 0,737 & 0,728 \\
WorldView & 0,320 & 0,444 & 0,739 & 0,734 & 0,729 \\
Landsat & 0,320 & 0,441 & 0,733 & 0,730 & 0,727 \\
Spot & 0,320 & 0,443 & 0,739 & 0,735 & 0,728 \\
CBERS 4 & 0,319 & 0,442 & 0,740 & 0,734 & 0,730 \\
Resourcesat & 0,300 & 0,404 & 0,738 & 0,712 & 0,676 \\
TERRA MODIS & 0,322 & 0,435 & 0,725 & 0,728 & 0,721 \\
RapidEye & 0,320 & 0,444 & 0,741 & 0,737 & 0,730 \\
\hline
\end{tabular}




\section{CONSIDERAÇÕES FINAIS}

Resultados dessa pesquisa indicaram que a radiometria de campo é fundamental para entender e solidificar os conhecimentos a respeito das interações entre a REM e a vegetação, pois permite compreender melhor os parâmetros biofísicos da vegetação; as curvas espectrais obtidas a campo foram coerentes com os dados pluviométricos, salientando a influência de cada fator em sua respectiva faixa espectral de atuação, como por exemplo, as faixas de absorção.

A estimativa de \%CV é mais favorável na estação chuvosa do que na estação seca ou, em outras palavras, quando a cobertura vegetal das pastagens encontra-se mais verde. Regra geral, o uso da faixa espectral do infravermelho próximo é mais indicado do que o da faixa espectral do visível e a banda denominada red-edge. Dentre os 12 índices de vegetação analisados, o SAVI e o EVI foram os que apresentaram melhor desempenho e as variações nas larguras das bandas não interferiram significativamente na correlação entre os índices de vegetação SAVI, EVI e \%CV. Os objetivos específicos propostos foram cumpridos com sucesso e na íntegra:

- Analisar o desempenho dos dados espectrorradiométricos originais de campo para estimar a porcentagem de cobertura verde de pastagens cultivadas do bioma Cerrado; dados espectrorradiométricos obtidos na estação chuvosa e nas faixas espectrais do infravermelho próximo e do vermelho apresentaram coeficientes de correlação superiores a 0,65 .

- Analisar o desempenho de dados espectrorradiométricos de campo, convertidos para diferentes índices de vegetação e diferentes larguras de faixas espectrais, para estimar a $\% \mathrm{CV}$ de pastagens cultivadas do bioma Cerrado: o SAVI e o EVI foram os índices de vegetação que apresentou melhores coeficientes de correlação; diferenças nas larguras de bandas no infravermelho próximo e vermelho não causaram alterações significativas na relação entre SAVI, EVI e \%CV.

Acerca dos resultados apresentados as recomendações técnicas que consideramos de suma importância são: 
1) Sugerem-se a inclusão de séries temporais mais robustas, série completa de um ano e coletas mensais. Por exemplo, é de suma importância a aquisição de dados de espectrorradiometria das pastagens nos meses de fevereiro, março e abril.

2) Análises espectrorradiométricas de outras espécies de pastagens cultivadas, por exemplo, Brachiaria Brizantha, Brachiaria Humidicola e Panicum.

3) O uso de espectrorradiômetros de campo que registram dados na faixa espectral mais ampla, como por exemplo de 400 a $2.400 \mathrm{~nm}$.

4) Faz-se necessárias análises estatísticas mais robustas como primeira e segunda derivadas e o método dos mínimos quadrados parciais (partial least square). 


\section{REFERÊNCIAS}

ABDON, M. M.; LUCIANO, A. C. S.; SILVA, J. S. V.; OLIVEIRA, M. S. Classificação de pastagens degradadas nos municípios de Corguinho e Rio Negro, MS, utilizando fusão de imagens CBERS. Geografia, v. 34, p. 709-720, 2009.

ALMEIDA, E.S.; BATISTA, G.T. Índice de vegetação versus precipitação na Amazônia. In: SIMPÓSIO BRASILEIRO DE SENSORIAMENTO REMOTO, 9, SANTOS - SP. Anais... São José dos Campos: Instituto Nacional de Pesquisas Espaciais, 1998, p. 1397-1407.

ALVIN, M.J.; PACIULLO, D.S.C.; CARVALHO, M.M.; AROEIRA, L.J.M.; CARVALHO, L.A.; NOVAES, L.P.; GOMES, A.T.; MIRANDA, J. E. C.; RIBEIRO, A.C.C.L. 2005. Sistema de produção de leite com recria de novilhas em sistemas silvipastoris. Sistema de Produção - Embrapa Gado de Leite. Versão eletrônica n. 07. Disponível em: < http://sistemasdeproducao.cnptia.embrapa.br/FontesHTML/Leite/LeiteRecriadeNovilhas/inde x.htm > Acesso em 20 dez.2014.

BALBINO, L.C.; CORDEIRO, L.A.M.; SILVA, V.P.; MORAES, A.; MARTÍNEZ, G.B.; ALVARENGA, R.C.; KICHEL, A.N.; FONTANELI, R.S.; SANTOS, H.P.; FRANCHINI, J.C.; GALERANI, P.R. Evolução tecnológica e arranjos produtivos de sistemas de integração lavoura-pecuária-floresta no Brasil. Pesquisa Agropecuária Brasileira, v. 46, n. 10, p. 1-13, 2011.

BARCELLOS, A.O.; VIANA FILHO, A.; BALBINO, L.C.; OLIVEIRA, I.P.; YOKOYAMA, L.P. Produtividade animal em pastagens renovadas em solo arenoso de cerrado. In: REUNIÃO ANUAL DA SOCIEDADE BRASILEIRA DE ZOOTECNIA, 34., 1997. Juiz de Fora. Anais.... Juiz de Fora: SBZ, v. 4, 1997, p. 207-209.

BATISTA, G.T.; RUDORFF, B.F.T.; OVIEDO, A.F.P. Resposta espectral da soja e sua relação com parâmetros agronômicos. In: SIMPÓSIO BRASILEIRO DE SENSORIAMENTO REMOTO, 5., Natal. Anais... São José dos Campos: Inpe, 1988. p. 406413.

BEZERRA, H.S.; SANO, E.E.; FERREIRA, L.G. Desempenho do satélite sino-brasileiro de recursos terrestres CBERS-2 no mapeamento da cobertura da terra no Distrito Federal, Brasil. Revista Brasileira de Geofísica, v. 25 n. 2, p. 171-185, 2007.

BODDEY, R.M.; ALVES, B.J.R.; OLIVEIRA, O.C.; URGUIAGA, S. Potencial para Acumulação e Sequestro de Carbono em Pastagens Brachiaria. In: LIMA, M. A.; CABRAL, O. M. R.; MIGUEZ, J. D. G. Mudanças Climáticas Globais e a Agropecuária Brasileira. Jaguariúna: EMBRAPA Meio Ambiente, 1ª ed., 397 p., 2001. 
BRANDÃO, A.S.P.; REZENDE, G.C.; MARQUES, R.W.C. Crescimento agrícola no período 1999/2004: a explosão da soja e da pecuária bovina e seu impacto sobre o meio ambiente. Economia Aplicada, v. 10, n. 2, p. 249-266, 2006.

BREUNIG, F.M.; GALVÃO, L.S.; FORMAGGIO, A.R. Caracterização espectral e temporal da vegetação nativa do Parque Estadual do Turvo e da Terra Indígena do Guarita - RS, com produtos MODIS. In: SIMPÓSIO BRASILEIRO DE SENSORIAMENTO REMOTO, 15., Curitiba - PR. Anais... São José dos Campos: Inpe, 2011, p.1765-1772.

BROGE, N.H.; LEBLANC, E. Comparing prediction power and stability of broadband and hyperspectral vegetation indices for estimation of green leaf area index and canopy chlorophyll density. Remote Sensing of Environment, v. 76, n. 2, p. 156-172, 2001.

BROSSARD, M.; BARCELLOS, A.O. Conversão do Cerrado em pastagens cultivadas em funcionamento de Latossolos. Cadernos de Ciência \& Tecnologia, v. 22, n. 1, p. 153-168, 2005 .

CASTRO, S.S.; ABDALA, K.; SILVA, A.A.; BÔRGES, V.M.S. A expansão da cana-deaçúcar no cerrado e no estado de Goiás: elementos para uma análise espacial do processo. Boletim Goiano Geografia, v. 30, n. 1, p. 171-191, 2010.

CNPC. Conselho Nacional da Pecuária de Corte. Balanço de pecuária bovídea de corte: 2001-2009. Disponível em: 〈http://www.cnpc.org.br/arquivos/Balanco.xls $>$. Acesso em: 29 dez. 2014.

DASH, J.; CURRAN, P.J. The MERIS terrestrial chlorophyll index. International Journal of Remote Sensing. v. 25, n. 23, p. 5403-5413, 2004.

DEDECEK, R.A.; RESCK, D.V.S.; FREITAS JUNIOR, E. Perdas de solo, agua e nutrientes por erosão em Latossolo Vermelho Escuro dos cerrados e de manejo da palhada do milho. Revista de Ciência do Solo, v. 10, p. 265-272, 1986.

DELEGIDO, J.; VERRELST, J.; MEZA, C.M.; RIVERA, J.P.; ALONSO, L.; MORENO, J. A red-edge spectral index for remote sensing estimation of green LAI over agroecosystems. European Journal of Agronomy. v. 46, p. 42-52, 2013.

DIAL, G.; BOWEN, H.; GERLACH, F.; GRODECKI, J.; OLESZCZUK, R. IKONOS satellite, imagery, and products. Remote Sensing of Environment. v. 88, p. 23-36, 2003.

DIAS FILHO, M.B. Degradação de Pastagens: Processos, causas e estratégias de recuperação. Belém - PA. $4^{\text {a }}$ Edição, Editora do Autor. 215p. 2011. 
DIAS FILHO, M.B. Produção de bovinos a pasto na fronteira agrícola. In: RODRIGUES, K.F.; FERREIRA, W.M.; MACEDO JR. G.L. (Org). Zootec 2010 - XX Congresso Brasileiro de Zootecnia - Anais... Palmas, Editora, 2010, p. 131-145.

DIGITAL GLOBE. WorldView-2 Data Sheet. Disponível em: <https://www.digitalglobe.com/sites/default/files/DG_WorldView2_DS_PROD.pdf>. Acesso em: 14 fev. 2015.

ELVIDGE , C.D.; CHEN, Z. Comparison of Broad-Band and Narrow-Band Red and NearInfrared Vegetation Indices. Remote Sensing of Environment. v. 54, p. 38-48, 1995.

EMBRAPA. Empresa Brasileira de Pesquisa Agropecuária. Sequestro de Carbono em Solos Sob Sistemas Agropecuários Produtivos. Equipe do projeto: BODDEY, R.; ALVES, B. J. R., URQUIAGA, S. S. Embrapa Agrobiologia. Seropédica, Rio de Janeiro, p.2, 2004.

EPIPHANIO, J.C.N.; HUETE, A.R. Dependence of NDVI and SAVI on sun/sensor geometry and its effect on fAPAR relationships in alfalfa. Remote Sensing of Environment, v. 51, p. 351-360, 1995.

ESA. CBERS-3 and 4. Disponível em: <https://directory.eoportal. org/web/eoportal/satellitemissions/c-missions/cbers-3-4>. Acesso em: 14 fev. 2015a.

ESA. Resourcesat-2. Disponível em: <https://directory.eoportal.org /web/eoportal/satellitemissions/r/resourcesat-2>. Acesso em: 14 fev. $2015 \mathrm{~b}$.

EXELIS. Visual Information Solutions. Vegetation analysis: using vegetation índices in ENVI. Disponível em: <http://www.exelisvis. com/Learn/WhitepapersDetail /TabId/802/ArtMID/2627/ArticleID/13742/Vegetation-Analysis-Using-Vegetation-Indices-inENVI.aspx >. Acesso em: 28 jan. 2015.

FAO. Food and Agriculture Organization. Review of Evidence on Drylands Pastoral Systems and Climate Change: Implications and Opportunities for Mitigation and Adaptation. Roma, 2009. Disponível em: <ftp://ftp.fao.org/ docrep/fao/ 012/i1135e/i1135e00.pdf >. Acesso em 15 nov. 2014.

FARIA, V.P.; PEDREIRA, C.G.S.; SANTOS, F.A.P. Evolução do uso de pastagens para bovinos. In: SIMPÓSIO SOBRE MANEJO DA PASTAGEM, 13, Piracicaba. Anais... Piracicaba: FEALQ, 1997, p.1-14.

FELIX, I. M.; KAZMIERCZAK, M. L.; ESPINDOLA, G. M. RapidEy e: a nova geração de satélite de Observação da Terra. In: SIMPÓSIO BRASILEIRO DE SENSORIAMENTO REMOTO, 15, Natal, Brasil. Anais... São José dos Campos: Instituo Nacional de Pesquisas Espacias, 2009, p. 7619-7622. 
FERNÁNDEZ, S.; VIDAL, D.; SIMÓN, E.; SOLÉ-SUGRAÑES, L. Radiometric characteristics of Triticum aestivum cv. Astral under water and nitrogen stress. International Journal of Remote Sensing. v. 15, n. 9, p. 1867-1884, 1994.

FERREIRA, L.G.; SANO, E.E.; FERNANDEZ, L.; ARAÚJO, F. Biophysical characteristics and fire occurrence of cultivated pastures in the Brazilian savanna observed by moderate resolution satellite data. International Journal of Remote Sensing. v. 34, n. 1, p. 154-167, 2012.

FERREIRA, L.G.; YOSHIOKA, H.; HUETE, A.R.; SANO, E.E. On the use of the EOSMODIS vegetation indices for monitoring the Cerrado region, Brazil: insights and perspectives In: SIMPÓSIO BRASILEIRO DE SENSORIAMENTO REMOTO, 10,. Foz do Iguaçu - PR. Anais... São José dos Campos: Inpe, 2001, p. 1601-1607.

FRANÇA-ROCHA, W.; SILVA, A.B.; NOLASCO, M.C.; LOBÃO, J.; BRITTO, D.; CHAVES, J,M.; ROCHA, C.C. Levantamento da cobertura vegetal e do uso do solo do Bioma Caatinga. In: SIMPÓSIO BRASILEIRO DE SENSORIAMENTO REMOTO, 13., Florianópolis. Anais... São José dos Campos: Inpe, 2007. p. 2629-2636.

FRANCO, J.B.S.; ROSA. R. Metodologia de Coleta de dados radiométricos em pastagens do gênero "Brachiaria" com diferentes estágios de degradação. In: SIMPÓSIO BRASILEIRO DE SENSORIAMENTO REMOTO, 11., Belo Horizonte - MG. Anais... São José dos Campos: Inpe, 2003, p.2483-2491.

GALVÃO, L.S.; VITORELLO, I.; ALMEIDA FILHO, R. Efeitos do posicionamento das bandas do vermelho e do infravermelho próximo nas determinações de NDVI para os Cerrados. In: SIMPÓSIO BRASILEIRO DE SENSORIAMENTO REMOTO, 9., Santos SP. Anais... São José dos Campos: Inpe, 1998, p. 1377-1384.

GITELSON, A.; MERZLYAK, M.N. Spectral reflectance changes associated with autumn senescence of Aesculus Hippocastanum L. and Acer Platanoides L. leaves. Spectral features and relation to chlorophyll estimation. Journal of Plant Physiology. v. 143, n. 3, p. 286-292, 1994.

GITELSON, A.A.; KAUFMAN, Y.J.; MERZLYAK, M.N. Use of a green channel in remote sensing of global vegetation from EOS-MODIS. Remote Sensing of Environment. v. 58, n. 3 p. 289-298, 1996.

GITELSON, A.A.; VINÃ, A.; TIMOTHY, J.; RUNDQUIST, D. C.; KEYDAN, G.; LEAVITT. B. Remote estimation of leaf area index and green leaf biomass in maize canopies.

Geophisical Research Letters. v. 30, n. 5, p. 1148, 2003. 
GREEN, R.O.; EASTWOOD, M.L.; SARTURE, C.M.; CHRIEN, T.G.; ARONSSON, M.; CHIPPENDALE, B.J.; GAUST, J.A.; PAVRI, B.E.; CHOVIT, C.J.; SOLIS, M.; OLAH, M.R.; WILLIAMS, O. Imaging spectroscopy and the airborne visible/infrared imaging spectrometer (AVIRIS). Remote Sensing of Environment, v. 65, n. 3, p. 227-248, 1998.

HABOUDANE, D.; MILLER, J. R.; PATTEY, E.; ZARCO-TEJADA, P. J.; STRACHAN, I. B.; Hyperspectral vegetation indices and novel algorithms for predicting green LAI of crop canopies: Modeling and validation in the context of precision agriculture. Remote Sensing of Environment, v. 90, p. 337-352, 2004.

HERNÁNDEZ, P. F.; PONZONI, F. J.; PEREIRA, M. N. Mapeamento da fitofisionomia e do uso da terra de parte da Bacia do Alto Taquari mediante o uso de imagens TM/Landsat e HRV/SPOT. Pesquisa Agropecuária Brasileira, v. 33, p. 1755-1762, 1998.

HERRMANN, I.; PIMSTEIN, A.; KARNIELI, A.; COHEN, Y.; ALCHANATIS, V.; BONFIL, D.F.; LAI assessment of wheat and potato crops by VEN $\mu$ S and Sentinel-2 bands. Remote Sensing of Environment. v. 115, p. 2141-2151, 2011.

HOUGHTON, R.A.; FORREST, H.; GOETZ, S.J. Importance of biomass in the global carbon cycle. Journal of Geophysical Research, v. 114, n. 3, p.1-13, 2009.

HUETE, A.R. A soil-adjusted vegetation index (SAVI). Remote Sensing of Environment. v. 25, n. 52, p. 295-309, 1988.

HUETE, A.R. A soil-adjusted vegetation index (SAVI). Remote Sensing of Environment. v. 25, n. 52, p. 295-309, 1988.

HUETE, A.; LIU, H.; BATCHILY. K.; VAN LEEUWEN, W. A comparison of vegetation indices over a global set of TM images for EOS-MODIS. Remote Sensing of Environment, v. 59, n. 3, p. 440-451, 1997.

HUETE, A.; JUSTICE C. MODIS Vegetation Index (MOD 13) Algorithm Theoretical Basis Document. NASA, v. 3, p.1-120, 1999.

HUETE, A.; DIDAN, K.; MIURA, T.; RODRIGUEZ, E.P.; GAO, X.; FERREIRA, L.G. Overview of the radiometric and biophysical performance of the MODIS vegetation indices. Remote Sensing of Environment, v.83, p.195-213, 2002.

IBGE. Instituto Brasileiro de Geografia e Estatistica. Censo Agropecuário 2006. Rio de Janeiro: $\quad$ IBGE, 2012. Disponível em: <http://www.ibge. gov.br/home/estatistica/economia/agropecuaria/censoagro/>. Acesso em: 20 jan. 2014. 
INPE - Instituto Nacional de Pesquisas Espaciais - Levantamento de informações de uso e cobertura da terra na Amazônia. Terra Class - 2010.

JACKSON, R.D.; HUETE, A. R. Interpreting vegetation indices. Journal of Preventive Veterinary Medicine, v.11, p.185-200, 1991.

JENSEN, J. R. Sensoriamento Remoto do Ambiente: uma Perspectiva em Recursos Terrestres. EPIPHANIO, J. C. N. (Coord. Trad.). São José dos Campos: Parêntese, 598 p., 1999.

JENSEN, J. R. Sensoriamento Remoto do Ambiente: uma Perspectiva em Recursos Terrestres. EPIPHANIO, J. C. N. (Coord. Trad.). São José dos Campos: Parêntese, 598p, 2009.

JIANG, Z.; HUETE, A. R.; DIDAN, K.; MIURA, T. Development of a two-band enhanced vegetation index without a blue band. Remote Sensing of Environment, v. 112, p. 38333845, 2008.

JORDAN, C.F. Derivation of leaf area index from quality of light on the forest floor. Ecology, v. 50, n. 4, p. 663-666, 1969.

JUNGES, A.H.; ALVES, G.; FONTANA, D.C. Estudo indicativo do comportamento do NDVI e EVI em lavouras de cereais de inverno da região norte do Estado do Rio Grande do Sul, através de imagens MODIS. In: SIMPÓSIO BRASILEIRO DE SENSORIAMENTO REMOTO, 13, FLORIANÓPOLIS - SC. Anais... São José dos Campos: Inpe, 2007, p. 241248.

JUSTICE, C.O.; VERMOTE, E.F.; TOWNSHEND, J.R.G.; DEFRIES, R.; ROY, P.D.; HALL, D.K.; SALOMONSON, V.; PRIVETTE, J.L.; RIGGS, G.; STRAHLER, A.; LUCHT, W.; MYNENI, R.B.; KNYAZIKHIN, Y.; RUNNING, S.W.; NEMANI, R.R.; WAN, Z.; HUETE, A.R.; LEEUWEN, W.V.; WOLFE, R.E.; GIGLIO, L.; MULLER, J.P.; LEWIS, P.; BARNSLEY, M. The moderate resolution imaging spectroradiometer (MODIS): land remote sensing for global change research. IEEE Transactions on Geoscience and Remote Sensing, v. 36, n. 4, p. 1228-1247, 1998.

JUSTICE， C.O.; TOWNSHEND， J.R.G.; VERMOTE， E.F.; MASUOKA， E.; WOLFE, R.E.; SALEOUS, N.; ROY, D.P.; MORISETTE, J.T. An overview of MODIS Land data processing and product status. Remote Sensing of Environment. v. 83, p. 3-15, 2002.

KING, C.; BAGHDADI, V.; LECOMTE, O.C. The application of remote-sensing data to monitoring and modelling of soil erosion. Catena, v. 62, n. 2-3, p. 79-93, 2005. 
LATORRE, M.L., ANDERSON, L.O., SHIMABUKURO, Y.E., CARVALHO JÚNIOR, O.A. Sensor MODIS: características gerais e aplicações. Espaço \& Geografia. v. 6, n. 1, p. 91-121, 2003.

LAU, C. Geomorphologic Distribution of Normalized Difference Vegetation Index. GIS development.net, AARS - ACRS, Geology, 1997. Disponível em: < http://www.a-a-rs.org/aars/proceeding/ACRS1997/Papers/GEO97-4.htm >. Acesso em: 07 out. 2014.

LI, X.; ZHANG, Y.; BAO, Y.; LUO, J.; JIN, X.; XU, X.; SONG, X.; YANG, G. Exploring the best hyperspectral features for LAI estimation using partial least squares regression. Remote Sensing, v. 6, p. 6221-6241, 2014.

LIU, L.; PENG, D.; HU, Y.; JIAO, Q. A novel in situ PPAR measurement method for low canopy vegetation based on a digital camera and reference panel. Remote Sensing. v. 5, p. 274-281, 2013.

LU, D. Aboveground biomes estimation using Landsat TM data in the Brazilian Amazon. International Journal of Remote Sensing. v. 26, n. 12, p. 2509-2525, 2005.

MACEDO, M.C.M.; ZIMMER, A.H. Sistema pasto-lavoura e seus efeitos na produtividade agropecuária. In: SIMPÓSIO SOBRE ECOSSISTEMAS DE PASTAGENS, 2, 1993, Jaboticabal. Anais... Jaboticabal: FUNEP, 1993. p. 216-245.

MACEDO, M. C. M. Pastagens no ecossistema Cerrado: evolução das pesquisas para o desenvolvimento sustentável. In: REUNIÃO ANUAL DA SOCIEDADE BRASILEIRA DE ZOOTECNIA, 42, 2005, Goiânia. Anais... Brasília: SBZ, 2005, p.56-84.

MACEDO, M.C.M. Integração lavoura e pecuária: o estado da arte e inovações tecnológicas. Revista Brasileira de Zootecnia. v. 38, p. 133-146, 2009.

MARTHA JUNIOR, G.B.; VILELA, L. 2002 Pastagens do Cerrado: Baixa Produtividade pelo uso Limitado de Fertilizantes. Documentos - Embrapa Cerrados Planaltina (DF). Brasília, v. 50, p. 1-32.

MARTHA JÚNIOR, G.B.; VILELA, L.; BARCELLOS, A.O. A planta forrageira e o agroecossistema. In: PEDREIRA, C.G.S.; MOURA, J.C.; SILVA, S.C.; FARIA, V.P. (Eds) As pastagens e o meio ambiente. (SIMPÓSIO SOBRE O MANEJO DA PASTAGEM, 23). Piracicaba: FEALQ, 2006, p.87-137.

MENESES, P.R; ALMEIDA, T. Introdução ao Processamento de Imagens de Sensoriamento Remoto. Brasília: Ed. UnB/ CNPq. 266p., 2012. 
MMA. Ministério do Meio Ambiente. Mapa de cobertura vegetal dos biomas Brasileiros. 2007. Disponível em: <http://www.mma.gov.br>. Acesso em: 12 set. 2014.

MOREIRA, M. M. Déficit hídrico na cultura do trigo e o impacto na região espectral e em parâmetros agronômicos. (Tese de Doutorado) - Escola Superior de Agricultura "Luiz de Queiroz", Universidade de São Paulo, Piracicaba, 142 p., 1997.

MUTANGA, O.; SKIDMORE, K. Narrow band vegetation indices overcome the saturation problem in biomass estimation. International Journal of Remote Sensing. v. 25, n. 19, p. 3999-4014, 2004.

NUMATA, I.; ROBERTS, D.A.; CHADWICK, O.A.; SCHIMEL, J.; SAMPAIO, F.R.; LEONIDAS, F.C.; SOARES, J.V. Characterization of pasture biophysical properties and the impact of grazing intensity using remotely sensed data. Remote Sensing of Evironment, v.109, p. 314-327, 2007.

OHGI, N.; IWASAKI, A.; KAWASHIMA, T.; INADA, H. Japanese hyper-multi spectral mission. In: INTERNATIONAL GEOSCIENCE AND REMOTE SENSING SYMPOSIUM (IGARSS 2010), Havai. Proceedings... IEEE, p. 3756-3759, 2010.

OLIVEIRA, P.P.A.; BOARETTO, A.E.; TRIVELIN, P.C.O.; OLIVEIRA, W.S.; CORSI, M. Liming and fertilization to restore degraded Brachiaria Decumbens pastures grown on an Entisol. Scientia Agricola, v. 60, n. 1, p. 125-131, 2003.

OLIVEIRA, P.P.A.; CORSI. M. 2005. Recuperação de pastagens degradadas para sistemas intensivos de produção de bovinos. Circular Técnica - Embrapa Pecuária Sudeste. São Carlos - SP. v. 38, p. 1-23.

PAPA, R.A. Comportamento espectro-temporal da cultura de feijão, por meio de dados obtidos por espectrorradiometria, câmera digital e imagem ASTER. (Dissertação de Mestrado) Faculdade de Agronomia e Medicina Veterinária, Universidade de Brasília. 132 p., 2009.

PEARLMAN, J.S.; BARRY, P.S.; SEGAL, C.C.; SHEPANSKI, J.; DEIXO, D.; CARMAN, S.L. Hyperion, a space-based imaging spectrometer. IEEE Transactions on Geoscience and Remote Sensing, v. 41, n. 6, p. 1160-1173, 2003.

PEKIN, B.; MACFARLANE, C. Measurement of Crown Cover and Leaf Area Index Using Digital Cover Photography and Its Application to Remote Sensing. Remote Sensing. v. 1, p. 1298-1320, 2009.

PERON, A.J.; EVANGELISTA, A.R. Degradação de Pastagens em Regiões de Cerrado. Ciência Agrotecnologia. v. 28, n. 3, p. 655-661, 2004. 
PONZONI, F.J.; SHIMABUKURO, Y.E. Sensoriamento Remoto no Estudo da Vegetação. São José dos Campos: Parêntese, 127 p., 2010.

PONZONI, F.J.; SHIMABUKURO, Y.E. Sensoriamento Remoto no Estudo da Vegetação. São José dos Campos: Parêntese, 127 p., 2007.

PRICE, K. P.; PIKE, D. A.; MENDES, L. Shrub dieback in a semiarid ecosystem: the integration of remote sensing and geographic information systems for detecting vegetation change. Photogrammetric Engineering and Remote Sensing. v. 58, n. 2, p. 455-463, 1992.

QI, J.; CHEHBOUNI, A.; HUETE, A.R.; KERR, Y.H.; SOROOSHIAN, S. A modified soil adjusted vegetation index. Remote Sensing of Environment. v. 48, p. 119-126, 1994.

RAMOELO, A.; SKIDMORED, A. K.; CHOA, M. A.; SCHERLEF, M.; MATHIEUA, R.; HEITKÖNIGD, I. M. A. Regional estimation of savanna grass nitrogen using the red-edge band of the spaceborne RapidEye sensor. International Journal of Applied Earth Observation and Geoinformation, v. 19, p. 151-162, 2012.

RATANA, P.; HUETE, A.; MIURA, T.; DIDAN, K; FERREIRA, L.; SANO, E. Characterization of biophysical vegetation - soil dynamics along an eco-climatic brazilian transect with MODIS vegetation indices. SIMPÓSIO BRASILEIRO DE SENSORIAMENTO REMOTO, 11., Belo Horizonte. Anais... São José dos Campos: Inpe. 2003, p.1433-1437.

REATTO, A.; MARTINS, E.S.; FARIAS, F.M.R.; SILVA, A.V.; ABÍLIO, O.C.Jr. 2004. Mapa Pedológico Digital - SIG atualizado do Distrito Federal escala 1:100.000. Documentos - Embrapa Cerrados Planaltina (DF). Brasília, v. 120, p.31.

RIZZI, R. Geotecnologias em um sistema de estimativa da produção de soja: estudo de caso no Rio Grande do Sul. Tese (doutorado) - Instituto Nacional de Pesquisas Espaciais, São José dos Campos, p212, 2004

RONDEAUX, G.; STEVEN, M.; BARET, F. Optimization of soil-adjusted vegetation indices. Remote Sensing of Environment. v. 55, p. 95-107, 1996.

ROSA, R. Introdução ao Sensoriamento Remoto, Uberlândia: EDUFU, 2003.

ROUJEAN, J.; BREON, F. Estimating PAR absorbed by vegetation from bidirectional reflectance measurements. Remote Sensing of Environment. v. 51, p. 375-384, 1995.

ROUSE, J.W.; HASS, R.H.; SHELL, J.A.; DEERING, D.W. Monitoring Vegetation Systems in the Great Plains with ERTS. In: Proceedings Of Third ERTS Symosium, Washington, p. 10-14, 1973. 
ROY, D.P.; WULDER, M.A.; LOVELAND, T.R.; WOODCOCK, C.E.; ALLEN, R.G.; ANDERSON, M.C.; HELDER, D.; IRONS, J.R.; JOHNSON, D.M.; KENNEDY, R.; SCAMBOS, T.A.; SCHAAF, C.B.; SCHOTT, J.R.; SHENG, Y.; VERMOTE, E.F.; BELWARD, A.S.; BINDSCHADLER, R.; COHEN, W.B.; GAO, F.; HIPPLE, J.D.; HOSTERT, P.; HUNTINGTON, J.; JUSTICE, C.O.; KILIC, A.; KOVALSKYY, V.; LEE, Z.P.; LYMBURNER, L.; MASEK, J.G.; MCCORKEL, J.; SHUAI, Y.; TREZZA, R.; VOGELMANN, J.; WYNNE, R.H.; ZHU, Z. Landsat-8: Science and product vision for terrestrial global change research. Remote Sensing of Environment. v.145, p. 154-172, 2014.

RUDORFF, B.F.T.; BATISTA, G.T.; ASSAD, E.D.; STORNER, E.; MOREIRA, L.; ITAMAR, P.; MACEDO, J. Relatório da campanha de medidas radiométricas da soja no Distrito Federal - safra 88/89. São José dos Campos: INPE, 1990.

SANO, E.E.; DAMBRÓS, L.A.; OLIVEIRA, G.C.; BRITES, R.S. Padrões de cobertura de solos do estado de Goiás. In: FERREIRA, L.G. (org.). A Encruzilhada Sócio-Ambiental: Biodiversidade, Economia e Sustentabilidade no Cerrado. Goiânia: UFG, Cap. 3, p. 91106, 2008.

SANO, E.E.; ROSA, R.; BRITO, J.LS.; FERREIRA, L.G. Land cover mapping of the tropical savanna region in Brazil. Environ Monitoring and Assessment, v. 166, p. 113-124, 2010.

SATELlTE IMAGING CORPORATION. Spot-6 Satellite Sensor. Disponível em: <http://www.satimagingcorp.com/satellite-sensors/spot-6/>. Acesso em: 14 fev. 2015.

SCHOWENGERDT RA. Remote Sensing, Models and Methods for Image Processing. San Diego: Academic Press, 2a ed., Cap. 9, p. 389-474, 1997.

SCHUSTER, C.; FÖRSTER, M.; KLEINSCHMIT, B. Testing the red edge channel for improving land-use classifications based on high-resolution multi-spectral satellite data. International Journal of Remote Sensing. v. 33, p. 5583-5599, 2012.

SEAQUIST, J.W.; OLSSON, L.; ARDO, J. A remote sensing-based primary production model for grassland biomes. Ecological Modelling. v. 169, p. 131-155, 2003.

SHIMABUKURO, Y.E.; VERONA, J.D.; LACRUZ, S.P.; HUETE, A.; FERREIRA, L.; YOSHIOKA, H.; SANO, E. Avaliação dos dados MODIS para o estudo da cobertura vegetal da Floresta Nacional do Tapajós no Estado do Pará. In: SIMPÓSIO BRASILEIRO DE SENSORIAMENTO REMOTO, 10., Foz do Iguaçu (PR). Anais... São José dos Campos: Inpe, 2001, p. 1761-1764.

SILVA, S. C.; SBRISSIA, A. F. A planta forrageira no sistema de produção. In: SIMPÓSIO SOBRE O MANEJO DE PASTAGEM, 17, 2000. Piracicaba. Anais... Piracicaba: FEALQ, p. 3-21, 2000. 
SOARES FILHO, C. V. Recomendações de espécies e variedades de Brachiaria para diferentes condições. In: SIMPÓSIO SOBRE MANEJO DE PASTAGEM, 11,. Piracicaba SP. Anais... Piracicaba: FEALQ, 1994, p.25-48.

SOUZA FILHO, A.P.S.; ALVES, S.M.; FIGUEIREDO, F.J.C.; DUTRA, S. Germinação de sementes de plantas daninhas de pastagens cultivadas: Mimosa pudica e Ipomoea asarifolia.

Planta Daninha, v. 19, n. 1, p. 23-31, 2001.

SOUZA, F.H.B. As sementes de espécies forrageiras do gênero Brachiaria no Brasil Central. In: II ENCONTRO PARA DISCUSSÃO SOBRE CAPINS DO GÊNERO BRACHIARIA, 2, 1991. Nova Odessa - SP. Anais... Instituto de Zootecnia, Nova Odessa. 1991, p.137-185.

SPAIN, J.M.; GUALDRÓN, R. Degradación y rehabilitación de pastures. In: VI Reunión del Comité Asesor de la RIEPT. Memórias. Red International de Evaluación de Pastos Tropicales. Veracruz, México. CIAT, p. 269-283, 1988

THENKABAIL, P.S.; SMITH, R.B.; PAUW, E. Evaluation of Narrowband and Broadband Vegetation Indices for Determining Optimal Hyperspectral Wavebands for Agricultural Crop Characterization. Photogrammetric Engineering \& Remote Sensing. v. 68, n. 6, p. 607621.2002.

THENKABAIL, P.S.; ENCLONA, E.A.; ASHTON, M.S.; VAN DER MEER, B. Accuracy assessments of hyperspectral waveband performance for vegetation analysis applications. Remote Sensing of Environment. v. 91, p. 354-376. 2004.

TUCKER, C. J. Red and photographic infrared linear combinations for monitoring vegetation. Remote Sensing of Environment, v. 8, p. 127-150, 1979.

TYC, G.; TULIP, J.; SCHULTEN, D.; KRISCHKE, M.; OXFORT, M. The RapidEye mission design. Acta Astronautica. v. 56, p. 213 -219, 2005.

UNGAR, S.G.; PEARLMAN, J.S.; MENDENHALL, J.A.; REUTER, D. Overview of the Earth Observing One (EO-1) mission. IEEE Transactions on Geoscience and Remote Sensing, v. 41, p. 1149-1153, 2003.

VRIELING, A. Satellite remote sensing for water erosion assessment: a review. Catena. v. 65 , p. 2-18, 2006.

WANG, F.; HUANG, J.; ZHOU, Q.; WANG, X. Optimal waveband identification for estimation of leaf area index of paddy rice. Journal of Zhejiang University SCIENCE B. $\mathrm{v}$. 12, n. 9, p. 953-963, 2008. 
WHITE, M.A.; ASNER, G.P.; NEMANI, R.R.; PRIVETTE, J.L.; RUNNING. S.W. Measuring fractional cover and leaf area index in arid ecosystems: digital camera, radiation transmittance, and laser altimetry methods. Remote Sensing of Environment. vol. 74, p. 45$57,2000$.

ZHENG, D.; RADEMACHER, J.; CHEN, J.; CROW, T.; BRESEE, M.; MOINE, J.L.; RYU, S.R. Estimating aboveground biomass using Landsat 7 ETM+ data across amanaged landscape in northern Wisconsin, USA. Remote Sensing of Environment, v. 93, p. 402-411, 2004. 
ANEXO

FOTOGRAFIAS DE CAMPO ORIGINAIS E CLASSIFICADAS 

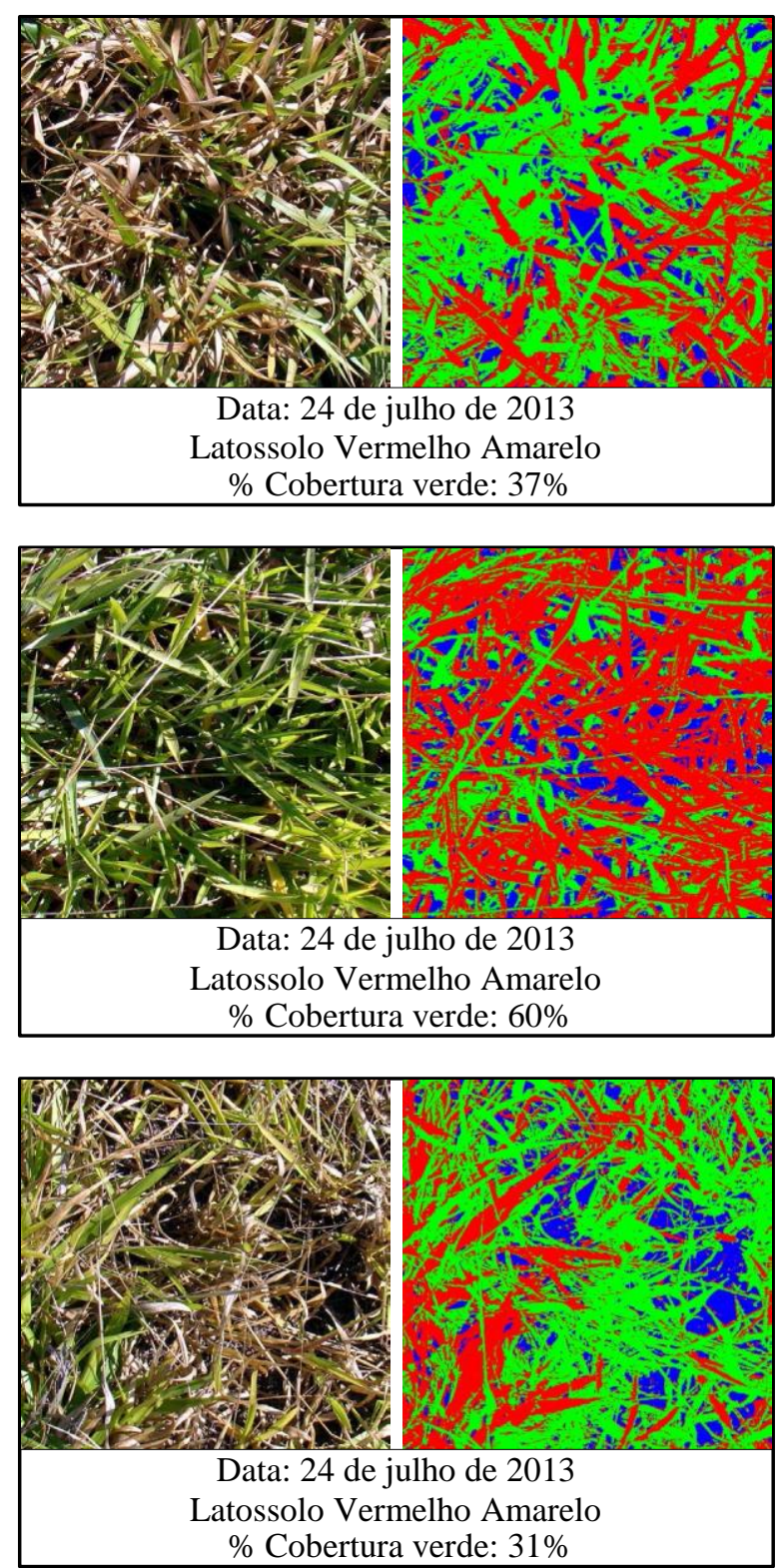
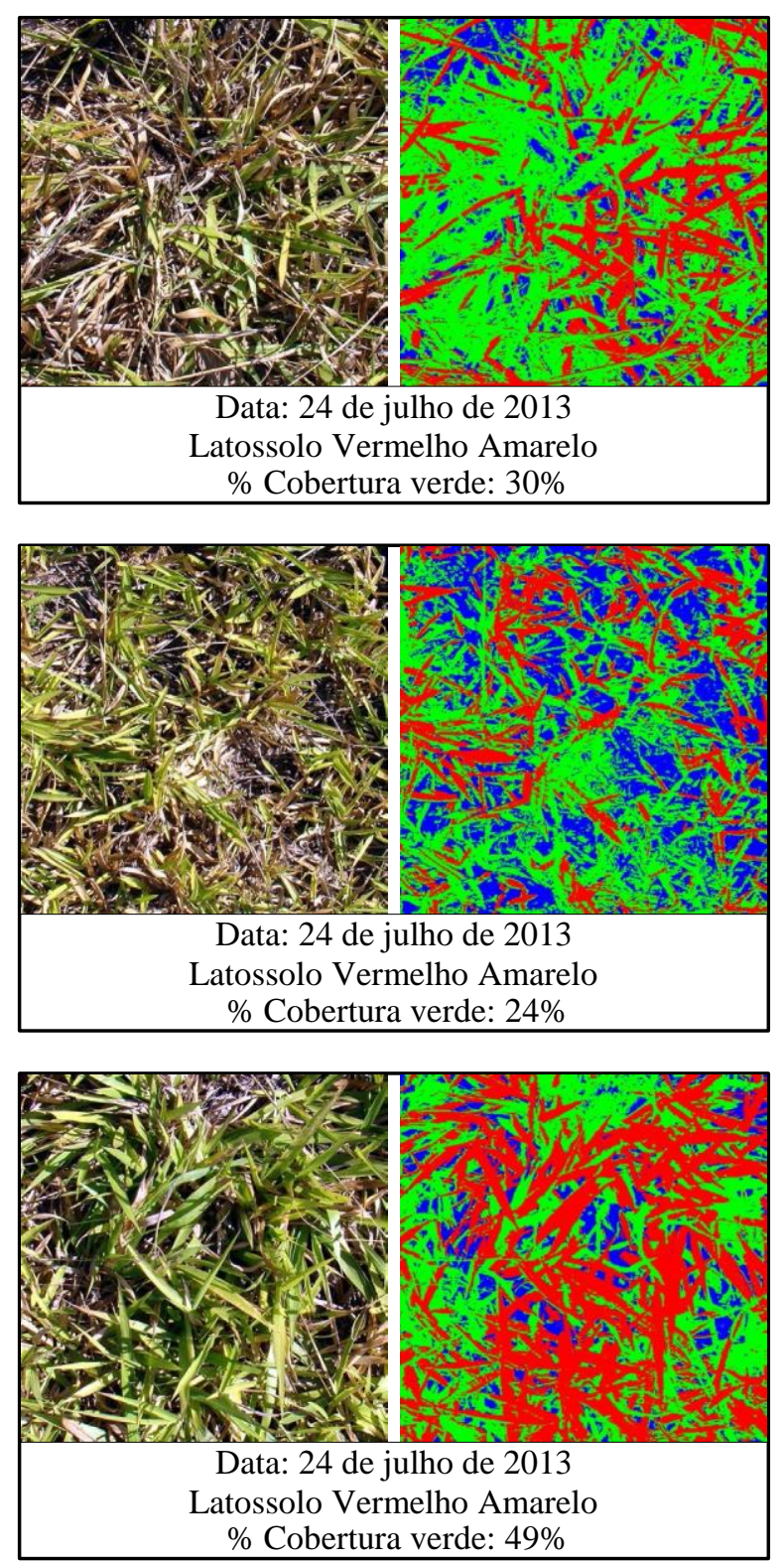
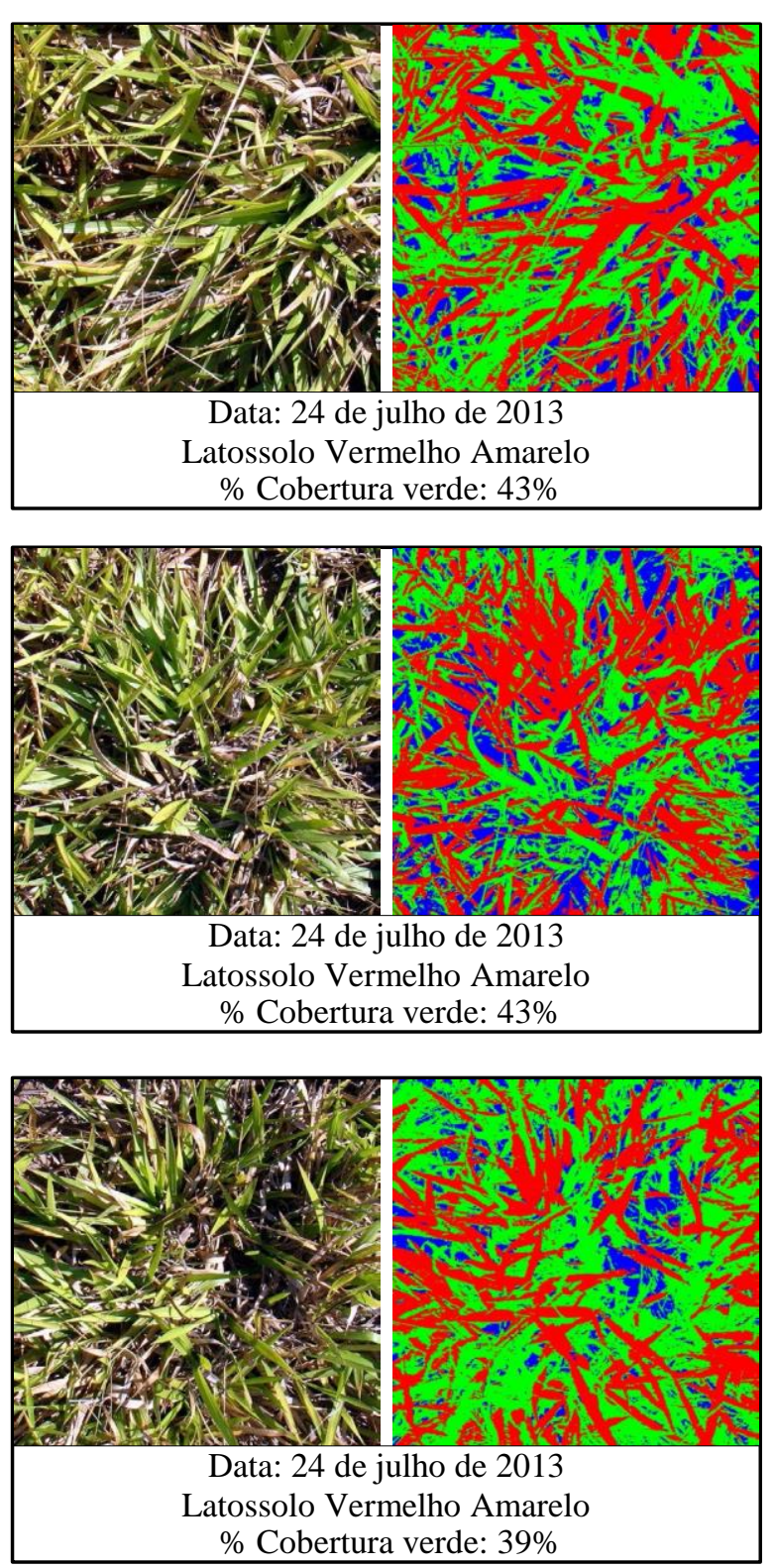

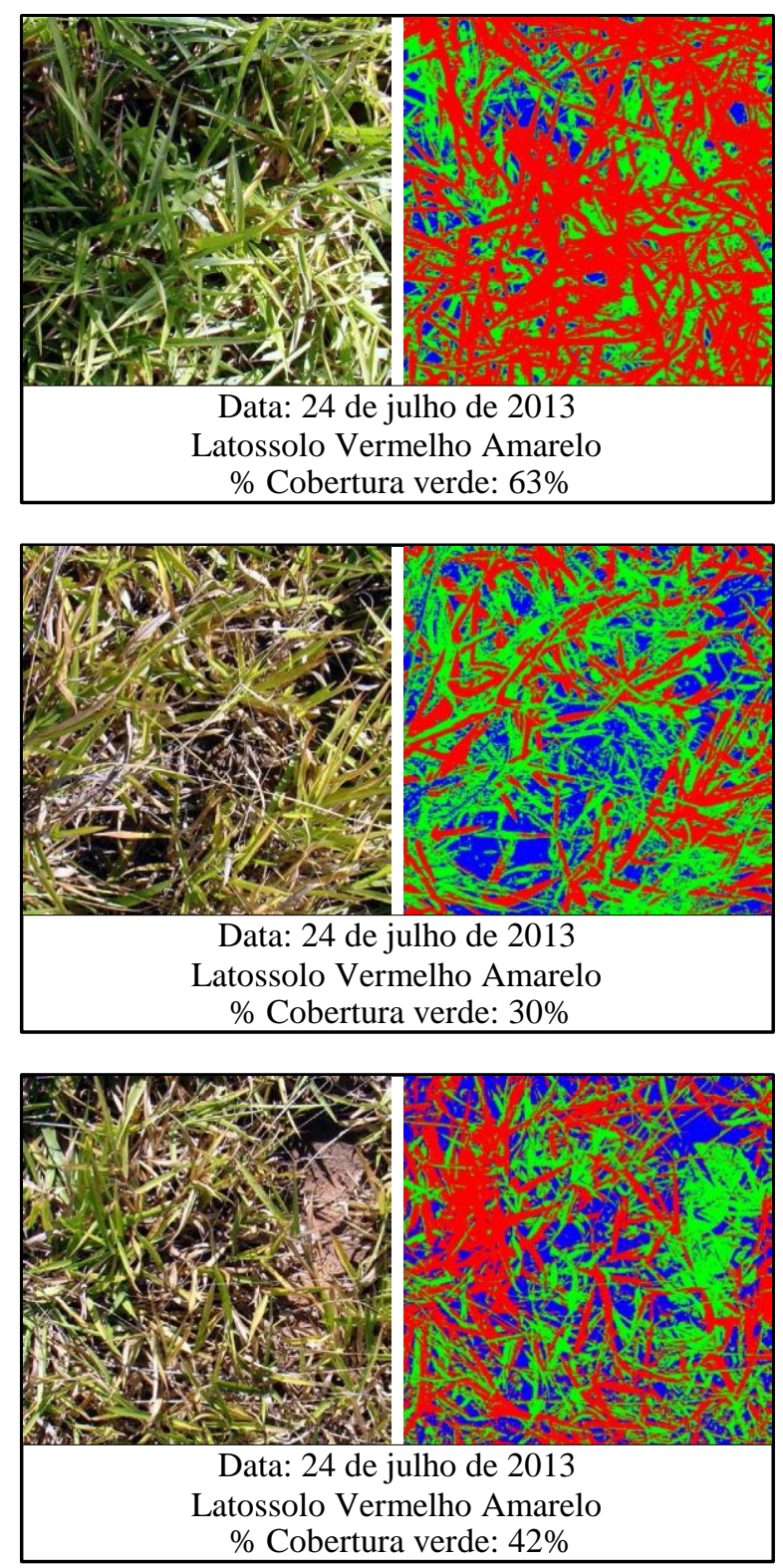
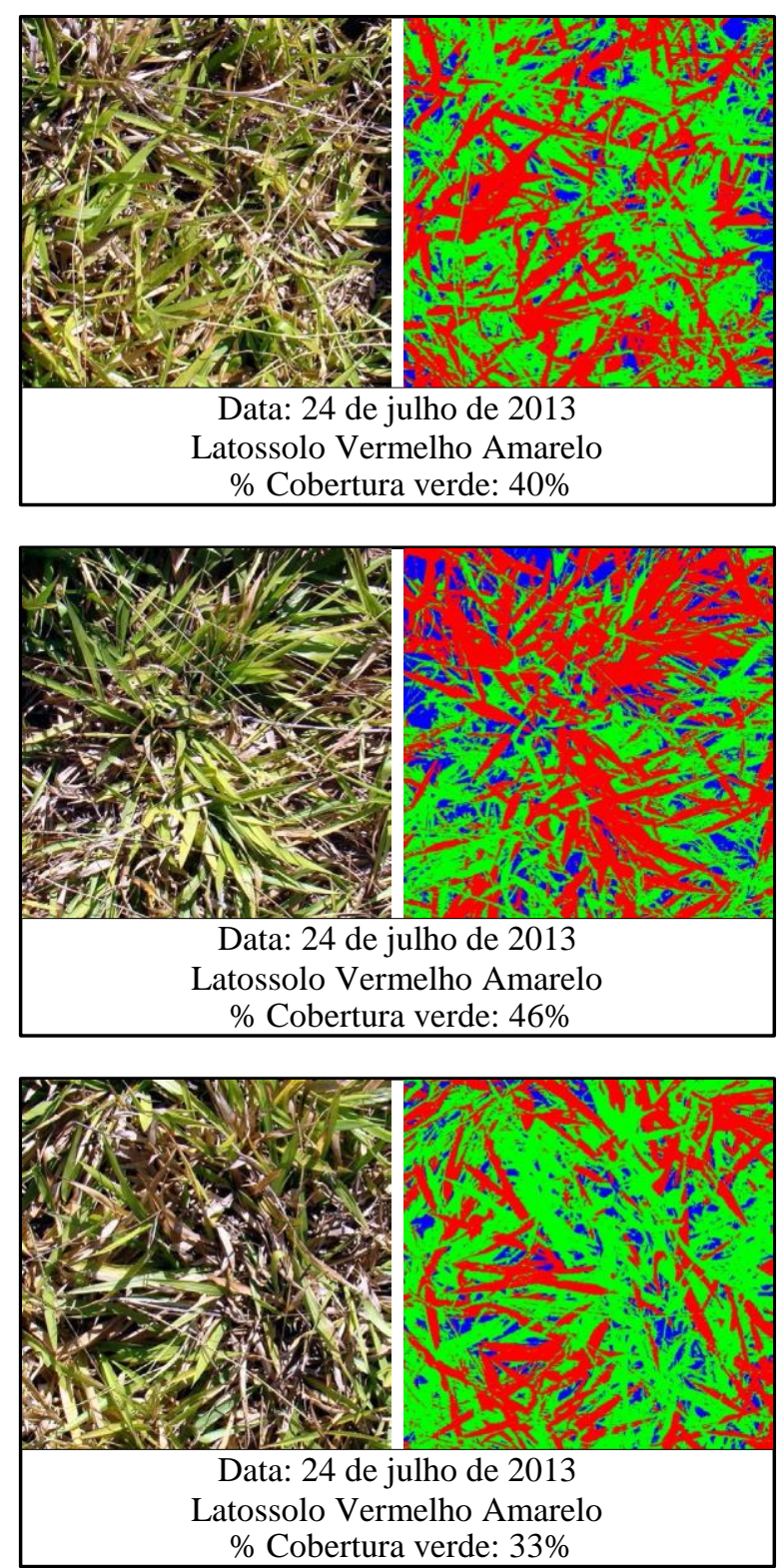
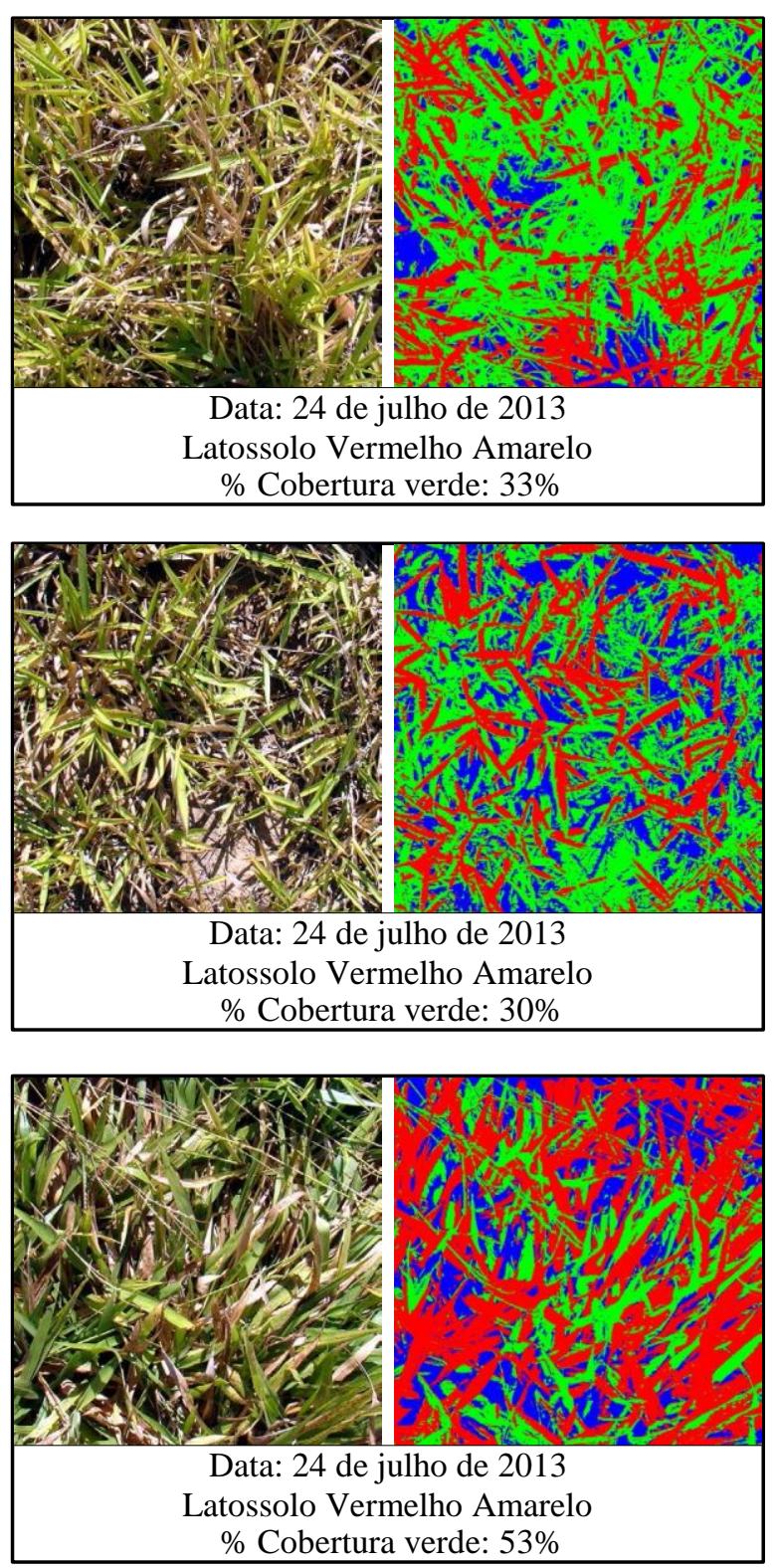

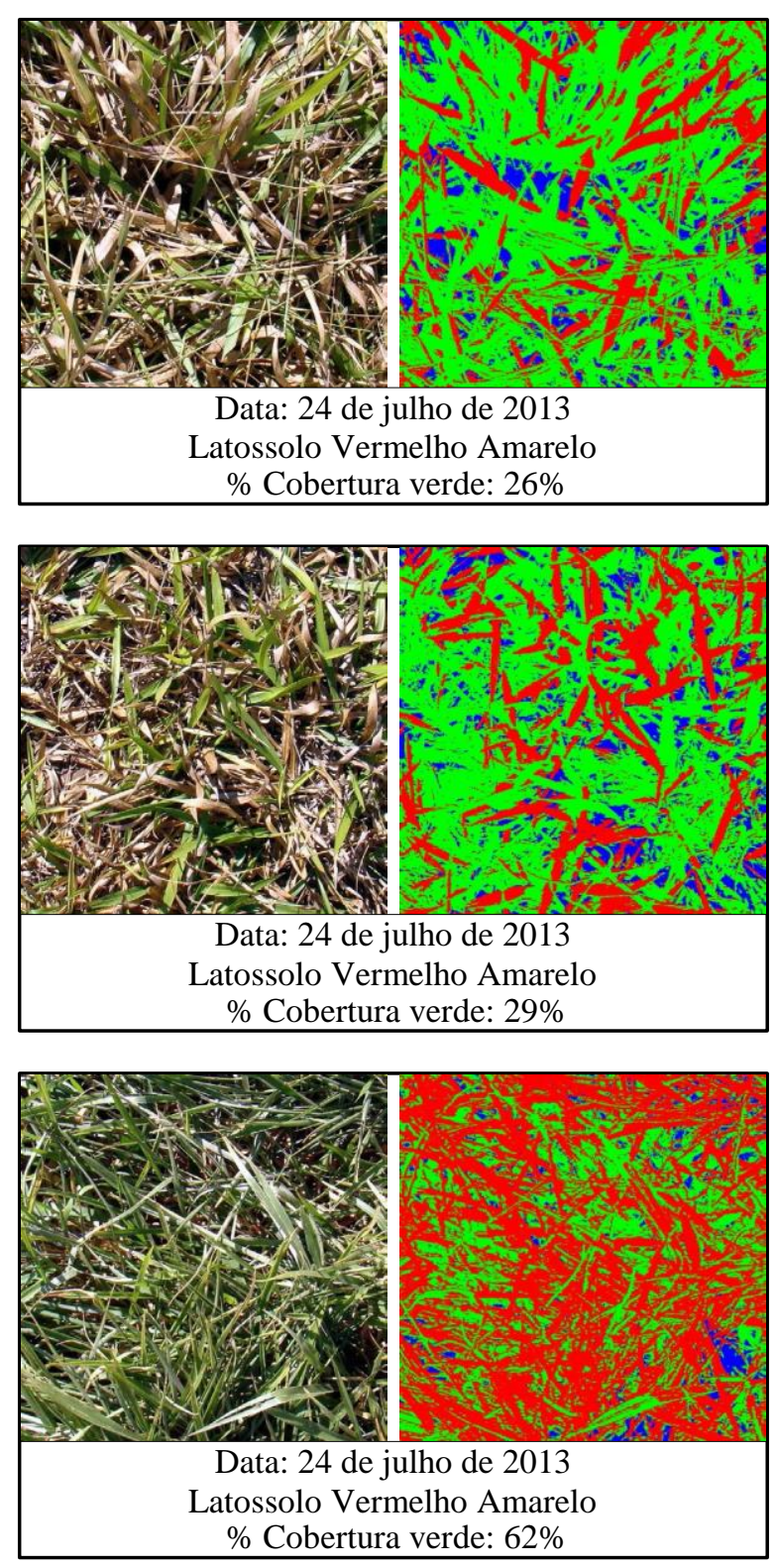
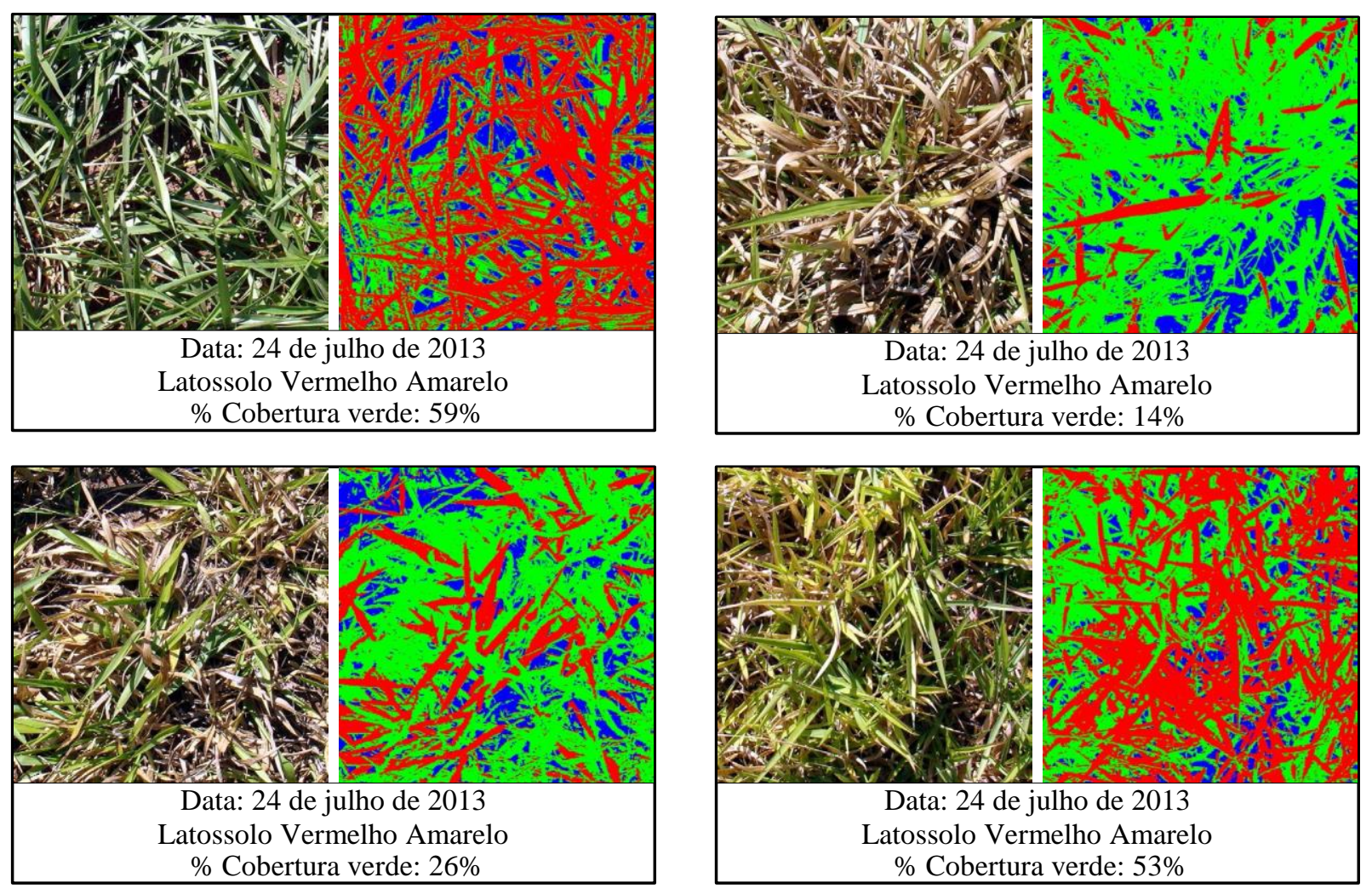

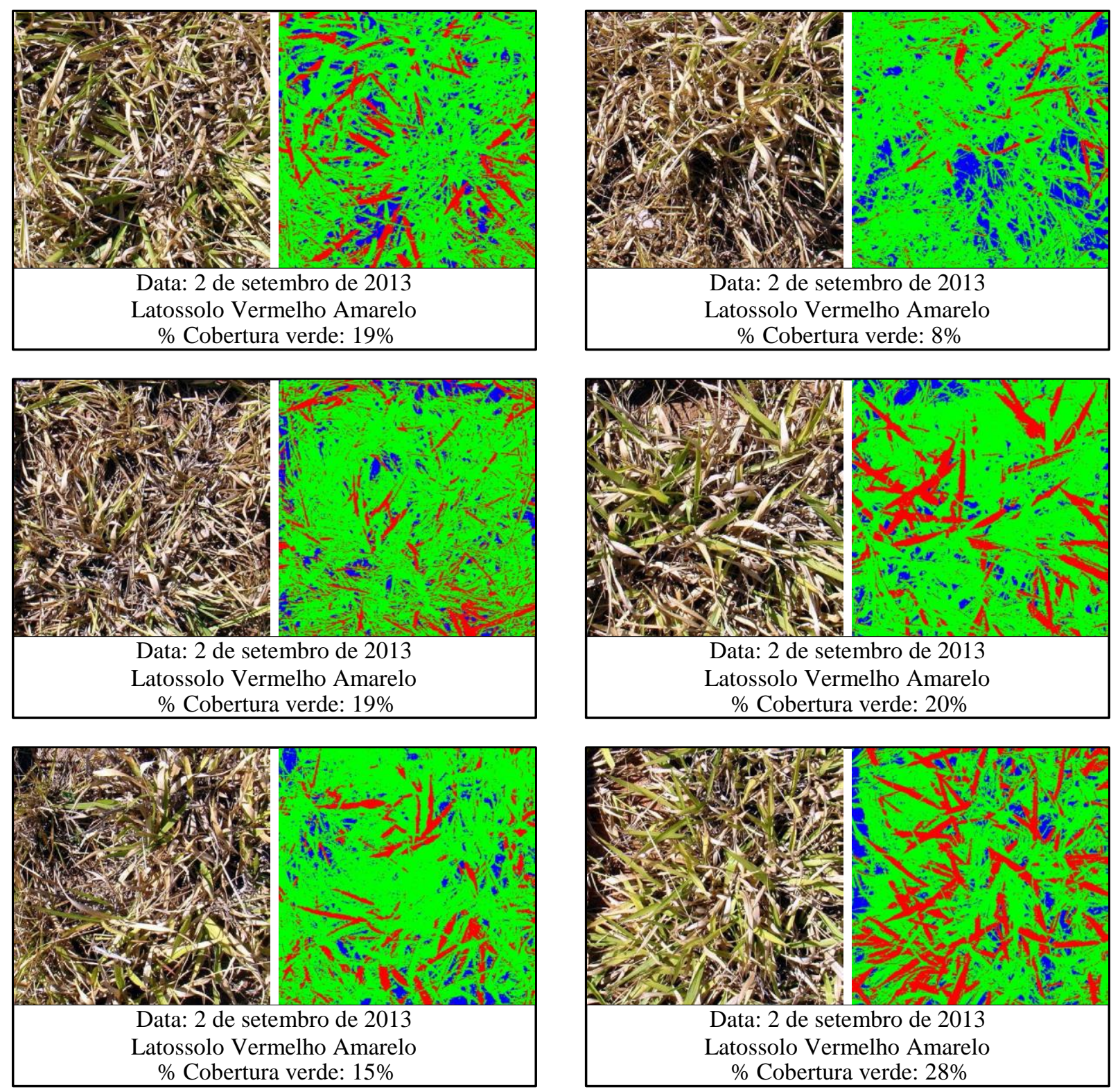
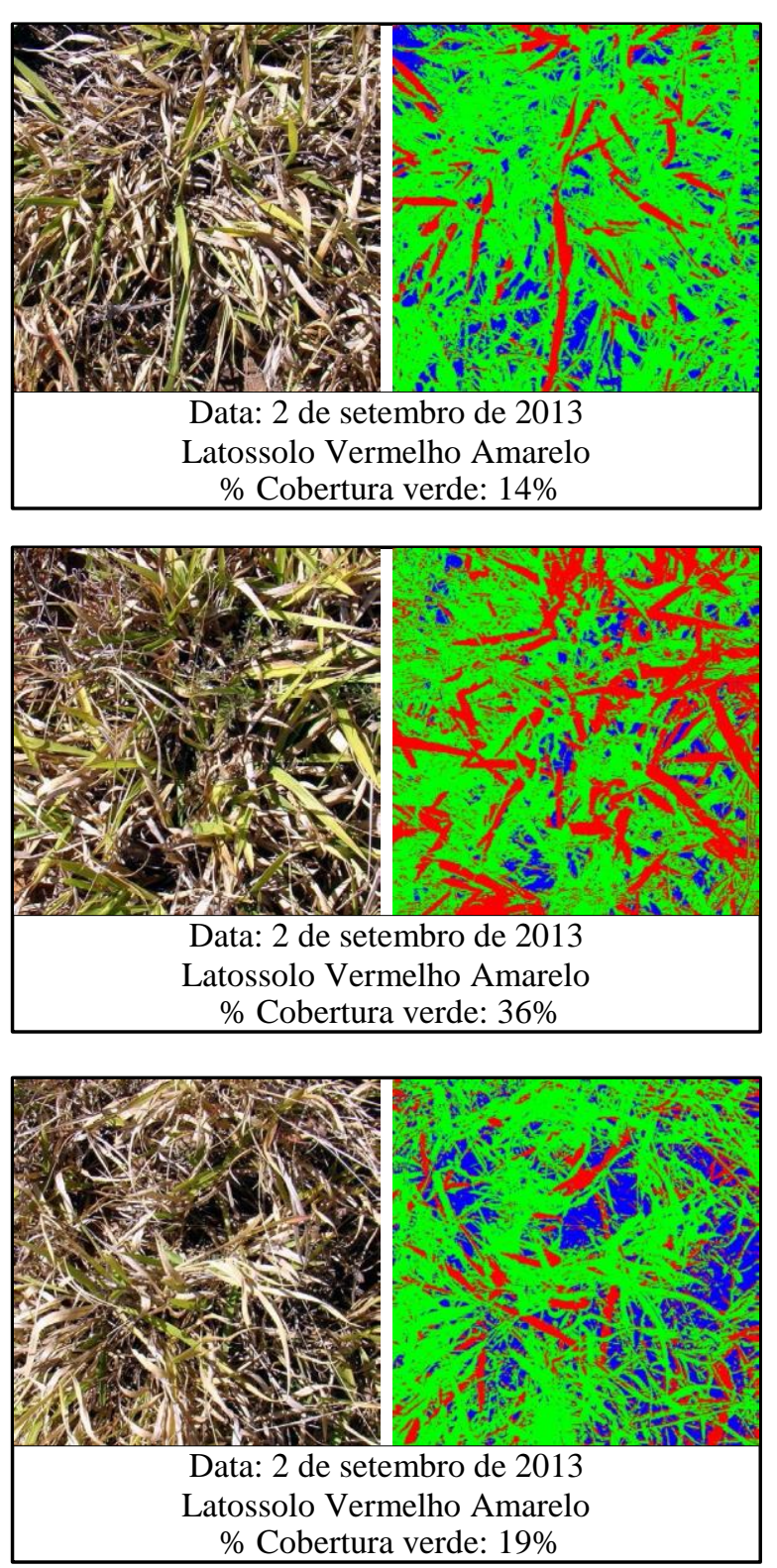

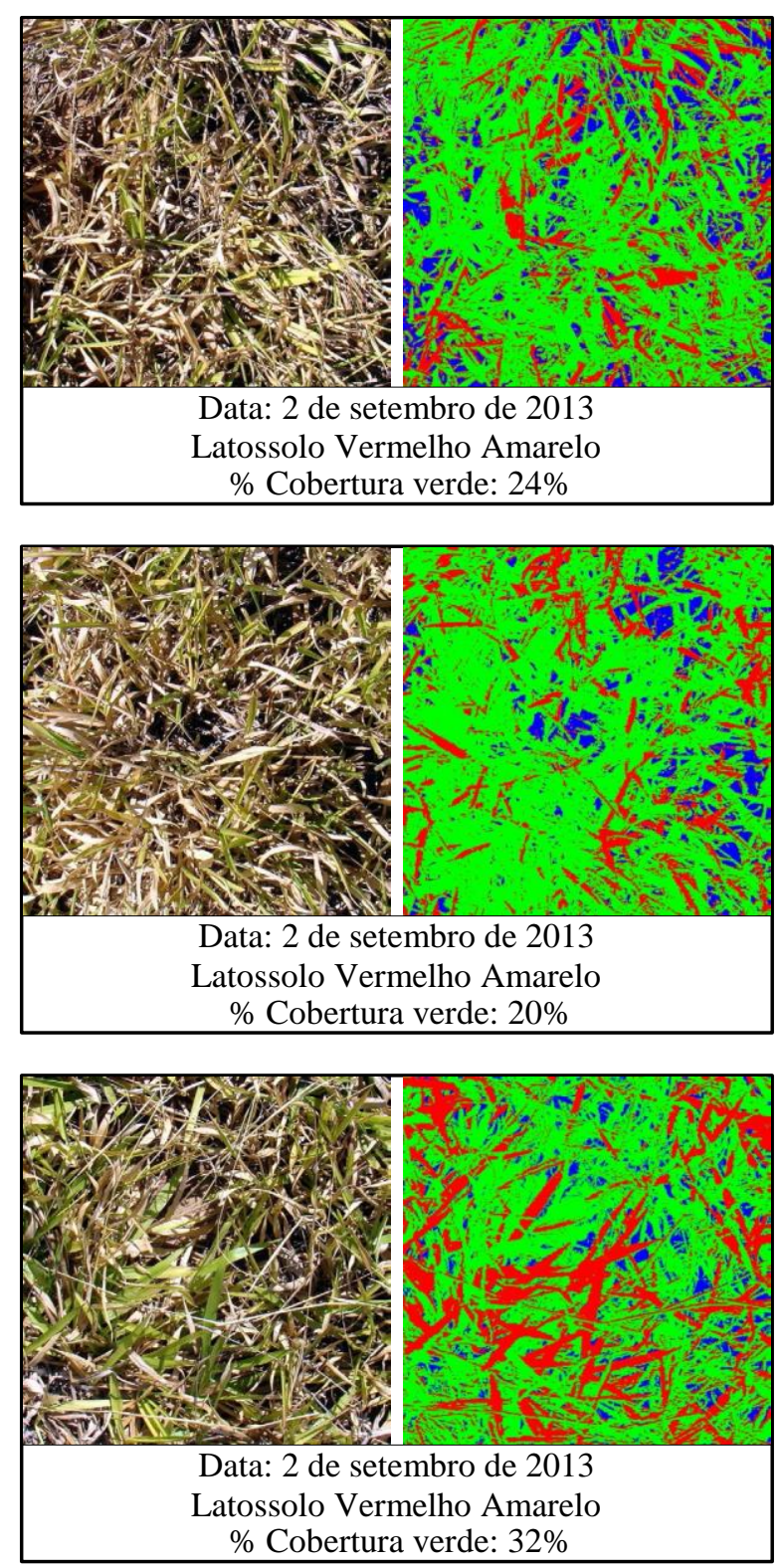
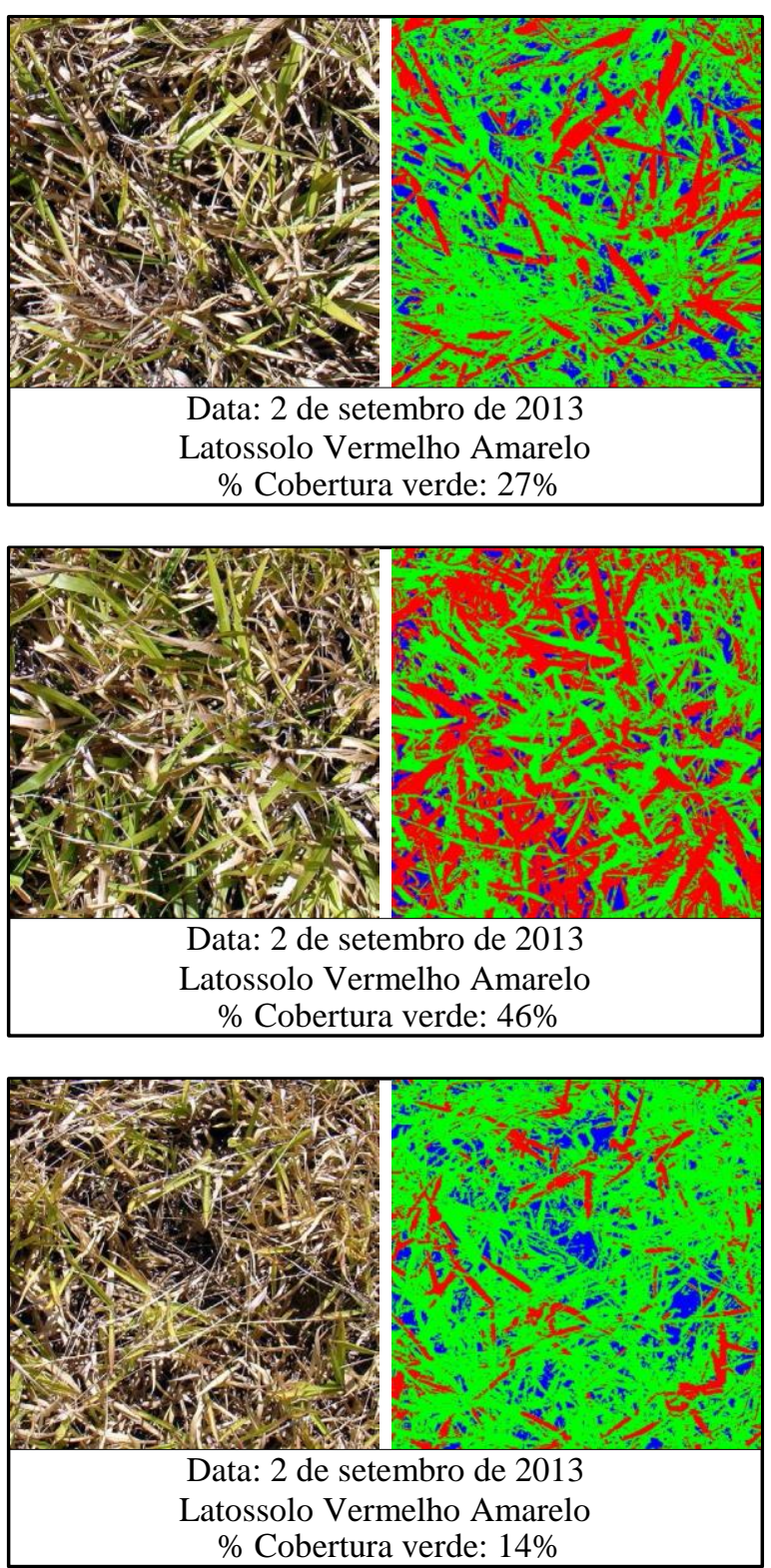
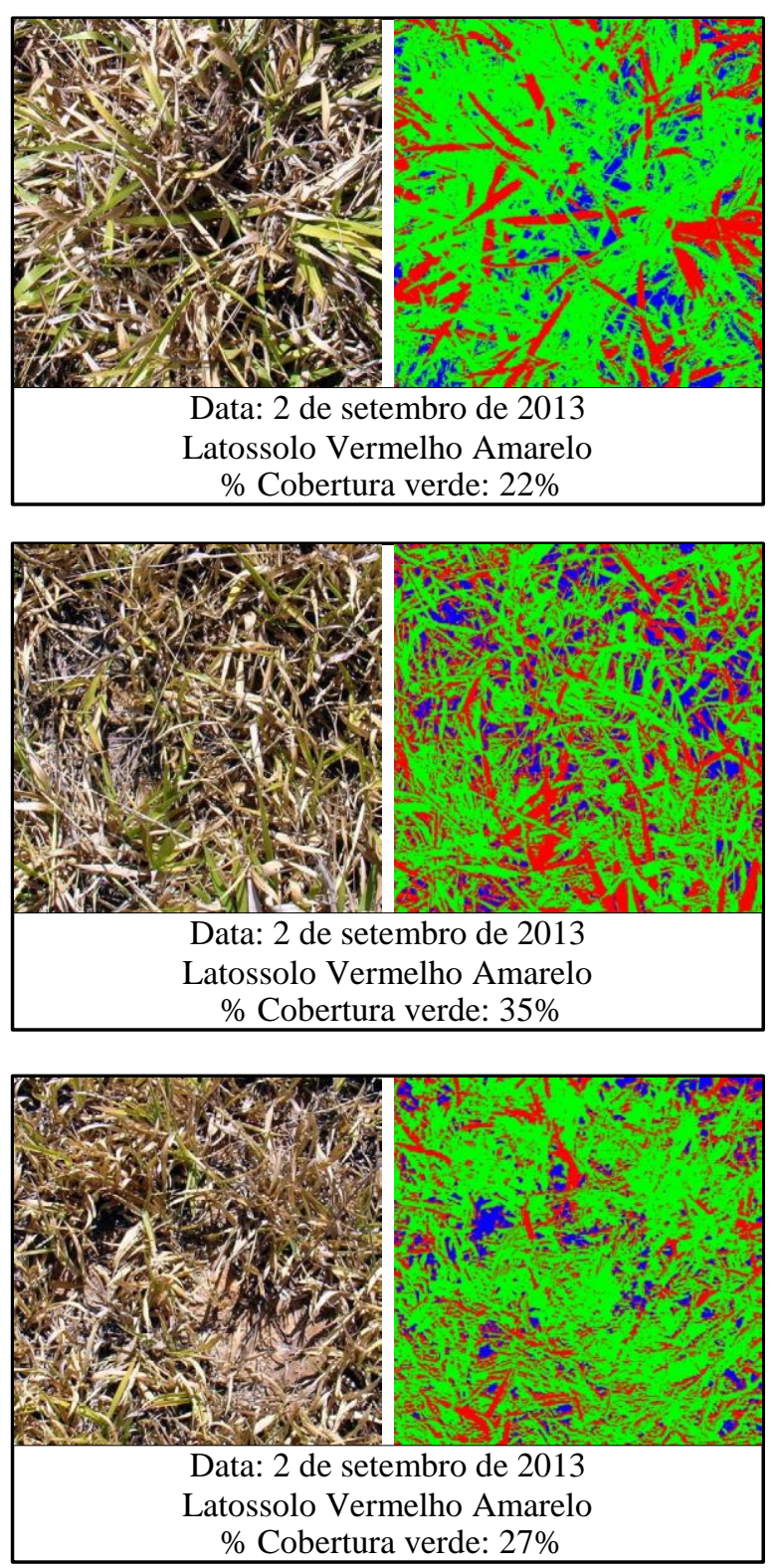

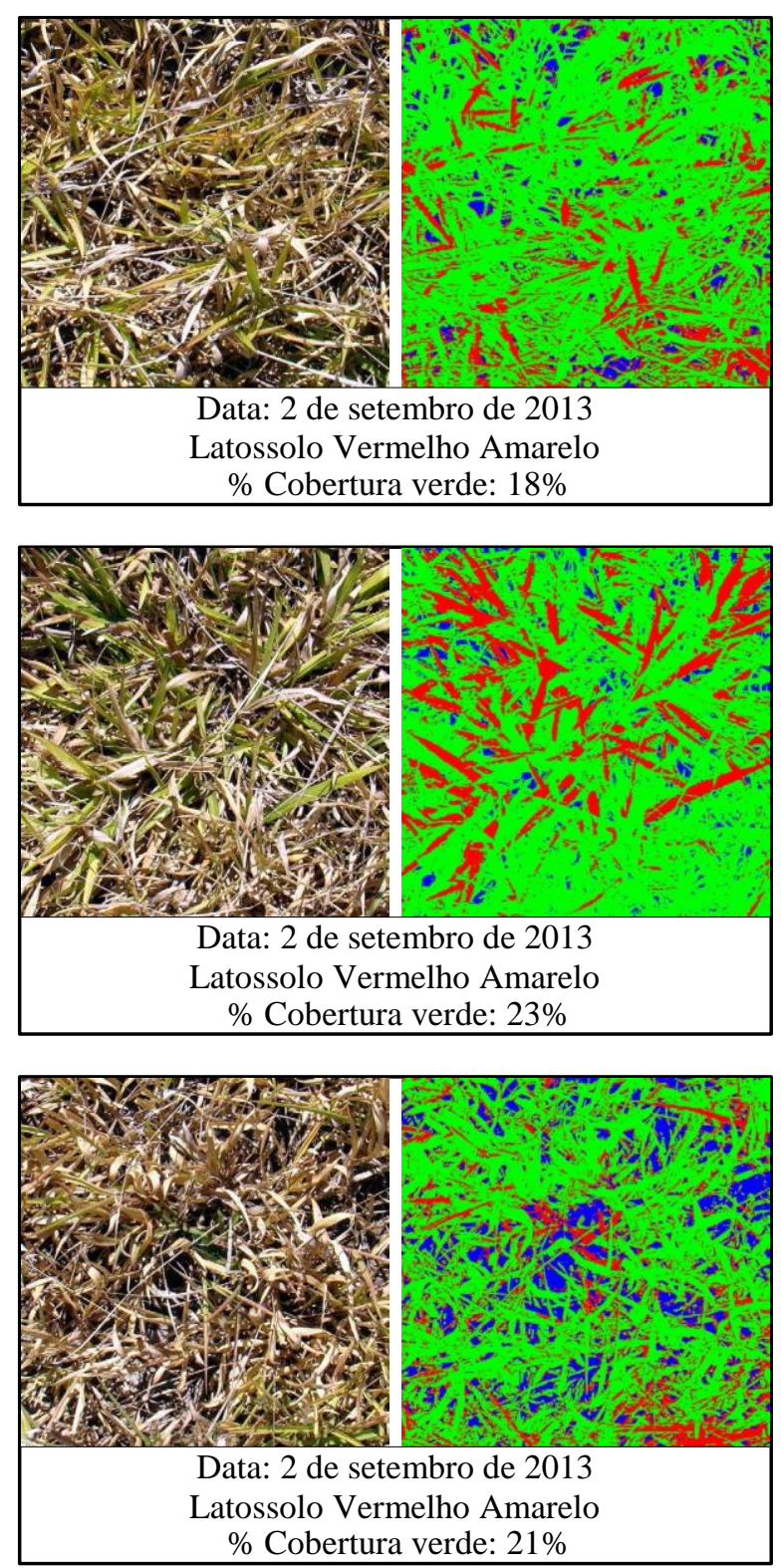
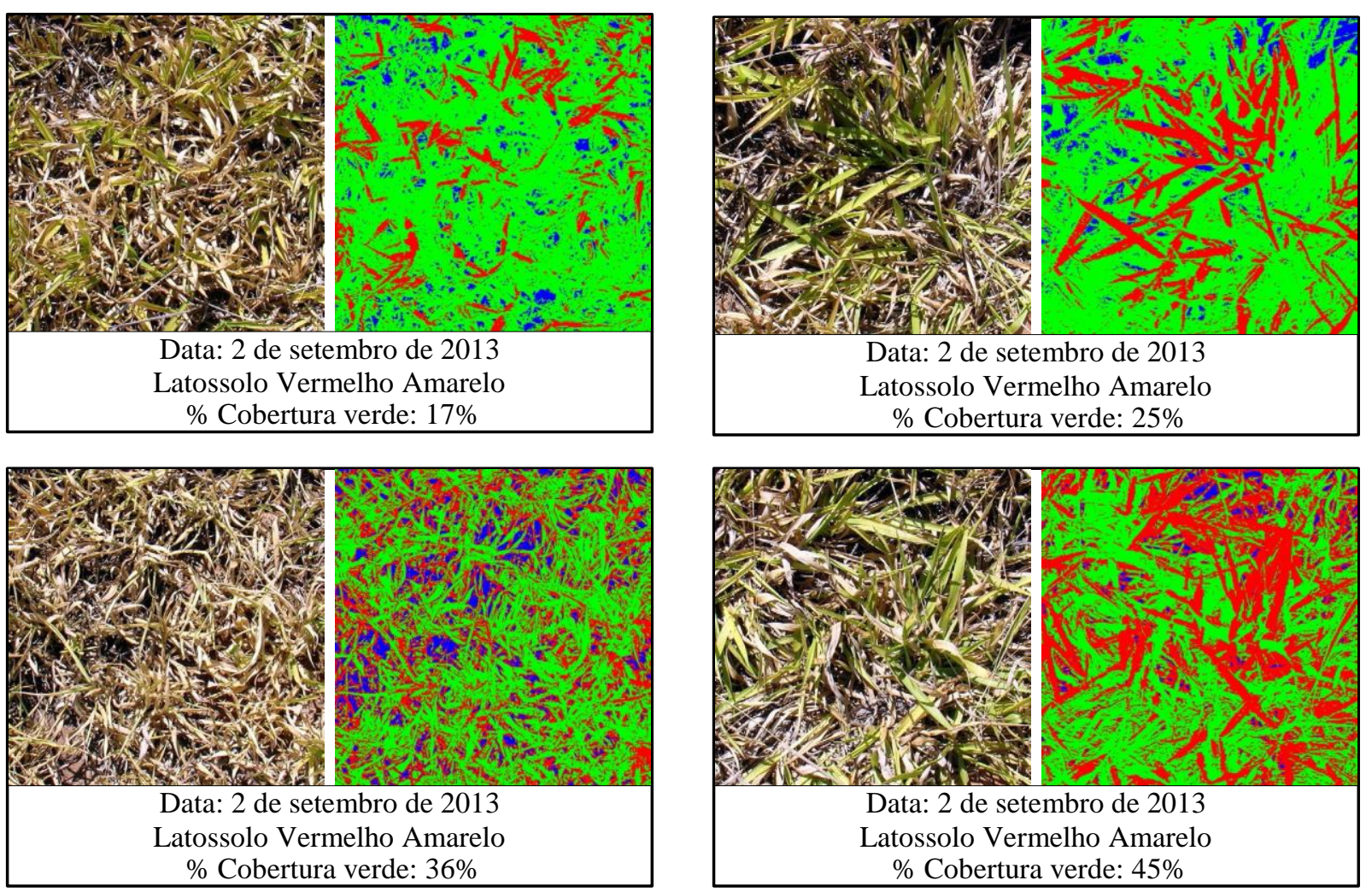

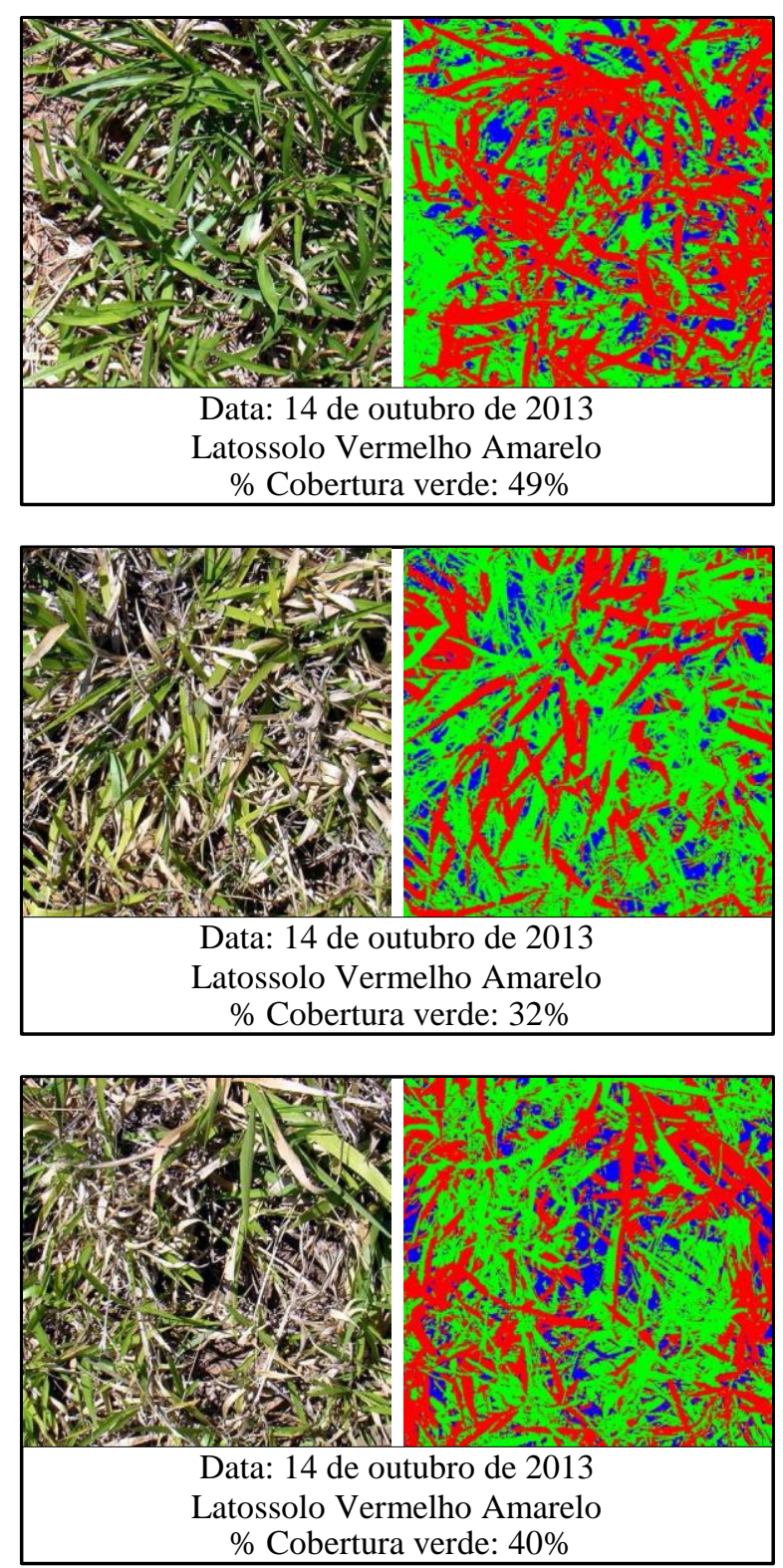
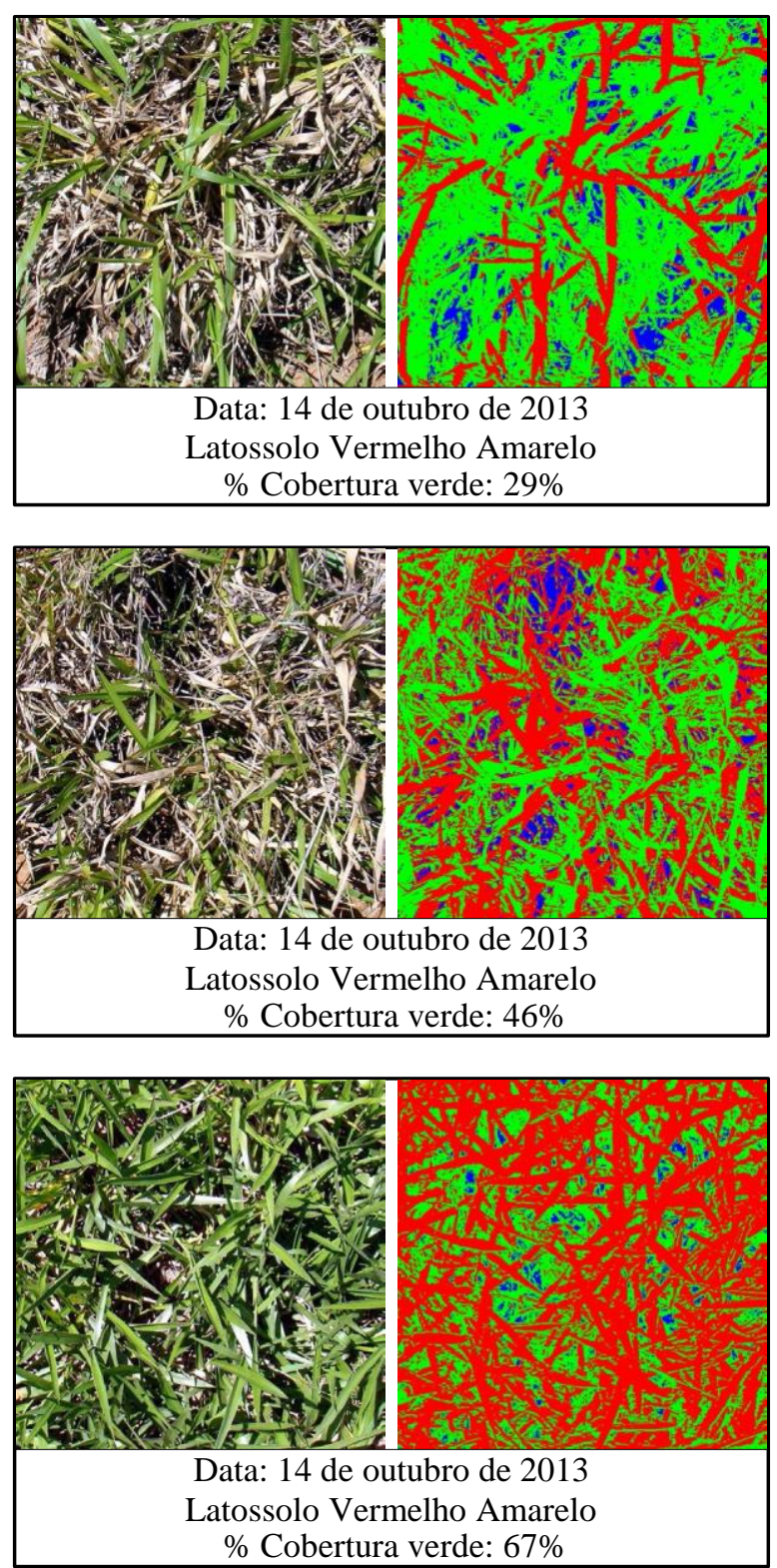
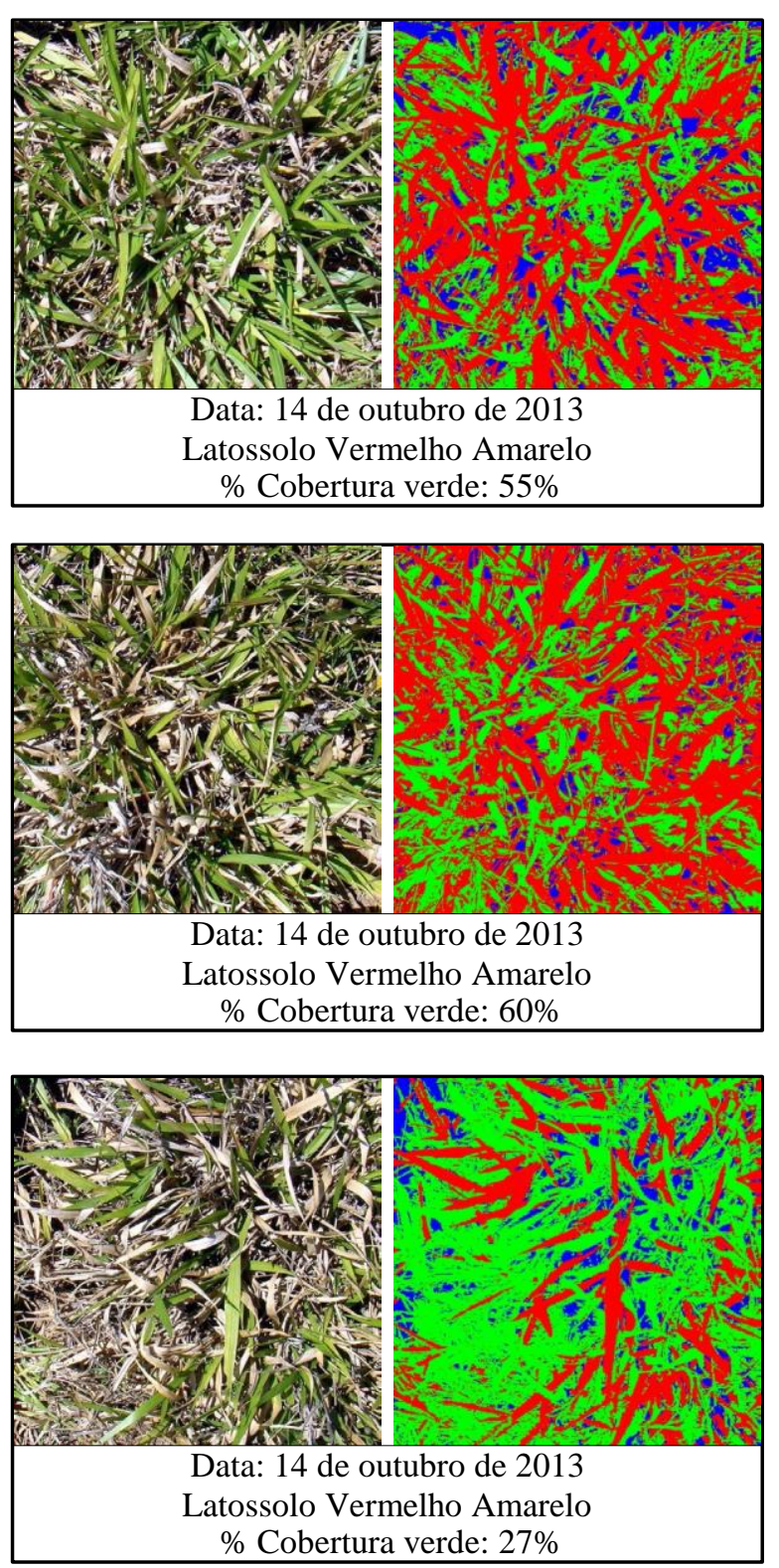

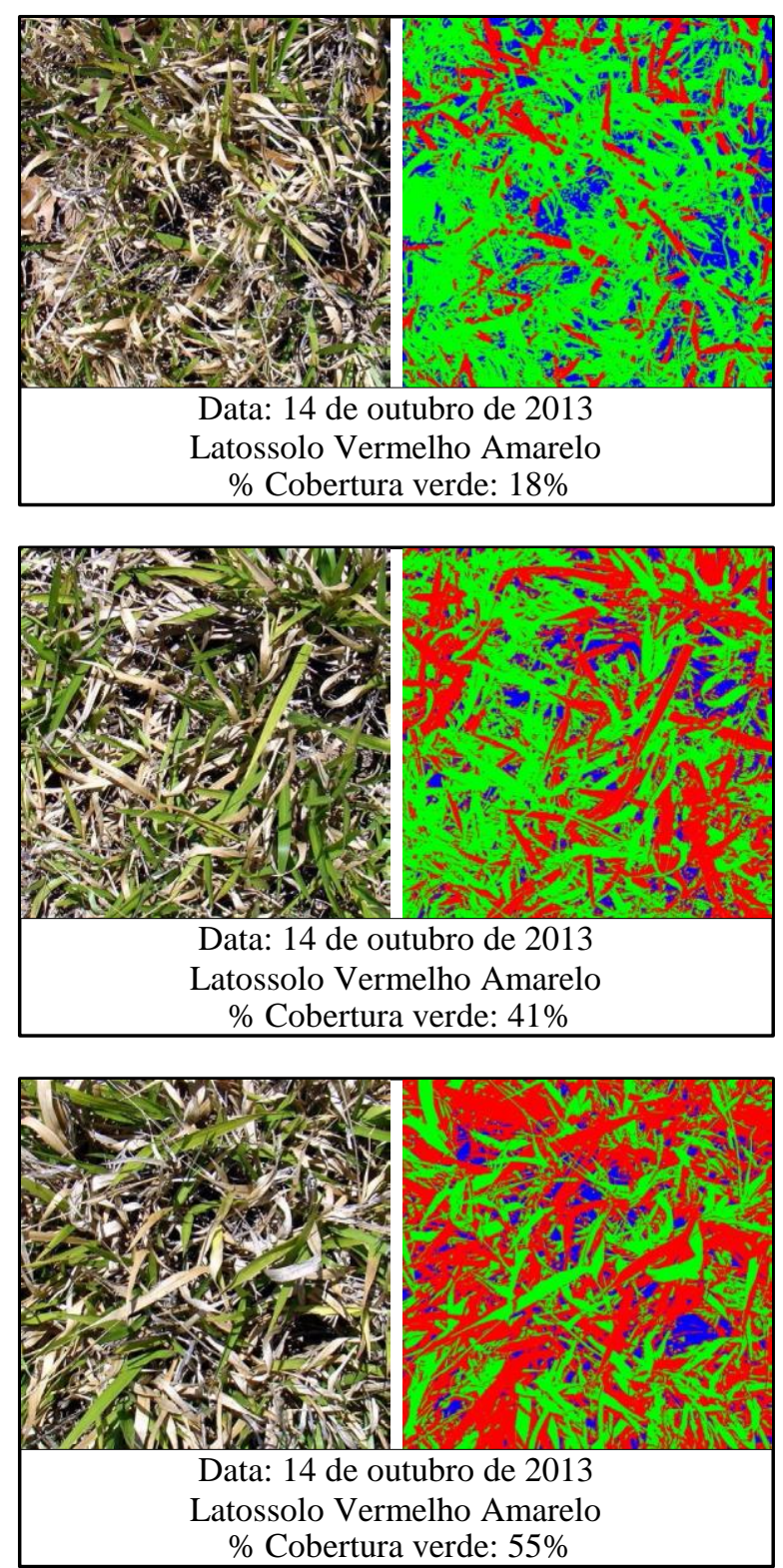
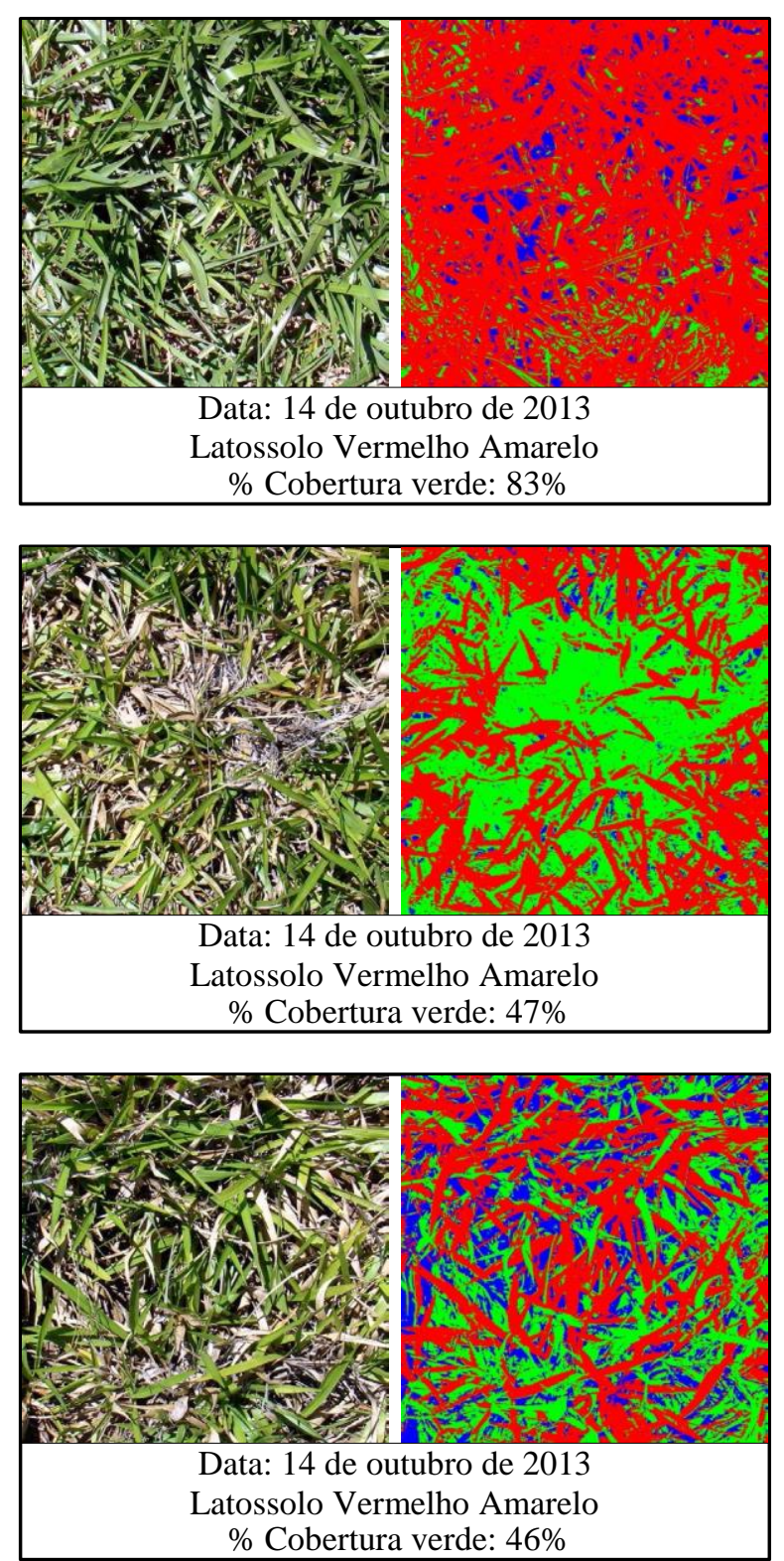
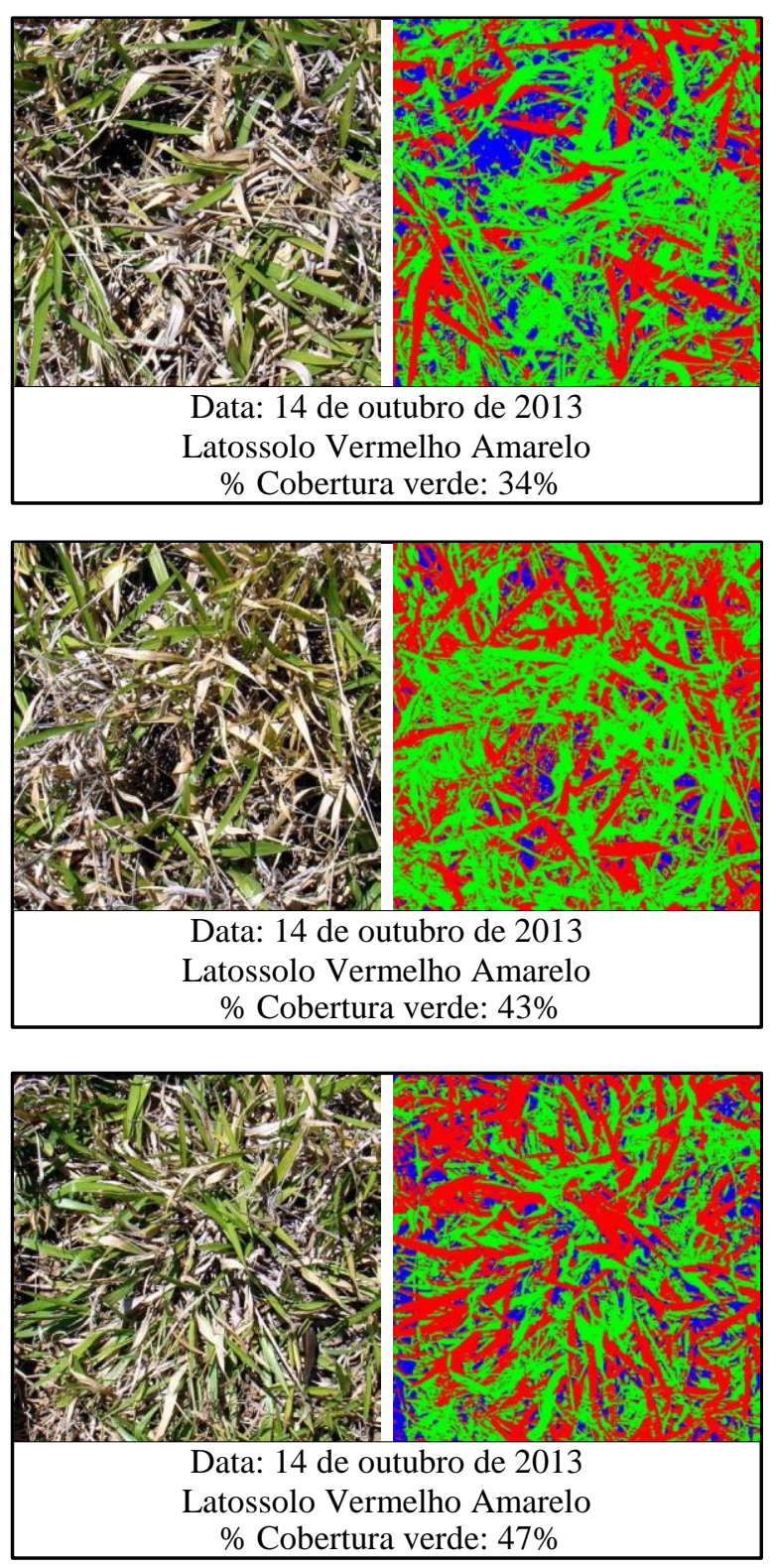

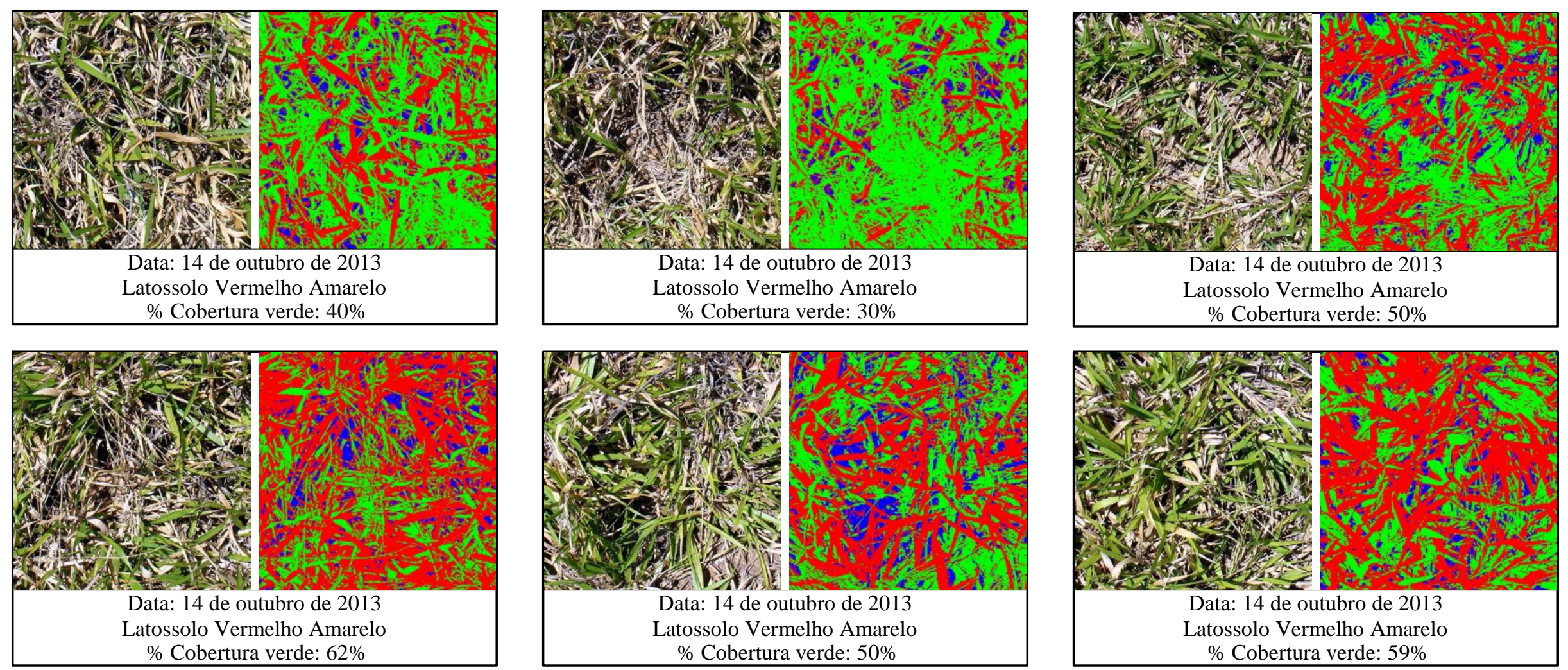

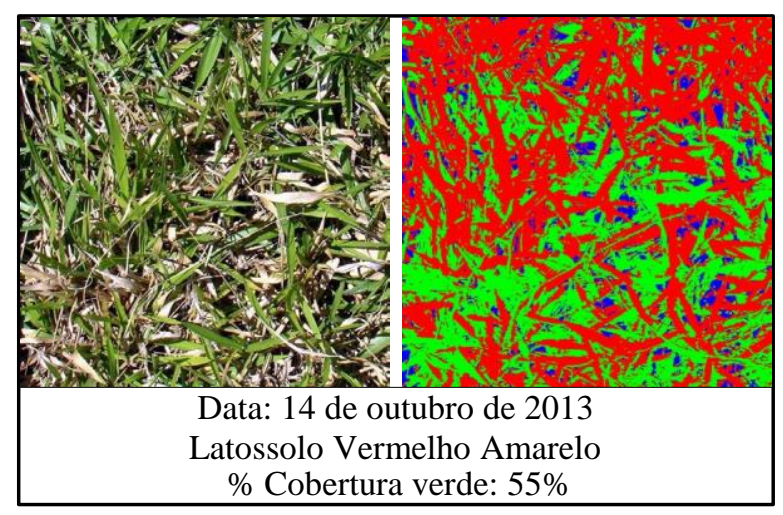



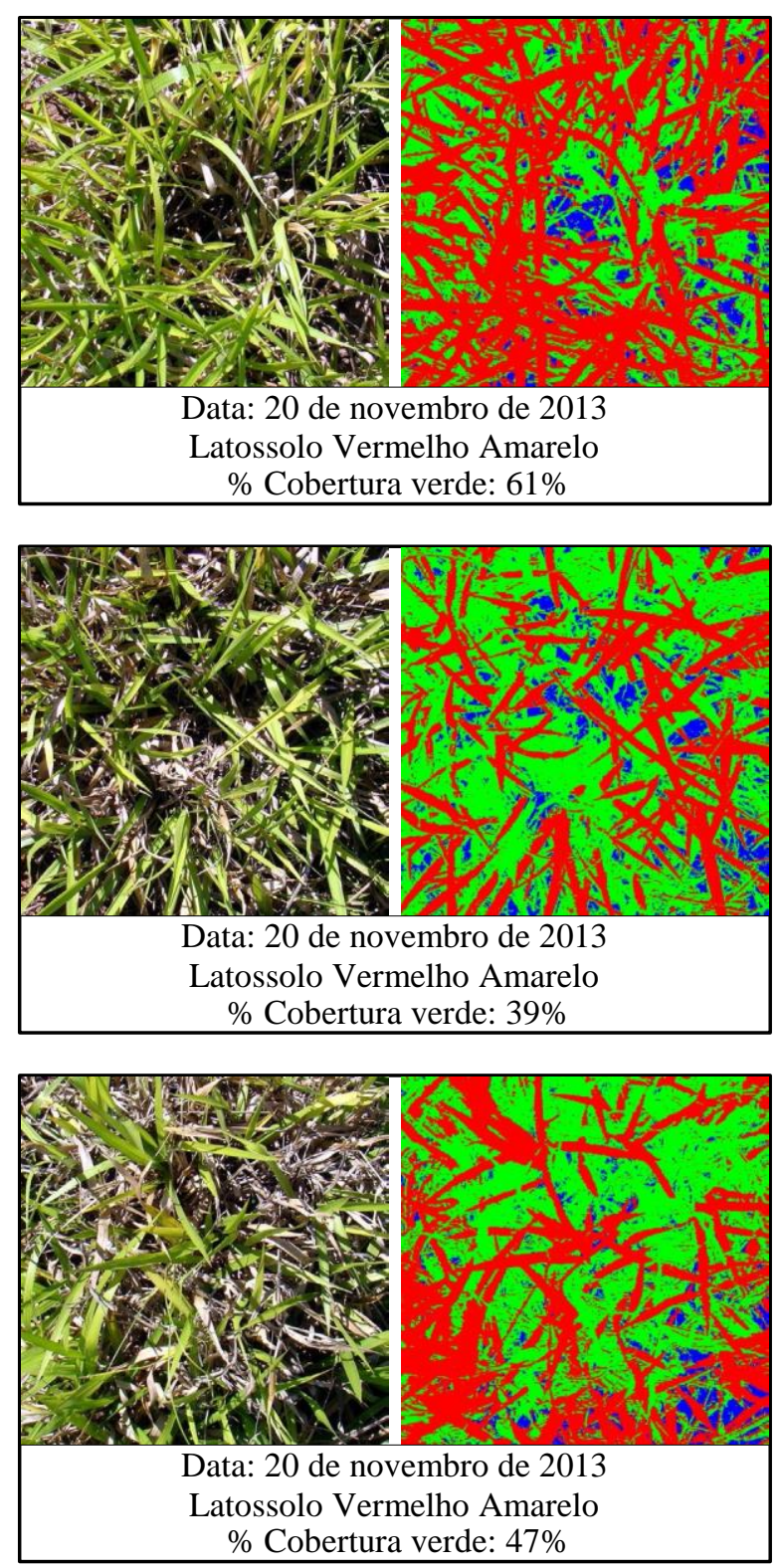
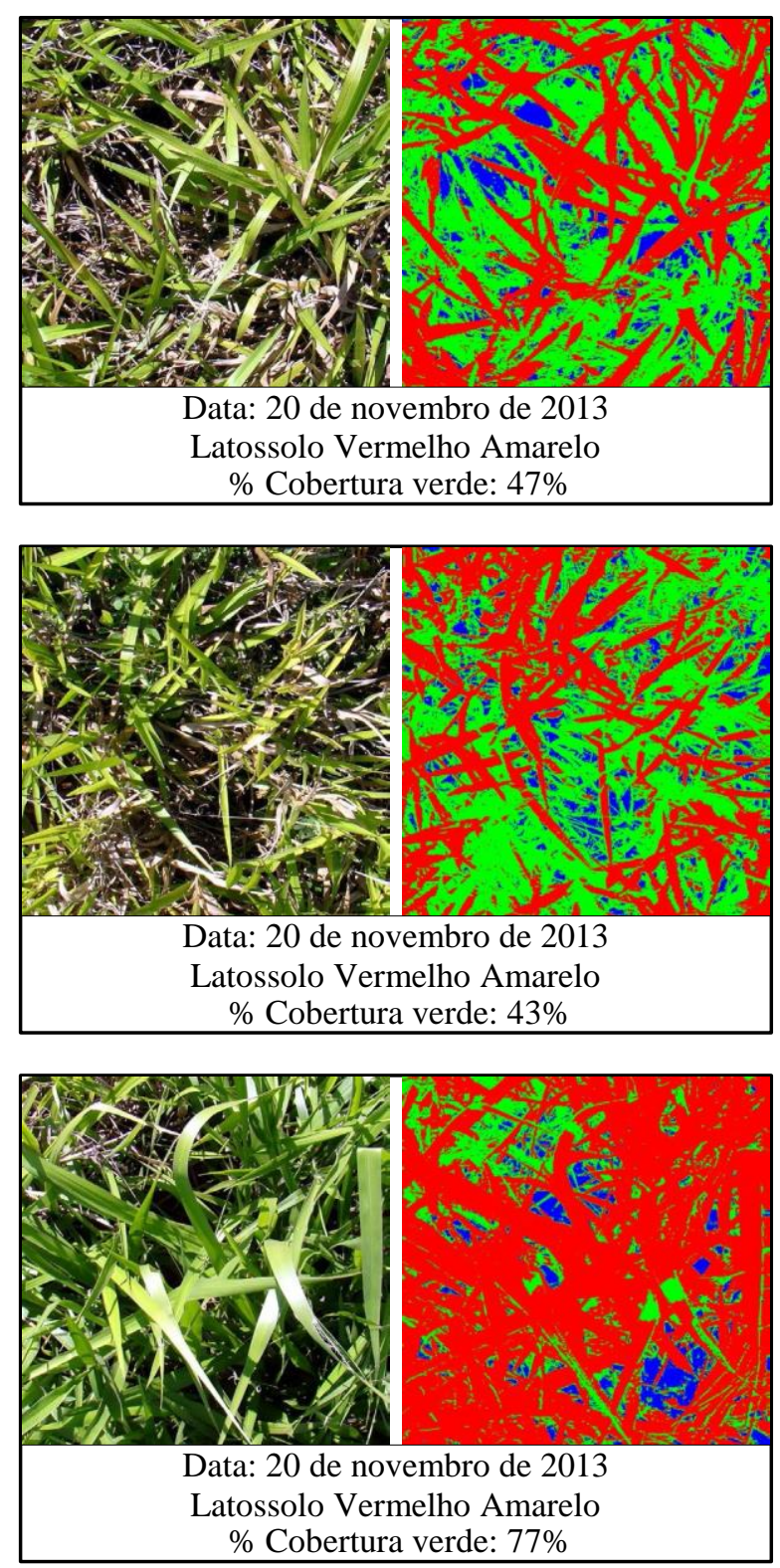
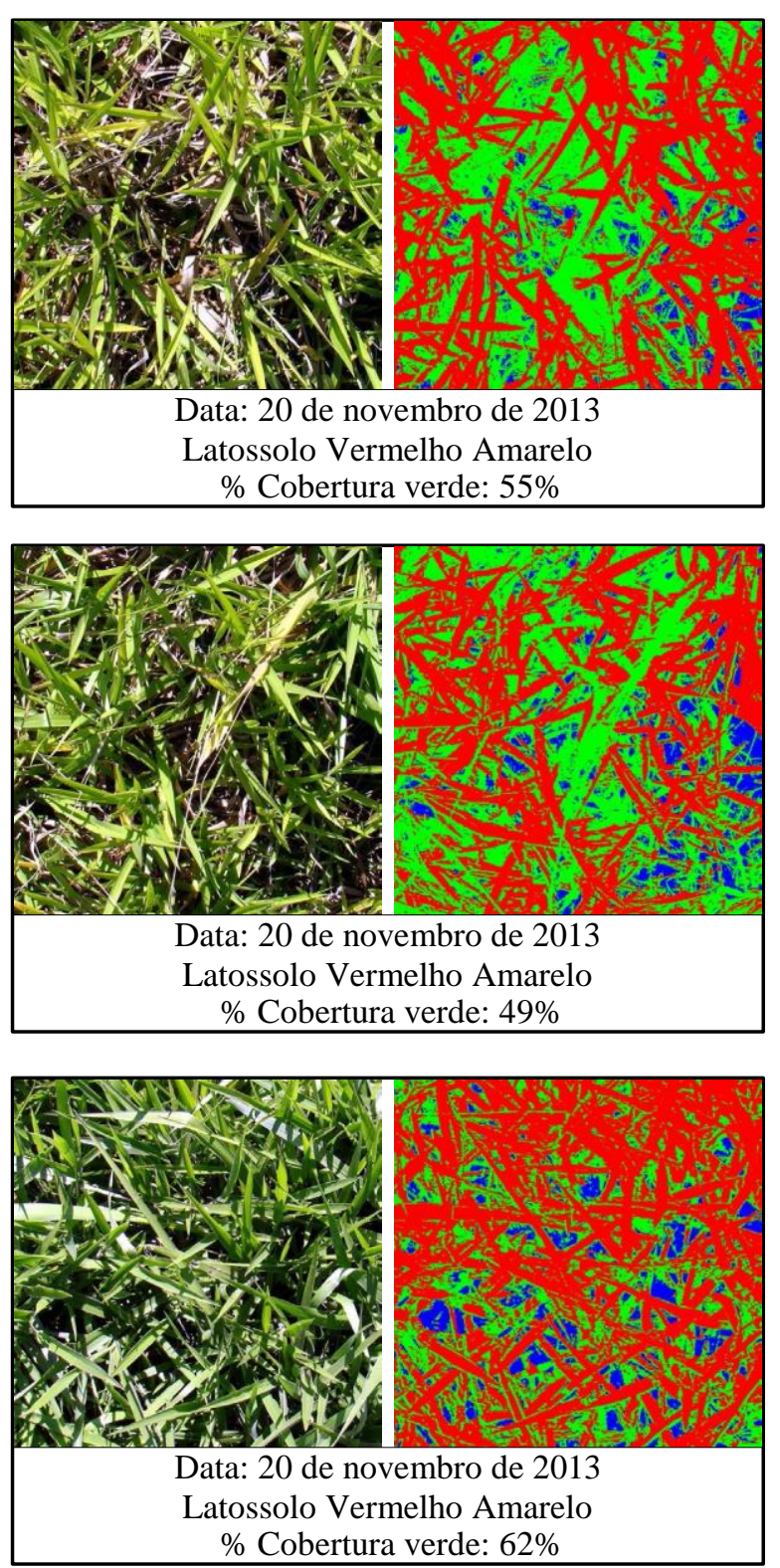
$\%$ Cobertura verde: $62 \%$ 

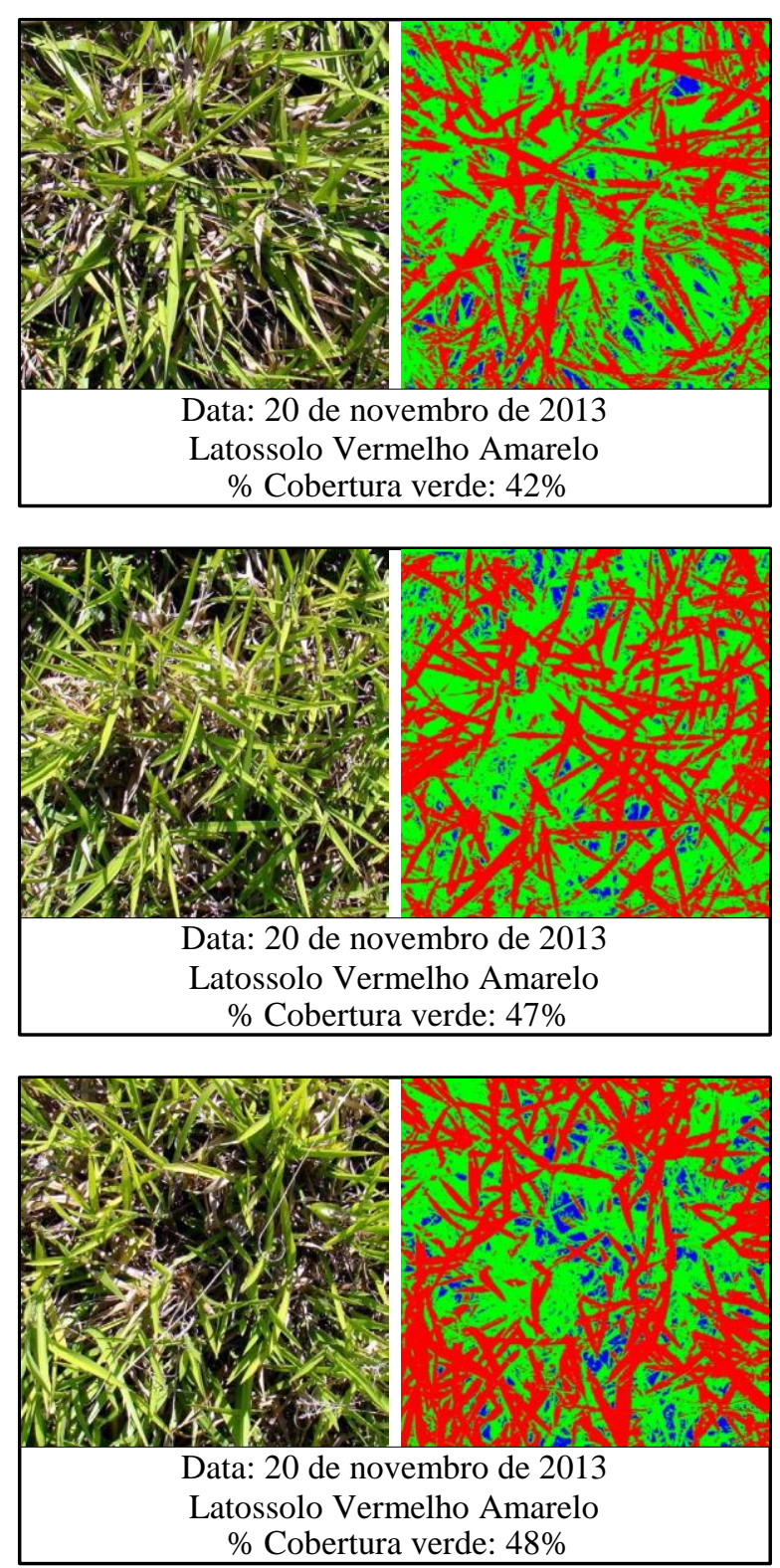
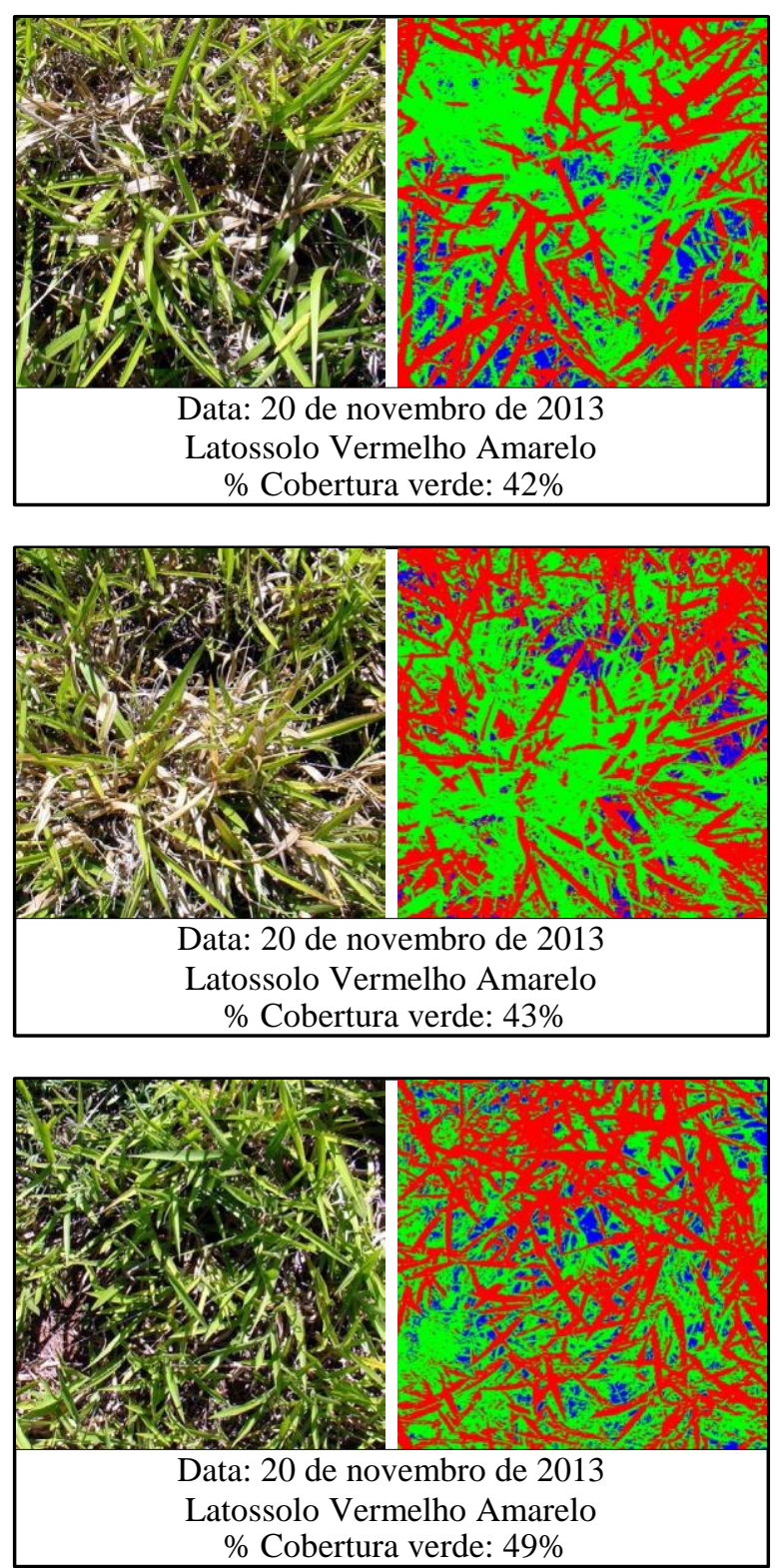
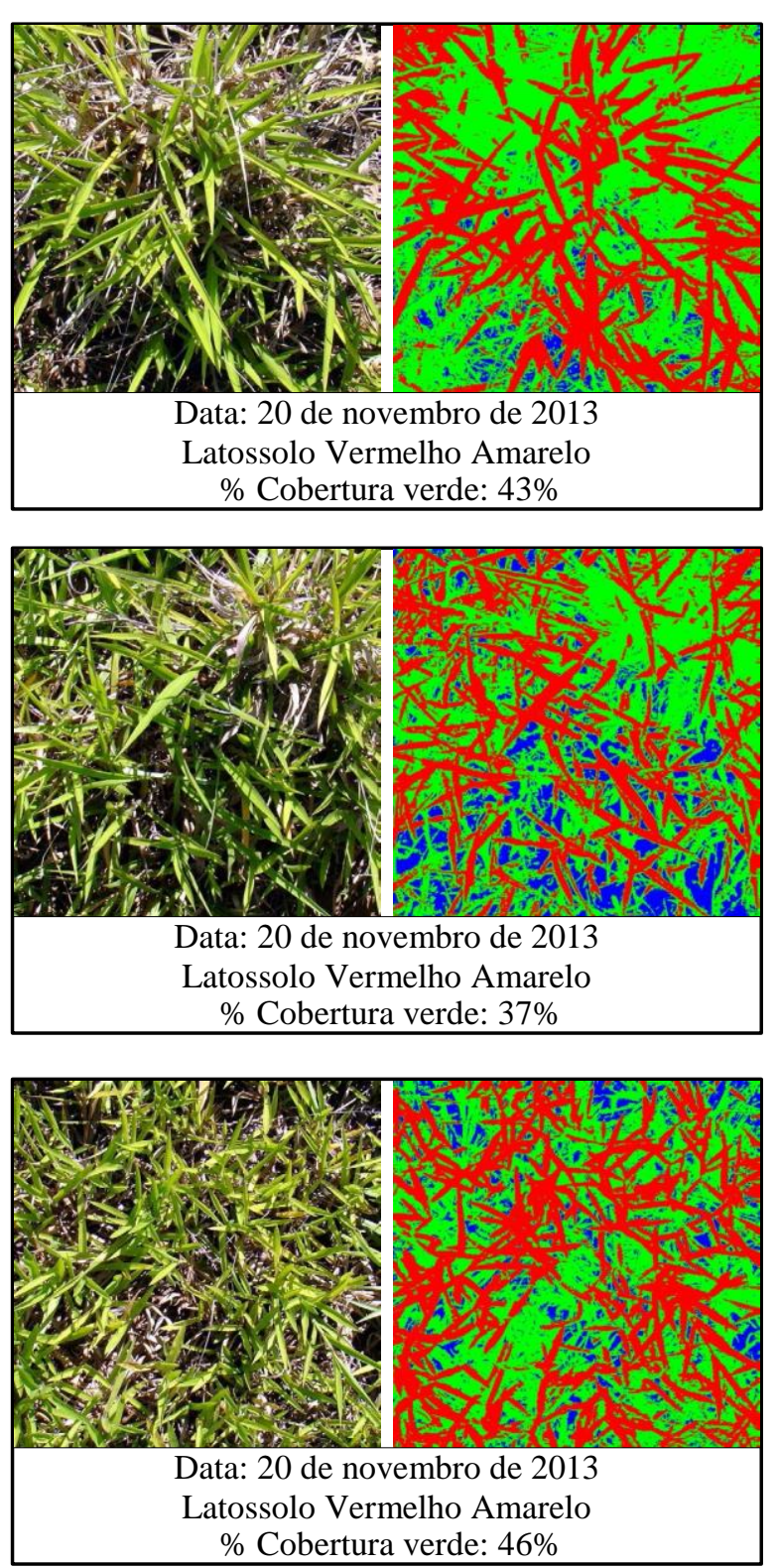

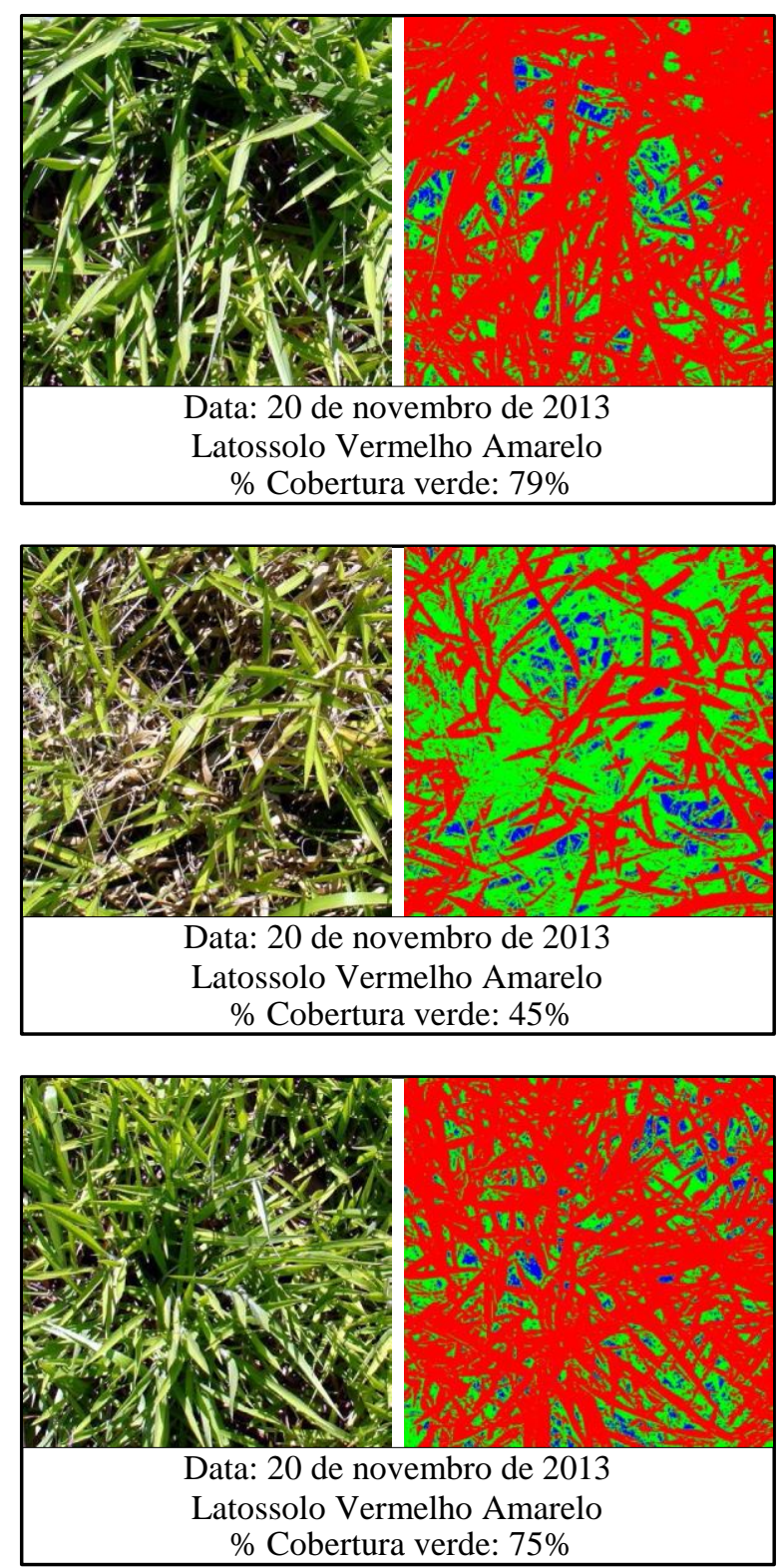
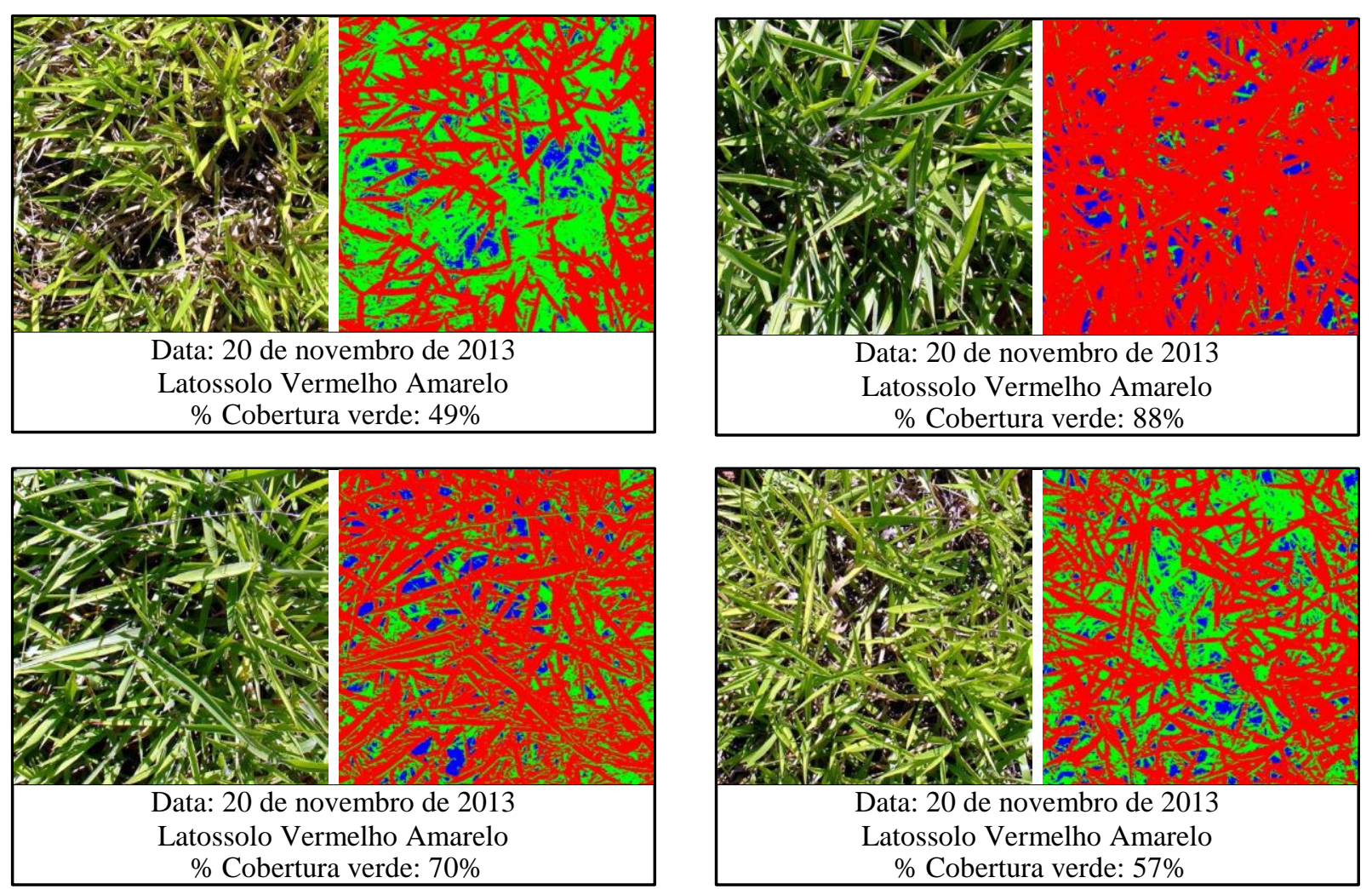

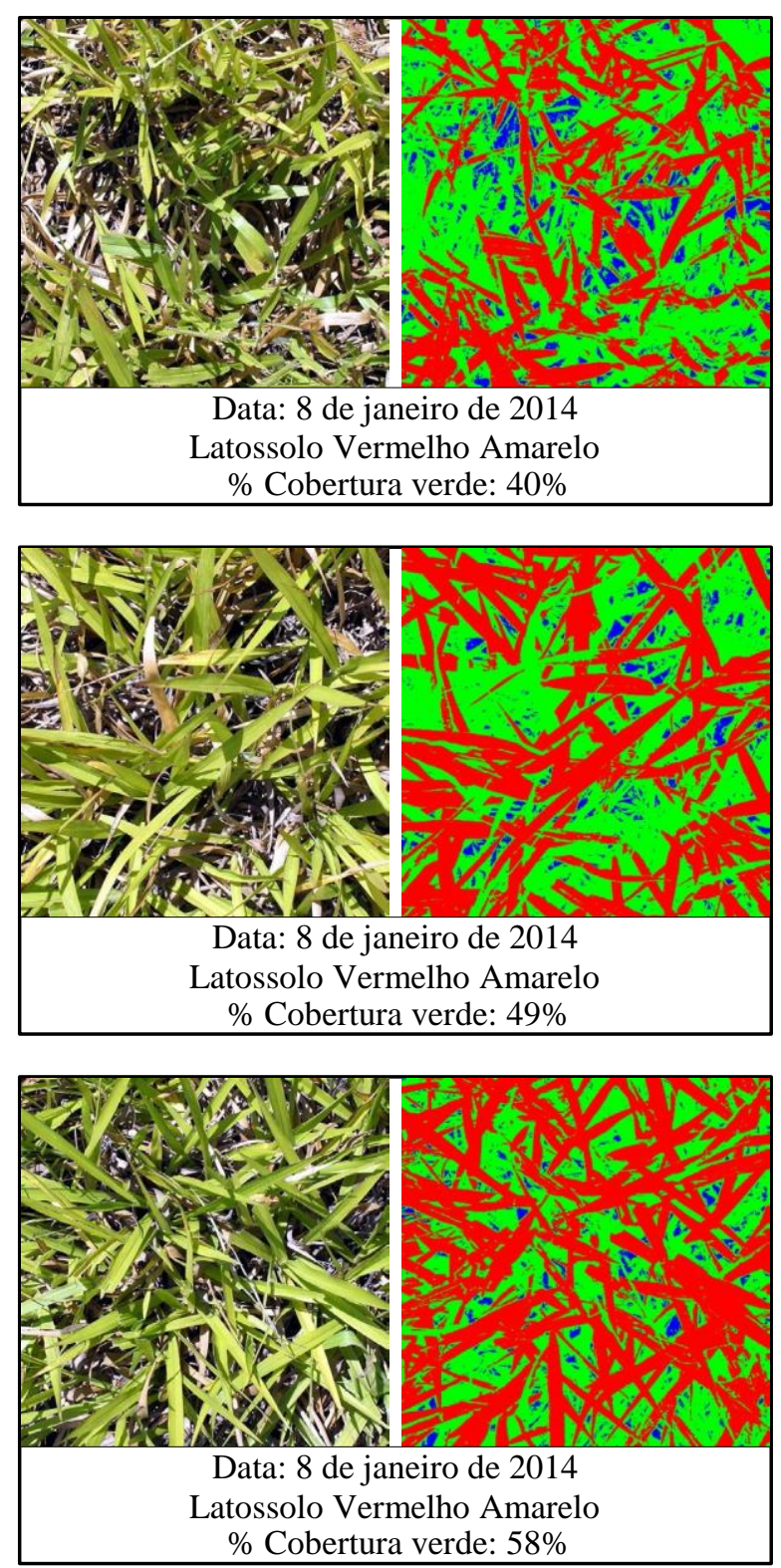
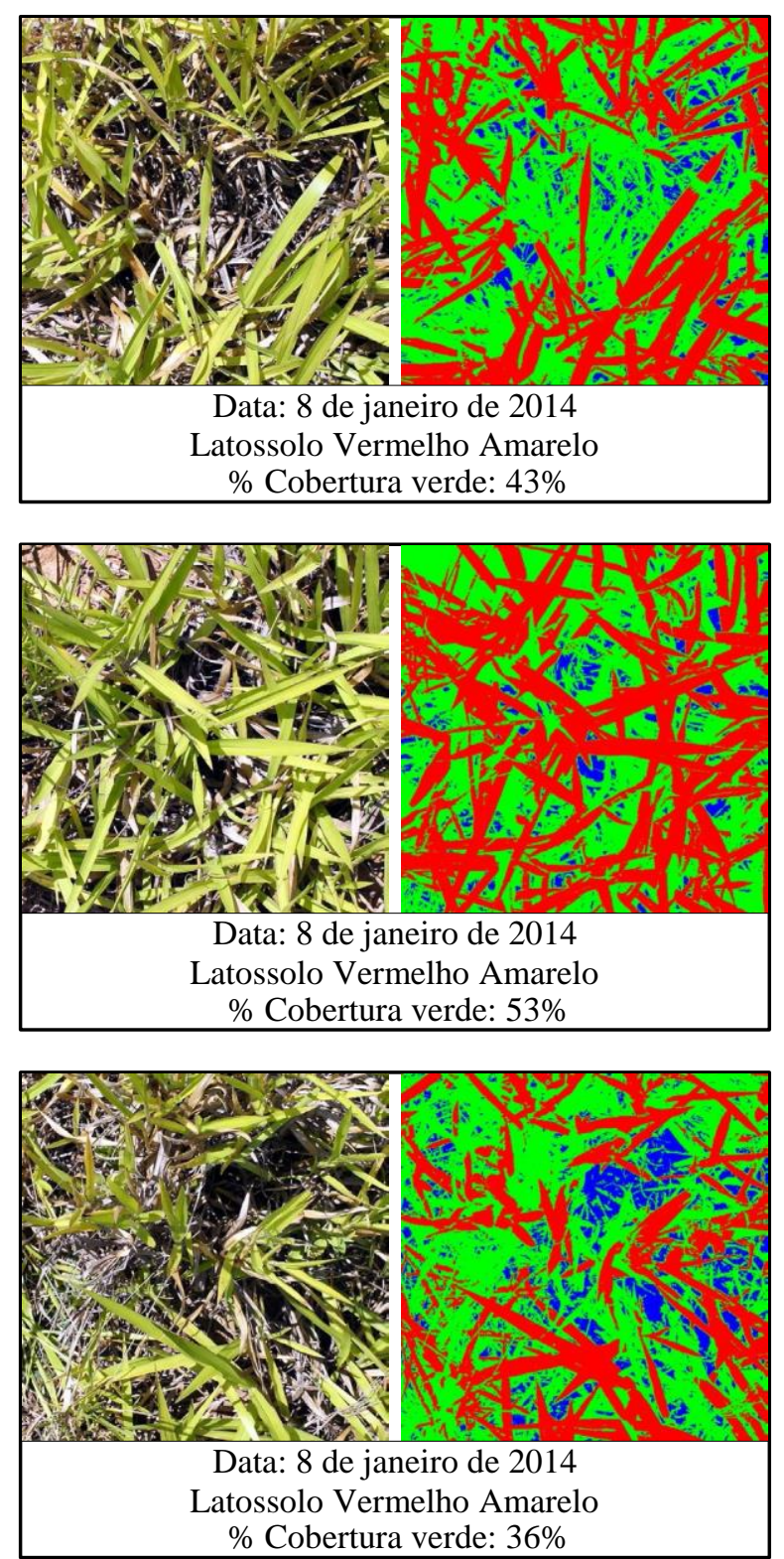
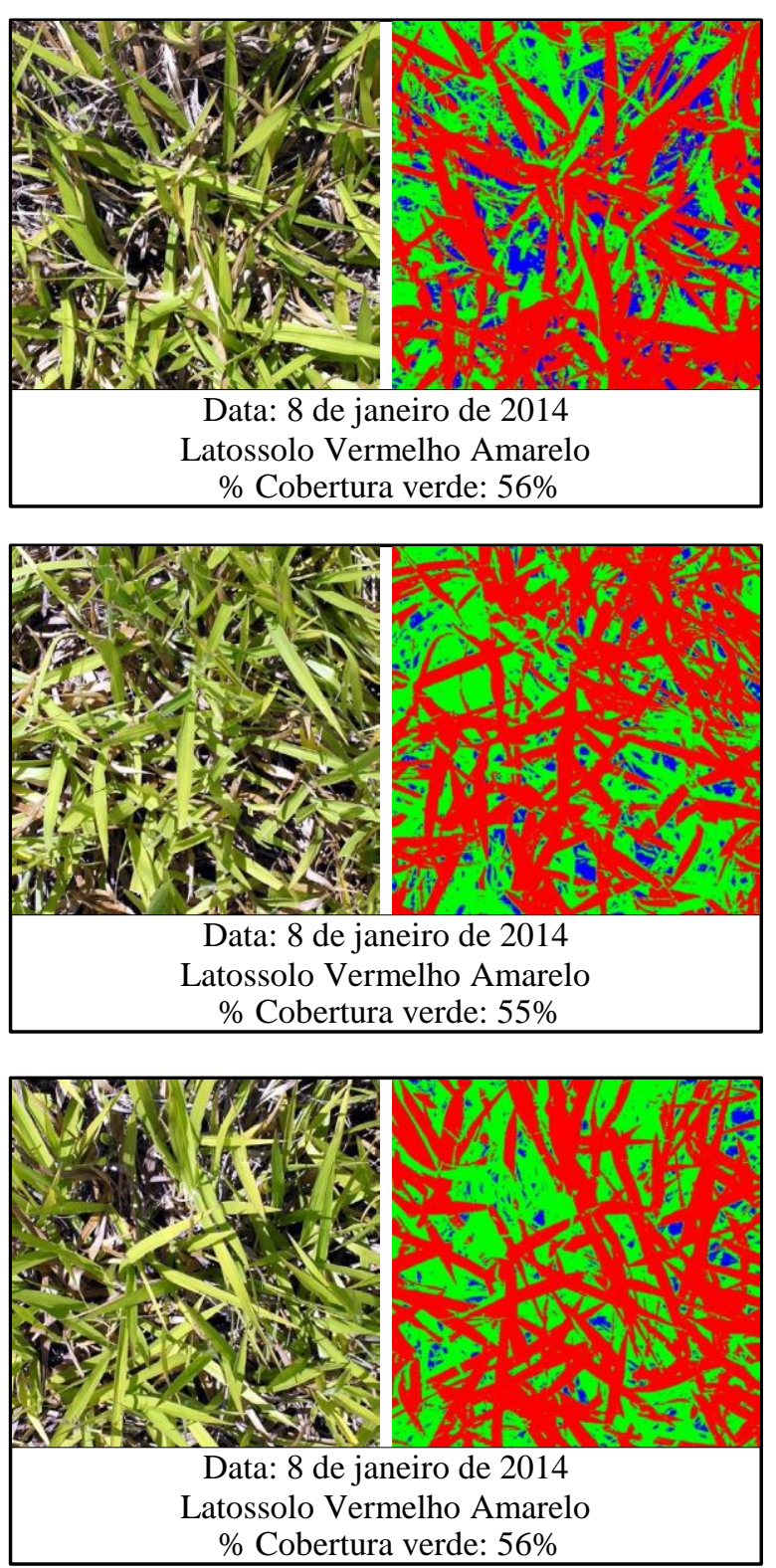

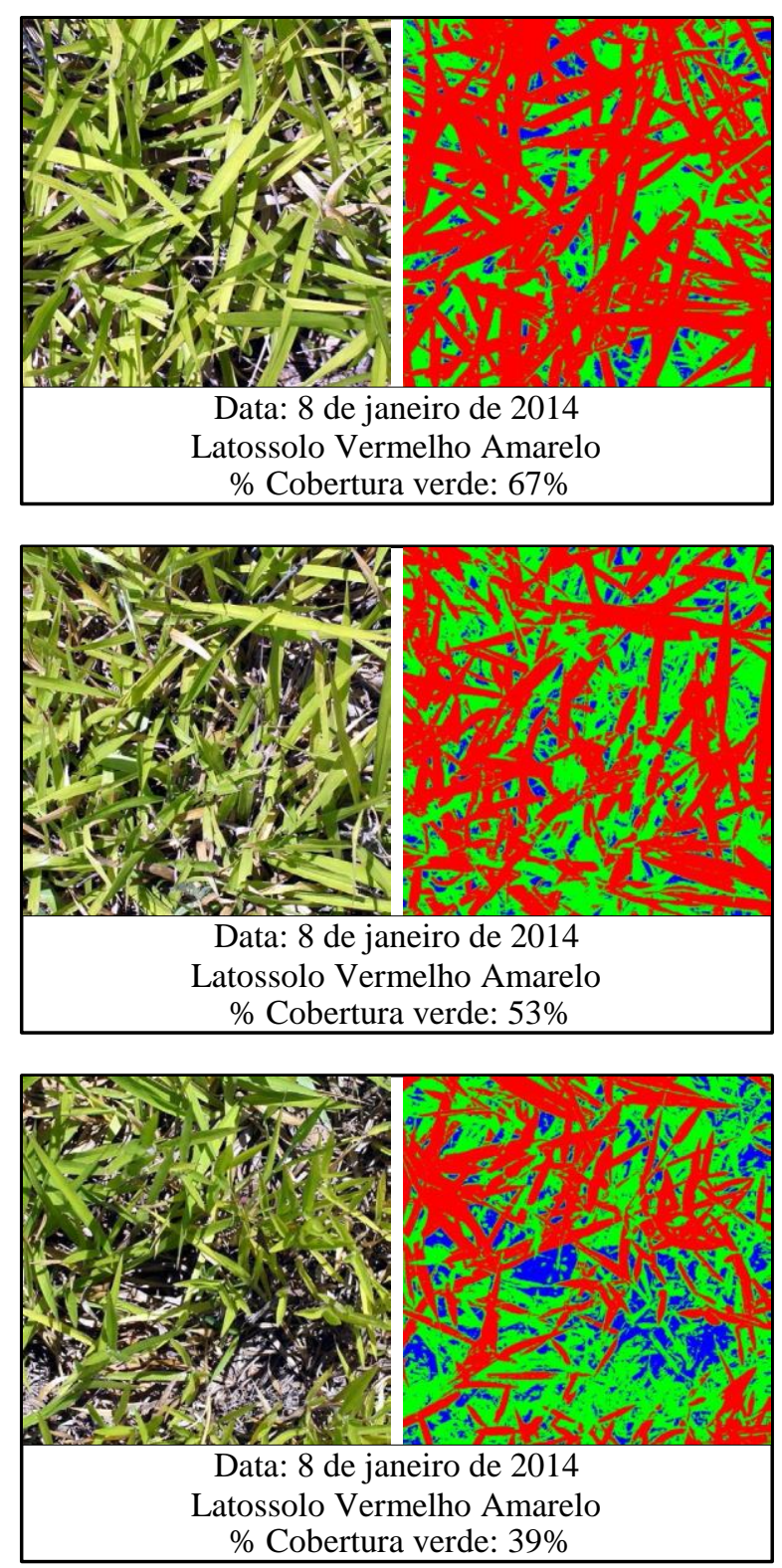
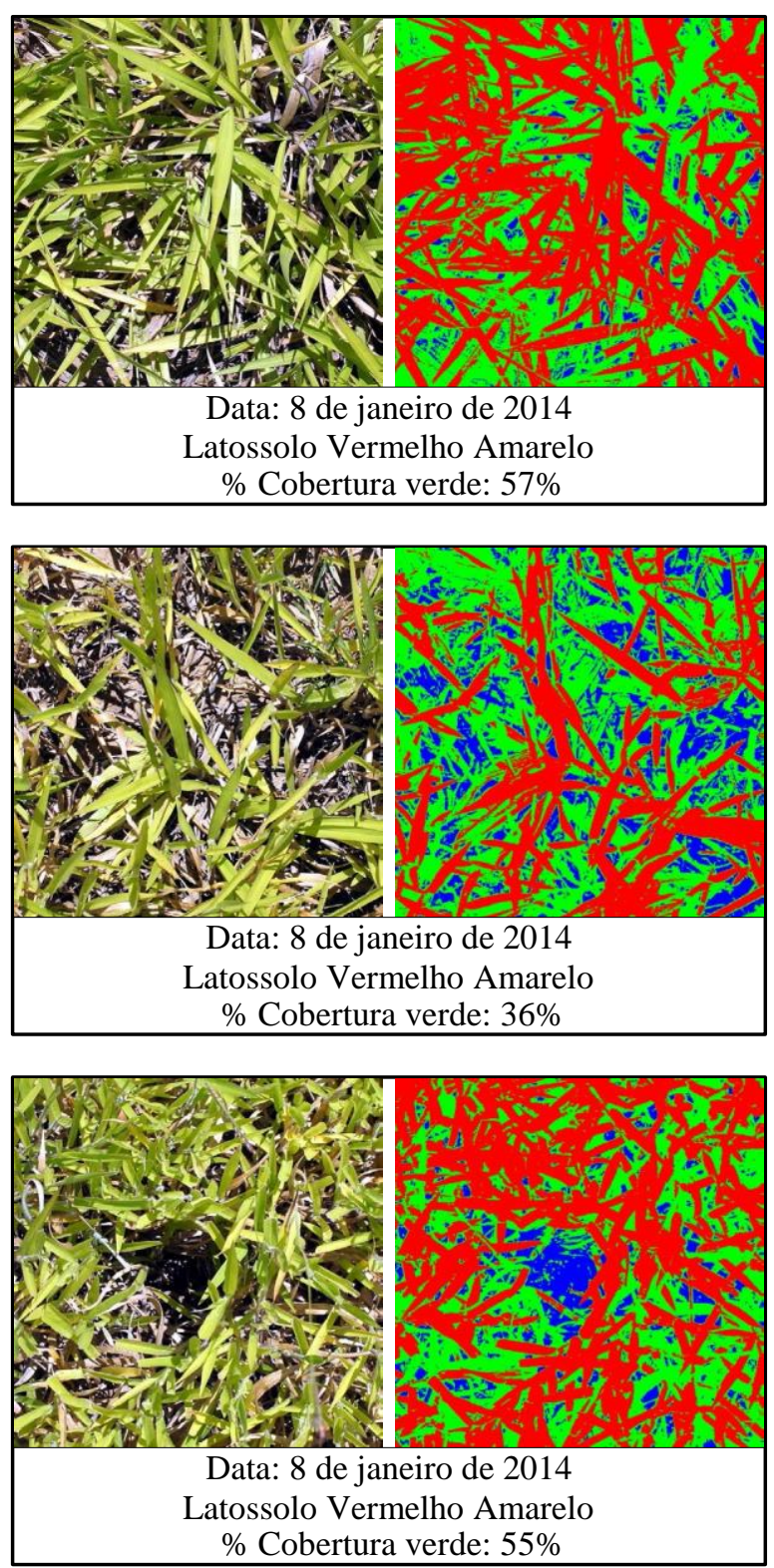
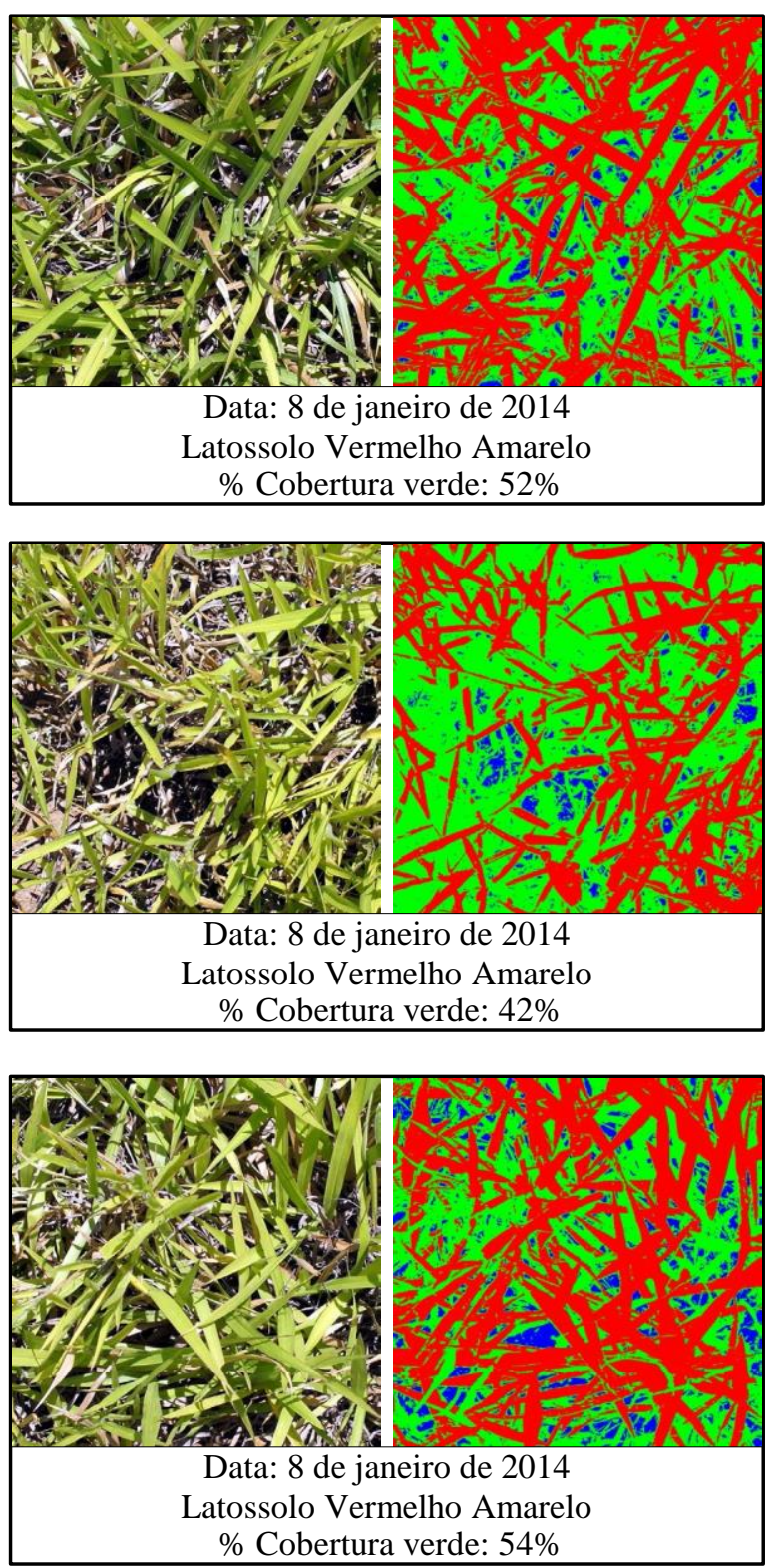

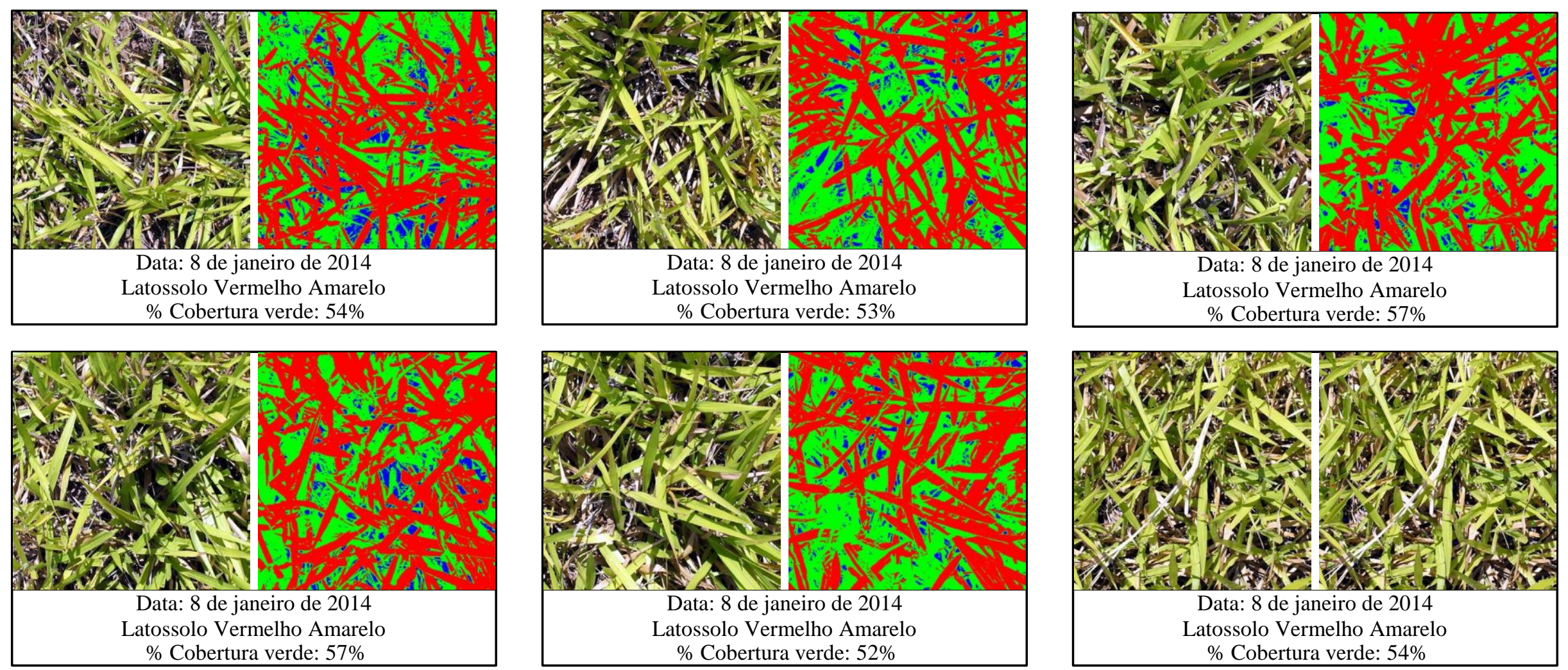

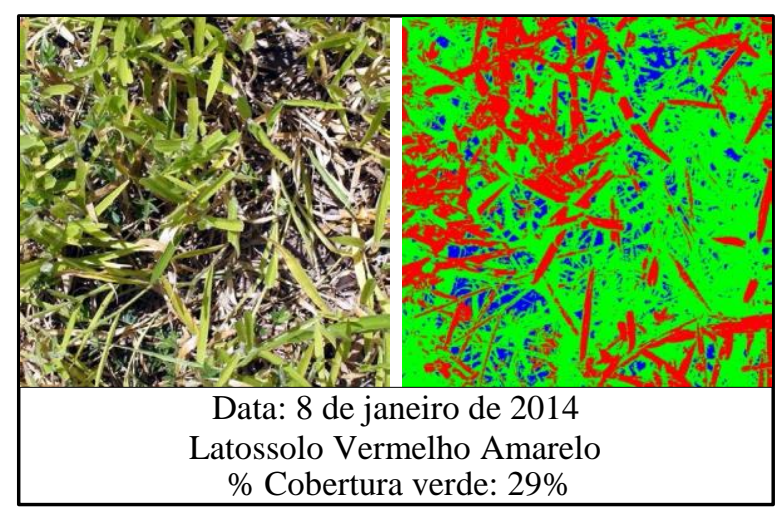



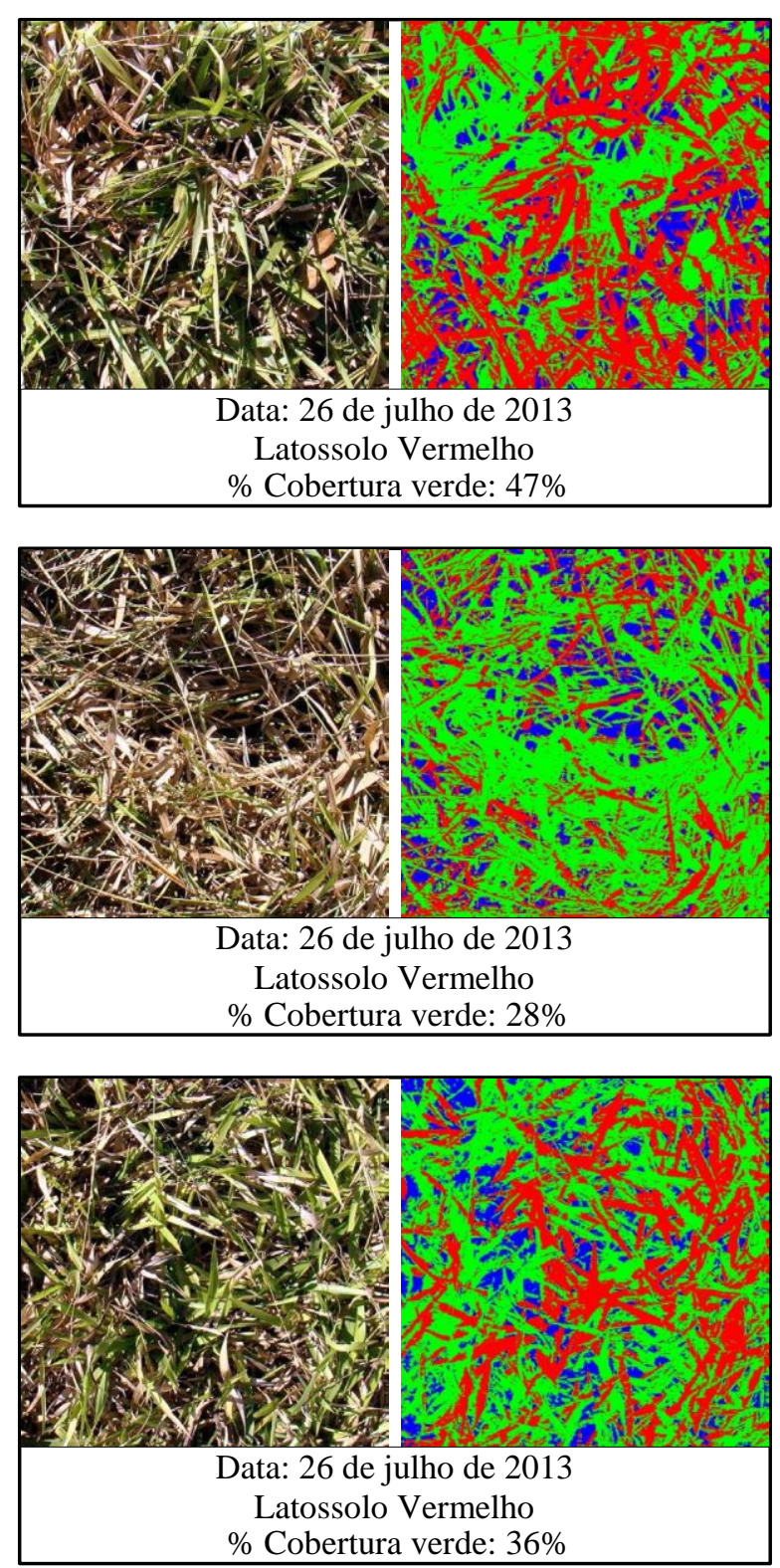
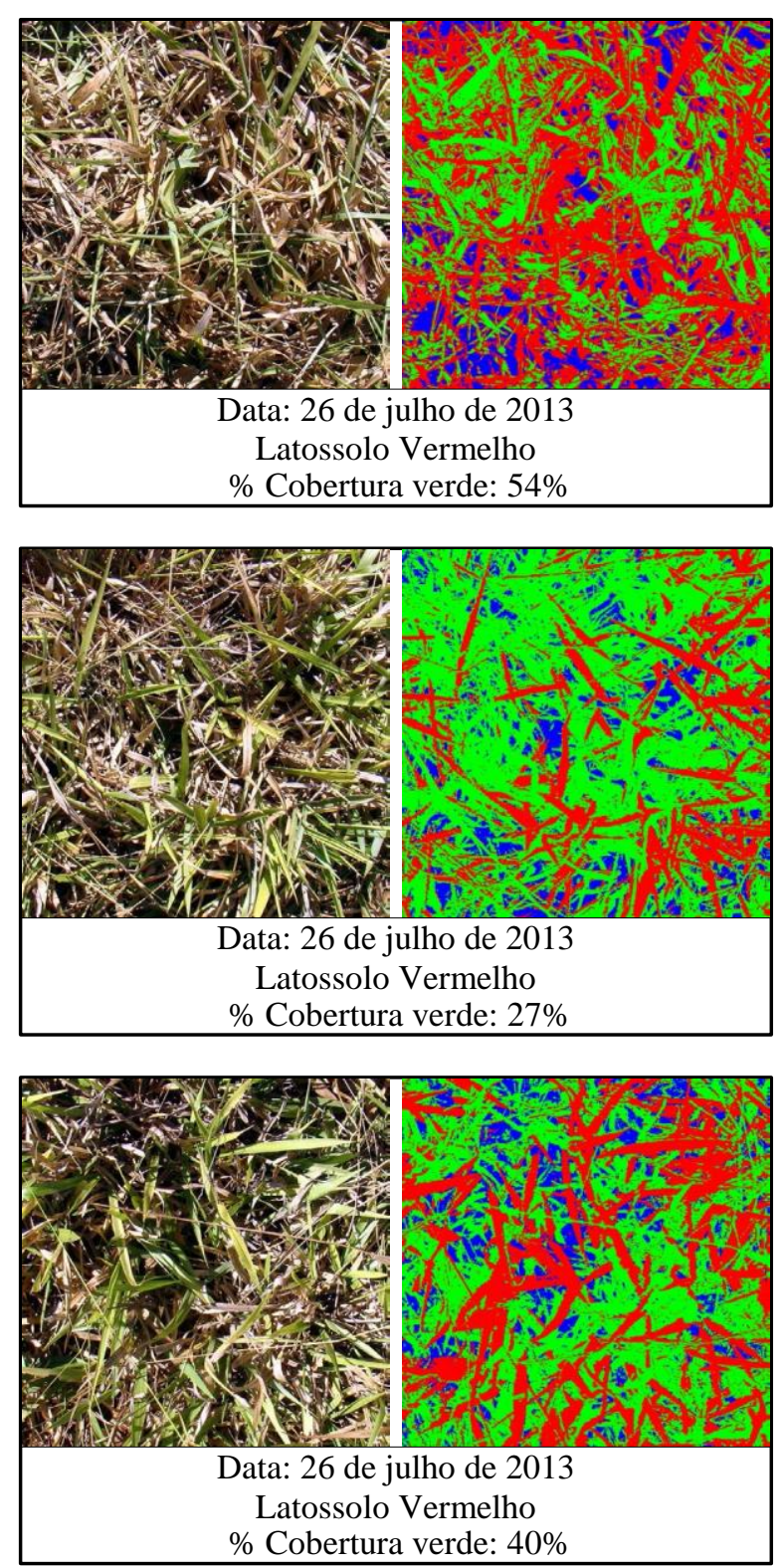
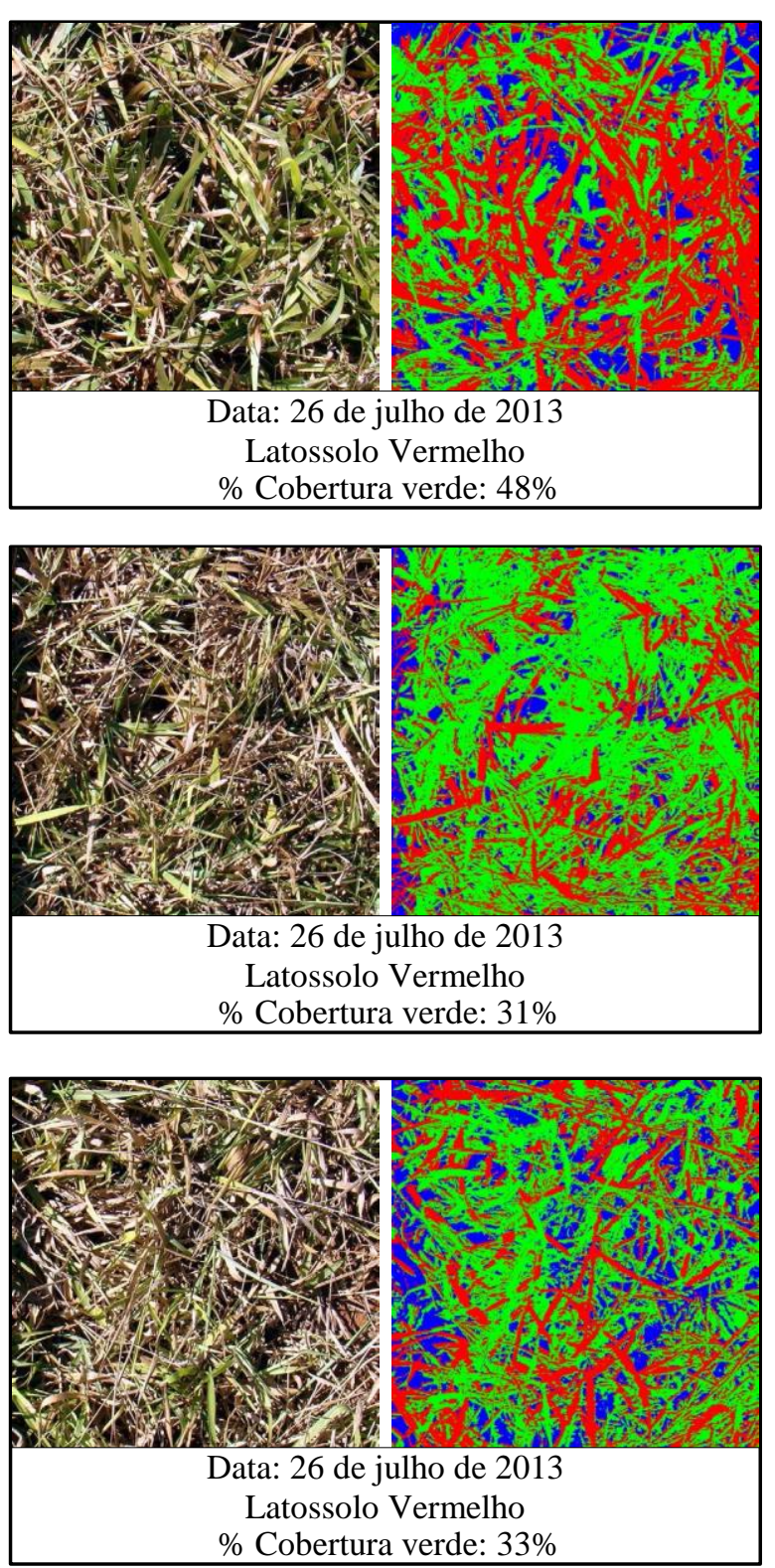

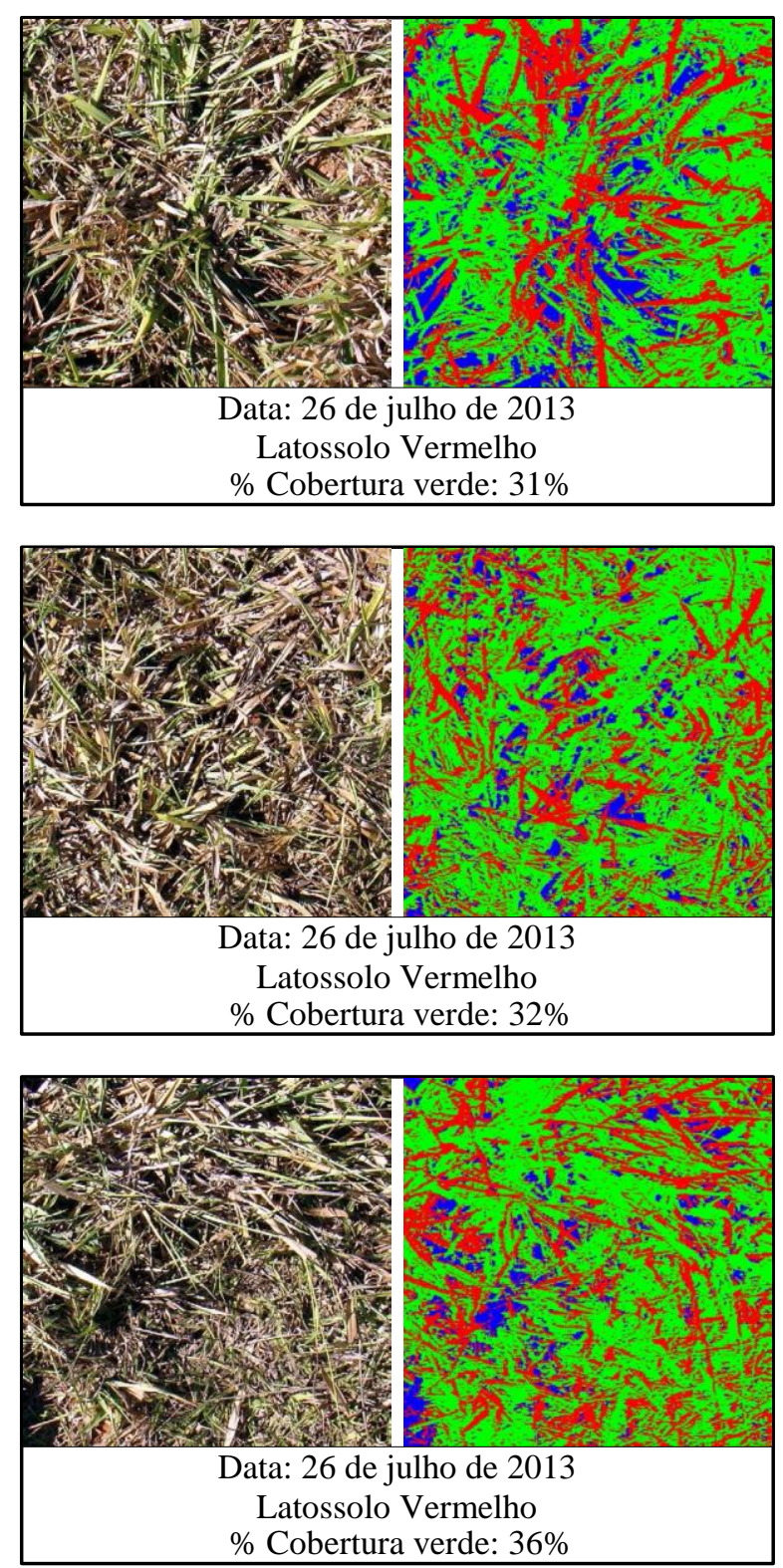
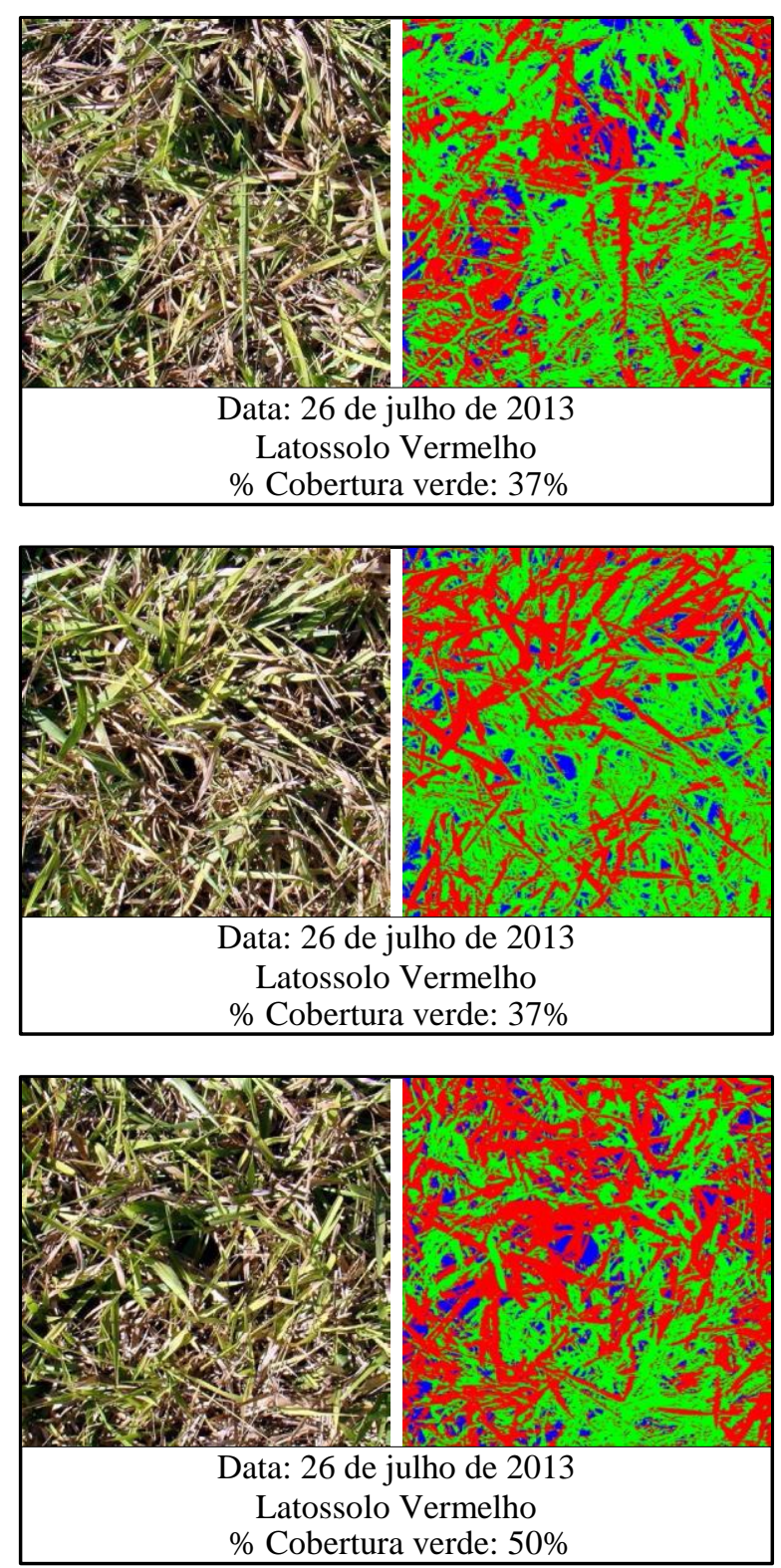
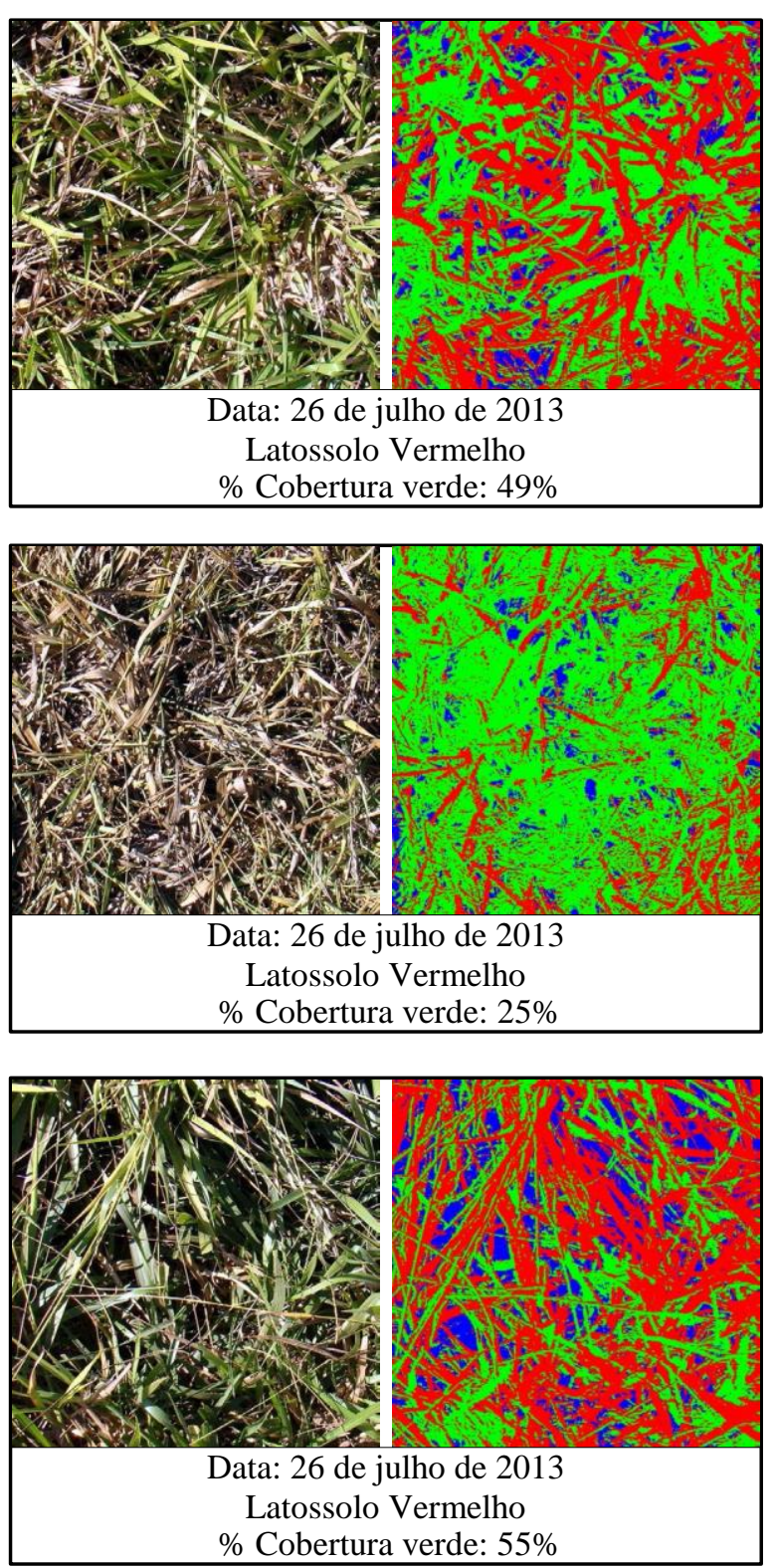

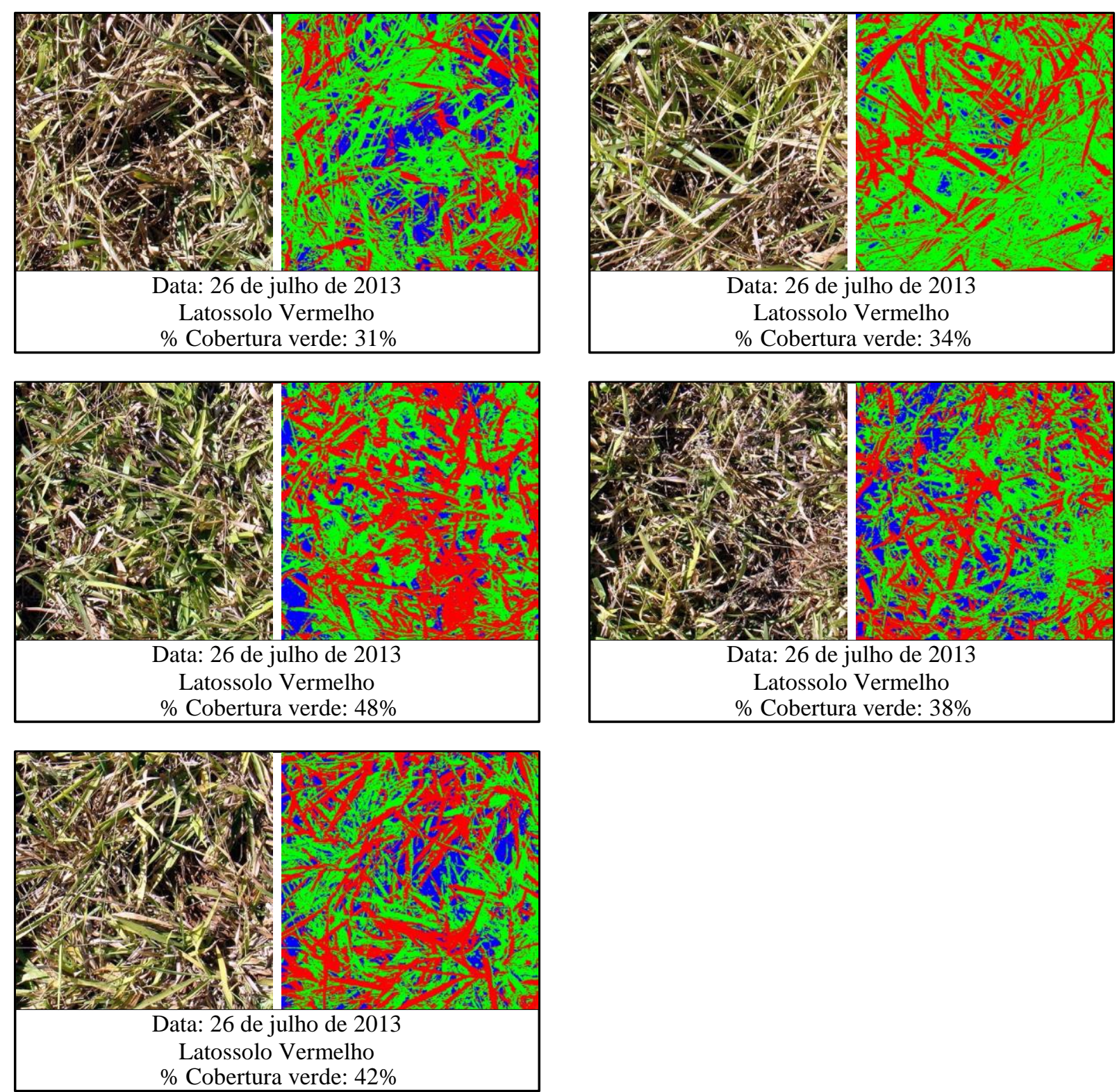
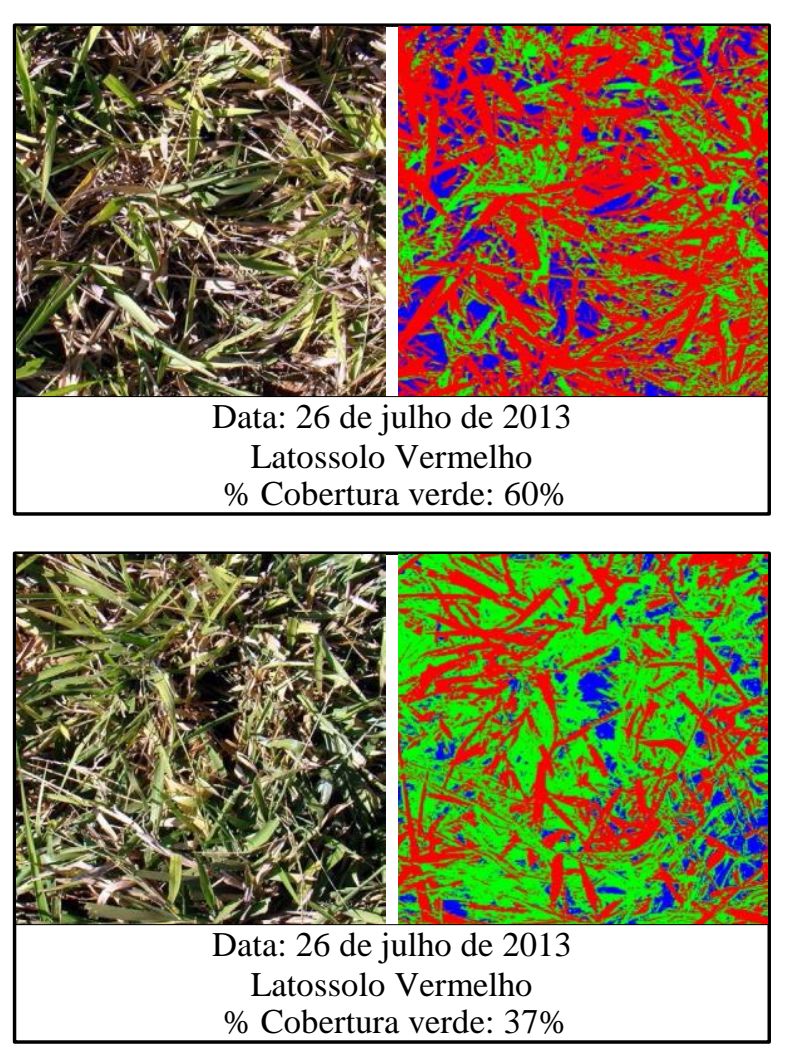

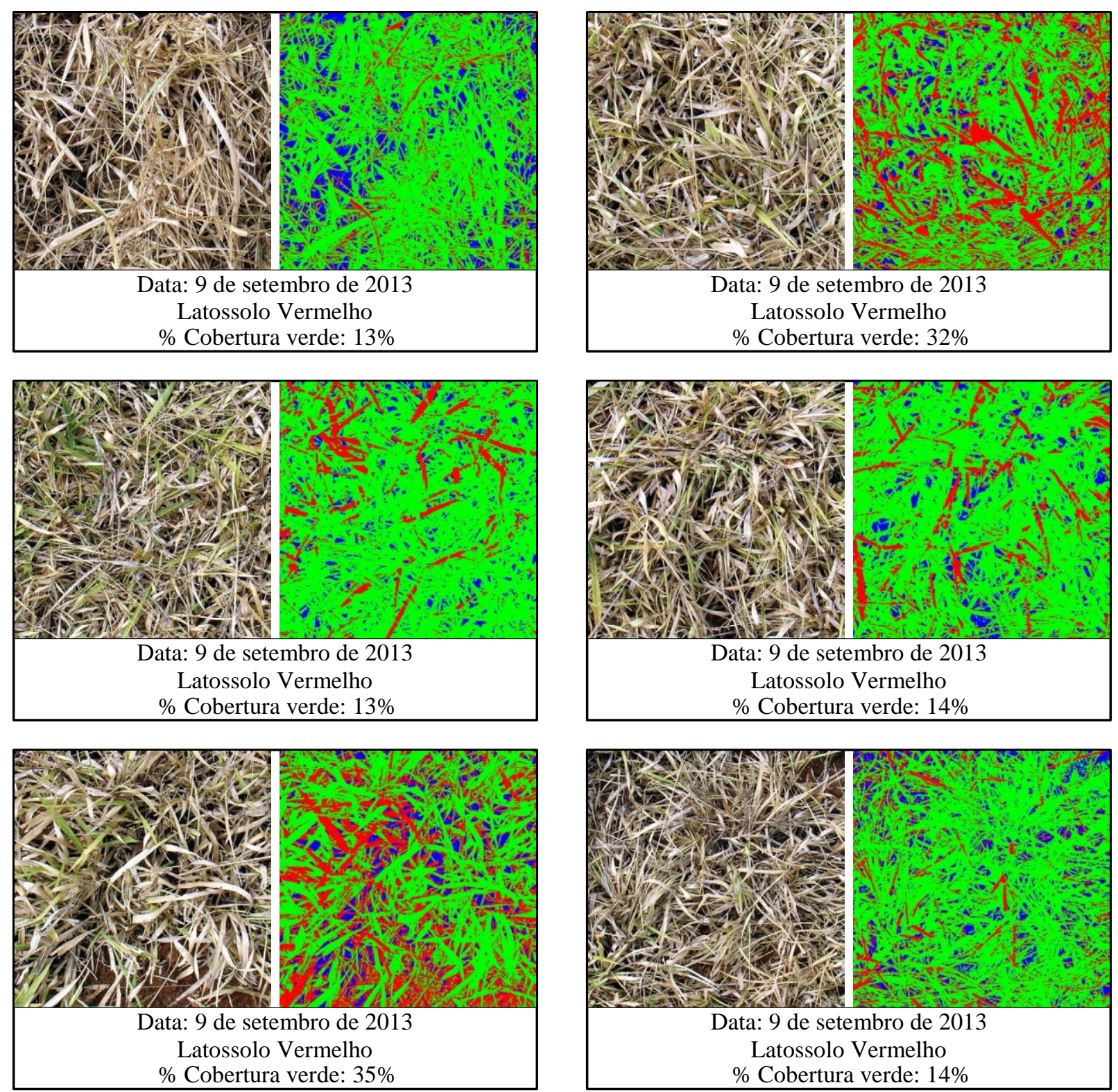
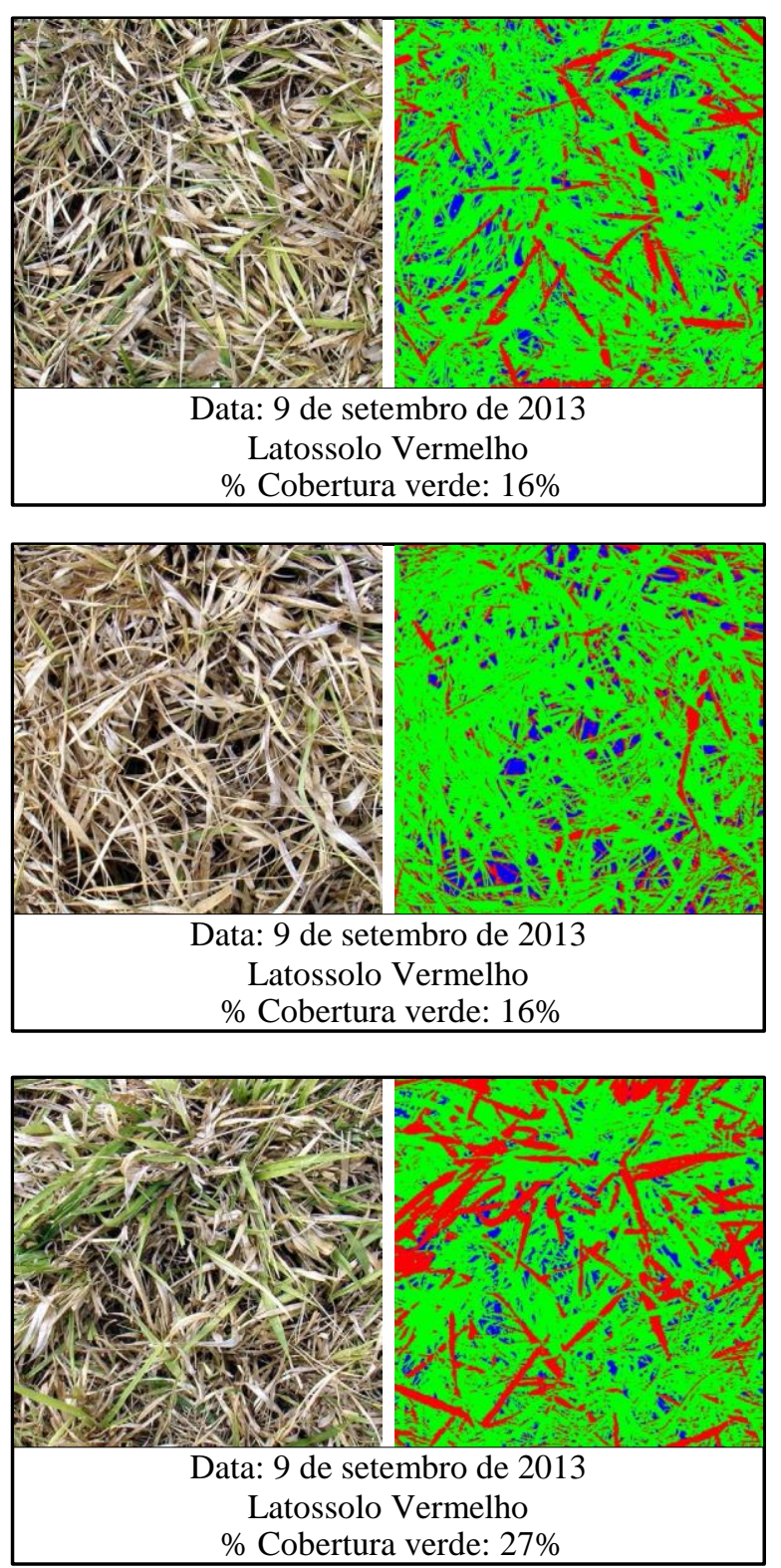

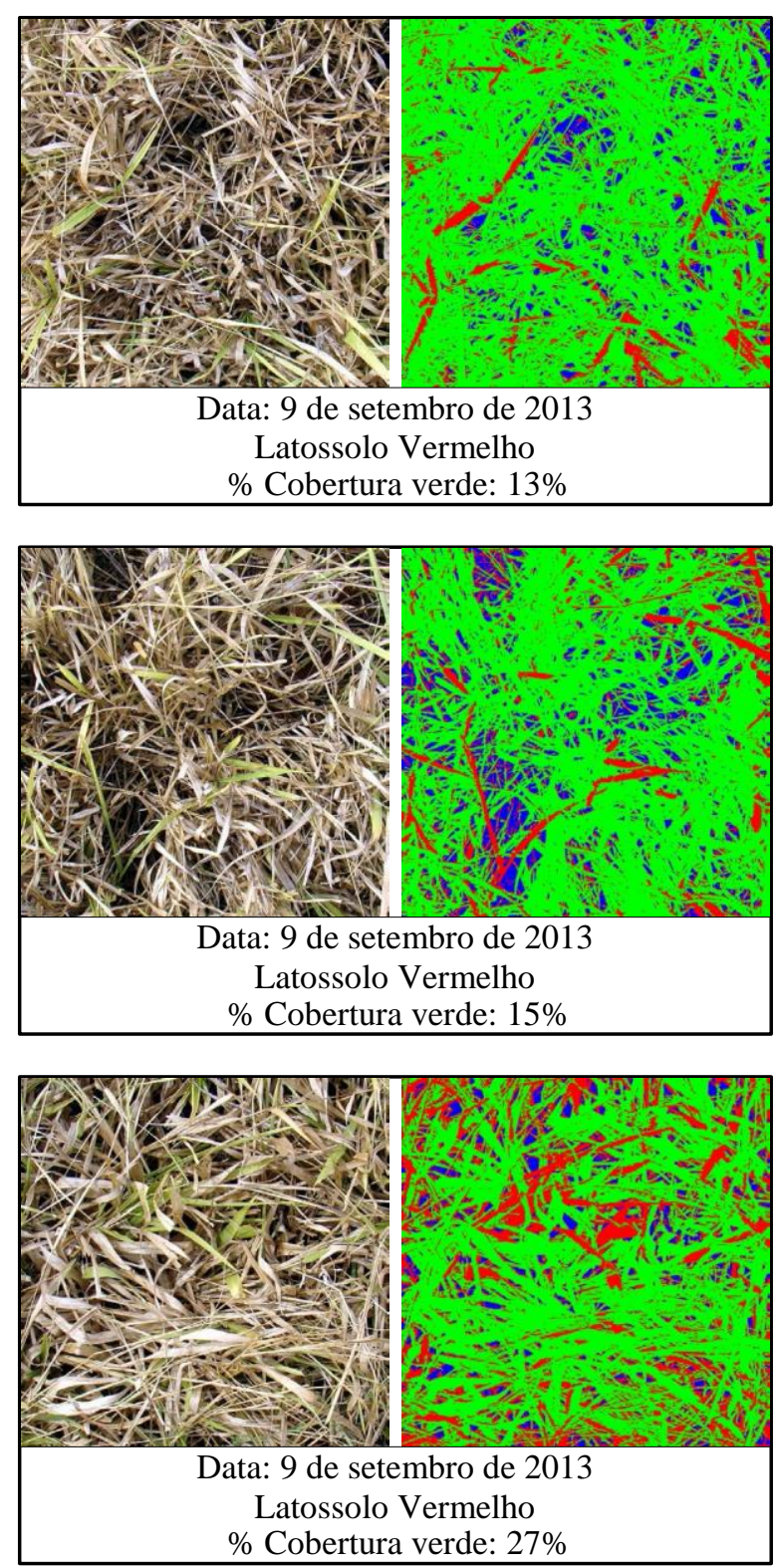
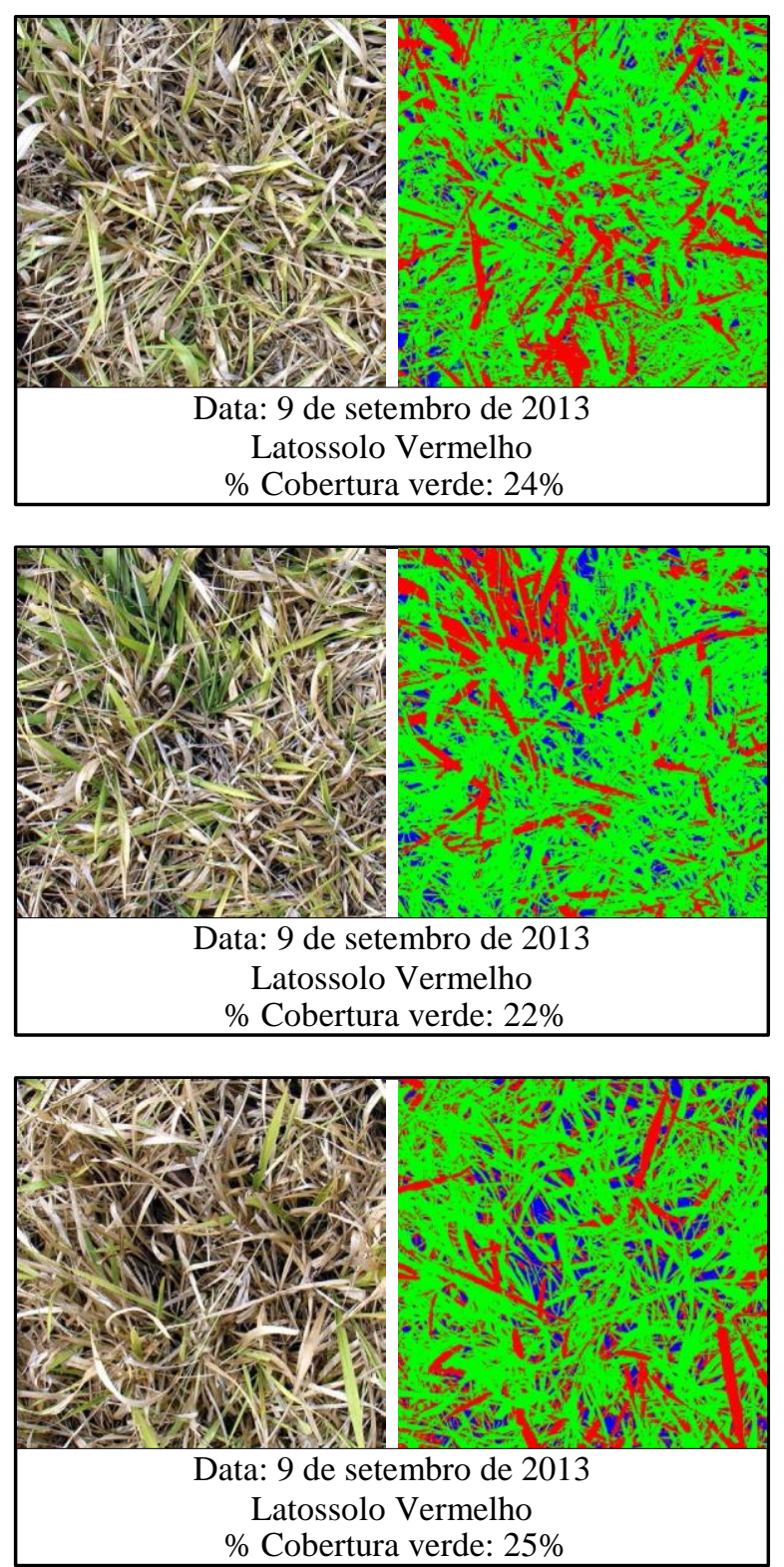
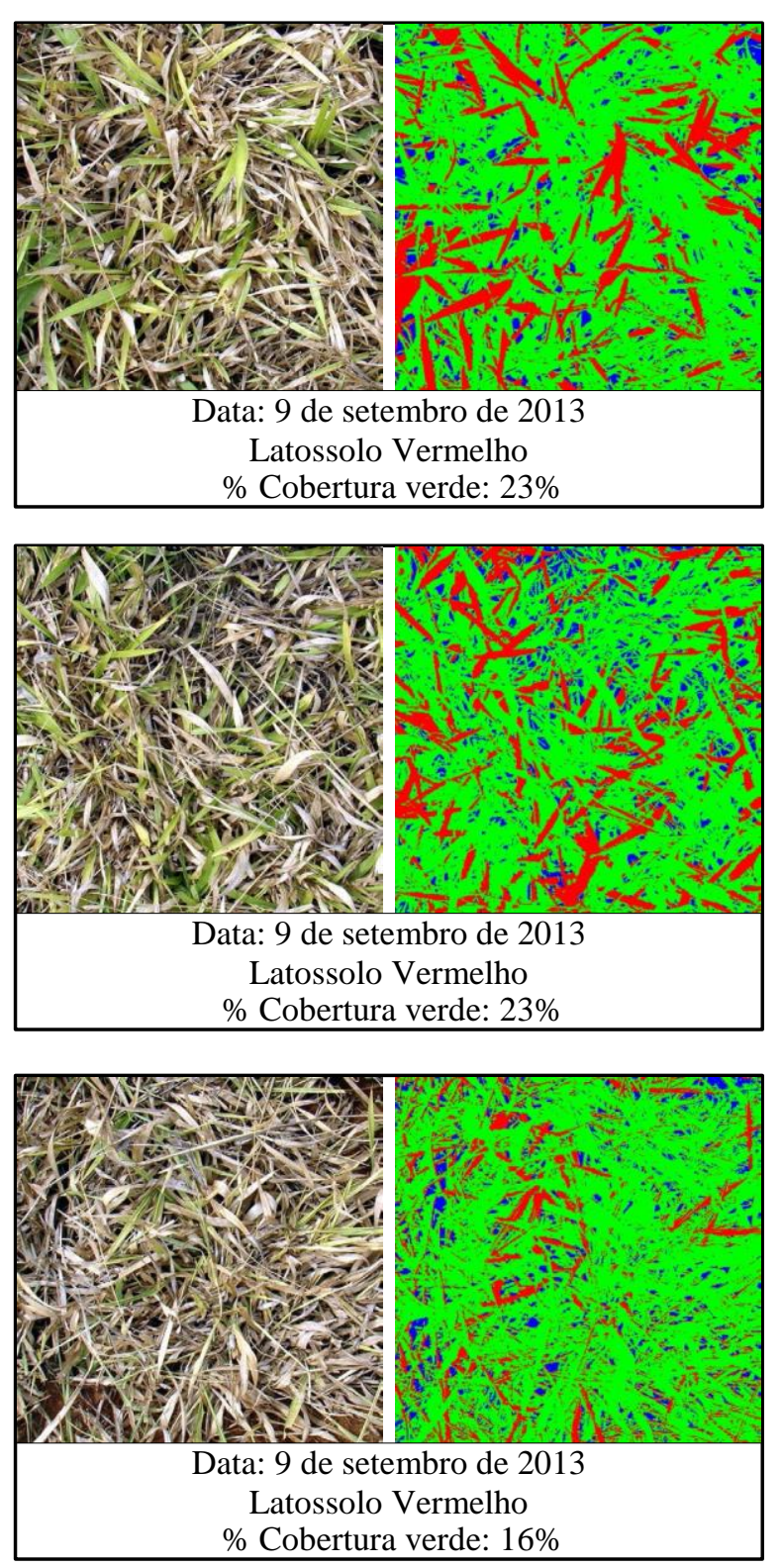

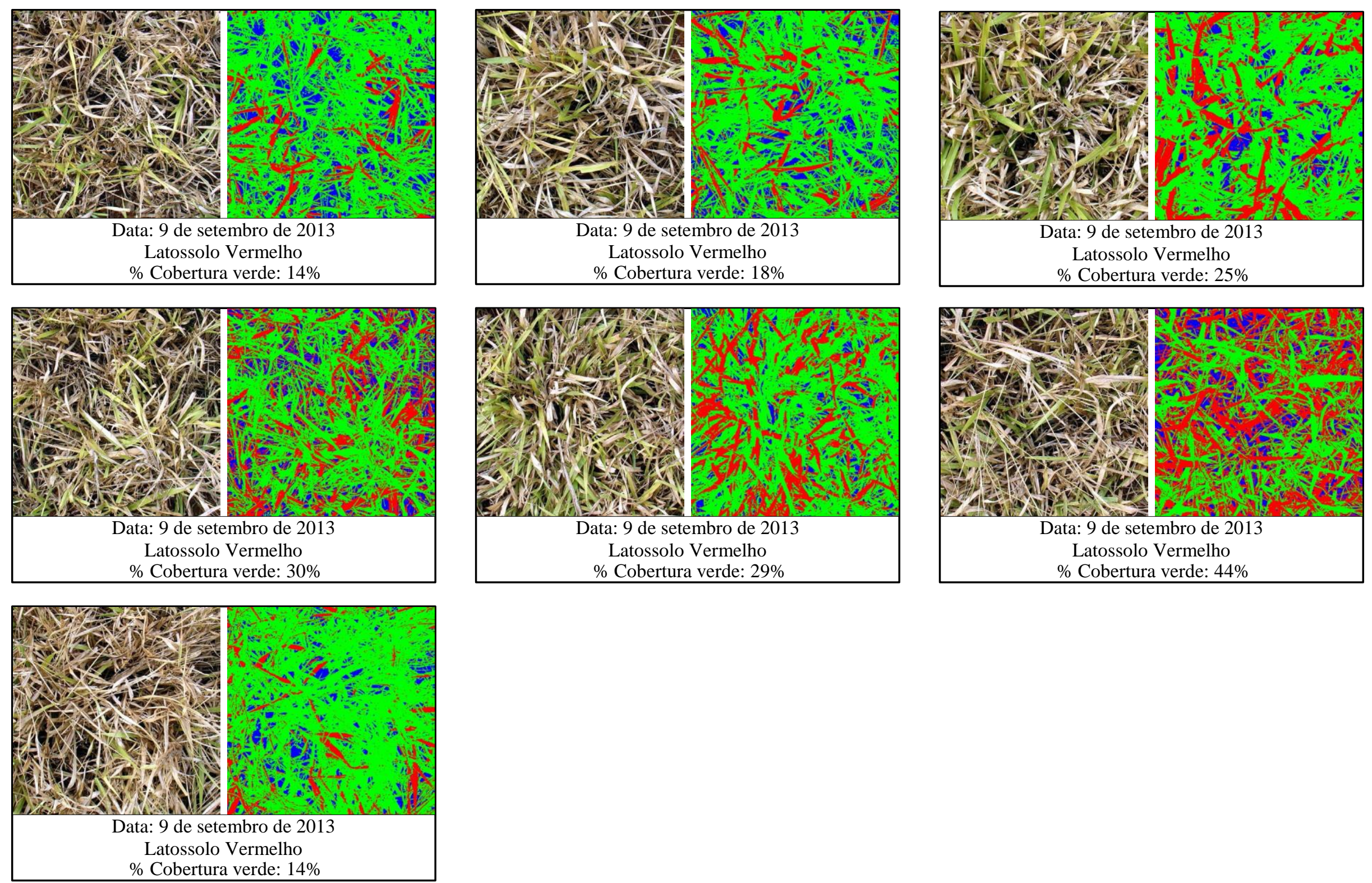

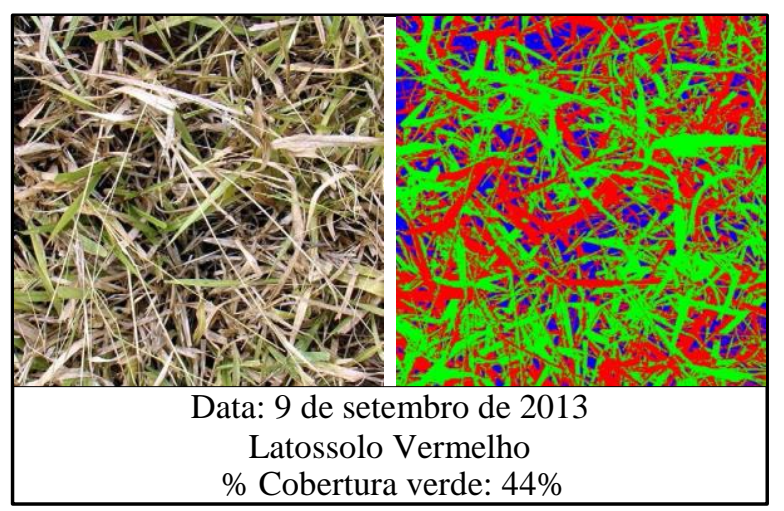



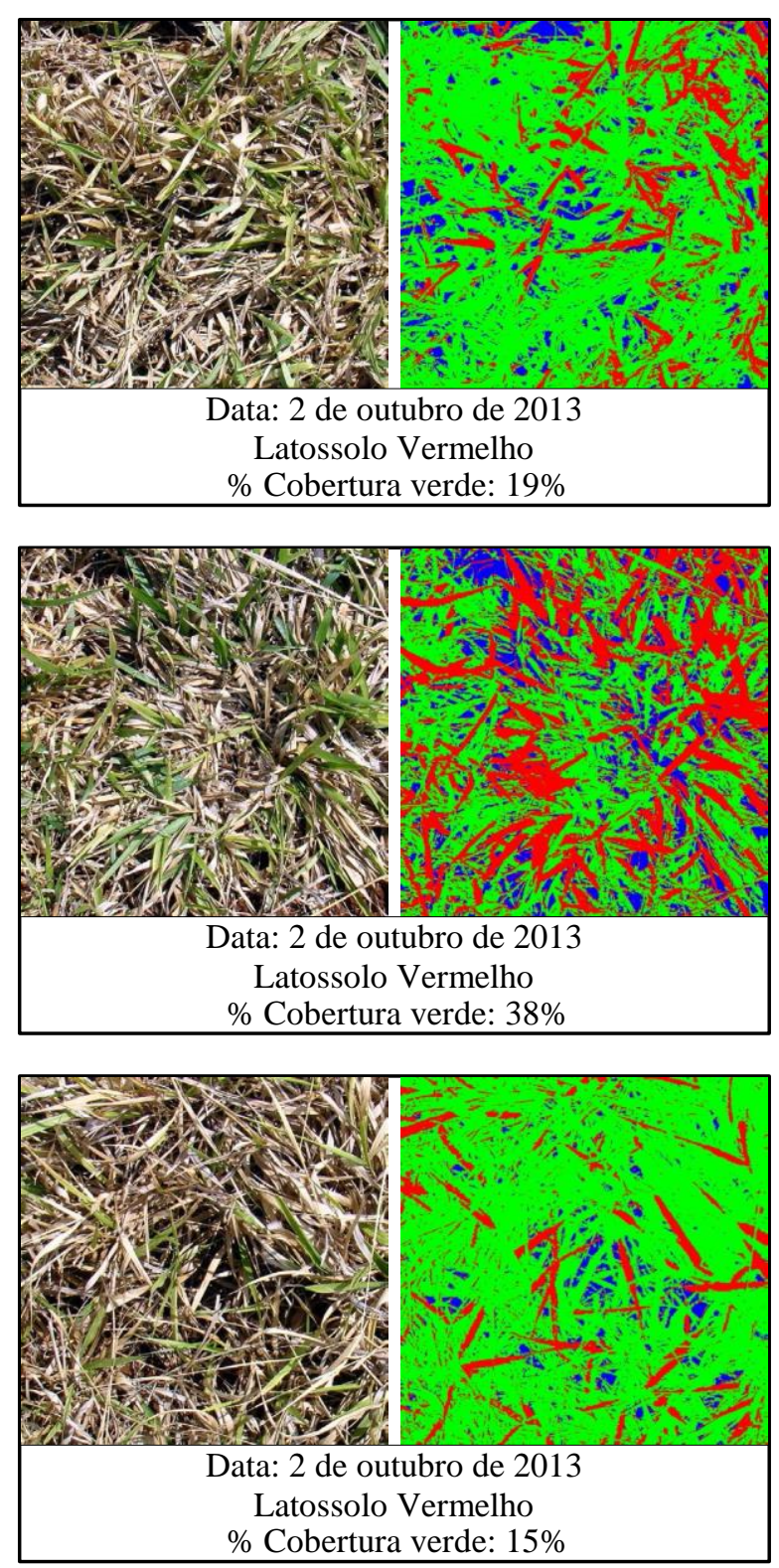
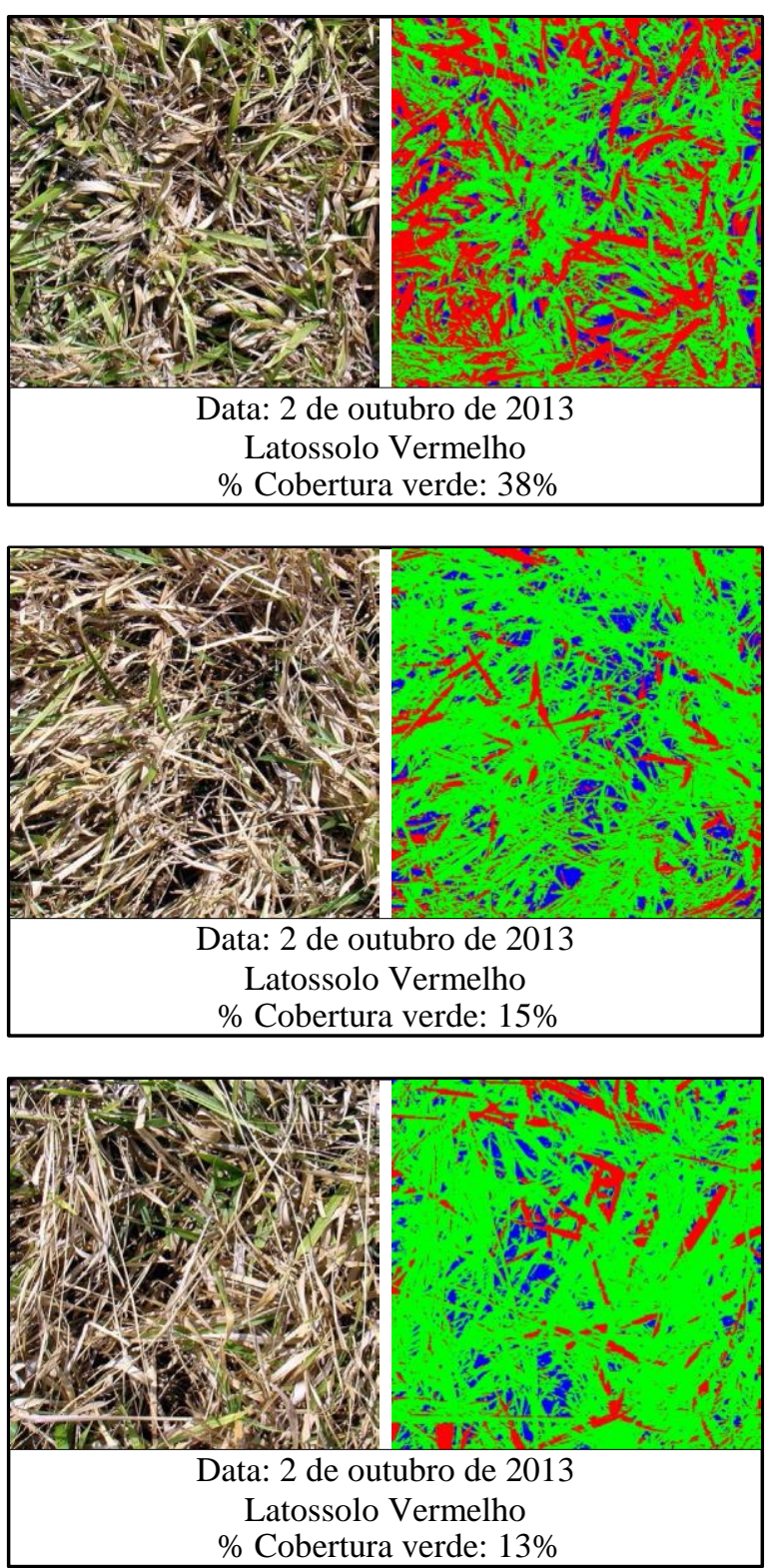
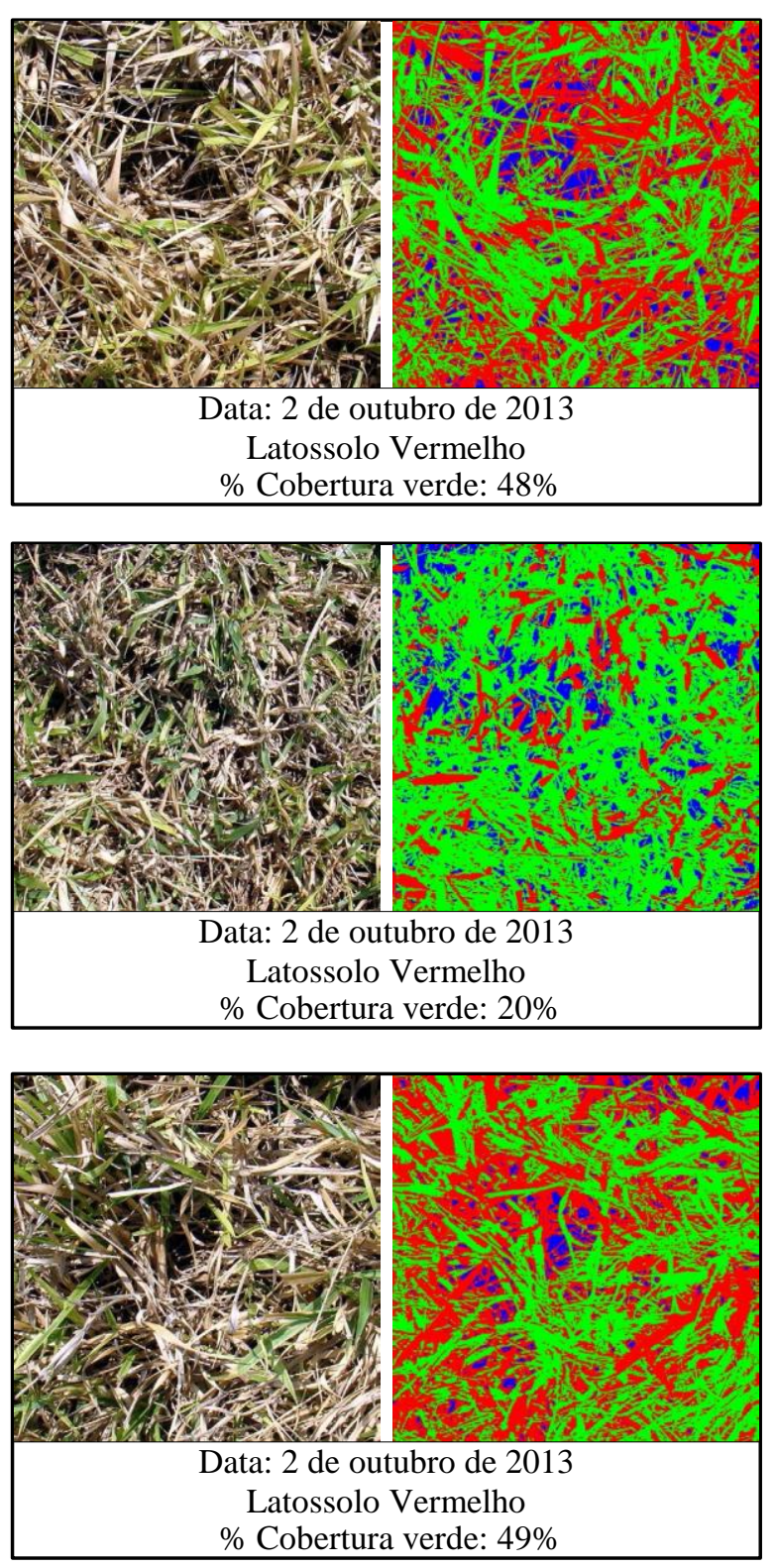

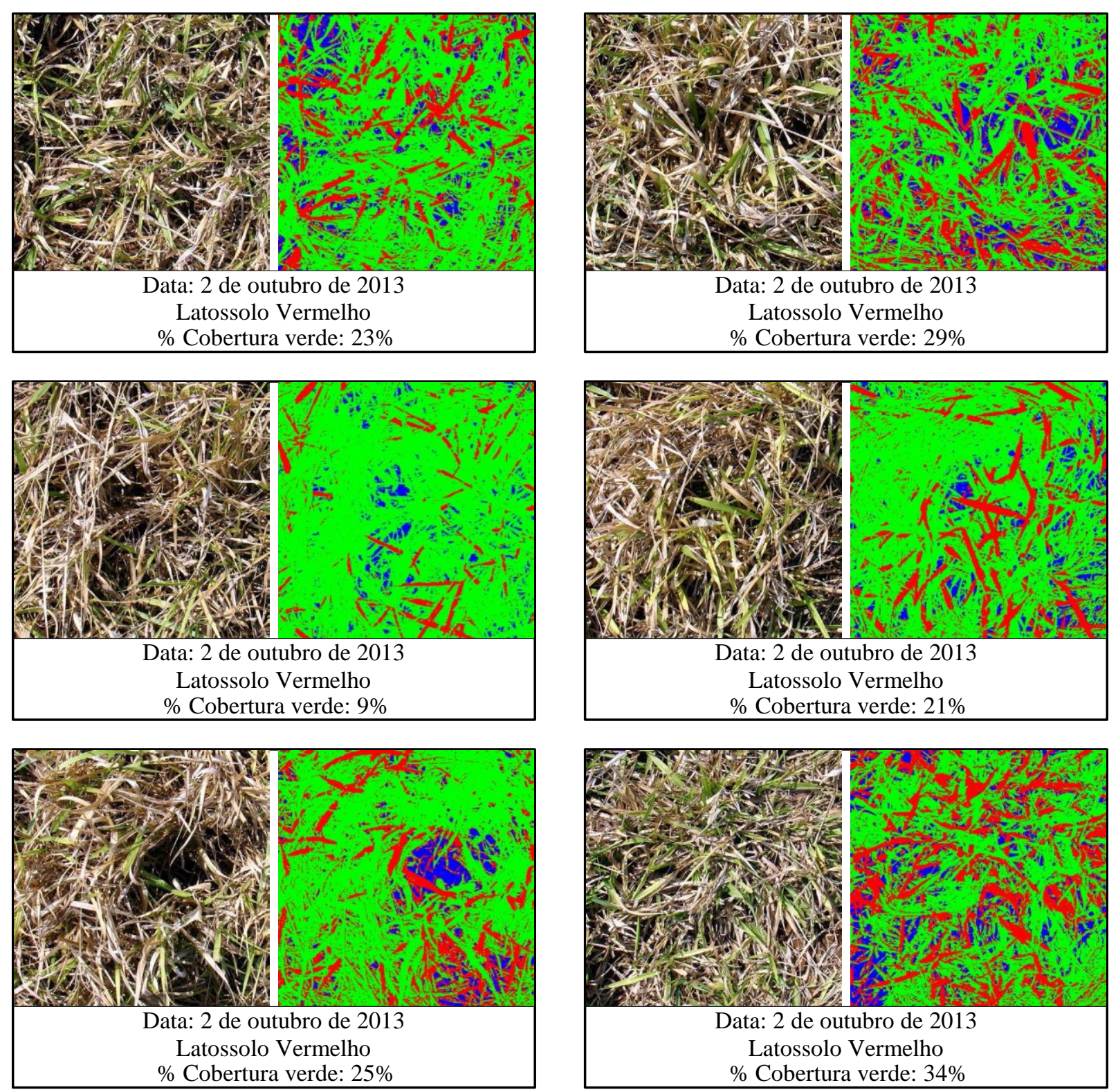
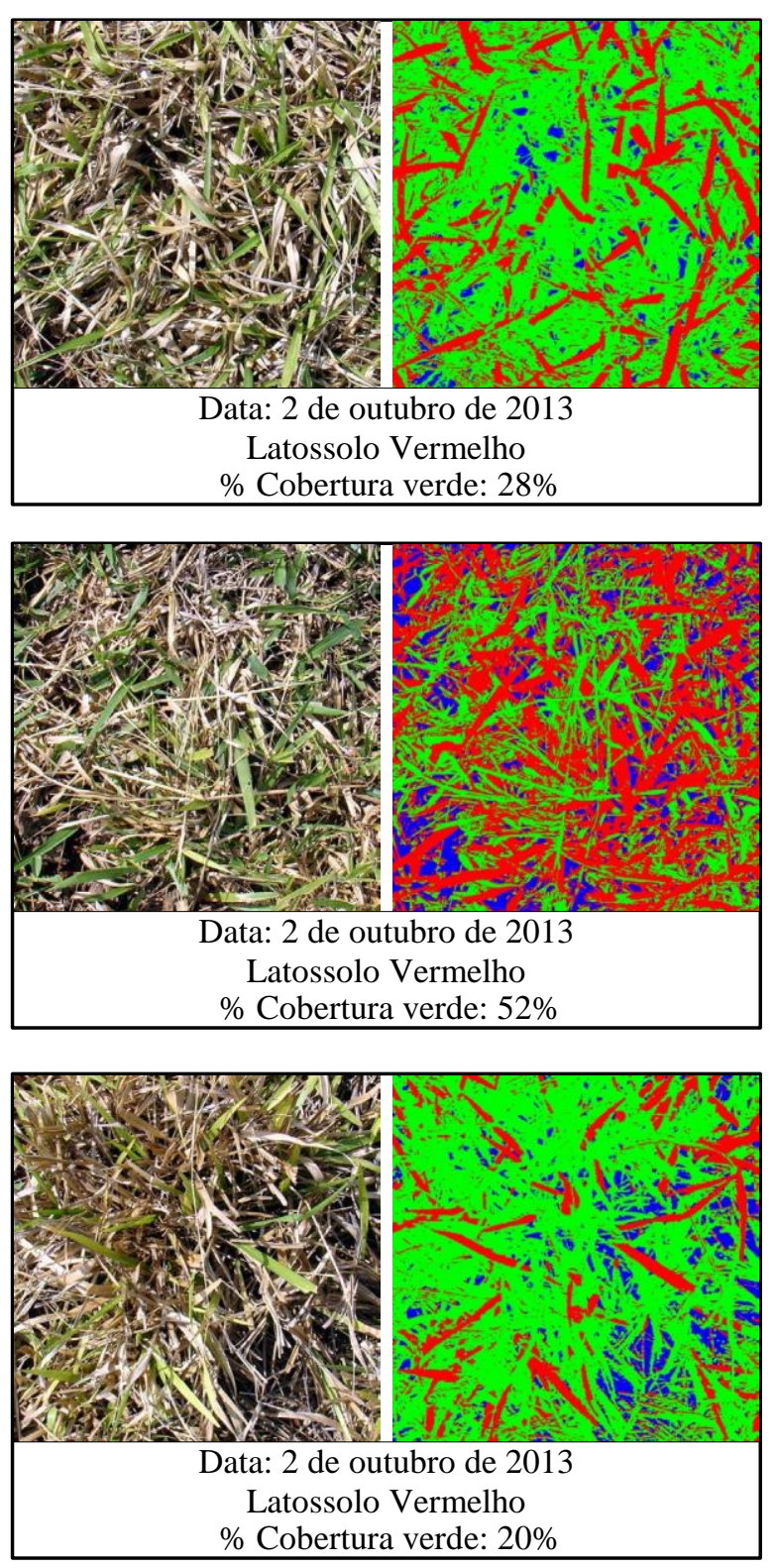

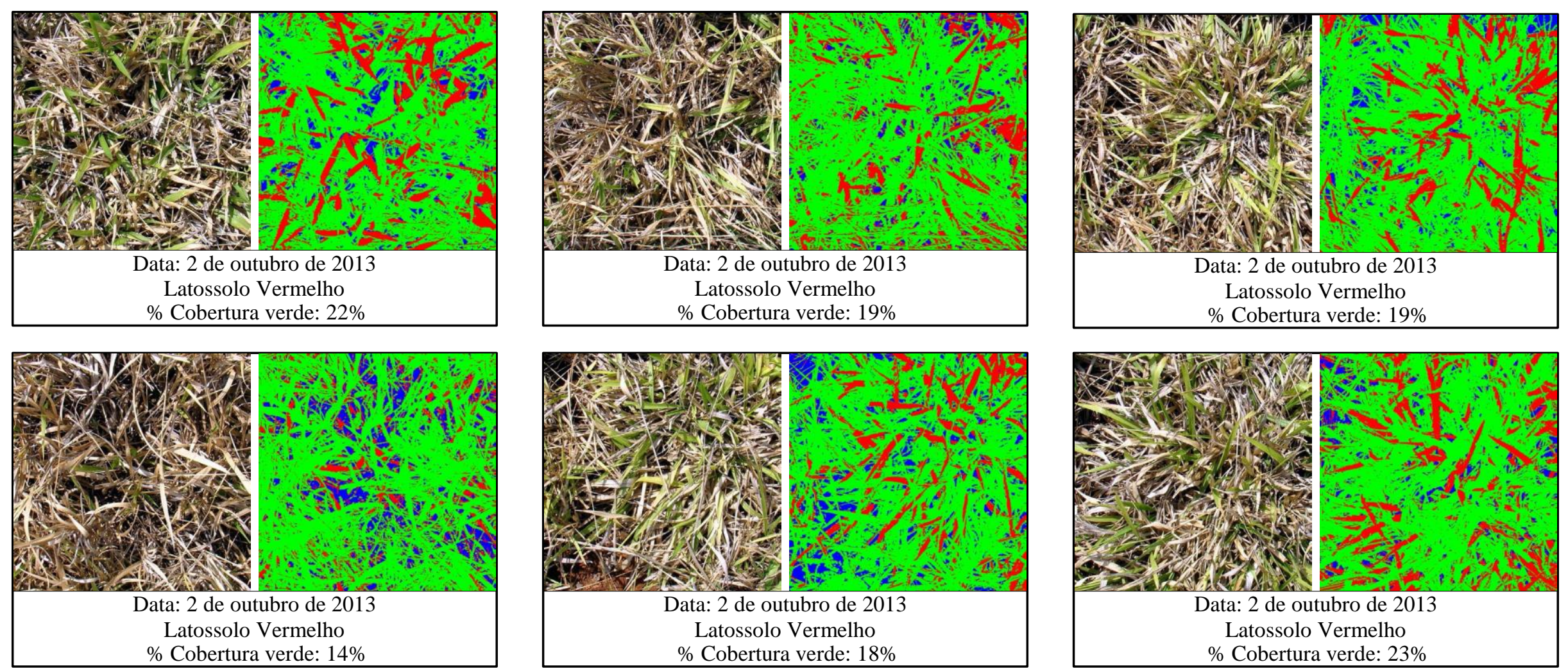

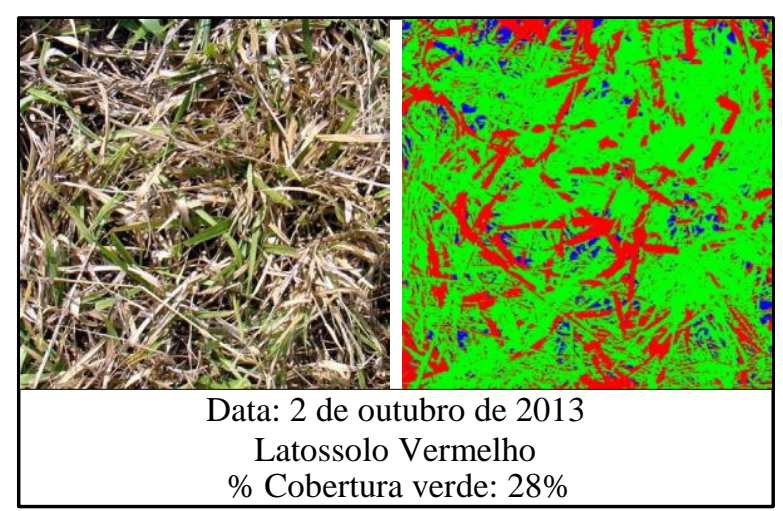



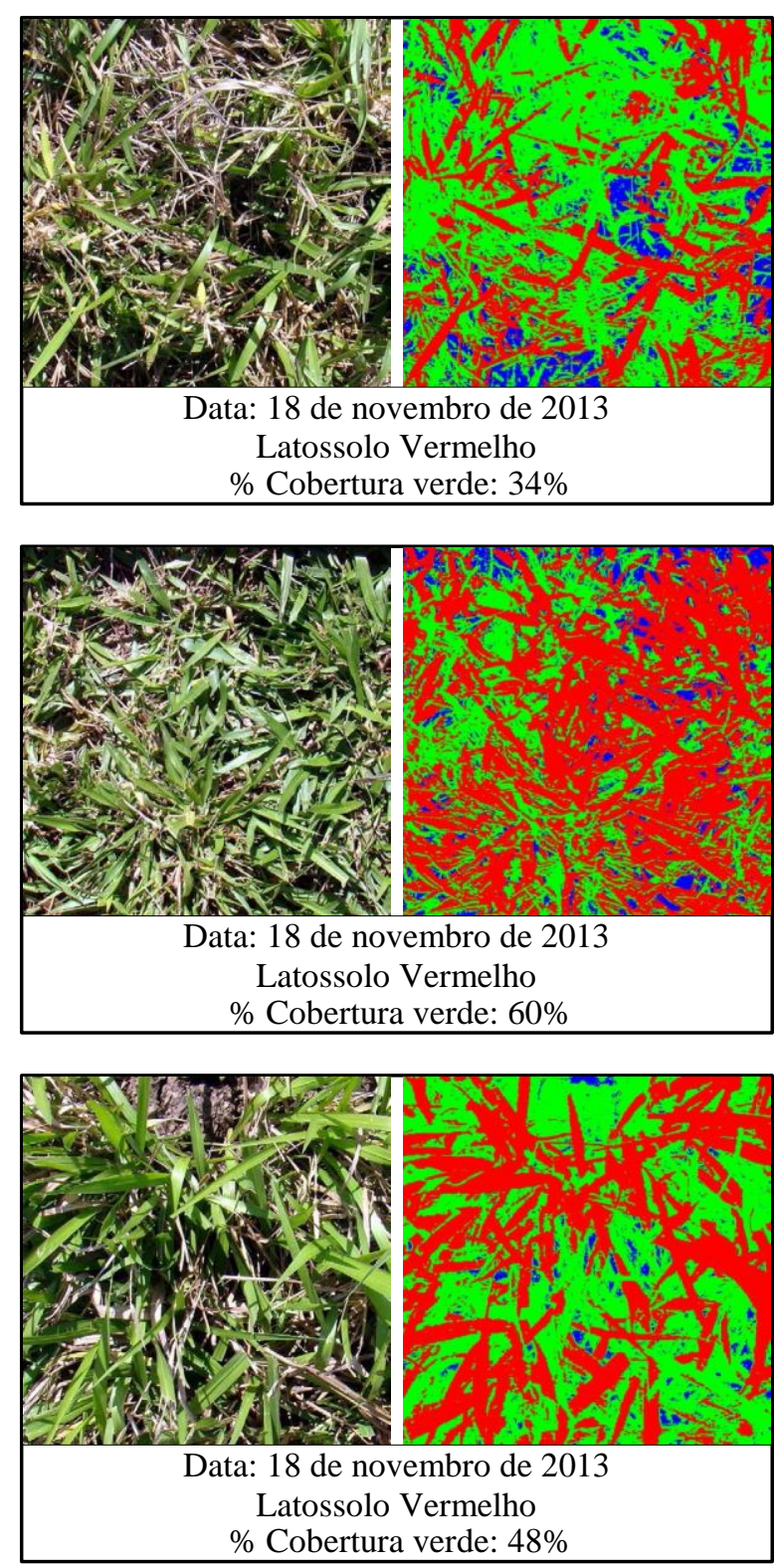
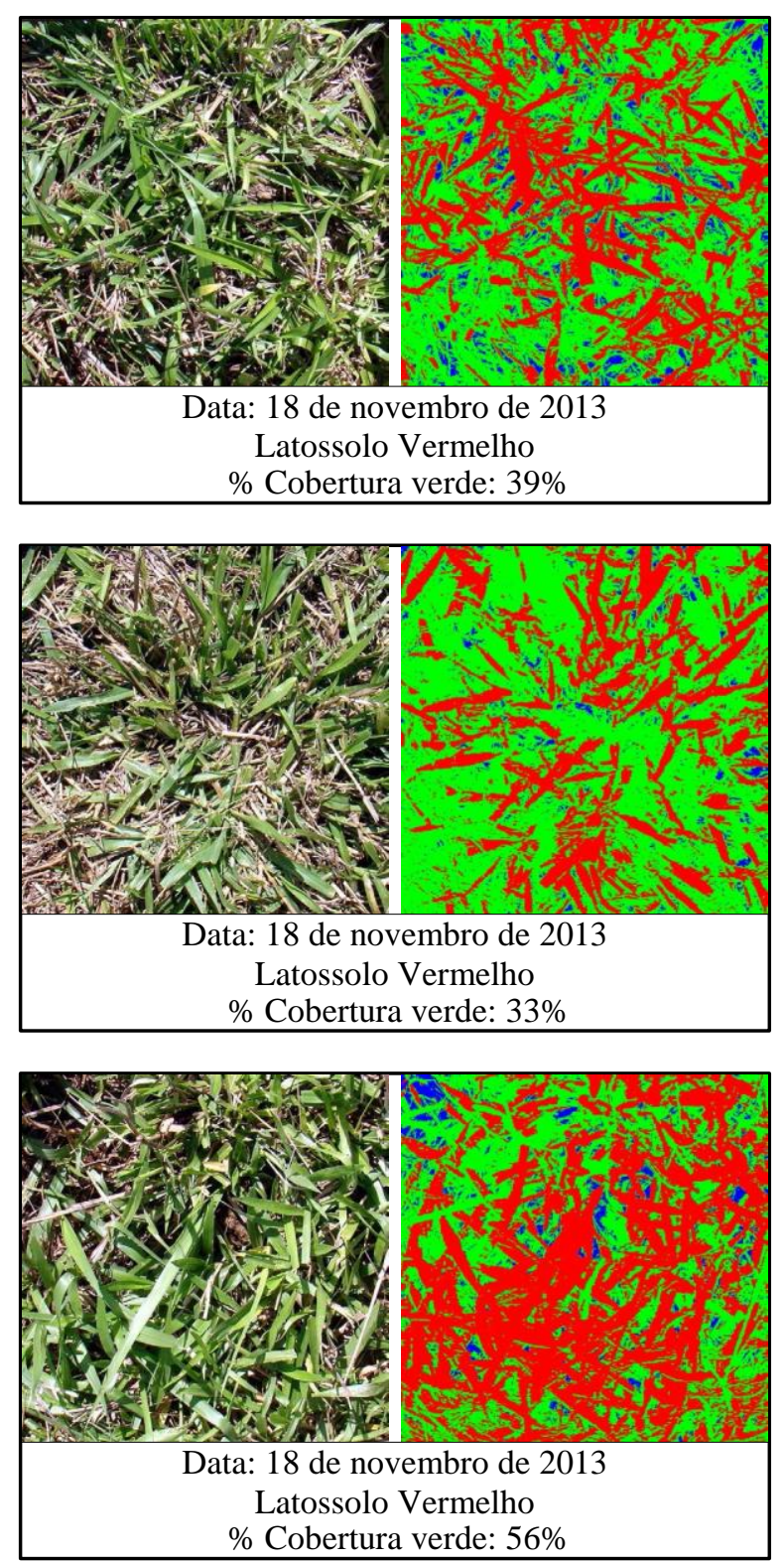
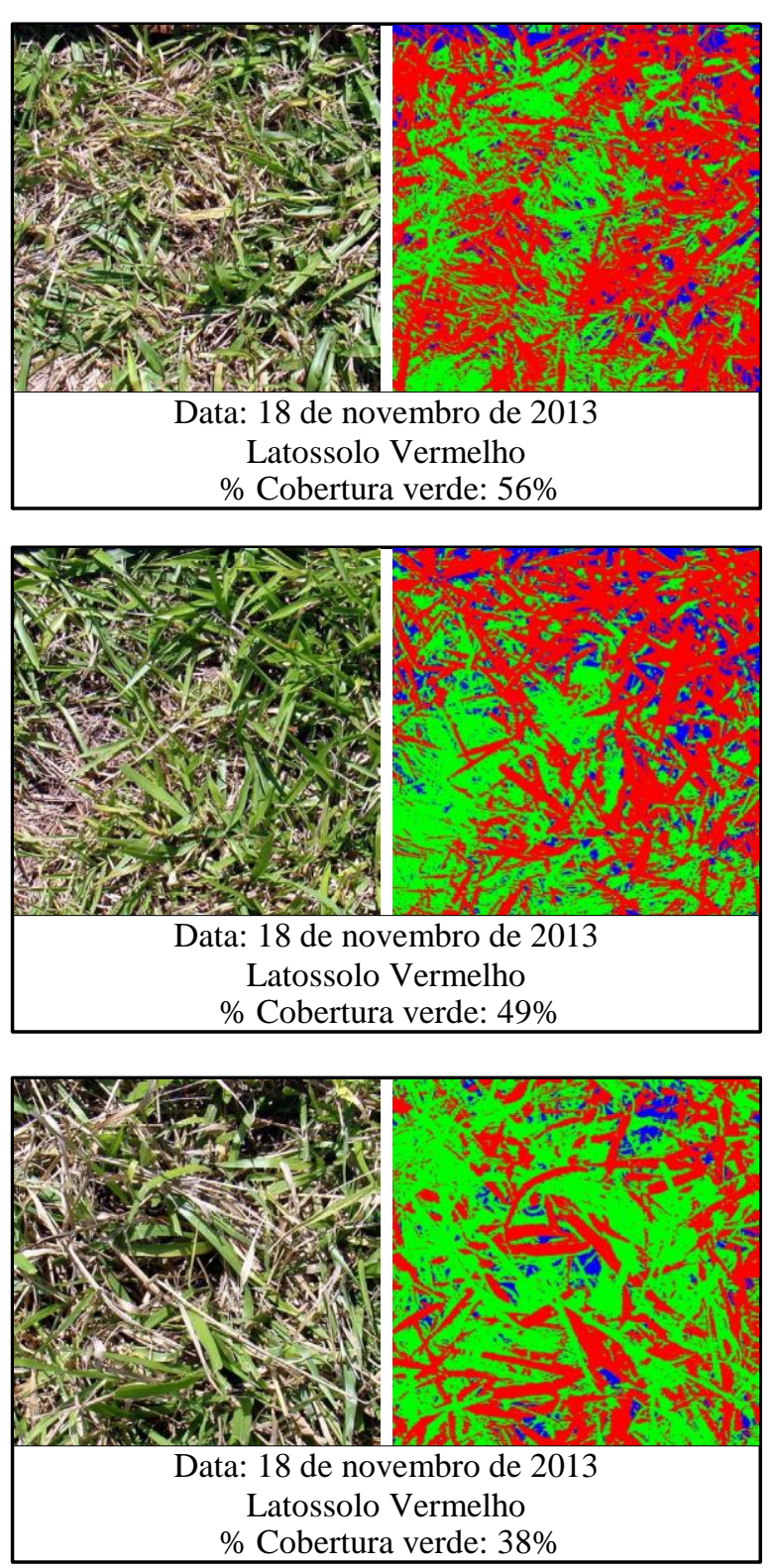

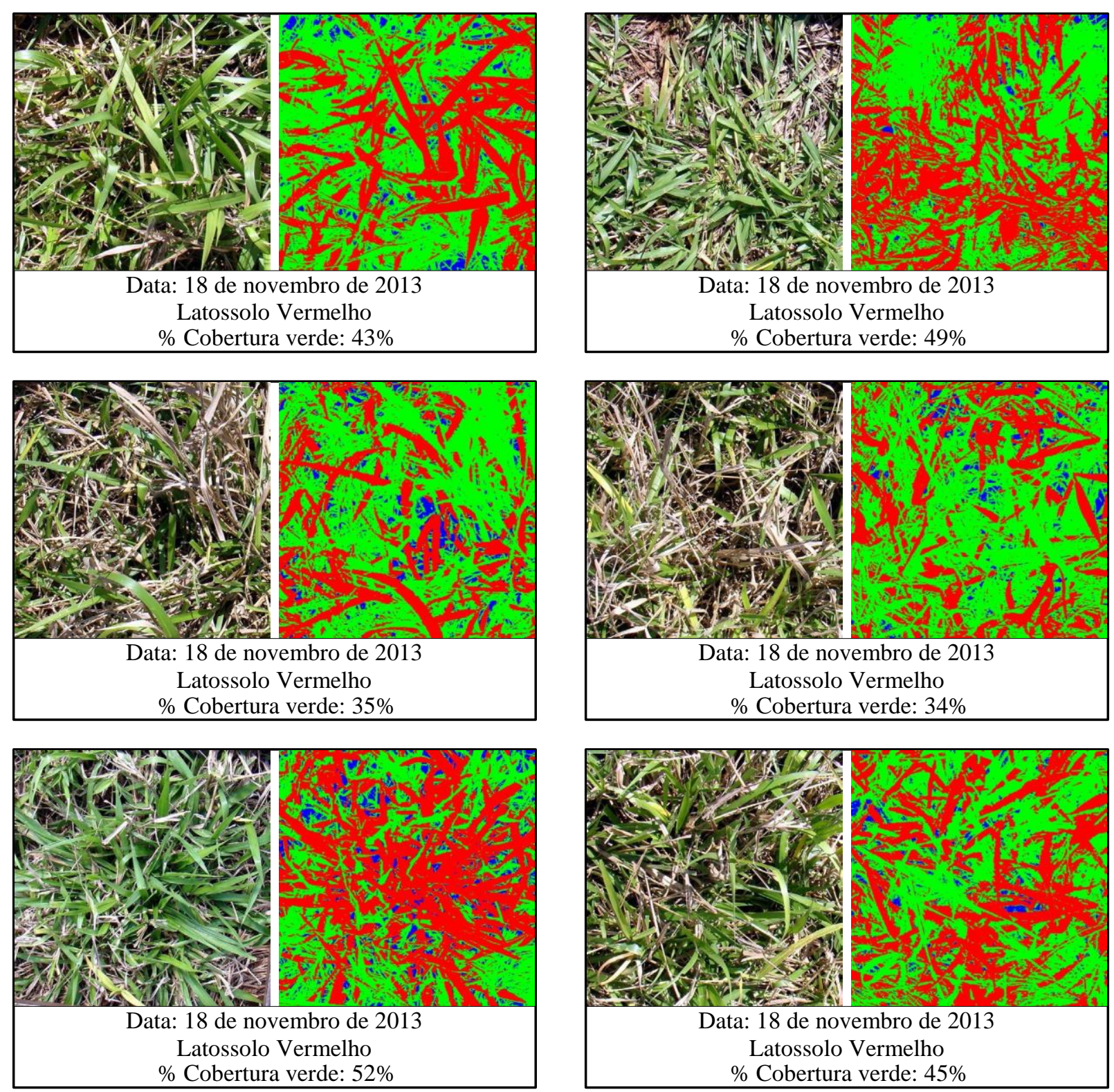
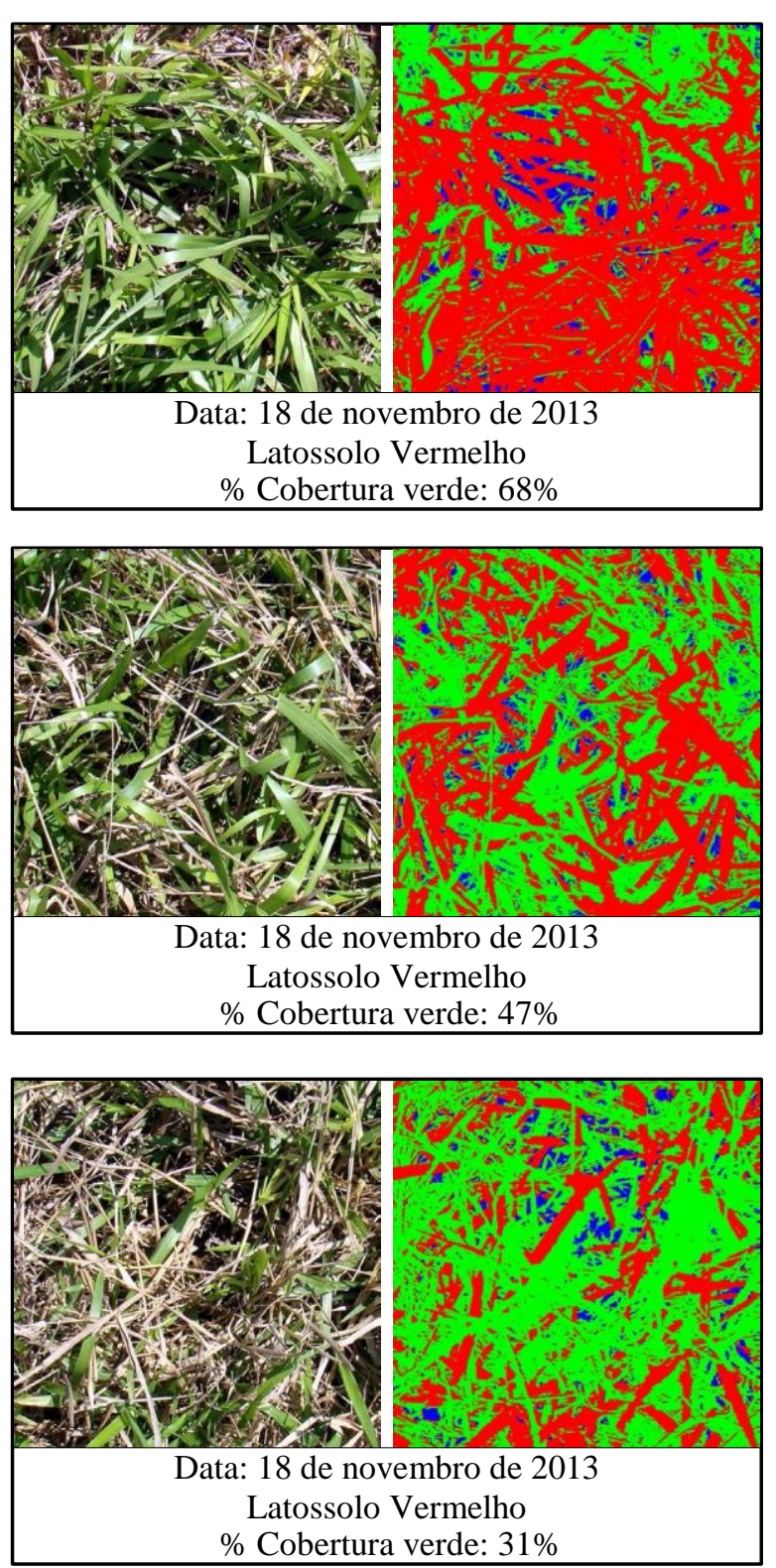

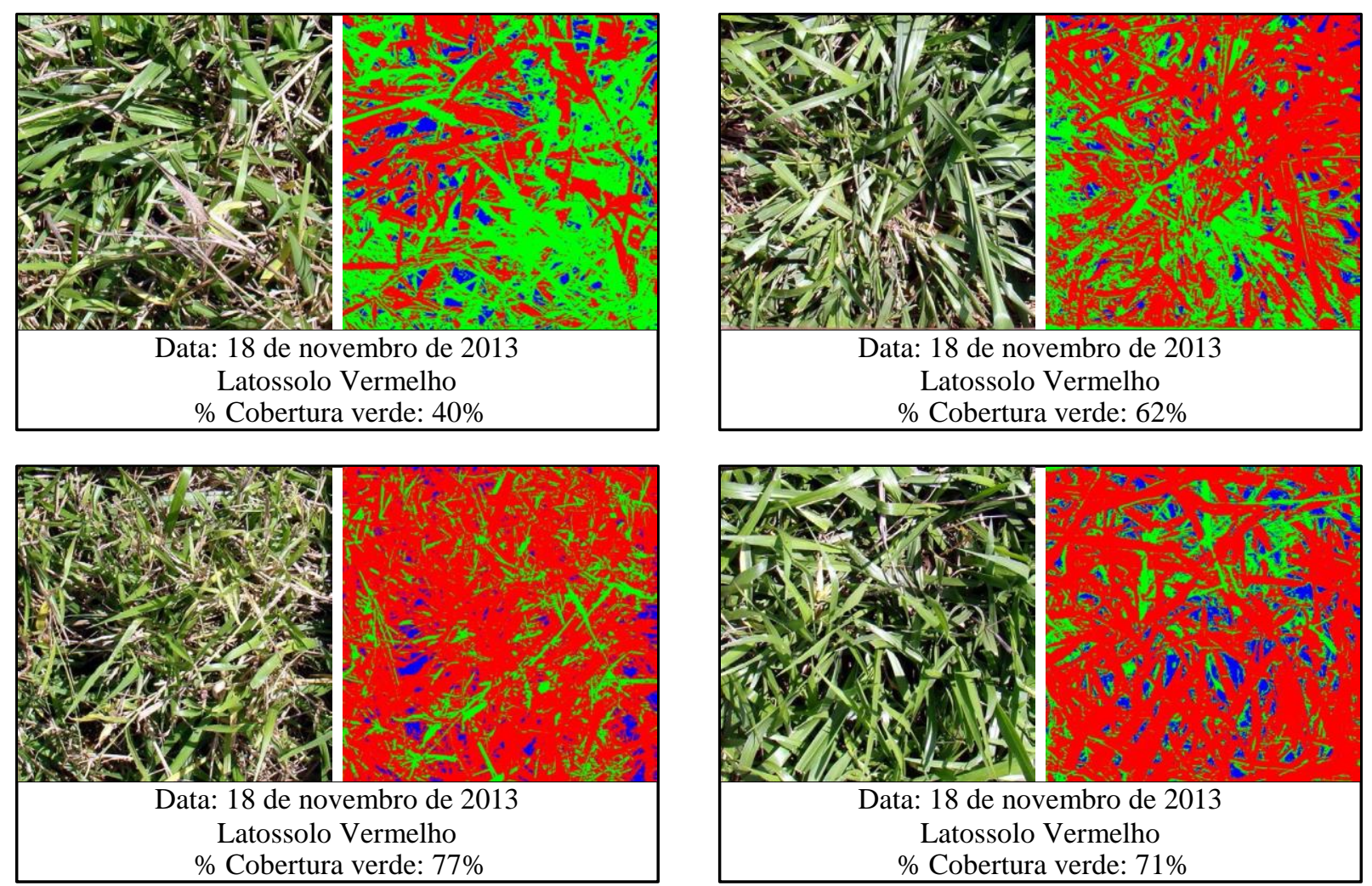

Lata: 18 de novembro
Latossolo Vermelho

$\%$ Cobertura verde: $62 \%$

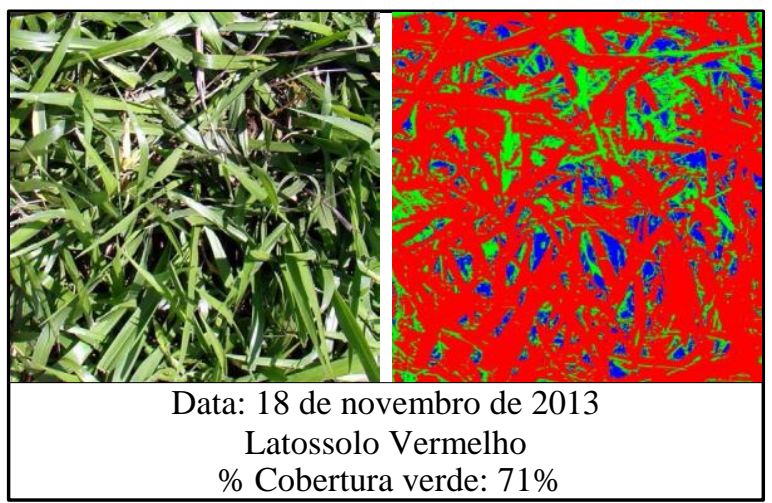

$\%$ Cobertura verde: $77 \%$

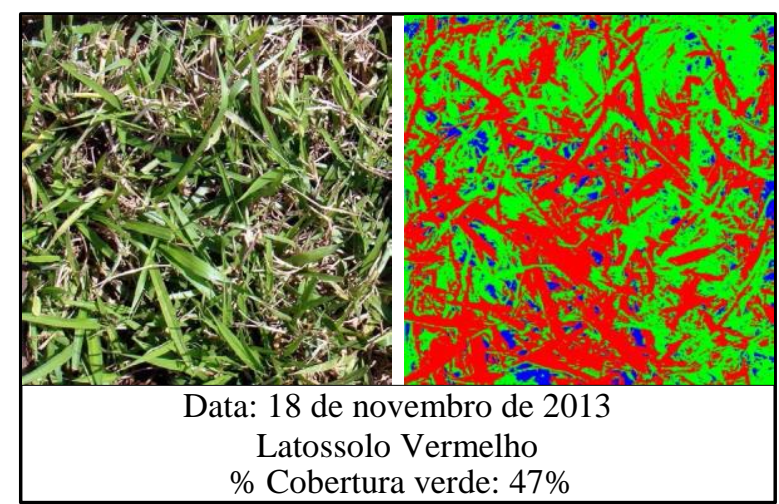

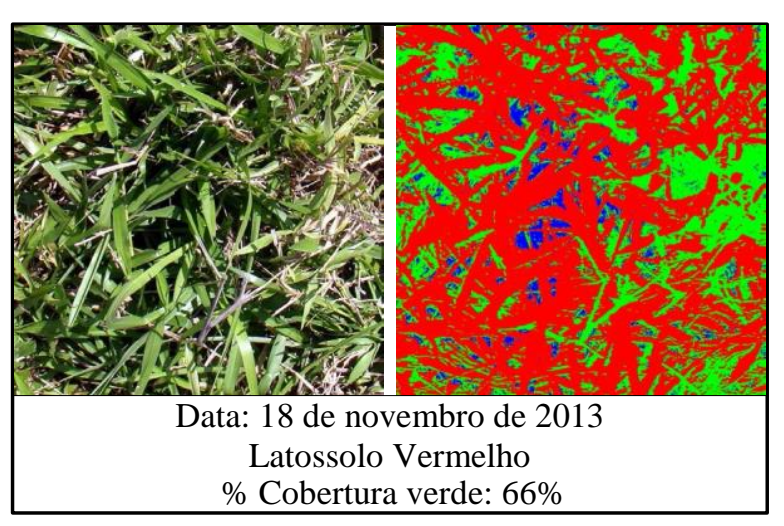

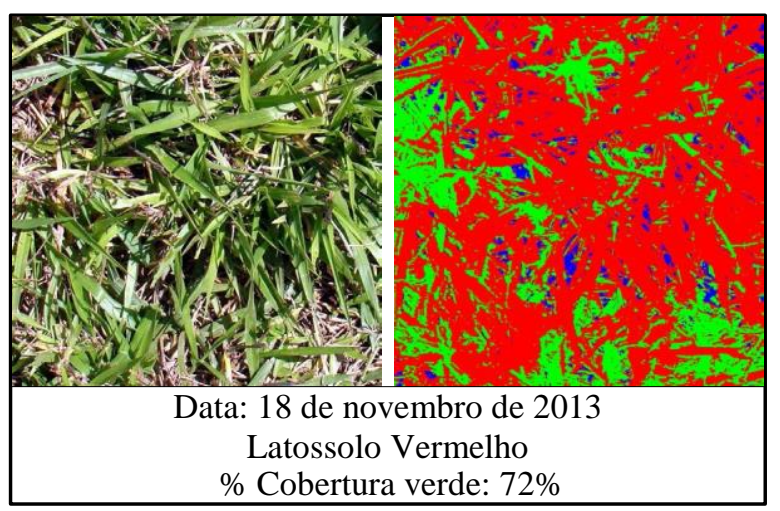



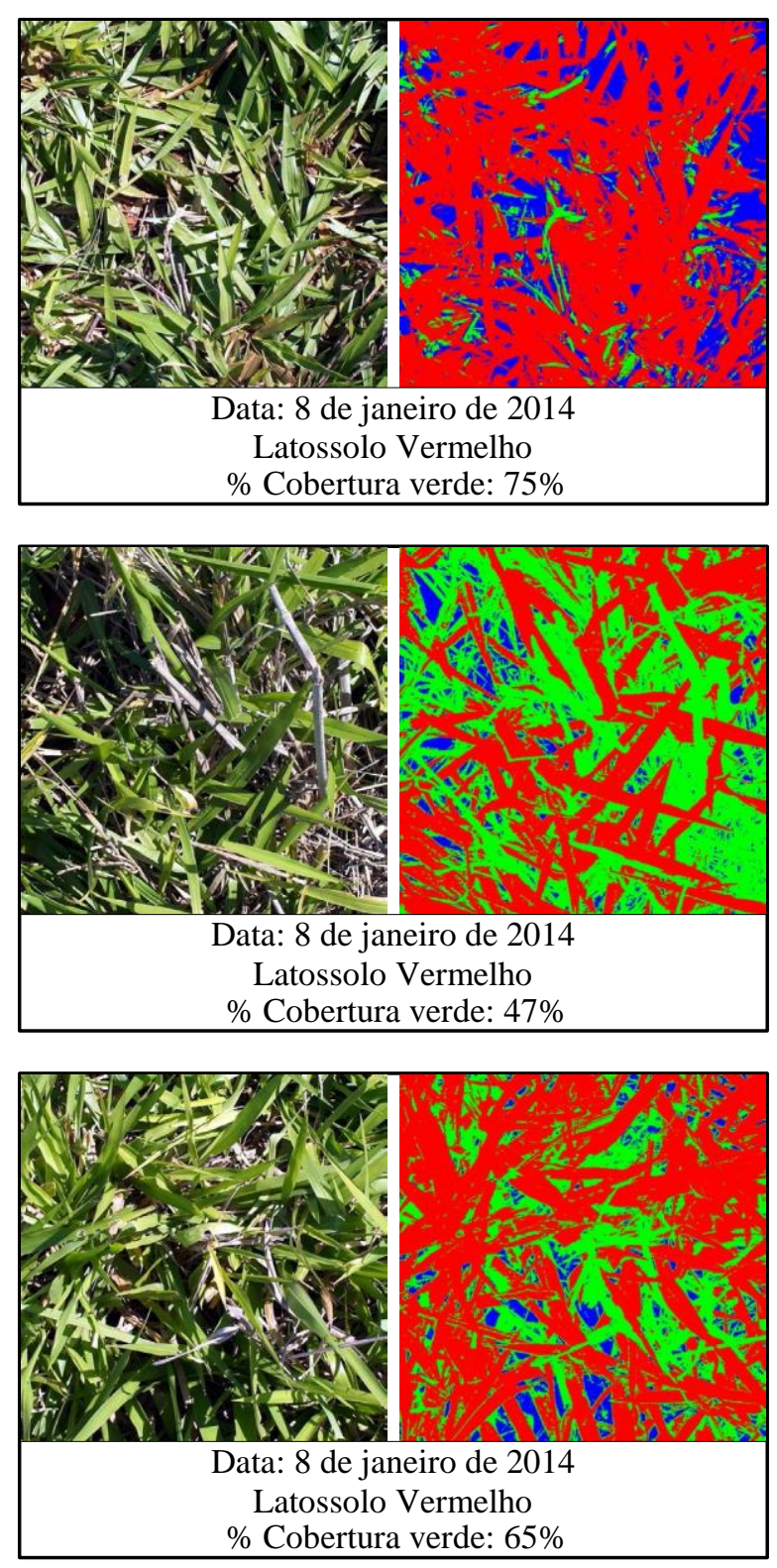
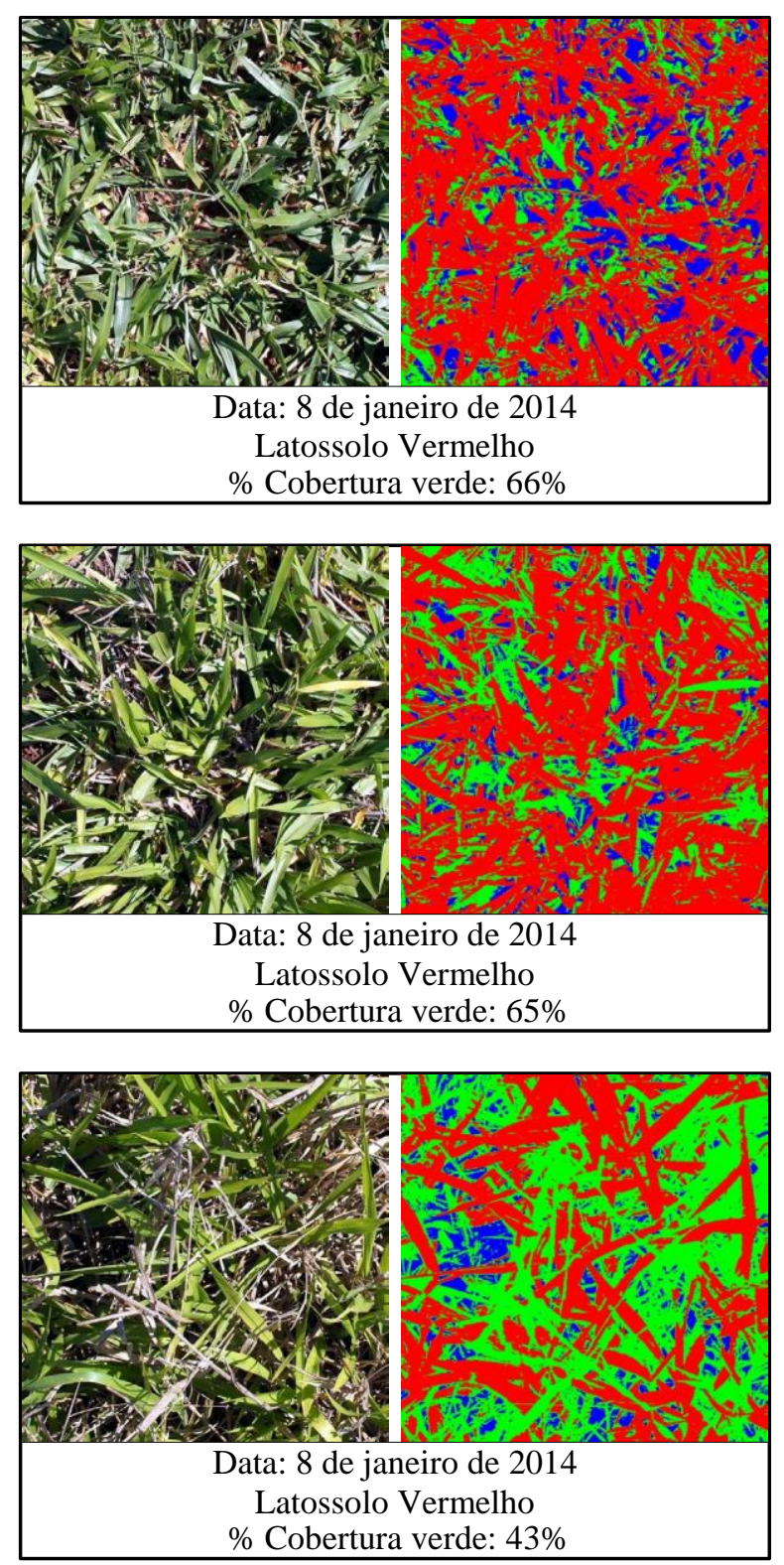
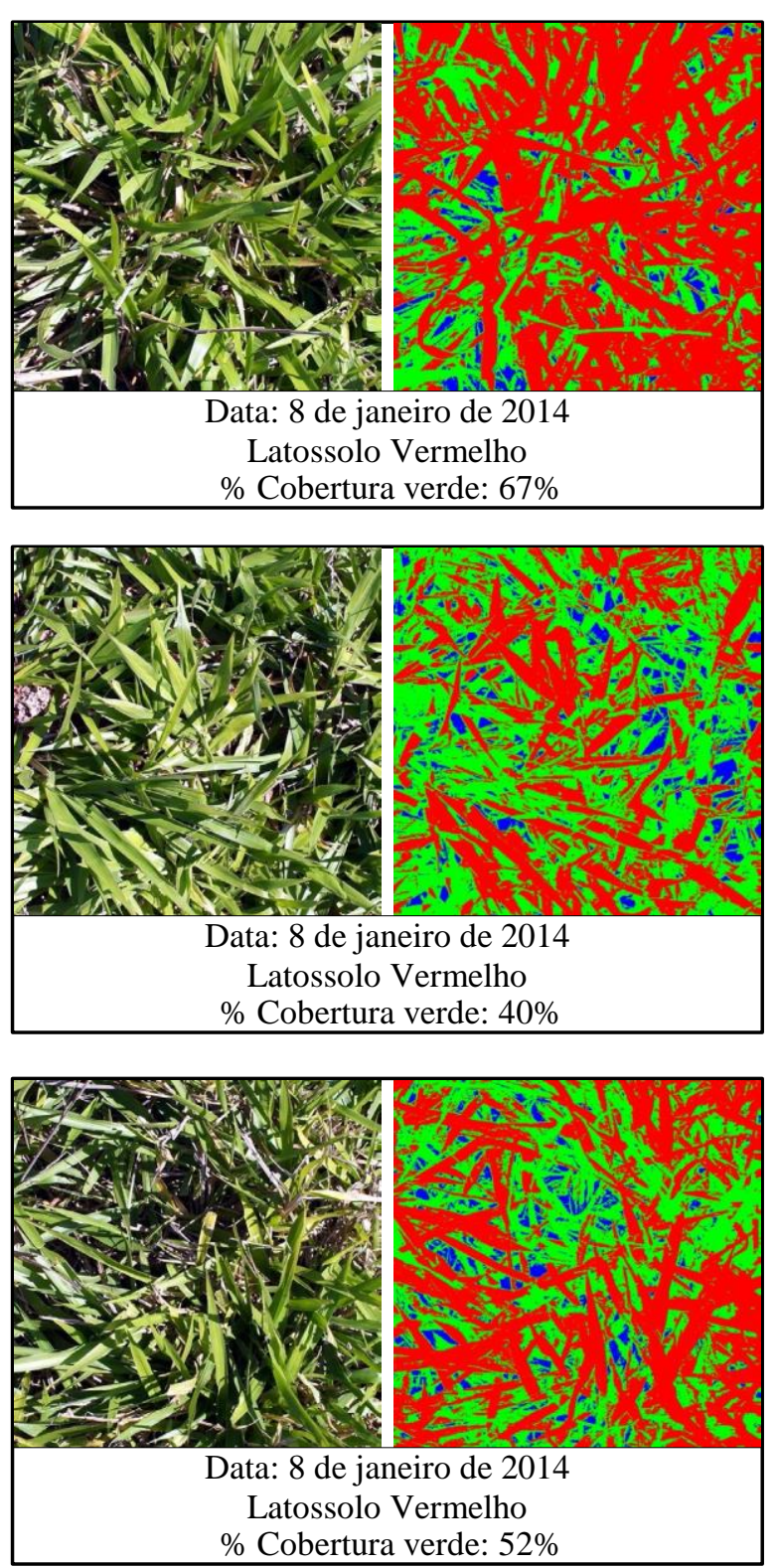

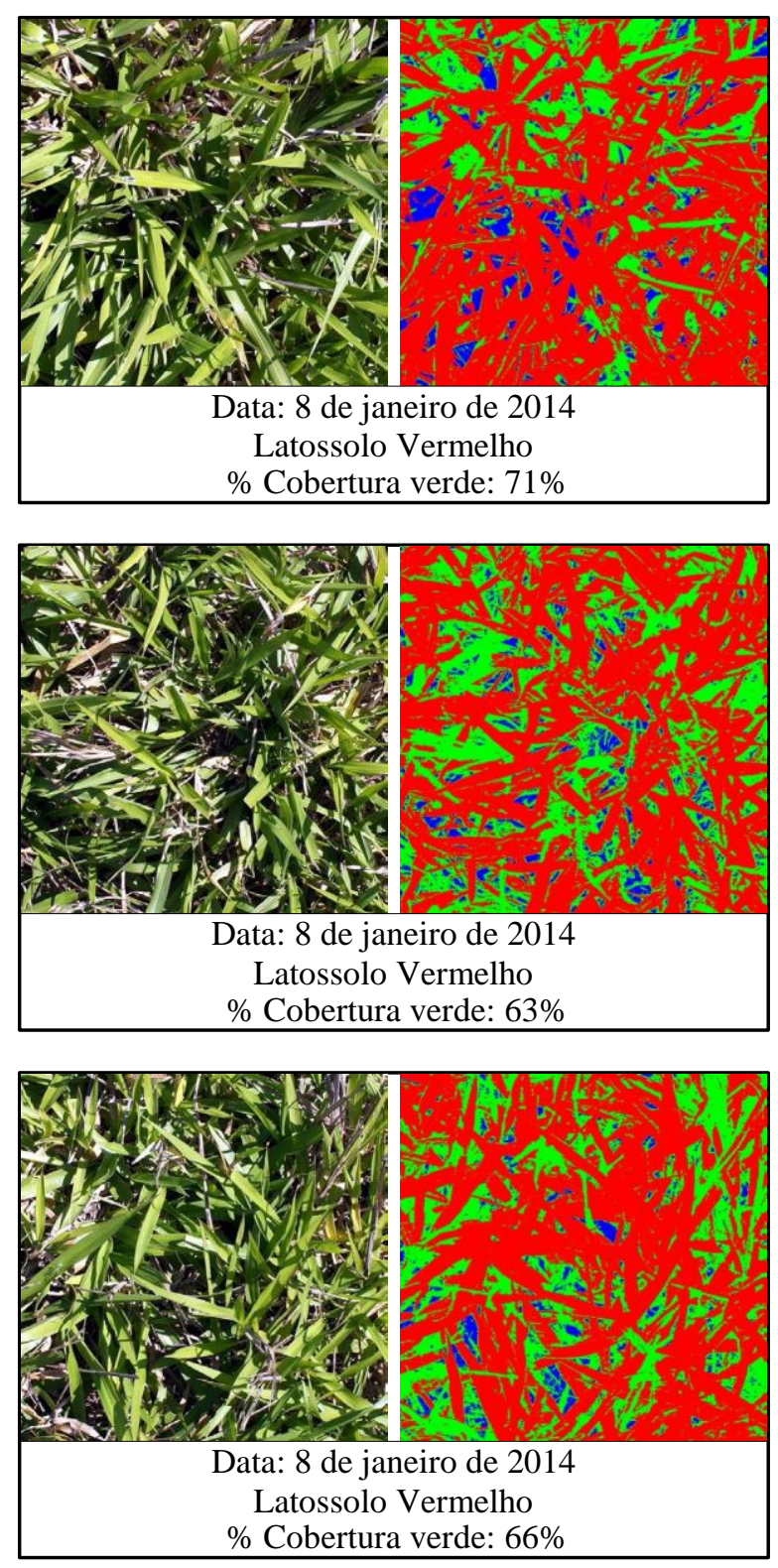
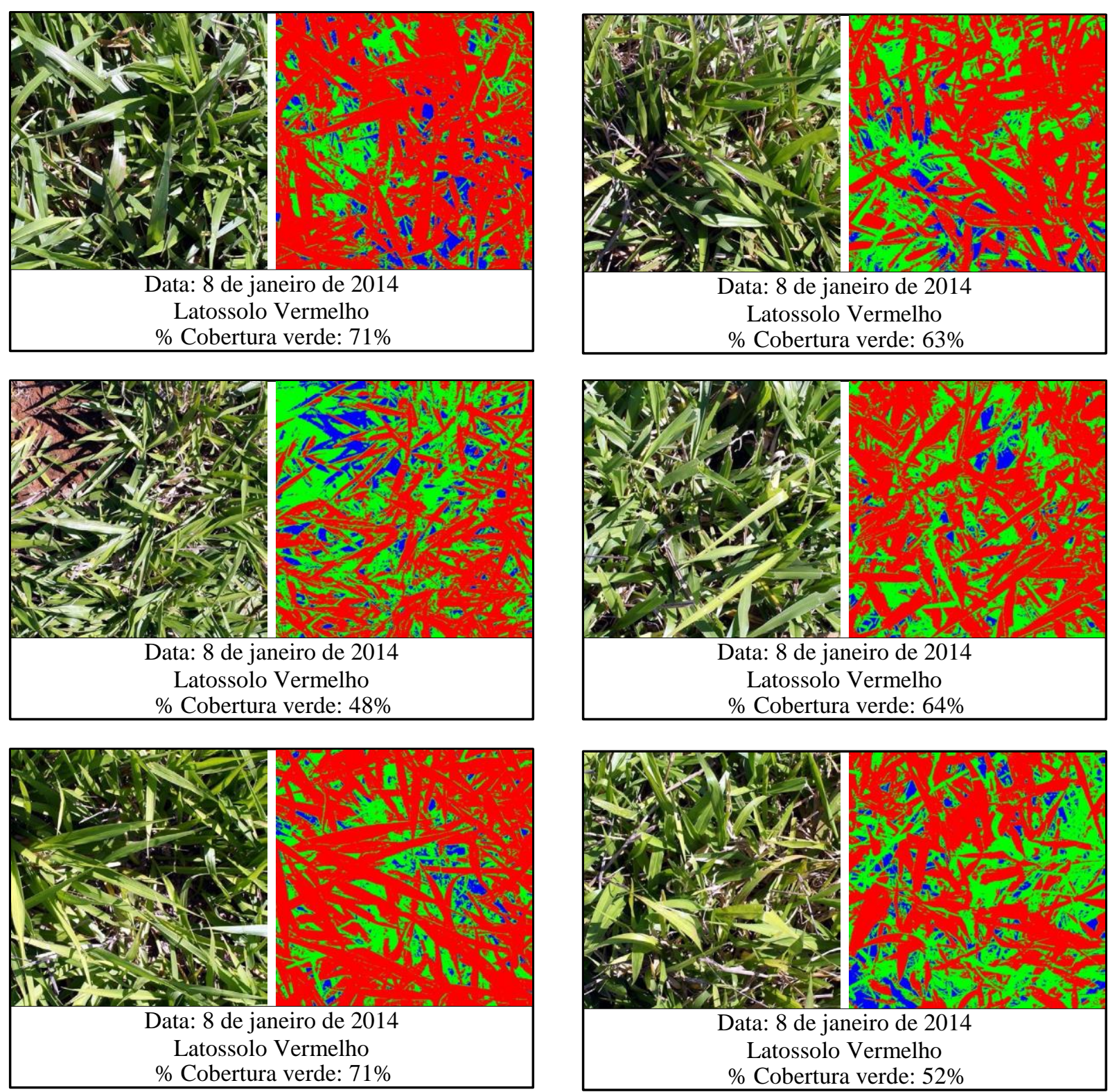

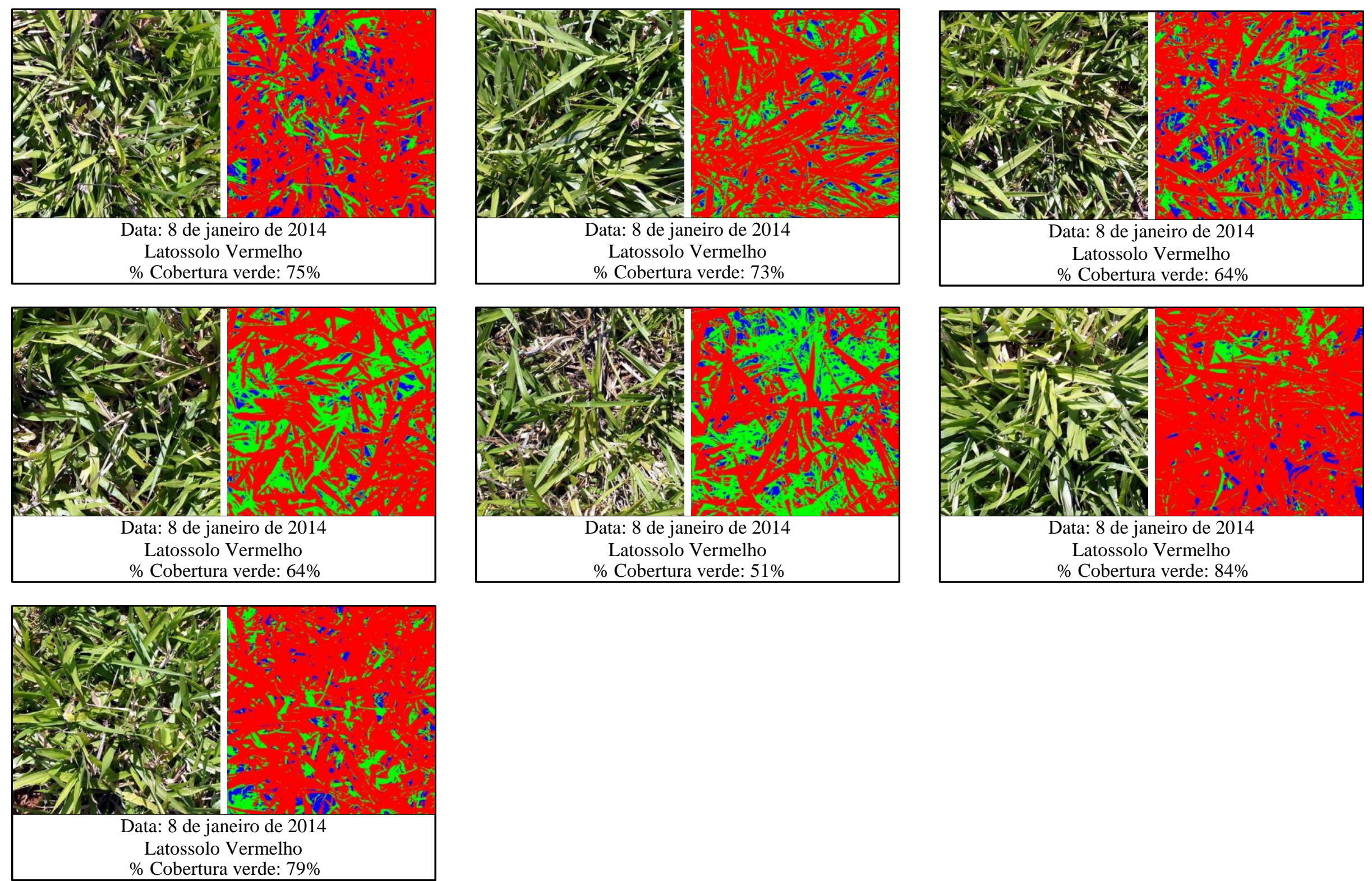

Latossolo Vermelho $\%$ Cobertura verde: $84 \%$ 